Portland State University

PDXScholar

1984

\title{
Tiltmeter analysis of Mount St. Helens, Skamania County, Washington
}

Edward Charles Brown

Portland State University

Follow this and additional works at: https://pdxscholar.library.pdx.edu/open_access_etds

Part of the Geology Commons, and the Volcanology Commons Let us know how access to this document benefits you.

\section{Recommended Citation}

Brown, Edward Charles, "Tiltmeter analysis of Mount St. Helens, Skamania County, Washington" (1984). Dissertations and Theses. Paper 3360.

https://doi.org/10.15760/etd.5241

This Thesis is brought to you for free and open access. It has been accepted for inclusion in Dissertations and Theses by an authorized administrator of PDXScholar. Please contact us if we can make this document more accessible: pdxscholar@pdx.edu. 
AN ABSTRACT OF THE THESIS OF EDWARD CHARLES BROWN FOR

the Master of Science in Geology presented June 6, 1984 .

Title: Tiltmeter Analysis of Mount St. Helens, Skamania County, Wa shing ton

APPROVED BY MEMBERS OF THE THESIS COMMITTEE:

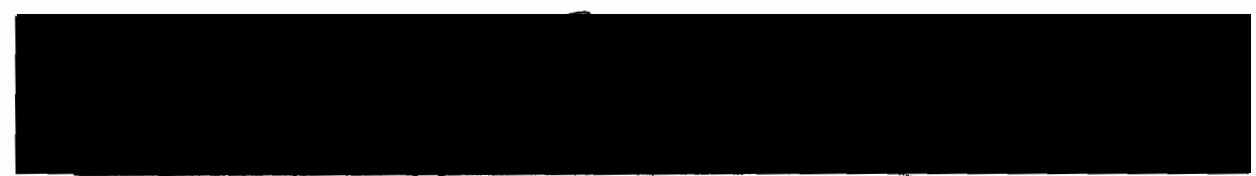

Ansel G. Johnsop, Chairman

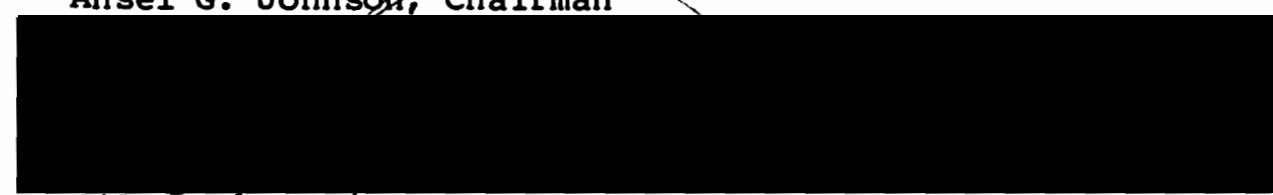

Gilbert T. Benson

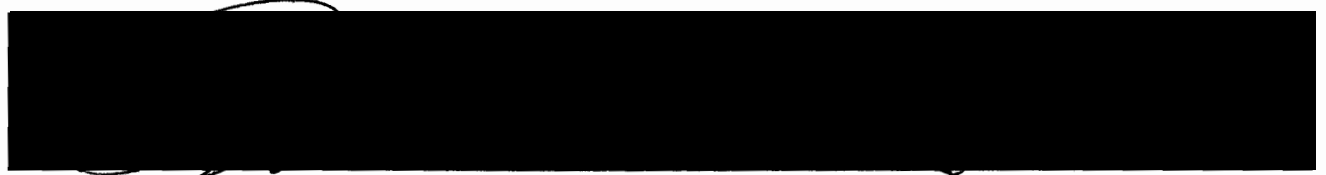

Leorard A. Palmer

Mount St. Helens returned to an active eruptive state March 20 , 1980. Since then explosive and dome building eruptions have caused major topographic changes to the mountain and surrounding drainages. Monitoring of the southern side of the mountain by six tiltmeters at distances between $6 \mathrm{~km}$ and $12 \mathrm{~km}$ was conducted during the period of July 1, 1980 to December 31, 1980. Records obtained from the tiltmeters were analyzed and compared to data from precision geodetic surveys. 
Results of this analysis indicated that minimal correlation existed between any of the tiltmeter sites and geodetic surveys at any given time. Correlation of tiltmeter change to eruptive events was also minimal. Short term changes in tilt correlative to eruptive event onset were not distinguishable above background noise. Possible minor correlation of tilt change to the October, 1980 eruption exists for the Ape Cave and Ape Cave North tilt sites, but absolute correlation was not possible. Long term tilt results indicated that the borehole tiltmeter sites recorded downslope soil movement greatly in excess of predicted volcanic deformation.

Results of deformation modeling indicated that at distances greater than $6 \mathrm{~km}$ from the vent, changes in tilt would be less than 3 urad for any eruption, commonly near 1 rrad. Records from all of the tiltmeter sites indicated changes from any eruption during the study period were less than 1 urad. Single chamber model deformation curves fit early 1980 deformation patterns, explaining recorded eruption related tilt change at Ape Cave North during the May 18, 1980 eruption. Evolution of the magmatic system into a two chamber system by October, 1980 correlates well to modeled surficial deformation from a two chamber model.

Conclusions from the study in terms of far-field tiltmeter use in monitoring Mount St. Helens are: 1) based on modeled deformation patterns, for volume changes of less than $.05 \mathrm{~km}^{3}$, the deformation changes at distances greater than $6 \mathrm{~km}$ from the vent termination will be indistinguishable above background noise at any tiltmeter site in use during this study, 2) all borehole tiltmeters sites used in this study 
recorded soil creep in great excess of expected volcanic deformation changes, and 3) that use of far-field tiltmeters for real time monitoring of this type of deformation system is of little value. 
TILTMETER ANALYSIS OF MOUNT ST. HELENS,

SKAMANIA COUNTY, WASHINGTON

by

EDWARD CHARLES BROWN

A thesis submitted in partial fulfillment of the requirements for the degree of

MASTER OF SCIENCE

in

GEOLOGY

PORTLAND STATE UNIVERSITY

1984 
TO THE OFFICE OF GRADUATE STUDIES AND RESEARCH:

The members of the Committee approve the thesis of Edward Charles Brown presented June 6, 1984.

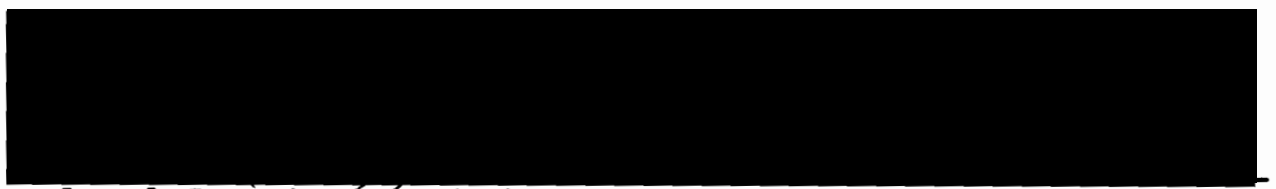

Ansel G. Johngon, Chairman

Gilbert T. Benson

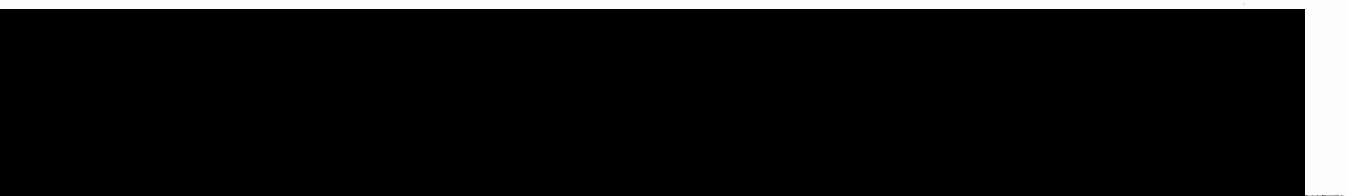

Leonard A. Palmer

AP PROVED:

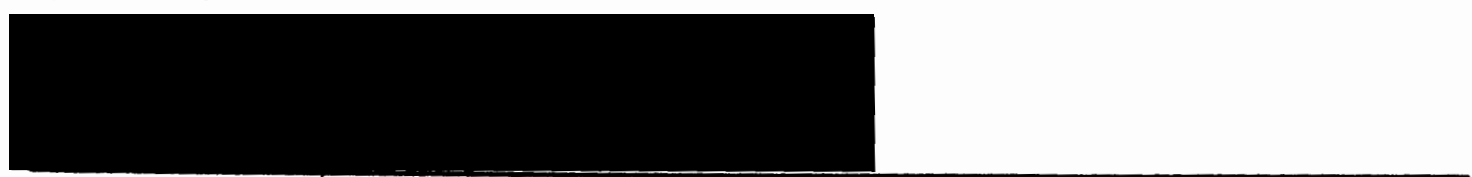

Paul E. Hammond, Head, Department of Earth Sciences

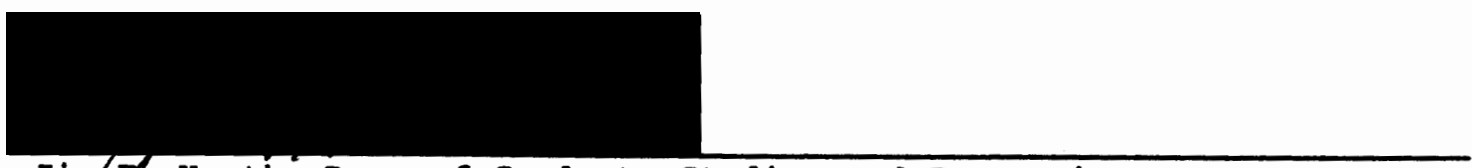

Jim. F. Heath, Dean of Graduate Studies and Research 


\section{ACKNOWLEDGEMENTS}

I wish to thank the members of my committee, Dr. Ansel Johnson, Dr. Gilbert Benson, and Dr. Leonard Palmer for their critical review of this manuscript and helpful suggestions.

Special thanks are expressed to Dr. John Dvorak, U.S.G.S. geophysicist, who suggested this area of study and helped in the initiation of this project. To Dr. Dan Dzurisin, U.S.G.S. geophysicist, for his comments suggestions and review of the thesis. Also to Dr. Roger Denlinger, U.S.G.S. geophysicist, for his critical review and suggestions in modeling the volcanic system.

Thanks to the staff of the David Johnston Cascades Volcano Observatory, for the ir temperance, tolerance and help during the writing of this report. A special thanks is given to Bruce Furukawa, Tom Murray, Virginia Johnson and Steve Finneran for their inestimable contributions to the completion of this thesis.

In addition I would also like to express my appreciation to Fred Gullixson and Jon Bounds for their suggestions and comments.

Financial support was provided through personal donations and the U.S. Geological Survey.

Support for the Portland State University tiltmeter site installation and data collection was provided by the Mazamas. 
TABLE OF CONTENTS

PAGE

ACKNOWLEDGEMENTS . . . . . . . . . . . . . . . . . . $^{-} i$ LIST OF TABLES . . . . . . . . . . . . . . . . . . . . . vi vi LIST OF FIGURES . . . . . . . . . . . . . . . . . . . . . viii CHAPTER

I INTRODUCTION . . . . . . . . . . . . . . . 1

A. Location ................. . 1

B. Purpose ..................... 1

C. Previous Work ................... . 4

II GENERAL GEOLOGY •. . . . . . . . . . . . . . 6

A. Regional Geologic Setting .. . . . . . . . 6

B. General Stratigraphy of Mount St. Helens . . . 8

C. General structure of the Mount St. Helens Region 11

D. Summary of 1980 eruptions . . . . . . . . 16

III INSTRUMENTATION . . . . . . . . . . . . 20

IV SITE LOCATION AND SITE GEOLOGY . . . . . . . . 23

A. Ape Cave Tiltmeter . . . . . . . . . . 23

B. Ape Cave North Tiltmeter . . . . . . . . . 25

C. Blue Lake Tiltmeter . . . . . . . . . . 25

D. June Lake Tiltmeter . . . . . . . . . . 26

E. PSU \#2 Tiltmeter ................ 27

F. PSU $\# 3$ Tiltmeter .............. 27

V DATA ANALYSIS ................. 28

A. Data Aquisition . . . . . . . . . . . 28

B. Initial Analysis ............. 28

C. Detrending and Smoothing .. . . . . . . 29

D. Spectral Analysis .............. . 31

E. Correlation of Data . . . . . . . . 32

F. Site and Location Evaluation ........ 32 
VI

RESULTS

A. Comparison of eruptive sequences . . . . . . 48

July Eruption . . . . . . . . . . . . 48

August Eruption .............. 54

October Eruption ....... . . . . . . 62

December Eruption ............. 71

VII THEORETICAL MODELS . . . . . . . . . . . . 79

A. Mogi Model (single magma chamber) . . . . . 80

B. Mogi Model (multiple magma chamber) . . . . 85

VIII DISCUSSION . . . . . . . . . . . . . 96

A. Discussion of Results . . . . . . . . . 96

B. Problems and Sources of Error . . . . . . . . 99

C. System Improvments .............. 100

IX SUMMARY AND CONCLUDING REMARKS . . . . . . . . 102

BIBLIOGRAPHY . . . . . . . . . . . . . . . . 108

APPENDIX A Plots of Raw Monthly Tilts . . . . . . . . . . 113

APPENDIX B Equation Derivations . . . . . . . . . . . . 147

APPENDIX C Chronology of Volcanic Events: July, 1980

through December, 1980 . . . . . . . . . . 152 


\section{LIST OF TABLES}

TABLE

PAGE

I Comparison of Eruptive Periods, Output Volumes, Dome

Dimensions, Dates of Dome Emplacement and Extrusion

Rates for Mount St. Helens During 1980 . . . . .

II Tiltmeter Operational Data, Net Tilt and Average Daily

Tilt Fluctuations at Mount St. Helens Between July 1

and December 31, 1980 .............. . . 44

II Pre-eruption Tilt. Vector Orientation, Pre-eruption Tilt

Rate, Post-eruption Tilt Vector Orientation,

Post-eruption Tilt Rate, Net Tilt Since Julian Day 180

at Mount St. Helens for the July 22, 1980 Eruption .

IV Pre-eruption Tilt Vector orientation, Pre-eruption Tilt

Rate, Post-eruption Tilt Vector Orientation,

Post-eruption Tilt Rate, Net Tilt Since Last Major

Eruption at Mount st. Helens for the August 7, 1980

Eruption . . . . . . . . . . . . . 55

V Pre-eruption Tilt Vector Orientation, Pre-eruption Tilt

Rate, Post-eruption Tilt Vector Orientation,

Post-eruption Tilt Rate, Net Tilt Since Last Major

Eruption at Mount St. Helens for the October 16, 1980

Eruption . . . . . . . . . . . . . . . . 
VI Pre-eruption Tilt Vector Orientation, Pre-eruption Tilt Rate, Post-eruption Tilt Vector Orientation, Post-eruption Tilt Rate, Net Tilt Since Last Major Eruption at Mount St. Helens for the December 1980 Eruption ................... 72

VII Average Chemical Analysis in Weight Percent, of Eruptive Products from Major Eruptions of Mount St. Helens, Washington Between June 1980 and December 1980 . . . 88 


\section{LIST OF FIGURES}

FIGURE

PAGE

1. General location map showing the Cascade Range and major volcanic peaks to the Pacific Northwest . . . . . 2

2. Index map showing the location of the study area . . . . 3

3. Map showing the major high Cascade volcanic peaks, with the gross stratigraphic units of the Cascades • - 7

4. Generalized geologic map of the study area . . . . . . 12

5. Map showing the approximate trace of the Mount St. Helens seismic zone .. . . . . . . . . . . . . 14

6. Map and cross section diagram of Mount St. Helens showing hypocenter locations .............. 15

7a. Diagram showing the USGS borehole tiltmeter installation . 22

7b. Diagram showing the PSU borehole tiltmeter installation . 22

8. Diagram showing standard platform tiltmeter installation - 22

9. Diagram showing the locations of the tiltmeter sites for

this study and outer-network USGS geodetic survey studies...................... 24

10. Plot of raw data from Ape Cave tiltmeter site for 190 days 37

11. Plot of raw data from Ape Cave North tiltmeter site for 
12. Plot of raw data from Blue Lake tiltmeter site for 190 days 39

13. Plot of raw data from June Lake tiltmeter site for 190 days 40

14. Plot of raw data from PSU $\$ 2$ tiltmeter sitefor 190 days. . 41

15. Plot of raw data from PSU \$3 tiltmeter sitefor 150 days . . 42

16. Plot of smoothed power spectrum for the the Ape Cave tiltmeter site, north-south tilt axis......... 46

17. Three component plot showing the detrended and smoothed

tilt axes and temperature record for the PSU $\# 2$

tiltmeter site ....................

18a. Plot of raw tilt data from Ape Cave North, July 21, 1980

through July 25, 1980, north-south axis of tilt... .

18b. Plot of smoothed tilt data from Ape Cave North, July 21,

1980 through July 25, 1980, north-south axis of tilt .

19a. Plot of raw tilt data from June Lake, July 21, 1980

through July 25, 1980, north-south axis of tilt. . .

19b. Plot of smoothed tilt data from June Lake, July 21, 1980

through July 25, 1980, north-south axis of tilt... •

20. Diagram showing the relative magnitudes and direction of

tilt from the tiltmeters before and after the

July 25, 1980 eruption . . . . . . . . . .

2la. Plot of raw tilt data from Ape Cave, August 5, 1980

through August 9, 1980, north-south axis of tilt . . 56

21b. Plot of smoothed tilt data from Ape Cave, August 5, 1980

through August 9, 1980, north-south axis of tilt ... 
22a. Plot of raw tilt data from Ape Cave North, August 5, 1980 through August 9, 1980, north-south axis of tilt . .

22b. Plot of smoothed tilt data from Ape Cave North, August 5, 1980 through August 9, 1980, north-south axis of tilt.

23a. Plot of raw tilt data from June Lake, August 5, 1980

through August 9, 1980, north-south axis of tilt . . 58

23b. Plot of smoothed tilt data from June Lake, August 5, 1980

through August 9, 1980, north-south axis of tilt . . 58

24a. Plot of raw tilt data from PSU \#3, August 5, 1980 through

August 9, 1980, north-south axis of tilt .......

24b. Plot of smoothed tilt data form PSU \#3, August5, 1980

through August 9, 1980, north-south axis of tilt . .

25a. Plot of raw tilt data from Blue Lake, August 5, 1980

through August 9, 1980, east-west axis of tilt . . . 60

25b. Plot of smoothed tilt data from Blue Lake, August 5, 1980

through August 9, 1980, east-west axis of tilt ...

26. A diagram of the tilt vector directions and relative

magnitudes recorded before and after the August ?,

1980 eruption . . . . . . . . . . . . .

27a. Plot of raw tilt data from Ape Cave, October 14, 1980

through October 23,1980 , north-south axis of tilt . 65

27b. Plot of smoothed tilt data from APe Cave, October 14, 1980 through October 23, 1980, norht-south axix of tilt . 
28a. Plot of raw tilt data from Ape Cave North, October 14, 1980 through October 23,1980 , north-south axis of tilt . 66

28b. plot of smoothed tilt data from Ape Cave North, October 14, 1980 through October 23, 1980, north-south axis of tilt 66

29a. Plot of raw tilt data from June Lake, October 14, 1980

through October 23,1980, north-south axis of tilt . 67

29b. Plot of smoothed tilt data from June Lake, October 14, 1980 through October 23, 1980, north-south axis of tilt . 30a. Plot of raw tilt data from PSU \#2, October 14, 1980

through October 23,1980, north-south axis of tilt . 68

30b. plot of smoothed tilt data from PSU $\$ 2$, October 14,1980

through October 23,1980 , north-south axis of tilt . . 68

31. A diagram of the tilt vector directions and relative magnitudes recorded before and after the October 16 , 1980 eruption . . . . . . . . . . . . . . 69

32a. Plot of raw tilt data from Ape Cave, December 26, 1980

through December 31, 1980, north-south axis of tilt.. 74

32b. Plot of smothed tilt data from Ape Cave, December 26, 1980 through December 31, 1980, north-south axis of tilt. . 74

33a. Plot of raw tilt data from Ape Cave North, December 26, 1980 through December 31, 1980, north-south axis of tilt ....................... 75 
33b. Plot of smoothed tilt data from Ape Cave North, December 26, 1980 through December 31, 1980, north-south axis of tilt .........................

34a. Plot of raw tilt data from June Lake, December 26, 1980 through December 31, 1980, north-south axis of tilt . 76

34b. Plot of smoothed tilt data from June Lake, December 26 , 1980 through December 31, 1980, north-south axis of tilt....................... 76

35. A diagram of the tilt vector directions and relative magnitudes recorded before and after the December 1980 eruption . . . . . . . . . . . . . . . . 77

36. Idealized diagram of a Mogi volcanic system showing the major axis of stress as described by Machado . . . . 82

37. Surficial deformation diagram representing the projected maximum and mimimum theoretical vertical deformation from a point source . . . . . . . . . . . . .

38. Idealized deformation patterns resulting from a large volume at depth . . . . . . . . . . . . .

39. Idealized diagram of a two chamber volcanic system ....

40. Time verses depth plot of relative hypocenter locations under the Mount St. Helens crater for JulY, 1980 . . 90

41. Time verses depth plot of relative hypocenter locations under the Mount St. Helens crater for August, 1980 . 
42. Time verses depth plot of relative hypocenter locations under the Mount St. Helens crater for October, 1980 .

43. Time verses depth plot of relative hypocenter locations under the Mount St. Helens crater for December, 1980 .

44. Idealized deformation patterns caused by a two chamber

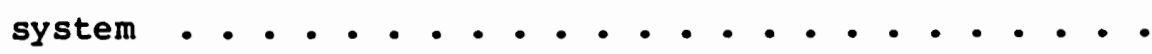
93

45. Idealized deformation diagram of a two chamber magmatic system that could have existed during the October, 1980 eruption . . . . . . . . . . . . . .

46a. Plot of resultant tilt from Ape Cave and Ape Cave North tiltmeter stations for the May 18 eruption ...... 98

46b. Plot of resultant tilt from Ape Cave and Ape Cave North tiltmeter stations for the May 25 eruption . . . . . 98

47. Proposed chamber shape and depth model for early 1980 eruptions of Mount St. Helens . . . . . . . . 104

48. Proposed chamber shape and depth model for late 1980 eruptions of Mount St. Helens . . . . . . . . 107

49. Julian day conversion chart for Leap year use only . . . 115

50. East-west and north-south components of tilt at Ape Cave tiltmeter site, July 1, 1980 through July 30, 1980 • 116

51. East-west and north-south components of tilt at Ape Cave tiltmeter site, August 1, 1980 through August 30, 1980 
52. East-west and north-south components of tilt at Ape Cave tiltmeter site, September 1, 1980 through September 30,1980 . . . . . . . . . . 118

53. East-west and north-south components of tilt at Ape Cave tiltmeter site, October 1, 1980 through October 30,1980 . . . . . . . . . . . 119

54. East-west and north-south components of tilt at Ape Cave tiltmeter site, November 1, 1980 through November 30,1980 . . . . . . . . . . . 120

55. East-west and north-south components of tilt at Ape Cave tiltmeter site, December 1, 1980 through December 30,1980 . . . . . . . . . . . 121

56. East-west and north-south components of tilt at Ape Cave North tiltmeter site, July 1, 1980 through July 30,1980 . . . . . . . . . . . . 122

57. East-west and north-south components of tilt at Ape Cave North tiltmeter site, August 1, 1980 through

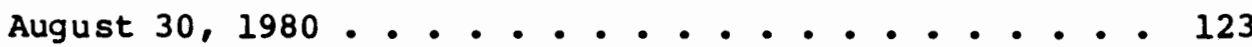

58. East-west and north-south components of tilt at Ape Cave North tiltmeter site, September 1, 1980 through September 30,1980 . . . . . . . . . . . 124

59. East-west and north-south components of tilt at Ape Cave North tiltmeter site, October 1, 1980 through October 30, 1980 . . . . . . . . . . . 125 
60. East-west and north-south components of tilt at Ape Cave

North tiltmeter site, November 1,1980 through

November 30,1980 . . . . . . . . . . . . 126

61. East-west and north-south components of tilt at Ape Cave

North tiltmeter site, December 1,1980 through

December 30,1980 . . . . . . . . . . . 127

62. East-west and north-south components of tilt at Blue Lake tiltmeter site, July l, 1980 through July 30,1980 • 128

63. East-west and north-south components of tilt at Blue Lake

tiltmeter site, August 1, 1980 through August 30, 1980129

64. East-west and north-south components of tilt at Blue Lake

tiltmeter site, September 1, 1980 through

September 30,1980 . . . . . . . . . . 130

65. East-west and north-south components of tilt at Blue Lake

tiltmeter site, October 1, 1980 through

October 30,1980 . . . . . . . . . . .

66. East-west and north-south components of tilt at Blue Lake

tiltmeter site, November 1, 1980 through

November 30,1980 . . . . . . . . . . 132

67. East-west and north-south components of tilt at Blue Lake

tiltmeter site, December 1, 1980 through

December 30,1980 . . . . . . . . . . 133

68. East-west and north-south components of tilt at June Lake tiltmeter site, July 1, 1980 through July 30, 1980 • 134 
69. East-west and north-south components of tilt at June Lake tiltmeter site, August 1, 1980 through August 30, 1980135 70. East $\rightarrow$ west and north-south components of tilt at June Lake tiltmeter site, September 1, 1980 through September 30,1980 .............. 136

71. East-west and north-south components of tilt at June Lake tiltmeter site, October 1, 1980 through October 30, 1980 . . . . . . . . . . 137

72. East-west and north-south components of tilt at June Lake tiltmeter site, November 1, 1980 through November 30,1980 .............. 138

73. East-west and north-south components of tilt at June Lake tiltmeter site, December 1, 1980 through December 30,1980 . . . . . . . . . . 139

74. East-west and north-south components of tilt at PSU $\$ 2$ tiltmeter site, July l, 1980 through July 30,1980 • 140

75. East-west and north-south components of tilt at PSU \#2

tiltmeter site, August 1, 1980 through August 30, 1980

76. East-west and north-south components of tilt at PSU \#2

tiltmeter site, September 1, 1980 through

September 30,1980 . . . . . . . . . . . 142

77. East-west and north-south components of tilt at PSU 2 tiltmeter site, October 1, 1980 through October 30,1980 ............... 143 
xvii

FIGURE

PAGE

78. East-west and north-south components of tilt at PSU $\$ 3$

tiltmeter site, August 1, 1980 through August 30, 1980144

79. East-west and north-south components of tilt at PSU

tiltmeter site, September 1, 1980 through

September 30, 1980 . . . . . . . . . . . . 145

80. East-west and north-south components of tilt at PSU \$3

tiltmeter site, October 1, 1980 through

October 30,1980 . . . . . . . . . . . . 146 


\section{CHAPTER I}

\section{INTRODUCTION}

\section{A. LOCATION}

Mount st. Helens is located in the southwestern portion of Skamania County, Washington at $122.11^{\circ}$ west longitude and $46.12^{\circ}$ north latitude, about $85 \mathrm{~km}$ northeast of Portland, Oregon. It is one of a series of volcanoes forming the Cascade Range (Figure 1) which extends from Mount Garibaldi in British Columbia, Canada to Lassen Peak in northern California. The primary area of study (Figure 2) comprises approximately 157 square kilometers $\left(\mathrm{km}^{2}\right)$ in a semicircular pattern, extending $10 \mathrm{~km}$ radially to the west, east and south from the central crater of Mount st. Helens.

Access to the area since the renewed volcanic activity of 1980 is limited, with the primary mode of transportation being by helicopter. It is possible however to reach many portions of the area by ground transportation, but the condition of the road beds is generally poor with washouts and bridge failures common.

\section{B. PURPOSE}

The purpose of this study at Mount St. Helens was to analyze tiltmeter data recorded during the period of July 1, 1980 to December 31, 1980 and compare it with concurrent volcanic activity. Three major 


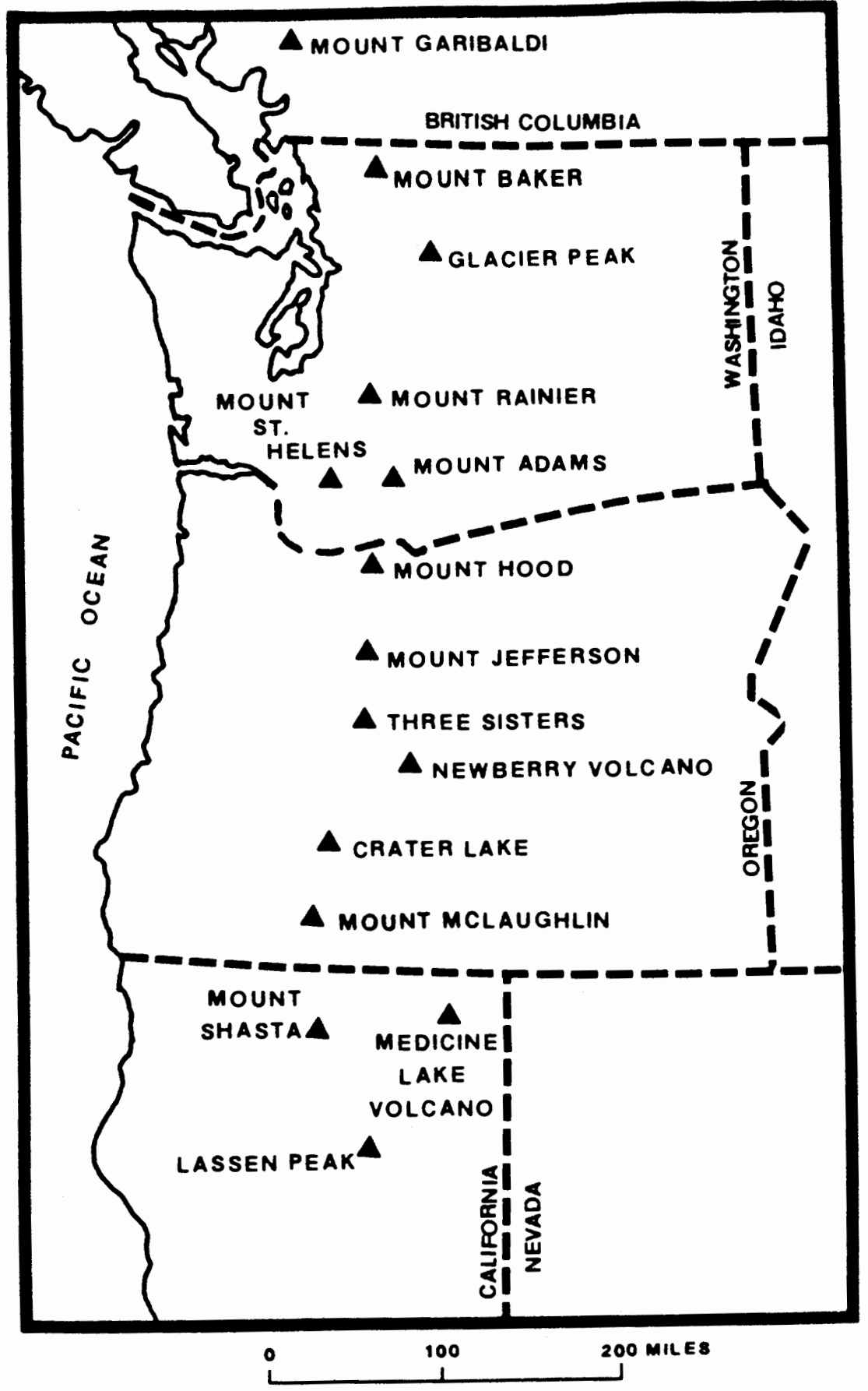

Figure 1. General location map showing the relationship of the Cascade Range and major volcanic peaks to the Pacific Northwest. 


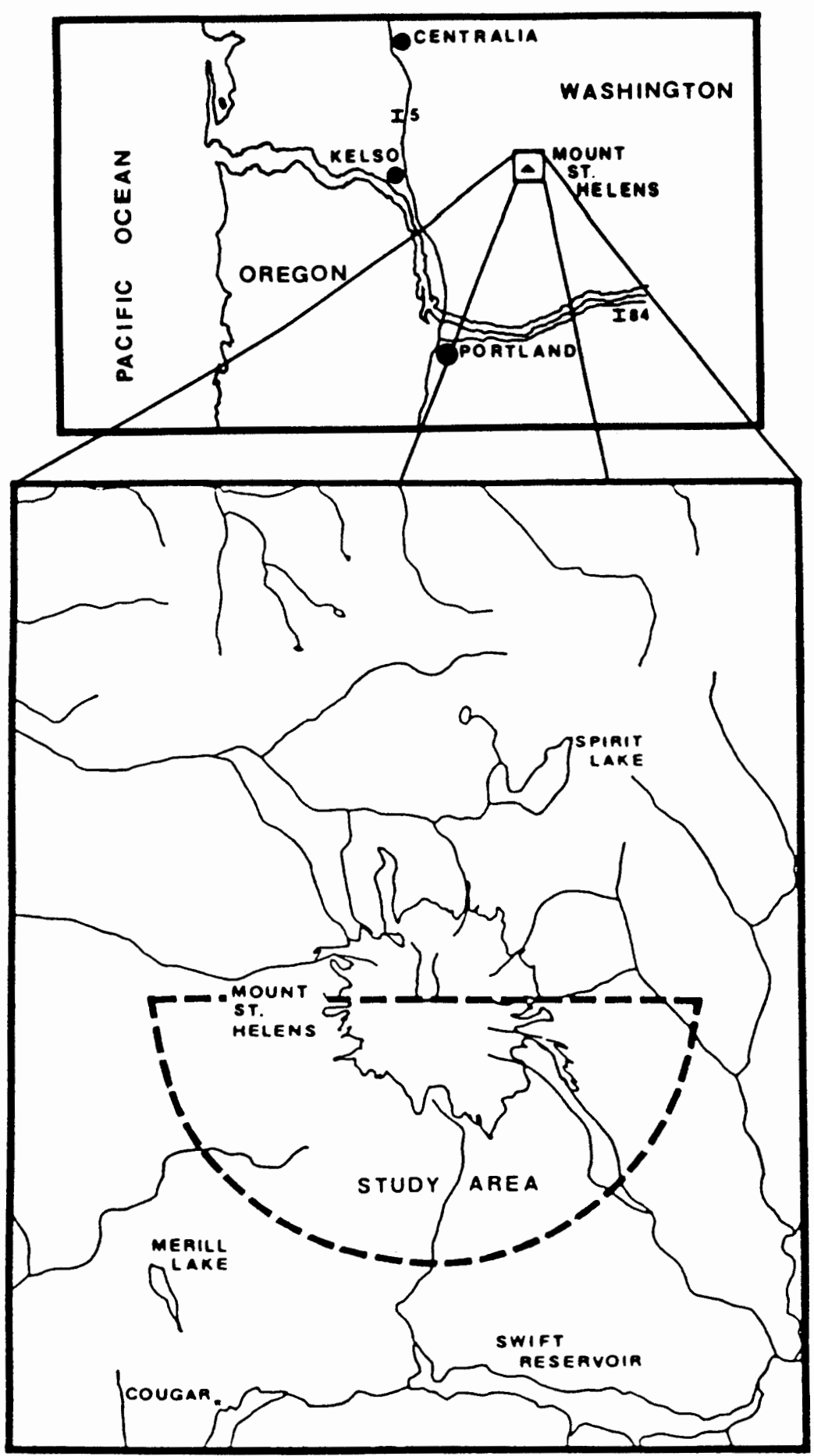

Figure 2. Index map showing the location of the study area with reference to Mount $s t$. Helens. 
topics were addressed in the course of this study: the first, was analysis of the data for the relationships of tilt to eruptive events; the second, to correlate output from the tiltmeters based on distance from the mountain and tiltmeter type; and the third, to analyze and correlate tiltmeter data to results from geodetic and seismic studies during the same period.

\section{PREVIOUS WORK}

The earliest formal geologic investigation in the area was done by Verhoogen (1937) culminating in a general geologic map of the Mount St. Helens area. More recently investigations by Crandell (1971), Crandell and others (1962, 1973), Hopson (1971, 1980), Hyde $(1970,1975)$ and Mullineaux and Crandell (1960) have focused on the stratigraphy and relative ages of the volcaniclastic deposits surrounding the mountain.

Several geophysical investigations involving the Mount st. Helens region have been conducted since the late 1960's. Gravity studies by Danes (1969), Braile (1970), D. Williams and R. Spidel (1981, personal communication) using a regional data base have tried to interpret the structure of Mount St. Helens based on the appearance of local anomalies. Seismological studies of the region (Weaver and others, 1981, Weaver and Smith, 1983) have shown the existence of a major fault zone in the Mount st. Helens region.

The first subsurface modeling of volcanic structures using tilt data was done by Mogi (1958), who developed a practical approach for the determination of size and location of magmatic chambers based on surface deformation at Sakurazima Volcano, Japan. Since that time 
major studies at Kilauea, Hawai (Kinoshita and others, 1969, 1974, Swanson and others, 1976, and Fiske and Kinoshita, 1969), and Krafla, Iceland (Tryggvason, 1978, Bodvarsson and others, 1980, and Axelsson, 1980) have used platform or borehole tiltmeters in association with other geodetic measurements to assess the physical parameters of the magma chamber in active volcanic situations. The studies at Kilauea and Krafla volcanoes have indicated that both platform and borehole tiltmeters can succesfully measure surface deformation associated with volcanic eruptions, the results of these measurements aiding in the analysis and prediction of volcanic activity.

The current monitoring of Mount St. Helens, necessitated with the start of eruptive activity in March, 1980, has created a large information base. Deformation studies using geodetic survey techniques (Swanson and others, 1981, Chadwick and others, 1983), have indicated that measurable changes to Mount St. Helens have occurred since March, 1980. Petrological studies of eruptive output from Mount St. Helens between 1980 and 1984 (Cashman and Taggert, 1983, Lipman and others, 1981, Melson, 1983, Sarna-Wojcicki and others, 1981) have indicated that there has been only one source for eruptive outputs. Tiltmeter studies at Mount St. Helens (Dvorak and others, 1981, Dzurisin and others, 1983) have indicated that discernible changes in tilt occur in conjunction with both explosive volcanic activity and exogenous dome growth. Geophysical modeling of inner-crater deformation patterns (Denlinger, 1984, personal communication) has indicated that a small piston-like intrusive body is a possible cause of the late 1980 and early 1981 deformation of the crater floor. 
GENERAL GEOLOGY

A. REGIONAL GEOLOGIC SETTING OF MOUNT ST. HELENS

Mount St. Helens is located within the north-south trending belt of the Cascade Mountains forming a portion of the western Cordilleran Mountain System. The Cascade Mountains are characterized by high Plio-Pleistocene strato-volcanoes built on Tertiary volcanic rocks in the south and, pre-Tertiary rocks at the northern termination.

Rocks of the Cascade Range have been statigraphically and physiographically divided into two major groups (Hammond, 1979); the Western Cascade Group (50-0 Million years Ago (MA)) and the High Cascade Group (4-0 MA), as shown in Figure 3. The Western Cascade Group composed of lower, middle and upper members, consists primarily of calc-alkaline andestites, rhyodacites, basalts, mudflows, volcaniclastic deposits and pyroclastic deposits. The High Cascade Group is predominantly composed of high-alumina olivine basalt, basaltic andesite forming shield volcanoes and cinder cones and, in smaller quantities hornblende and/or pyroxene andesite and dacite forming large strato-volcanoes.

In general the Western Cascade Group has been extensively eroded in comparison to the High Cascades Group. Arching of the Cascade Range during the Plio-Pleistocene resulted in greater erosion of the Western Cascades. The High Cascade Group is generally located to the east of 


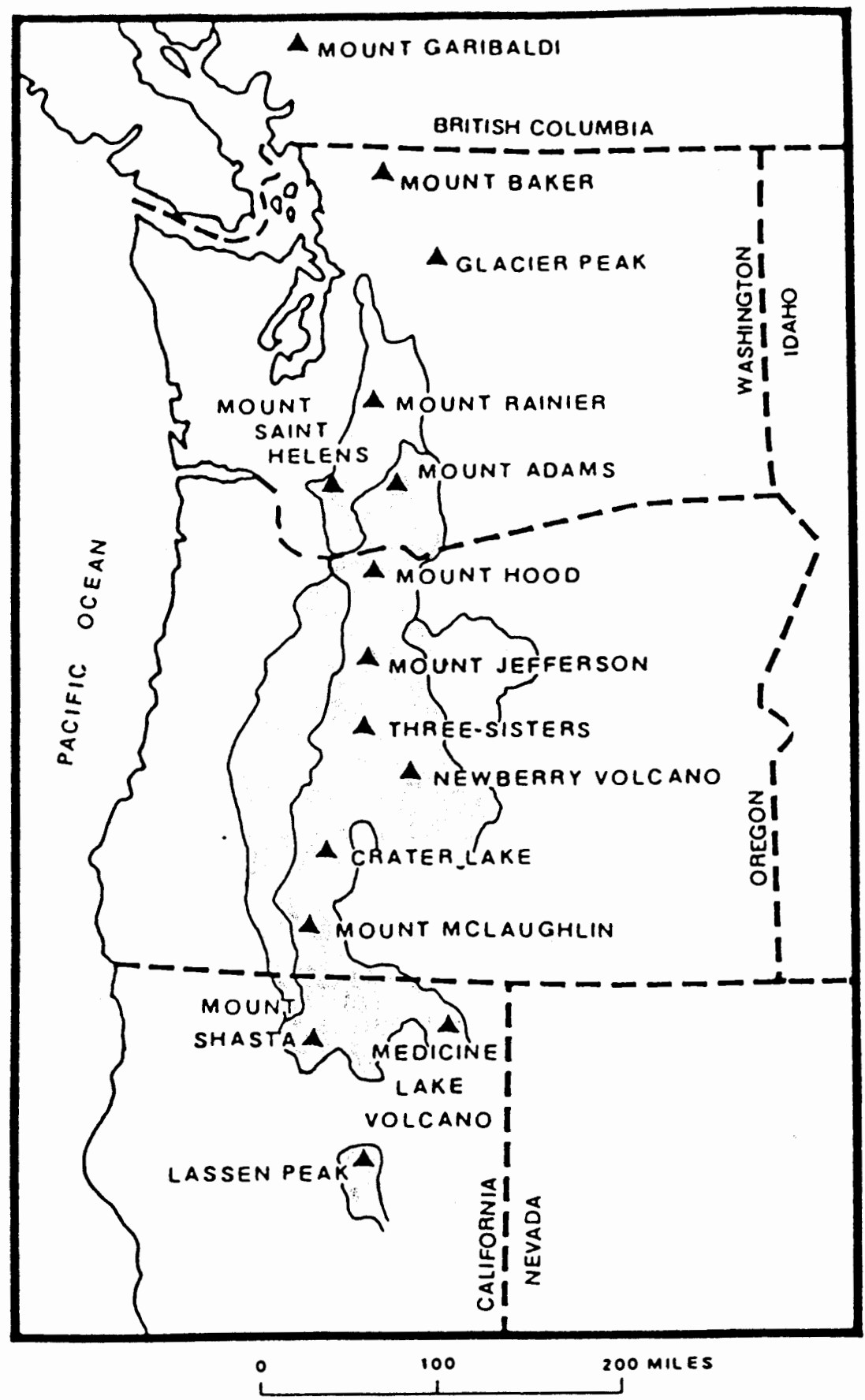

Western Cascade Group, andesite basalt complex

High Cascade Group, olivine basalt complex

Figure 3. A map showing the major high Cascade volcanic peaks, with the gross stratigraphic units of the Cascades (after Hammond, 1979). 
the Western Cascade summit with High Cascade Group formations commonly covering Western Cascade Group formations.

The position of Mount St. Helens is about $45 \mathrm{~km}$ west of the Cascade Crest very near the western edge of the Tertiary volcanic rocks of the Western Cascades. This positioning is almost due west of Mount Adams, another High Cascade volcano, and west of the general axis of the High Cascade group strato-volcanoes. Location of Mount St. Helens is also in the area where the Cascade Range may be changing from a compressive tectonic environment in the north to an extensional environment in the south (Nakamura, 1977, Weaver and Smith, 1983).

\section{B. GENERAL STRATIGRAPHY OF MOUNT ST. HELENS}

Since the purpose of this study is not to describe the detailed geology of Mount St. Helens, only a brief summary of the general stratigraphic character of the volcano will be presented here. More complete stratigraphic descriptions can be found in; Verhoogen, (1937), Mullineaux and Crandell, (1960, 1981), and Fiske, (1963).

The Mount st. Helens area in general is composed of two ages of volcanic rock (Mullineaux and Crandell, 1960); the complex of Late Eocene to Pleistocene age rocks and the predominantly Holocene age (younger than 37,000 B.P.) material which forms the present mountain. The major pre-Mount st. Helens rock unit is the Ohanapechosh Formation, primarily exposed south of the mountain. In the area of Mount St. Helens, the Ohanapechosh Formation generally consists of andesitic and dacitic tuff-breccia, pyroxene andesite lava flows with associated breccias, or volcani-clastic sedimentary beds dipping $5^{\circ}$ 
to $200 \mathrm{SE}$ in the study area. Widespread zeolite facies alteration is common in the Ohanapechosh Formation. Age of the Ohanapechosh Formation is Late Eocene to Oligocene (?) (Verhoogen, 1937; Fiske, 1963) and is the oldest unit exposed in the study area.

During the Miocene, the Ohanapechosh Formation was intruded by small plutonic bodies of epizonal granodiorite associated with Mitchell Peak. Following the Mitchell Peak event was the emplacement of hypabyssal intrusive rocks, primarily pyroxene microdiorite and granodiorite porphyry forming the Spirit Lake pluton. Concurrent with the Spirit Lake pluton emplacement was the intrusion of a similar complex south of Merrill Lake (Hopson, 1981, unpublished).

Emplacement of the Goat Mountain plug, a biotite-hornblende dacite porphyry, occurred during the Late Pliocene. This was followed by the formation of Marble Mountain during the Early Pleistocene, which is considered by Hopson (1981, unpublished) to be the last major event belonging to the pre-Mount St. Helens complex.

The present Mount St. Helens volcanic center is a complex composite volcano formed of numerous dacitic domes intruded into an andesitic strato-volcano. Based on radio carbon dates of terrace deposits and tephera layers surrounding the mountain, it is believed that the present cone is a feature probably less than five hundred years old (Mullineaux and Crandell, 1960, 1981) that started forming during the Kalama eruptive period.

Volcanic products from Mount st. Helens are varied, ranging from silicic andesite and dacitic domes, to mafic a and pahoehoe basalt flows (Crandell and others, 1962, Mullineaux and Crandell, 1981). The 
eruptions in recent history (younger than 1,000 yrs. before present (B.P.)) have been closely spaced in time (Crandell and Mullineaux, 1978), with the recent lava flows emanating from the flanks, and dacite plug domes commonly intruding volcanic rock at the 2,000 meter level and at the summit.

During formation of the mountain, explosive events created numerous tephra deposits. The most notable of these deposits are the $W$ and $Y$ layers. The $W$ layer, dated at $500 \mathrm{yrs}$. B.P. has a thickness of 7 meters on the volcano flank. The $Y$ layer, dated at 3,200 yrs. B.P., extends to the northeast having a thickness of greater than one meter in Randle, Washington, $41 \mathrm{~km}$ northeast of the present cone (Crandell and others, 1962).

Major products of volcanic activity at Mount St. Helens have been mud flows, debris flows and lahars. These primary flows, interbedded with tephras and pyroclastic flows commonly form the major constituents of terrace deposits found in the drainage system of the mountain. Remnants of the largest debris flow deposits can be found extending as far from the mountain as the Columbia River (Hyde, 1970).

The eruption of May 18, 1980 was accompanied by the ejection of large volumes of ash, the removal of the summit by a landslide and the creation of a new central crater. Material derived from a massive landslide of the northern side of the mountain was deposited on the plain between the mountain and spirit Lake. Large debris flows resulting from the eruption traveled as far as the Columbia River. For details of the lateral extent of the debris flows, depositional area of the landslide, post-May 18, 1980 eruption topography and geologic 
information concerning the eruption of May 18th, refer to either Lipman and Mullineaux (1981) or Foxworthy and Hill (1982).

Since May 18, 1980, several explosive eruptions and dome building sequences have occurred. A chronographic history of the events during the period of July l, 1980 through January 4, 1981 are listed in Appendix C. For this study the most important events are July 22, August 7, October 16, and December 28, 1980. For additional information concerning the first one hundred days of volcanic activity at Mount St. Helens during 1980, refer to Foxworthy and Hill (1982).

A preliminary geologic map of Mount St. Helens area was compiled by Hopson (1981, unpublished). Based on this map, a generalized geologic map (Figure 4) was constructed indicating the suspected gross physical properties of the various formations as they relate to the installation and response of tiltmeters.

\section{GENERAL STRUCTURE OF THE MOUNT ST. HELENS REGION}

Limited erosion of Recent rock units forming Mount St. Helens has left many of the older Plio-Pleistocene units in the study area covered. Because of this, the postulated existence of major structural features in near proximity to the mountain are based on geophysical evidence collected from seismic networks and gravity surveys. Deformation of recent units forming Mount St. Helens has been limited to soft sediment deformation in unconsolidated deposits.

Major structural control for this area is recorded in the older Ohanapecosh Formation, which is considered to be the basement formation in this study. Structural modifications to the Ohanapechosh Formation 


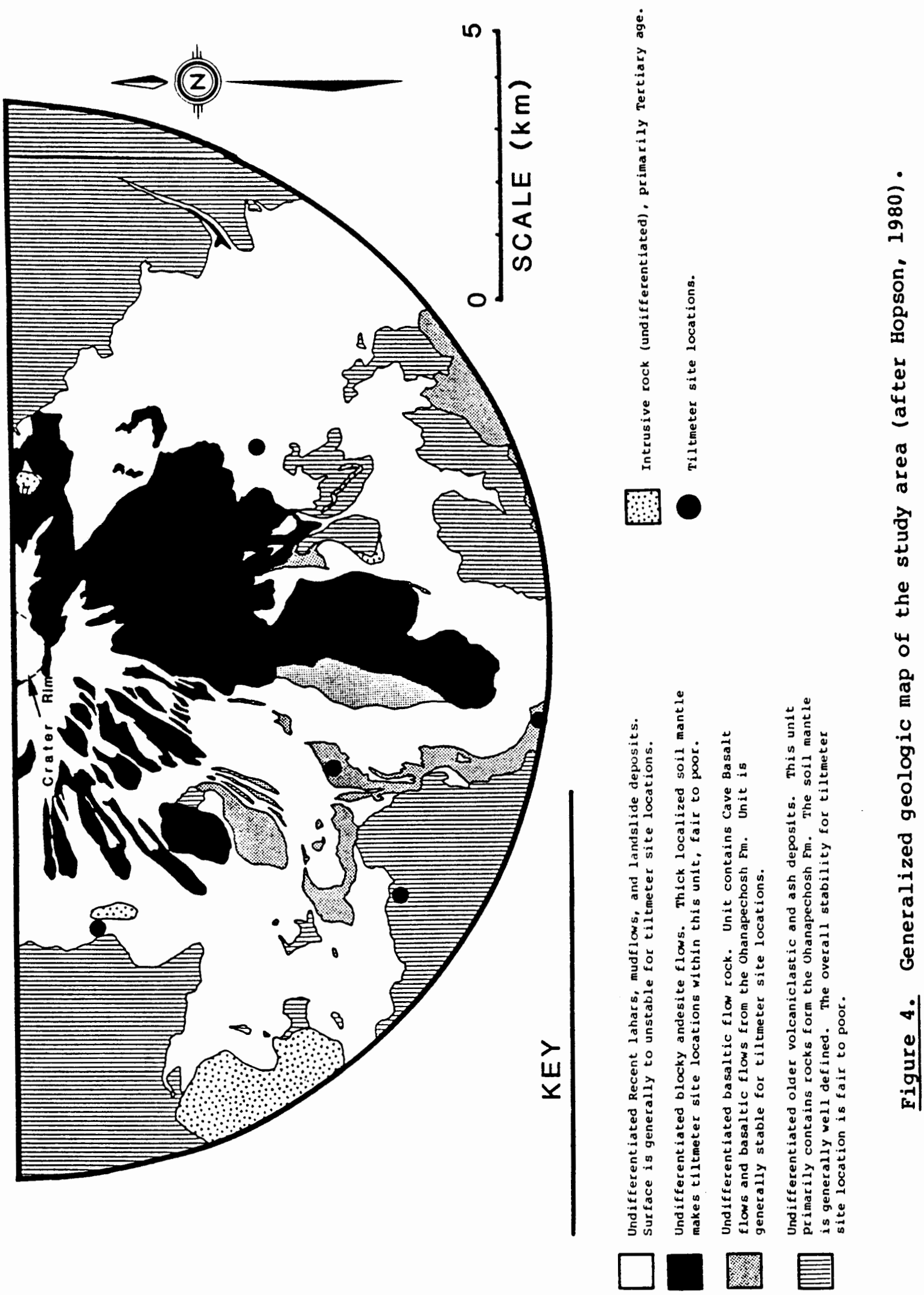


have resulted from horizontal SW to NE tectonic compression of the Mount St. Helens region (Weaver and others, 1981) and localized volcanic deformation. This is consistent with regional tectonic stress patterns with the fold axis of the major compressional stress direction at approximately N. $30^{\circ}$ W. (Roägers, 1979). Recent seismic investigations (Weaver and others, 1981, Weaver and Smith, 1983) have shown the major compressional tectonic axis in the Mount St. Helens area to be at N. $25^{\circ}$ พ.

A major fault zone trending approximately N. $5^{\circ} \mathrm{W}$. through the Mount St. Helens area initially described by Weaver and others, (1981) has been informally named the St. Helens seismic zone (SHz) (Weaver and Smith, 1983). The SHz is characterized as a right lateral strike-slip fault zone with a near vertical dip, north or south of Mount st. Helens. Beneath Mount St. Helens, the SHz remains right lateral but focal mechanisms suggest a possible thrust component with a slight westward dipping of the fault plane. The relationship of hypocenter locations of magnitude greater than 1.0 to Mount st. Helens during 1980, with approximate fault zone locations is shown in Figure 5. The trace of the northeast trending fault may be a controlling mechanism for location of Mount st. Helens magmatic conduit (Weaver and others, 1983). The pattern of the hypocenter locations beneath the mountain (Figure 6) at a depth of approximately $7 \mathrm{~km}$ bifurcate. This pattern, described by Scandone and Malone (in review) represents the competent zone where earthquakes are located surrounding a seismically free zone which they interpret to be a magma chamber. Based on the hypocenter data, Malone has characterized the chamber to be about $1.5 \mathrm{~km}$ in 


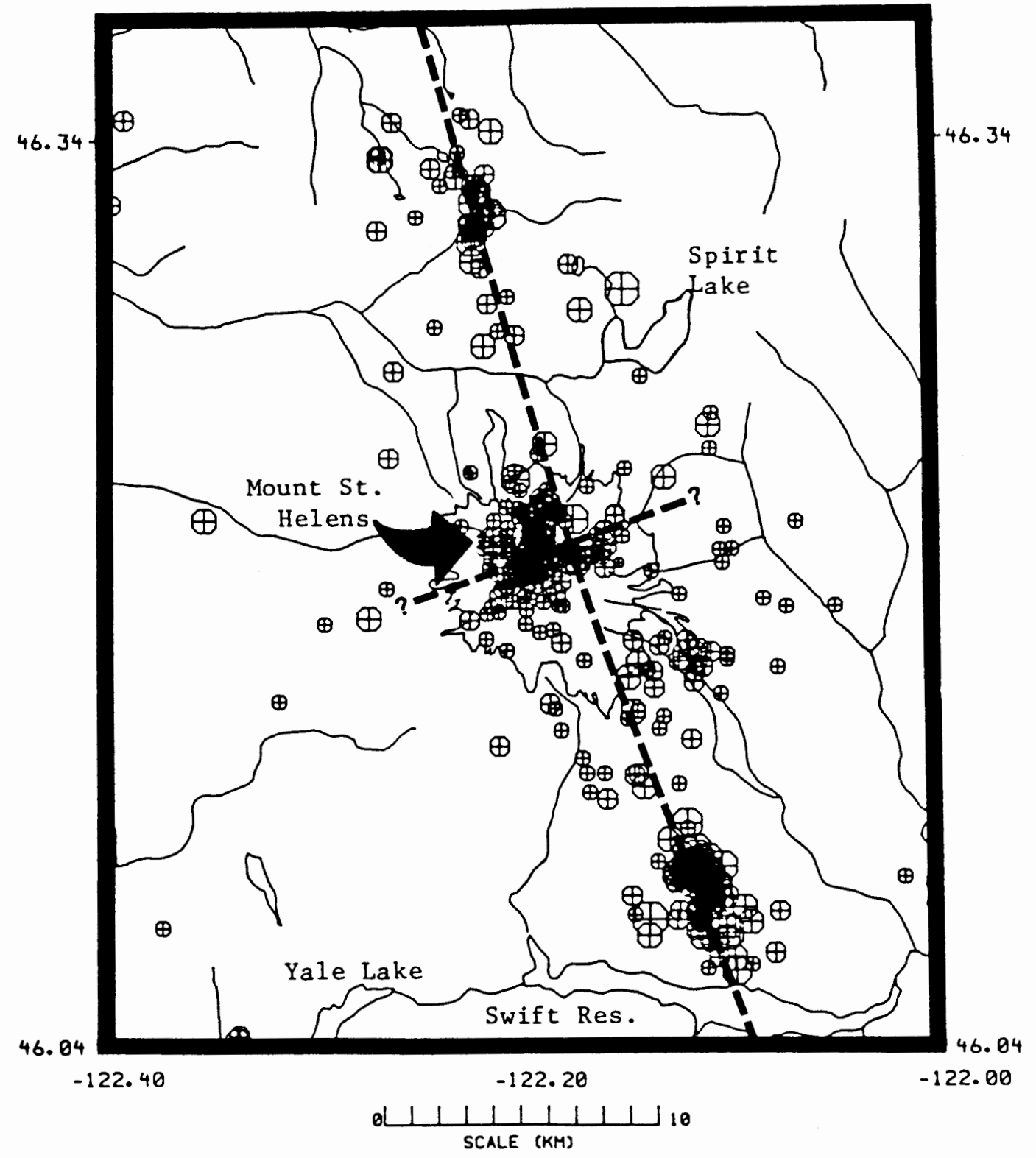

Figure 5. Map showing the approximate trace of the St. Helens seismic zone (after Weaver and others, 1981; Weaver and Smith, 1983) based on seismic data.

diameter with a vertical extent of greater than $6 \mathrm{~km}$. This would give the chamber a nominal volume of $10-20 \mathrm{~km}^{3}$. Additionally Malone noted that the chamber shape was relatively constant throughout of 1980 . 
122.27

122.10
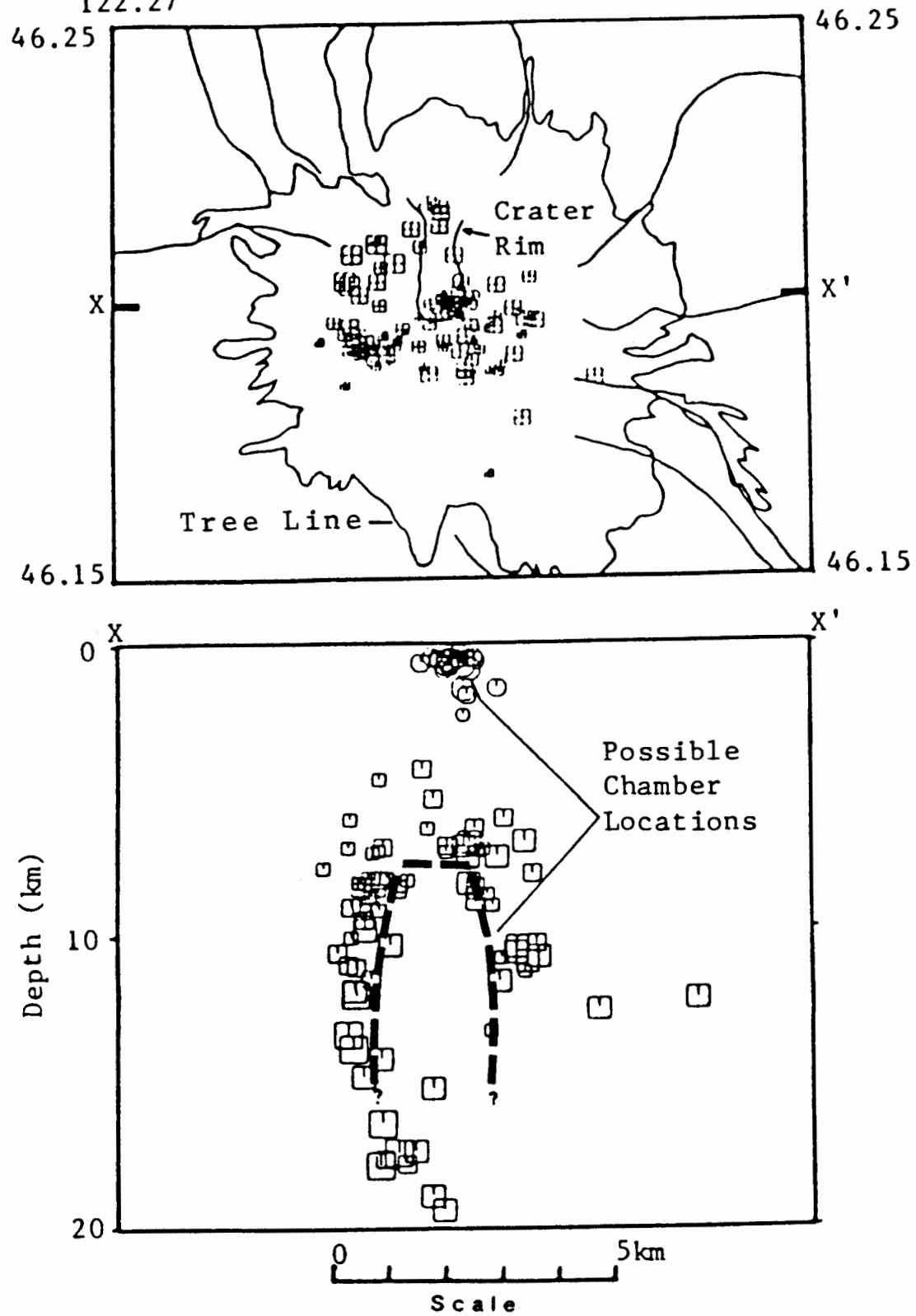

Figure 6. Map and cross section diagram of Mount St. Helens showing hypocenter locations for earthquakes of magnitude greater than 1, associated with volcanic phenomena. Circles indicate the 30 best identified precursory earthquakes to the March 19, 1980 eruption. Squares indicate the 90 best identified earthquakes immediately following explosive eruptions of 1980. Increasing symbol size denotes increased magnitude. Hypocenter locations have been horizontally superimposed onto a single plane from up to $2.5 \mathrm{~km}$ north or south of the cross section. 


\section{SUMMARY OF 1980 ERUPTIONS}

The following section is a short synopsis of the major volcanic events of 1980. A chronologic listing of the major volcanic events during this study is given in Appendix C. Important statistics concerning the major eruptions during the study are shown in Table I.

On March 20, 1980 Mount St. Helens returned to an active state with a series of volcanic tremors. Tremors continued increasing in number for the next five days, peaking March 25 in the late afternoon. A subsequent decrease in tremor activity followed for the next two days. On the afternoon of March 27 the first explosive eruption occurred leaving a small crater in the summit of the mountain. Over the next two days more than a dozen explosive events occurred and a second crater was created separated from the first by a septum of rock and ice. A bulge began to form March 27, on the north flank of the mountain centered over the main area of earthquake activity.

The first harmonic tremor occurred April 1 and was followed by twenty-one days of sporadic non-harmonic tremor. The frequency of explosive eruptions continued on the wane through mid-April temporarily ceasing on April 22.

Explosive activity resumed on May 7 and continued sporadically through May 14. The bulge that had begun to grow on the north flank had increased in height by $150 \mathrm{~m}$ and had moved northward by $106 \mathrm{~m}$ (Christiansen and Peterson, 1981).

On May 18 at 15:32 GMT (Greenwich Mean time, 8:32 PDT) the major eruption of 1980 occurred. The area of the bulge on the north flank suffered slope failure following a magnitude 5+ earthquake. This was 


\section{TABLE I}

COMPARISON OF ERUPTIVE PERIODS, OUTPUT VOLUMES, DOME DIMENSIONS, DATES OF DOME EMPLACEMENT AND EXTRUSION RATES

FOR MOUNT ST. HELENS DURING 1980

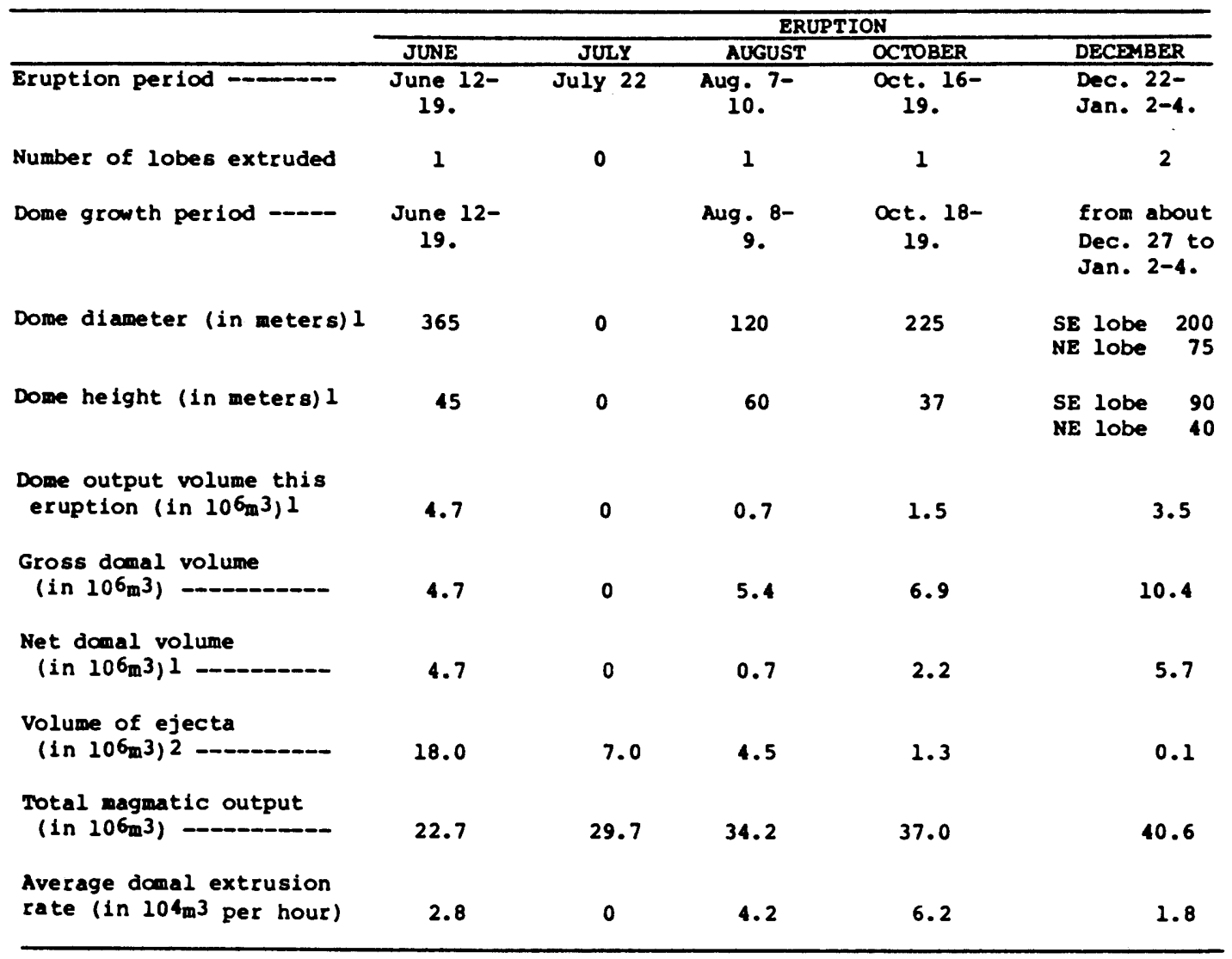

\footnotetext{
lFrom Swanson and other 8,1982

2Modifled from: Lipman and other 8, 1981; Sarna-Wojcicki and other8, 1981; Rowley and others, 1981.
}

followed in rapid succession by a lateral explosive blast and a Plinian column. The results were a large debris avalanche down the north side of the mountain and Toutle River drainage and devastation of an area of $600 \mathrm{~km}^{2}$ north of the mountain. The summit of the mountain was removed and a large breached crater $1.5 \mathrm{~km} \times 3 \mathrm{~km}$ across and 700 meters deep was formed, opening to the north. 
The next large eruptive event with associated pyroclastic flows occurred on May 25 emanating from the crater. On June 12 the third major eruption of the mountain took place. This eruption produced several new ash flows that traveled down the north flank. The first lava dome created during the eruptive series that started May 18th was sighted June 15. Dome growth continued for at least the next five days with observations on June 28 showing stabilization.

The eruption of July 22 was also an explosive eruption similar to the eruptions of May 25 and June 12. The eruption was not accompanied by premonitory harmonic tremor (Malone and others, 1981) as occurred in the June 12 eruption. This eruption destroyed the dome created in the June 12 eruption, but did not produce a new dome. Geodetic measurements made during this time suggested a northward movement of a section of the crater known as the "rampart" of about $5 \mathrm{~cm} /$ day (Christiansen and Peterson, 1981).

Following the July 22 eruption by 16 days another major eruption occurred. The August 7 eruption was preceded by harmonic tremor (Malone and others, 1981) and a northward expansion of the "rampart" area. The eruption created a small pumiceous ash flow. Following the main eruptive burst small deep earthquakes $(5 \mathrm{~km})$ occurred and the intensity of harmonic tremor decreased. A new dome was first observed the morning of August 8 and continued growing until August 10. After the dome stopped growing, seismicity returned to low levels, remaining low for the next two months. In the "rampart" area of the crater, movement continued in a northerly direction.

Earthquakes resumed in October gradually increasing in number 
until October 16, when a series of separate pyroclastic eruptions occurred over a three day period. Small pyroclastic flows occurred during two of the events on the north flank. Following the last pyroclastic eruption of this sequence on October 18, a new dome was extruded. The dome extrusion lasted for a day, creating the largest dome since May 18, 1980.

The mountain remained relatively quite until late November when low-level seismic events began to accompany low-level harmonic tremor. On December 13, a small portion of the dome was blasted away by a gas emission. Following the blast, seismicity began to increase and on December 25 a new dome began extruding along side the October dome. This extrusion continued until early January, 1981 and was the last event of 1980. 


\section{CHAPTER III}

\section{INSTRUMENTATION}

Tiltmeters are electronic devices designed to measure extremely small $\left(.8 * 10^{-8}\right.$ radians) tilts about two principal axis ( $X$ and $Y$ ). Based on the movement of a bubble in an electrolytic fluid, sensors are used to measure resistance changes that indicate the attitude of the bubble and fluid container with respect to vertical. By the addition of electronic circuitry, output from the sensors can be directly related to attitude changes of the tiltmeter (Kinemetrics, 1975).

The intention of the U.S. Geological survey (USGS) installations was to establish a network of tiltmeters around the base of the mountain to provide early detection of inflation or deflation. The tiltmeter network was also designed to provide a large data base for geologic interpretations, such as intrusive body depth and prediction of future volcanic episodes. Tiltmeter installations on the north side of Mount St. Helens were destroyed during the May 18, 1980 eruption and the sites abandoned (Dvorak and others, 1981).

The instrumentation network for this project is based on the use of two different types of tiltmeters; the biaxial shallow borehole type (Kinimetrics model $T M-1 B$ ), and the short base biaxial platform type (Kinimetrics model TM-lA). Two shallow borehole tiltmeters belonging to the USGS were installed using the standard installation procedure described by Mortensen and others, (1977). 
Two other borehole tiltmeters, belonging to Portland state University (PSU) were installed in a modified version of the USGS procedure. A diagramatic comparison of the two borehole installation procedures is shown in Figure 7. Two short base platform type tiltmeters belonging to the USGS were installed (Figure 8) in lava tubes on solid rock outcrops.

The site selection for the various tiltmeters was determined by the apparent stability of the site, and in the case of the PSU tiltmeters, road access. A major concern was the susceptibility of the site to future volcanic events. See Figure 9 for locations of the different tiltmeters related to Mount st. Helens.

The installation of the PSU tiltmeters postdated the May 18, 1980 eruption. Intent of the borehole installations was to obtain further data regarding volcanic activity in conjunction with the USGS tiltmeters. The PSU tiltmeters were setup to record tilt more precisely than the USGS tiltmeters, enabling the PSU sites to monitor earthtides.

All of the data from the USGS tiltmeters was electronically digitized and telemetered at ten minute intervals to Vancouver, Washington. The data collected by the PSU tiltmeters was recorded on site by Rustrak strip chart recorders and later hand digitized by Ansel Johnson. 


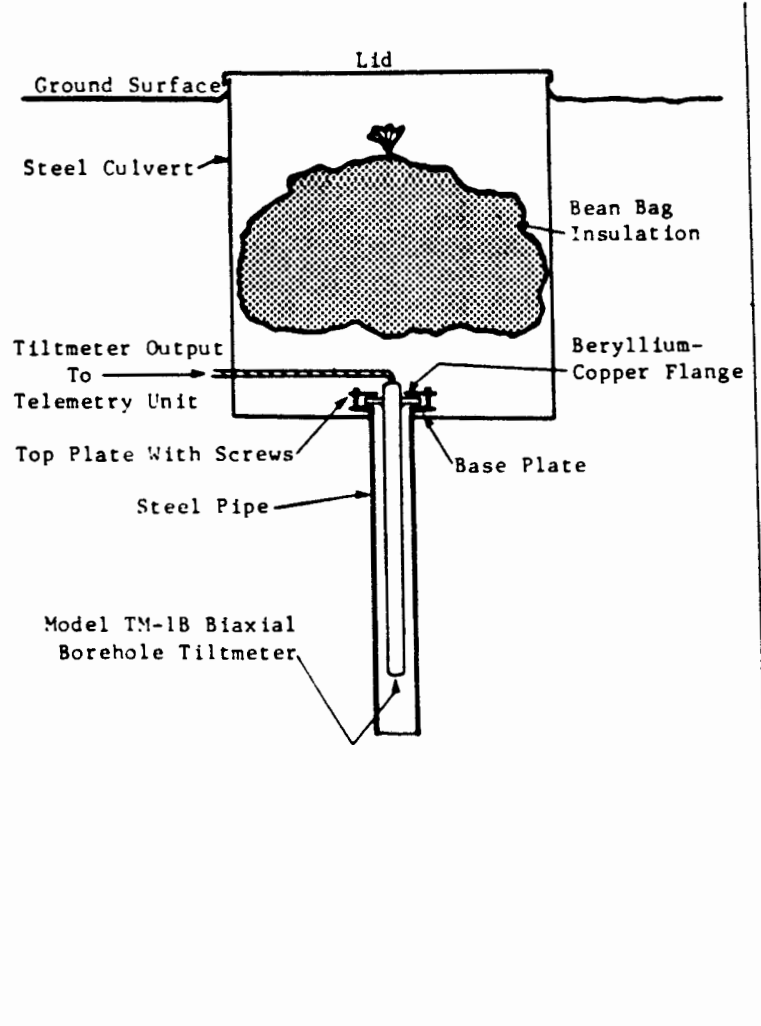

A

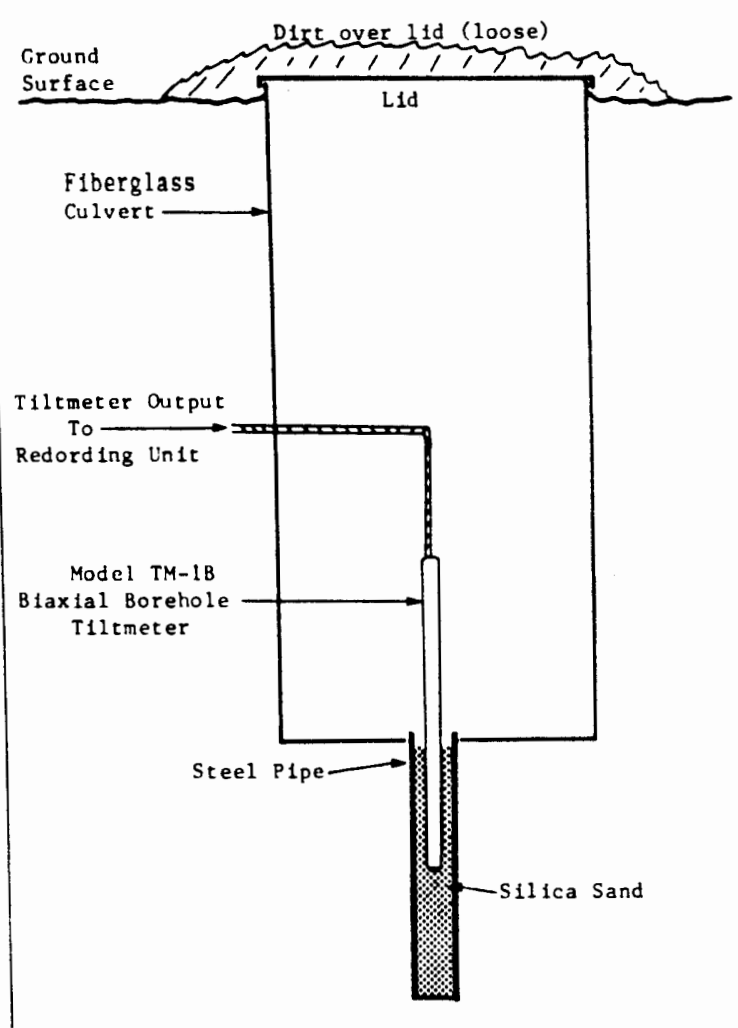

B

Figure 7. Diagram showing the two different versions of borehole installations used in this study. Figure 7a. is the USGS installation and Figure $7 b$. is the Portland state version.

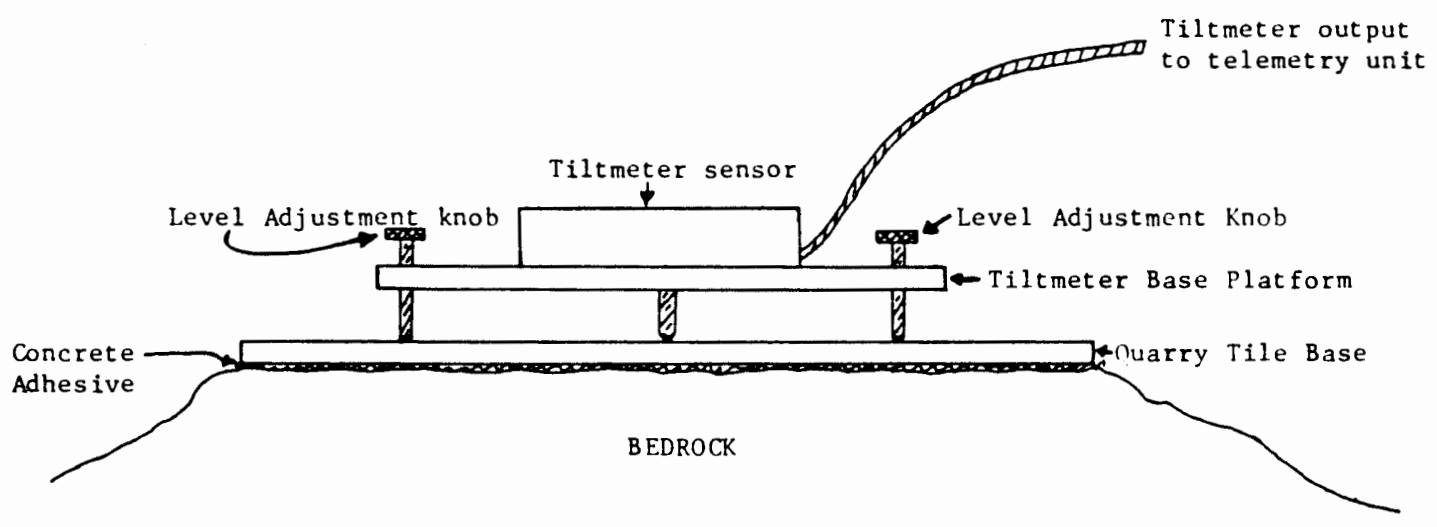

Figure 8. Diagram showing standard platform tiltmeter installation at Mount St. Helens. 
SITE LOCATION AND SITE GEOLOGY

The following site descriptions are generalized in terms of geologic information. Classification of the units is based on the gross physical properties rather than individual rock type. Also contained in the site descriptions are physiographic descriptions and other information pertinent to the site. The locations of each site are shown in Figures 4 and 9. Generalized geology for the study area can be seen in Figure 4.

\section{A. APE CAVE TILTMETER}

The Ape Cave tiltmeter (platform type biaxial tiltmeter) was installed April 19, 1980 and is located approximately $9 \mathrm{~km}$ southwest of Mount St. Helens, at $625 \mathrm{~m}$ elevation, in a lava tube of the Ape Cave basalt flows. The site was selected because of the inherent stability of the rock unit. It was also assumed that the basalt flow would act as a cohesive unit when deformation occurred. Suspected stable thermal conditions that the cave offered were also considered in the selection of this site. Location of the tiltmeter was near the lower entrance to the lave tube. Depth to the tiltmeter from the surface was about 10 meters. Access to the the lava tube was through an opening created by tube collapse. There were no major cracks in the remaining tube structure in the near proximity of the tiltmeter. 


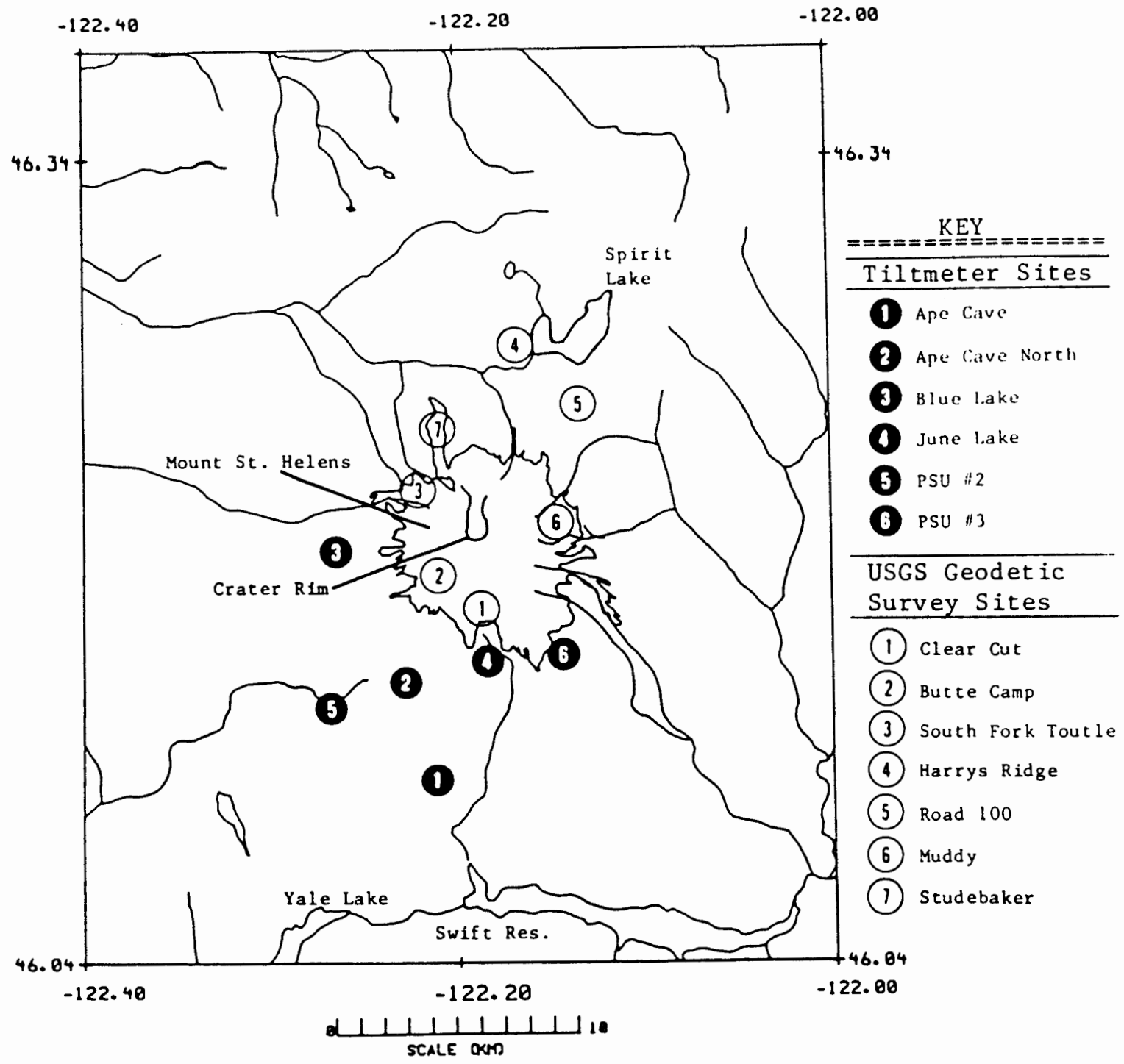

Figure 9. Diagram showing the locations of the tiltmeter sites for this study and outer-network USGS geodetic survey studies (after Swanson and others, 1981).

The basic geology of the site is that of a pahoehoe basalt flow containing lava tubes overlying assorted mudflows and pyroclastic flows. The basalt is a primitive diktytaxitic olivine basalt flow (approx. $1925 \pm 95$ years B.P.; Greely and Hyde, 1972) that varies chemically to an olivine andesitic basalt. The volcanic deposits 
overlie the volcaniclastic sediments of the Ohanapecosh Formation.

\section{B. APE CAVE NORTH TILTMETER}

The tiltmeter installed at Ape Cave North was a short base platform type biaxial tiltmeter (Figure 8). The site was installed May 18, 1980, and is located about $6.1 \mathrm{~km}$ southwest of Mount St. Helens, at $975 \mathrm{~m}$ elevation. The site is geologically similar to the Ape Cave site, located in a lava tube of the same basalt flow. The Ape Cave North site is located about $3 \mathrm{~km}$ closer to Mount $\mathrm{st}$. Helens than the Ape Cave site.

In the area of the tiltmeter, the basalt previously described has a thickness of about 12 meters. The basalt in this location has undergone negligible deformation since deposition. Access to the site was through an opening in the lava tube created by the collapse of a section of the tube north of the site. At the site, no evidence was found indicating continued collapse or cracking of the remaining tube structure.

Together, the two platform tiltmeters form a generally radial line from the mountain (see Figure 9). It was hoped that the two Ape Cave tiltmeters would show similar directions of relative tilt with amount of tilt a function of their respective distances to the mountain.

\section{BLUE LAKE TILTMETER}

The Blue Lake tiltmeter site, installed June 11, 1980, used a USGS borehole tiltmeter. The installation of the meter followed standard USGS procedures as shown in Figure 7a. Located about $5.2 \mathrm{~km}$ west of 
Mount St. Helens, at $1190 \mathrm{~m}$ elevation is the most northerly tiltmeter and the closest site to the mountain (see Figure 9).

The site is located on a mudflow deposit from previous Mount st. Helens eruption of Pine Creek age or older (Crandell and Mullineaux, 1973). The mudflow is generally poorly consolidated, matrix supported and consists primarily of volcanic and lithic fragments.

Topographically the site is located at a break in slope at the northern edge of a clear cut area. In the area of the site the ground slopes to the south-southeast with a gradient of between 5 and 10 degrees.

\section{JUNE LAKE TILTMETER}

The June Lake tiltmeter site located $5.8 \mathrm{~km}$ southeast of Mount St. Helens at $1175 \mathrm{~m}$ elevation, uses a USGS borehole tiltmeter (see Figure 8). The tiltmeter was installed June 15, 1980 using standard USGS installation techniques (see Figure 7).

The geology of the area surrounding this site consists of layers of mudflows of Pine Creek age exceeding 10 meters in total depth. The sediments probably overlie older andesite or basaltic andesite flows which in turn overlie the Ohanapechosh Formation. The tiltmeter itself is installed in a poorly consolidated mudflow deposit, which contains volcaniclastic sediments with rocks up to 1 meter in diameter.

The site is located on a small saddle that trends east to west near the center of a large clear-cut area. The slopes on either side dip away from the saddle with a gradient of 10 to 15 degrees. 


\section{E. PSU $\$ 2$ TILTMETER}

The PSU $\$ 2$ tiltmeter location used a Kinemetrics borehole tiltmeter belonging to Portland state University. The basic installation of the tiltmeter was completed in June 1980 using a modified installation technique based on the USGS procedure (Figure 7b.). The site was located on top of a ridge at 1020 m elevation, about $7.2 \mathrm{~km}$ southwest of Mount St. Helens (Figure 9). The tiltmeter was emplaced in the soil mantle that covers the ridge.

The geology of this site is dominated by a basaltic ridge of the Ohanapechosh Formation. The basalt at this point is fractured, but still coherent enough to form a cliff of approximately 250 meters. The site is located at an excavated area, that within the last ten years had been a base for "Highline" logging operations. The tiltmeter was situated about 40 meters from a north facing cliff.

\section{F. PSU \#3 TILTMETER}

The PSU \#3 tiltmeter site is also a Kinemeterics borehole type, installed in July 1980, using the same installation procedure as PSU \#2. The location is about $5.8 \mathrm{~km}$ southeast of Mount st. Helens at $1040 \mathrm{~m}$ elevation, slightly north of an old logging road. This is the eastern most tiltmeter site in the study (see Figure 9).

Geologically the site is similar to the June Lake site. The tiltmeter was placed in unconsolidated debris flow deposits of the same type. The slope in the area of the tiltmeter has a gradient of about 5 degrees to the south and southwest. 
CHAPTER V

DATA ANALYSIS

\section{A. DATA ACQUISITION}

Two methods of data collection were used in this study. The first method involved real time data recovery techniques by USGS equipment and personnel. The tilt data collected by the tiltmeter at each USGS site was telemetered from Mount st. Helens to Vancouver, Washington. This data was then manually transferred to a host computer system (Univ. of Washington, DEC PDP 11/70) for further processing.

A second method of data collection was conducted by the PSU geophysics group. Data from the tiltmeters was recorded on site using Rustract (model 288) strip chart recorders. Tiltmeter records and associated temperature and pressure records were retrieved every one to two weeks and returned to PSU. The data was then manually digitized by A. Johnson and transferred to the Univ. of Washington computer system for further analysis.

\section{B. INITIAL ANALYSIS}

Following entry of the data into the computer, data was evaluated and plotted. The preliminary evaluations of the data were done visually. These evaluations included the initial delineation and correction of data segments where missing points or obvious mechanical 
problems occurred. Common problems encountered in this study were:

1) Instrument resetting.

2) Electronic malfunctions, battery failures.

3) Telemetry malfunctions due to atmospheric changes.

4) Operator error in digitalization.

5) Improper equipment setup.

Following the initial evaluation, the corrected data segments where combined into contiguous data sets. Within these sets, initially offset chronologically adjacent segments were aligned based on previous trends. Short sections of missing data were temporarily inserted using linear interpolation to facilitate additional computations outlined in the following sections.

Possible effects of interference of thermal noise resulting from thermoelastic tilting of the ground (Berger, 1975) were removed by the use of a linear temperature correction factor. This correction factor is based on the ratio of tilt verses temperature and derived by calculating the slope of the best fit linear regression line. Correction for temperature was only done on the PSU tiltmeters because they were the only sites setup to record temperature.

\section{SMOOTHING AND DETRENDING}

Although signals associated with major equipment malfunctions are easily recognized, signals from minor equipment problems or transient instruments fluctuations are not easily isolated. Other outside signals that influence the tilt signal are temperature changes, pressure changes, instrument settling, lunar tides, earthtides and soil creep. 
In this study, these signals constitute "noise" in the data set, masking the desired signal. Since the main focus of the study is on a changing dynamic system with other studies (Swanson and others, 1981) indicating inflationary and deflationary changes, extraction of the primary tilt signal associated with these changes is critical. Removal of the "noise" is necessary for further analysis of the primary tilt signal.

Initial filtering of the data sets was done by the collection method. Signals with duration periods of less than one hour were not collected. Longer duration signals of known amplitudes were removed by use of specific frequency "notch" filter functions (Davis, 1973). Other signals that were highly variant in duration and amplitude (equipment fluctuations, settling, pressure or temperature) are not easily measured or removed, so that filtering by "notch" filter functions is not appropriate. The method chosen to remove these signals was the filtering of the data set by a cubic spline function (IMSL, 1982).

Detrending is a mathematical method used to remove linear signal functions from a data set. In this study, detrending of the entire data set would remove all linear tilting signals, although it would allow examination of earthtides. Since the majority of the stations where not setup to record signals in the earthtide range $\left(10^{-7}\right.$ urad) long term detrending of the data was not attempted. Instead, detrending of data collected during individual eruptions was done. The purpose being to isolate any tilt change that could be spatially associated with the eruption onset from long term tilt trends. 


\section{SPECTRAL ANALYSIS}

Spectral analysis of the tiltmeter data sets was done to define the major frequencies (cyclic events) in these data sets. The identification of the major frequencies is the initial step in removal of these frequencies by specific filters. Subsets of equal length from the same time period for each tiltmeter were used for the analysis. According to the concept of Nyquist frequencies (Davis, 1973) the minimum number of equally timed points required to identify a wave at a certain frequency is 3 . The minimum number of points required to define a wave is 5 and to completely reconstruct the wave is 8 . This means that the minimum frequency that can be evaluated in this study due to sampling interval is 4 hours, due to I hour sample interval.

The definition of cyclic events in a continuous data set is best accomplished using a Fourier Transform (FT). What the FT does is define a frequency spectra of the input time sequence. Because of the slow calculation speed involved the standard FT program was not used. In this study the Fast Fourier Transform (FFT) algorithm (Brigham, 1974) was used.

The basic formula for the discrete FFT at a given frequency $f$ is:

$$
F(f)=(1 / N) \sum_{j=0}^{N-1} x(j \Delta t) \exp (-i 2 \pi j \Delta t f)
$$

where $x(j \Delta t)$ is a time series of length $T=N \Delta t$. To improve the analysis speed, a FFT requires $N=2^{n}$, where $n$ is an integer and $f=k / N \Delta t$ for $k=0,1, \ldots N-1$. 
For a more complete discussion on the benifits and uses of FT techniques refer to Bath (1973), Claerbout (1976) or Davis (1973). A very good discussion of the uses, techniques and properties of FFT's can be found in Brigham (1974).

Results of the FFT analysis were then used for two purposes: 1) to define major frequencies present in each data set for subsequent removal and 2) for the comparison of frequencies (presence, absence, or power) between data sets.

\section{E. CORRELATION OF DATA}

Correlation of both the raw data and filtered data was done to determine the relationships between the data sets. In this study, two types of correlations were used; autocorrelation and cross-correlation. Autocorrelation of individual data sets was done to determine similarity between different segments of the same data set. This procedure defines the correlation of a time series with itself at different time offsets (lag) (Davis, 1973).

Cross-correlation is similar to autocorrelation, but uses the principle of linear correlation between two individual time series instead of one (Davis, 1973). The purpose of the cross-correlation effort in this study was to quantitatively analyze the relationships between the different tilt axes and to determine if the different tiltmeter sites responded in a similar manner during the study.

\section{F. Site AND LOCATION EVALUATION}

The reason for evaluating results and terrain differences between 
tiltmeter sites was to indentify and quantify what affects tiltmeter type or installation method had on results. Several factors where evaluated; 1) distance of the tiltmeter with respect to the mountain, 2) type of tiltmeter used, 3) the medium on which the tiltmeter was placed, and 4) the geology between the tiltmeter and the deformation source.

Distance of the tiltmeter from the deformation source is extremely important in terms of expected tiltmeter response. Tiltmeters measure the arc of change in an axis which is associated with vertical change of a point at distance $x$ away from the tiltmeter. This means that the relative location of the tiltmeter to the deformation source will determine the arc (tilt change) the tiltmeter will record. If the surface being deformed responds in a linear elastic manner, deformation would be expected to vary inversely with radial distance from the source. Visual evaluation of the resultant tiltmeter data sets should reveal the maximum deformation associated with any eruption, if the deformation was large enough to be recorded. Comparison of resultant tilt records to theoretical models should also indicate if the tiltmeters reacted as predicted in the model.

Tiltmeters used in this study are similar in function but dissimilar in container construction (see Figures 7 and 8 ). Borehole tiltmeters measure the partial derivative of horizontal displacement verses sensor depth and partial derivative of radial distance. Platform tiltmeters measure the partial derivative of vertical displacement verses the partial derivative of radial distance. This results in the borehole tiltmeter being highly sensitive to near 
surface shearing phenomena while the platform tiltmeter are relatively insensitive to near surface shearing. The cause of the sensitivity is the major variance in lengths of the respective tiltmeters vertical axis (see Figures 7 and 8 ). The difference between tiltmeter types becomes pronounced when installation of the tiltmeter into an unstable surface subject to soil creep (surface shear). Comparison of tiltmeter response to site environmental conditions was done by mathematical evaluation (correlation and FFT) of resultant tilt signals and visual evaluation of resultant tilt vector direction to physiographic characteristics of the site.

Site location in terms of soil or rock type was also extremely different in the two types of instrument sites. The borehole tiltmeter sites are emplaced in unconsolidated sediments. The sediments at these sites are not extremely efficient in terms of deformation transmission, since interfragmental shearing can occur at relatively low energy level. These sediments could act as a dampening or amplifying medium for short period signals, but should not effect the long period signals. The platform tiltmeters both rest on solid basalt which is by comparison a good transmitter of deformation. Evaluation of tilt changes during eruptive periods and during the entire study period in comparison to tiltmeter type, predicted deformation for models should be indicative of signal dampening at individual sites due to installation medium.

In utilizing the tiltmeter to analyze deformation patterns at any distance, assumptions must be made about the medium connecting the tiltmeter to the deformation source. Commonly the medium is assumed to 
act as a homogeneous mass, deforming in a linearly consistent manner relative to the deformation source. In theory, this makes the analysis of the deformation patterns and modeling of deformation source much simpler. In practice, changes in the medium (stratagraphic and lithologic changes, faulting, etc.) modify the deformation pattern, leading to possibly erroneous conclusions about the deformation source and deformation patterns. Geologic information (Hopson, 1980) and geodetic survey results (Swanson and others, 1981) around Mount St. Helens help define boundary conditions for modeling deformational patterns during this study. Resultant tilt vectors from each site are then spatially compared to these boundary conditions. The result is a theoretical model of a deformation source that meets as many of the conditions as possible. 


\section{CHAPTER VI}

\section{RESULTS}

The data obtained from the six tiltmeters in the Mount St. Helens study area between July 1, 1980 to December 31, 1980 is shown in Figures 10 through 15. In the following discussion, this data will be referred to as "raw data". These figures are the result of plotting both data from the north-south and east-west axis of tilt against time at hourly intervals. Plots of the raw data on a monthly time base for all tiltmeters are located in Appendix $A$.

Plots of the raw data for the study period (Figures 10 through 15) indicate all but one of the tiltmeters where relatively stable. This stability is also shown in the monthly plots (Appendix A), where fluctuations of the data are generally minor. The Blue Lake site (see Figure 12) however, was highly unstable during the study period. Tilt records from the Blue Lake site are characterized by extended periods of excessively fluctuating daily tilts and extremely sporadic output (Table II and Appendix A). The suspected cause of the instability at the Blue Lake site was very poor site selection and equipment problems generally related to the telemetry of data.

The raw tilt data from all the tiltmeters show the existence of long term variation or instrument drift and relatively short term variation. These periods of fluctuating tilt could result from any of 


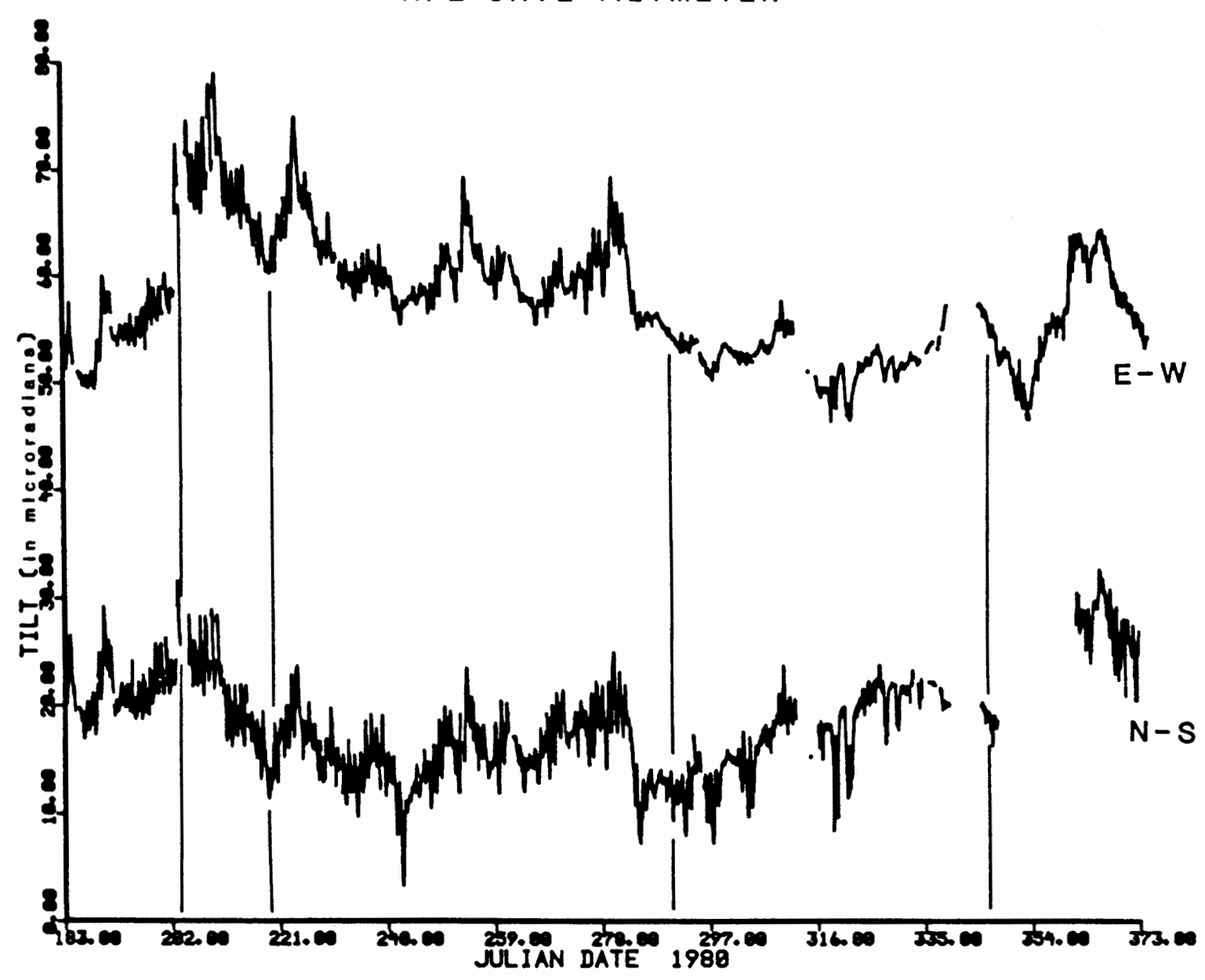

Figure 10. Plot of raw data from Ape Cave tiltmeter site. Shown are East-West and North-South components of tilt at Ape Cave tiltmeter site. A decrease in recorded values indicates East or North positive (inflation). Values are uncorrected hourly averages starting July 1,1980 and continuing through December 31, 1980. All times are GMT equivalents. Vertical lines indicate eruption onsets. Gaps in the plots indicate periods where no usable data was collected. 


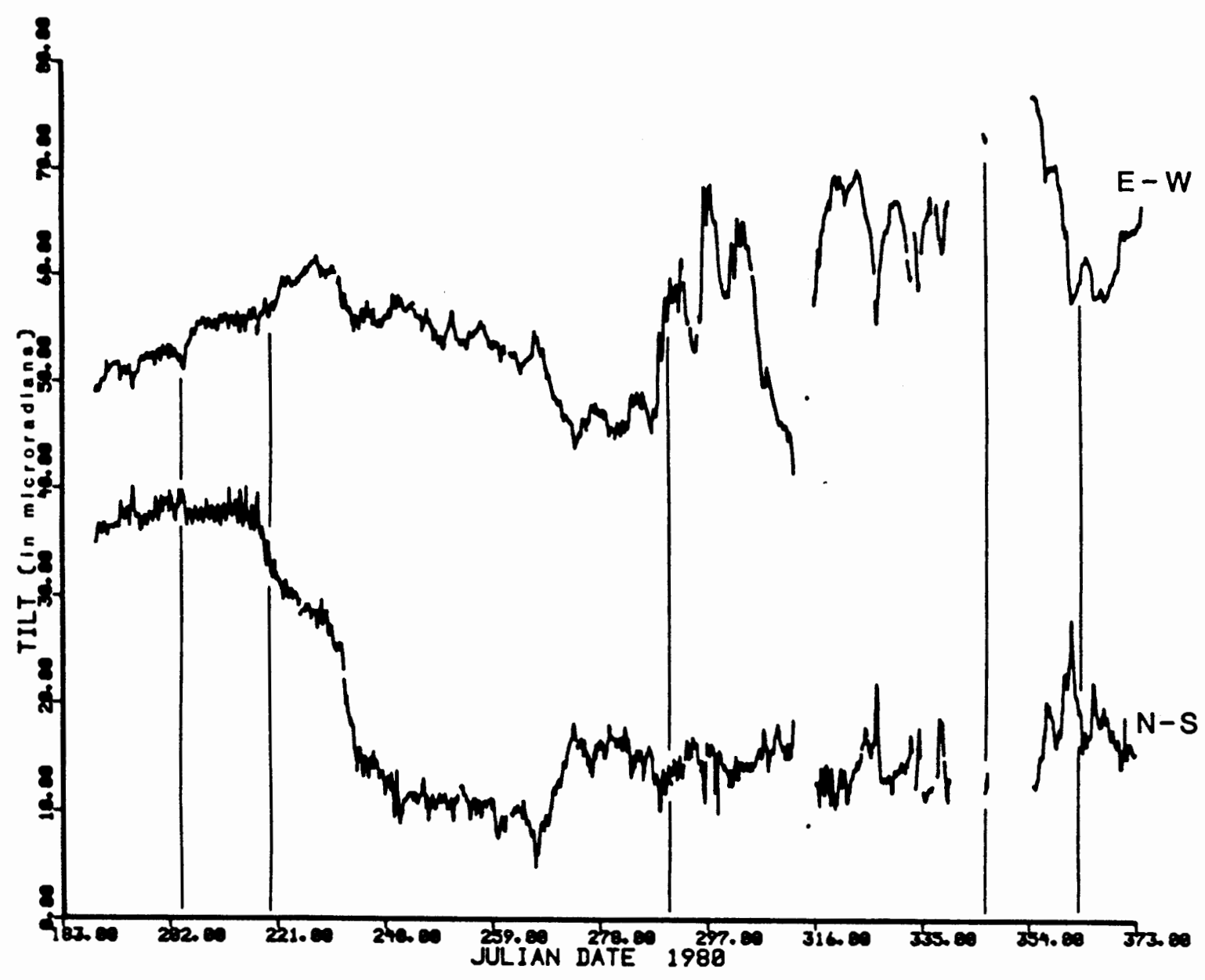

Figure 11. Plot of raw data from Ape Cave North tiltmeter site. Shown are East-West and North-South components of tilt at Ape Cave North tiltmeter site. A decrease in recorded values indicates East or North positive (inflation). Values are uncorrected hourly averages starting July 1,1980 and continuing through December 31, 1980. All times are GMT equivalents. Vertical lines indicate eruption onsets. Gaps in the plots indicate periods where no usable data was collected. 


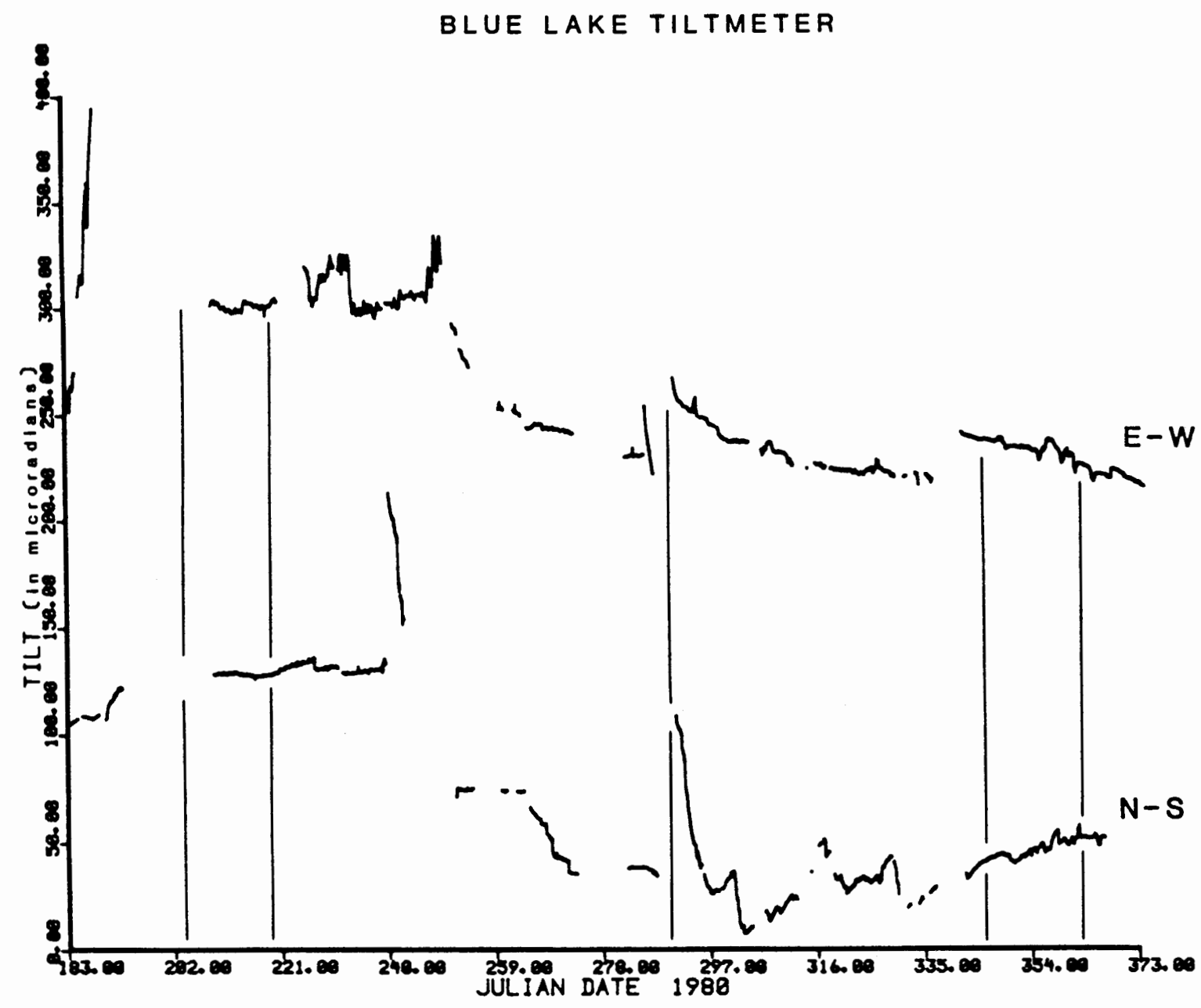

Figure 12. Plot of raw data from Blue Lake tiltmeter site. Shown are East-West and North-South components of tilt at Blue Lake tiltmeter site. A decrease in recorded values indicates East or North positive (inflation). Values are uncorrected hourly averages starting July 1,1980 and continuing through December 31, 1980. All times are GMT equivalents. Vertical lines indicate eruption onsets. Gaps in the plots indicate periods where no usable data was collected. 


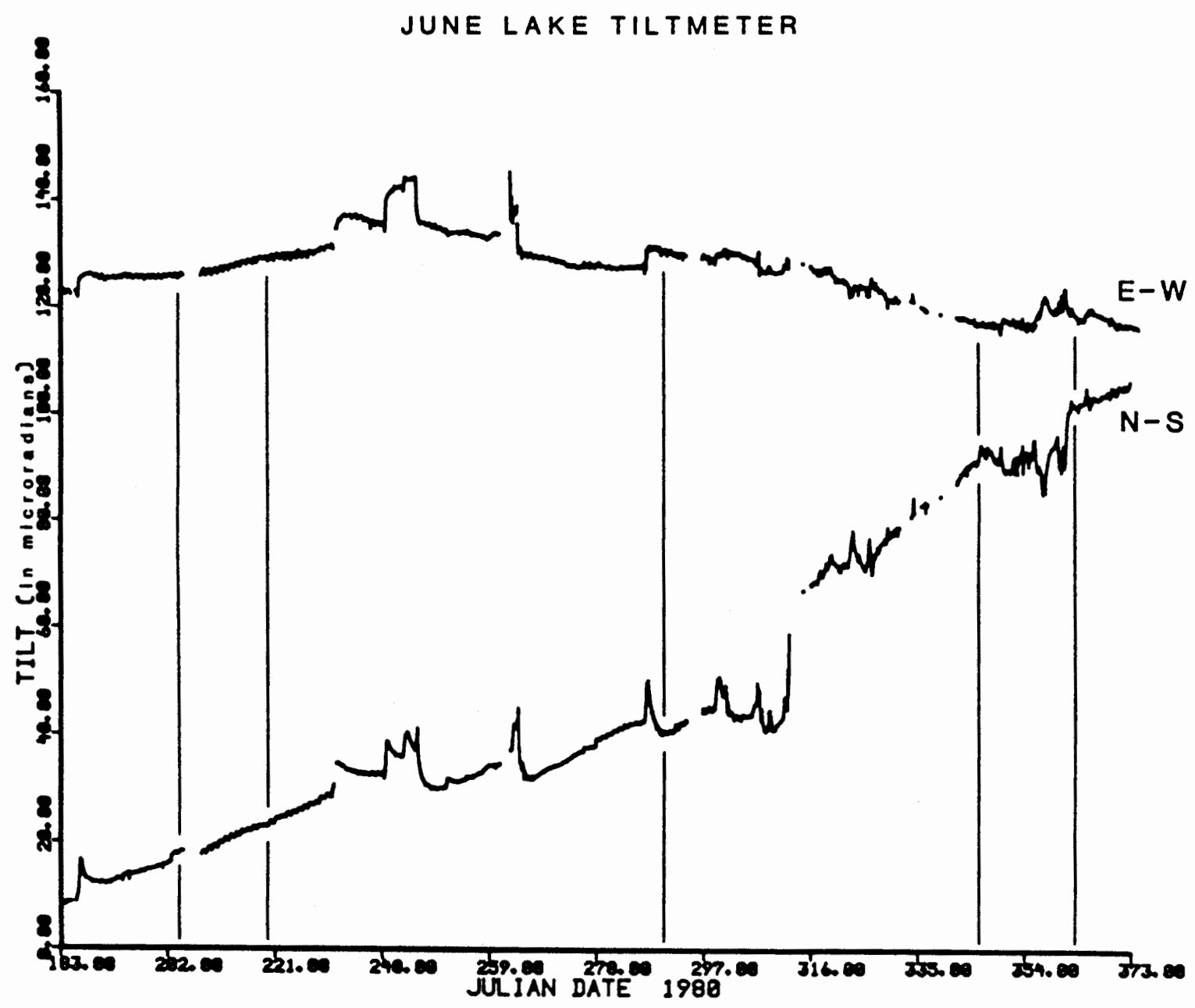

Figure 13. Plot of raw data from June Lake tiltmeter site. Shown are East-West and North-South components of tilt. A decrease in recorded values indicates East or North positive (inflation). Values are uncorrected hourly averages starting July 1,1980 and continuing through December 31, 1980. All times are GMT equivalents. Vertical lines indicate eruption onsets. Gaps in the plots indicate periods where no usable data was collected. 


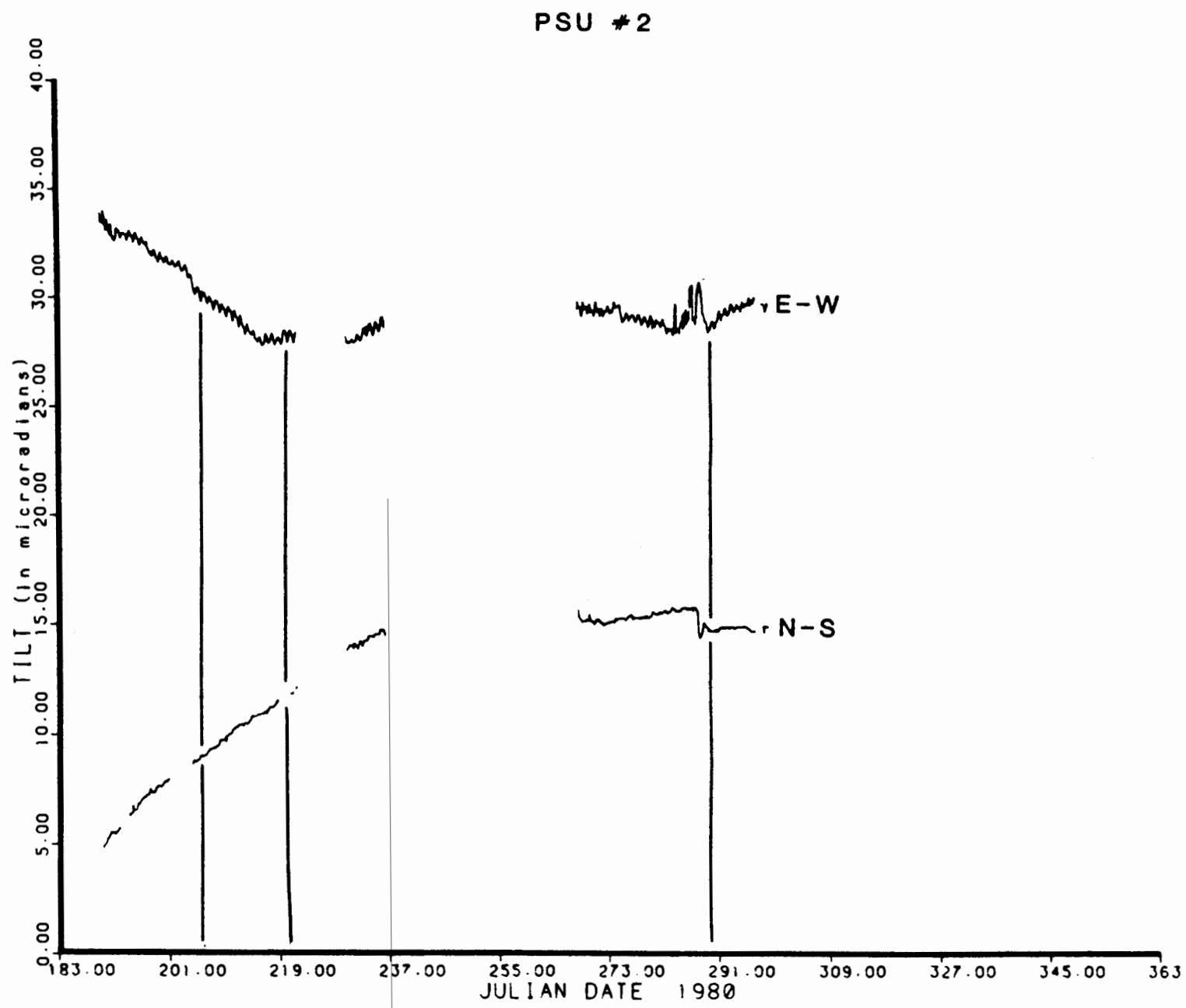

Figure 14. Plot of raw data from PSU $\$ 2$ tiltmeter site. Shown are East-West and North-South components of tilt. A decrease in recorded values indicates East or North positive (inflation). Values are uncorrected hourly averages starting July 1, 1980 and continuing through December 31, 1980. All times are GMT equivalents. Vertical lines indicate eruption onsets. Gaps in the plots indicate periods where no usable data was collected. 


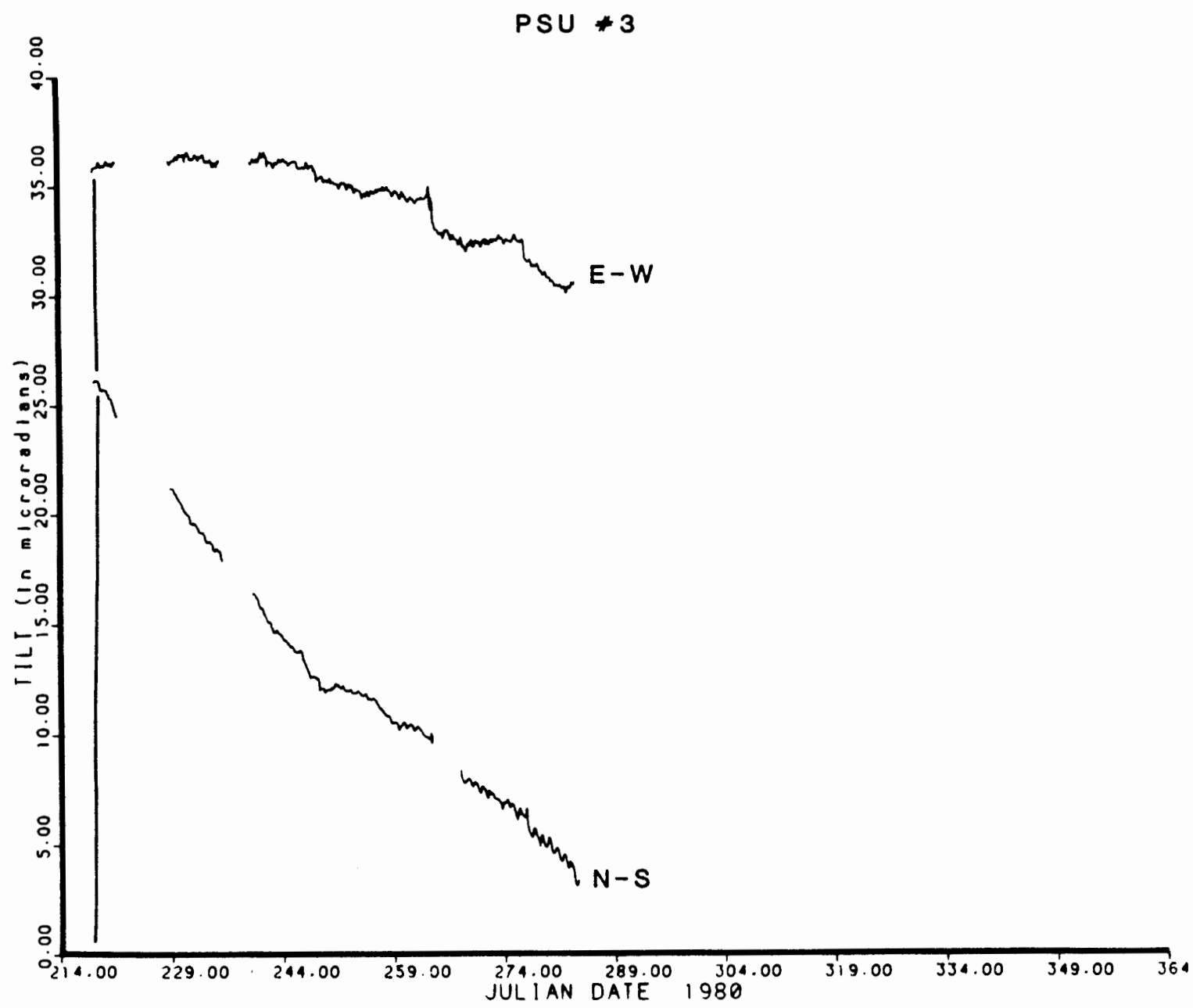

Figure 15. Plot of raw data from PSU \#3 tiltmeter site. Shown are East-West and North-South components of tilt. A decrease in recorded values indicates East or North positive. Values are uncorrected hourly averages starting August 1, 1980 and continuing through December 31, 1980. All times are GMT equivalents. Vertical lines ináicate eruption onsets. Gaps in the plots indicate periods where no usable data was collected. 
the following:

1) Meteorologic or thermal noise, since this study included data collected over a wide range of climatic conditions.

2) Settling of the instruments.

3) Instrument drift, diurnal variations or instrument instability.

4) Movement of the station in response to inflation or deflation of the mountain.

5) Changes due to stress relief on the St. Helens seismic zone.

6) Soil creep of the area around the instrument site.

General daily and cumulative performance data for each of the tiltmeters is shown in Table II. Included in Table II are the following performance statistics; number of days in operation, number of hours of usable data collected, number of full days in operation, total net tilt for the study period and average daily tilt fluctuation. The value given as number of hours of useable data collected represents the total number of hours where recognizable information was collected. The full days value relates the total number of number of 24 hour contiguous Julian date intervals represented in the data set. Average daily tilt is a calculated value based on the difference between the maximum and minimum tilt values for full days only.

By sampling at hourly intervals, effects of large short term (less than one hour) disturbances where minimized. Longer period disturbances were removed by use of notch and cubic spline filters. Since "earthtide" signals where not being evaluated within this study, detrending of large time base data sets was not done, because of the almost total dynamic signal loss involved in the process. 
TABLE II

TILTMETER OPERATIONAL DATA, NET TILT AND AVERAGE

DAILY TILT FLUCTUATIONS AT MOUNT ST. HELENS

BETWEEN JULY 1 AND DECEMBER 31, 1980

\begin{tabular}{|c|c|c|c|c|c|c|}
\hline & & $\begin{array}{c}\text { Daysl } \\
\text { in } \\
\text { operation }\end{array}$ & $\begin{array}{c}\text { Hours } \\
\text { in } \\
\text { operation }\end{array}$ & $\begin{array}{c}\text { Full3 } \\
\text { days in } \\
\text { operation }\end{array}$ & $\begin{array}{l}\text { Net tilt } \\
\text { during } \\
\text { study }\end{array}$ & $\begin{array}{c}\text { Average } \\
\text { daily tilt } \\
\text { fluctuation }\end{array}$ \\
\hline Ape Cave 5 & $\begin{array}{l}\mathbf{E} \\
\mathbf{N}\end{array}$ & $\begin{array}{l}184 \\
184\end{array}$ & $\begin{array}{l}3931 \\
3608\end{array}$ & $\begin{array}{l}109 \\
102\end{array}$ & $\begin{array}{r}-4 \\
5\end{array}$ & $\begin{array}{l}2.87 \\
4.57\end{array}$ \\
\hline $\begin{array}{l}\text { Ape Cave } \\
\text { Nor th } 5\end{array}$ & $\begin{array}{l}\mathbf{E} \\
\mathrm{N}\end{array}$ & $\begin{array}{l}184 \\
184\end{array}$ & $\begin{array}{l}3675 \\
3682\end{array}$ & $\begin{array}{l}107 \\
106\end{array}$ & $\begin{array}{r}17 \\
-21\end{array}$ & $\begin{array}{l}2.04 \\
2.25\end{array}$ \\
\hline Blue Lake 5 & $\begin{array}{l}\mathbf{E} \\
\mathbf{N}\end{array}$ & $\begin{array}{l}184 \\
184\end{array}$ & $\begin{array}{l}2732 \\
2731\end{array}$ & $\begin{array}{l}68 \\
66\end{array}$ & $\begin{array}{r}-8 \\
-11\end{array}$ & $\begin{array}{l}4.48 \\
4.06\end{array}$ \\
\hline June Lake 5 & $\begin{array}{l}\mathbf{E} \\
\mathbf{N}\end{array}$ & $\begin{array}{l}184 \\
184\end{array}$ & $\begin{array}{l}3808 \\
3809\end{array}$ & $\begin{array}{l}108 \\
108\end{array}$ & $\begin{array}{r}-4 \\
103\end{array}$ & $\begin{array}{l}1.32 \\
1.85\end{array}$ \\
\hline PSU $\# 2$ & $\begin{array}{l}\mathbf{E} \\
\mathbf{N} \\
\mathrm{T}\end{array}$ & $\begin{array}{l}116 \\
116 \\
116\end{array}$ & $\begin{array}{l}1638 \\
1439 \\
1537\end{array}$ & $\begin{array}{l}66 \\
49 \\
--\end{array}$ & $\begin{array}{r}-5 \\
9 \\
--\end{array}$ & $\begin{array}{l}0.65 \\
0.24 \\
---\end{array}$ \\
\hline PSU \#3 & $\begin{array}{l}\mathbf{E} \\
\mathbf{N} \\
\mathbf{T}\end{array}$ & $\begin{array}{l}70 \\
70 \\
70\end{array}$ & $\begin{array}{l}1297 \\
1206 \\
1205\end{array}$ & $\begin{array}{l}52 \\
48 \\
--\end{array}$ & $\begin{array}{r}-5 \\
-23 \\
--\end{array}$ & $\begin{array}{l}0.37 \\
0.47 \\
----\end{array}$ \\
\hline $\begin{array}{r}E=\text { East } \\
T=\text { Tempe } \\
\text { lPossible } \\
\text { period was } \\
\text { 2Total ho } \\
\text { 3Total d } \\
\text { 4Net til } \\
\text { Positive va } \\
\text { 5usgs ti. }\end{array}$ & rs & $\begin{array}{l}\text { tilt axis } \\
\text { re } \\
\text { al operatio } \\
\text { days. } \\
\text { of useable } \\
\text { here full } 2 \\
\text { nge for the } \\
\text { indicates }\end{array}$ & $\begin{array}{l}\text { nal days. } \\
4 \text { hour collec } \\
\text { axis duri } \\
\text { gest or sou }\end{array}$ & $\begin{array}{l}=\text { North-so } \\
=\text { No data } \\
\text { Maximum tim } \\
\text { ted. } \\
\text { rds where c } \\
\text { g the study } \\
\text { h relativel }\end{array}$ & $\begin{array}{l}\text { th tilt axi } \\
\text { or this valt } \\
\text { during the } \\
\text { llected } \\
\text { in } 10^{-6} \text { rad } \\
\text { up. }\end{array}$ & $\begin{array}{l}\text { s } \\
\text { study } \\
\text { ians. }\end{array}$ \\
\hline
\end{tabular}


Spectral analysis of the data was done to isolate cyclic functions and evaluate signal correlation between instruments. The data evaluated consisted of 2048 hours of contiguous data points between Julian day (JD) 214 00:00 GMT and JD 299 07:00 GMT (Aug. 1 through Oct. 25) for the USGS tiltmeters. The longest possible contiguous data set for the PSU tiltmeters was from JD 214 00:00 GMT to JD 256 15:00 GMT (Aug. I through Sept. 12) for a total of 1024 hours. An example of a smoothed $r$ aw power spectrum from the north-south axis of the Ape Cave tiltmeter is shown in Figure 16. Smoothed power spectra for the other tiltmeters are very similar to Figure 16 and are not shown. Comparison of the spectral analysis results indicated that all of the tiltmeter components had major frequency periods at 8 hours, 12 hours, 24 hours and 3 days. The presence of these major frequency spikes indicates that all of the tiltmeters responded in a similar manner to these cyclic functions. The intermediate and low frequency spikes are presumably multiples of the frequencies of the major spikes and random "noise".

Correlation of the long term tiltmeter records indicated an apparent lack of consistent trends in the data sets. Long term auto-correlation indicated that all of the tiltmeter records are stationary in terms of response trends. Cross-correlation analysis, utilizing the first 1024 hours of data from sets used in the FFT analysis, indicated a lack of correlation between tiltmeters in terms of resultant tilt response patterns. The best signal correlation recorded was between the June Lake and PSU $\$ 2$ tiltmeters.

The effects of thermal variance on the PSU tiltmeters were next 


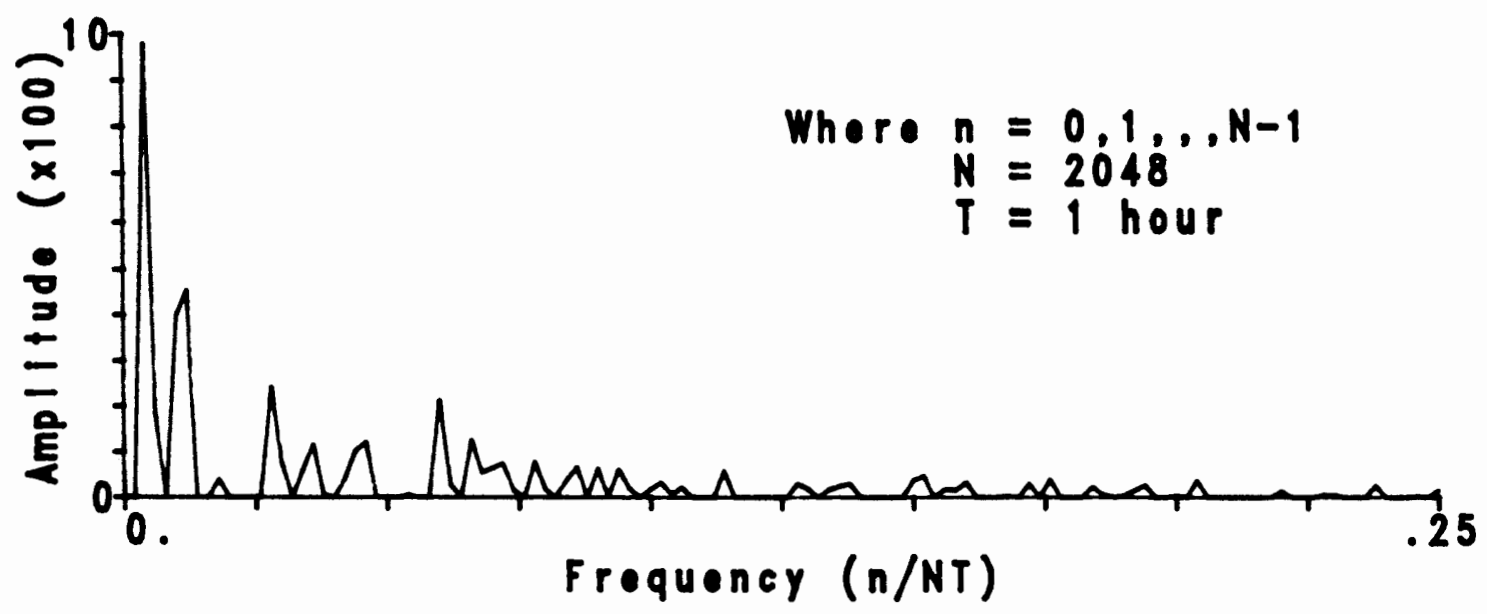

Figure 16. Plot of smoothed power spectrum from the north-south tilt component of the Ape Cave tiltmeter.

examined. The results of plotting tilt verses temperature for PSU $\# 2$ north-south and east-west tilt axes (Figure 17) shows the average temperature correction factor to be greater than $20 \mathrm{deg} / \mu \mathrm{rad}$ (in degrees Fahrenheit) indicating minimal tilt variance with temperature change. Tilt variance in the east-west axis is much grater than in the north-south axis, but the variance was less than $1 \mu \mathrm{rad} / \mathrm{day}$. Temperature correction factors for the remaining axes of both the PSU $\$ 2$ and PSU $\$ 3$ sites tilt were all on the order of greater than 20 deg/urad (in degrees Fahrenheit). Temperature variance effects on the USGS tiltmeters can only be speculated since temperature was not recorded. Based on the PSU results, temperature effects on the USGS borehole sites are expected to be minimal. The effects of temperature on the platform sites also appears to be minimal after visual examination.

Apparent "earthtides" were recorded at both of the PSU sites (Appendix A). These "earthtide" signals are an order of magnitude too 


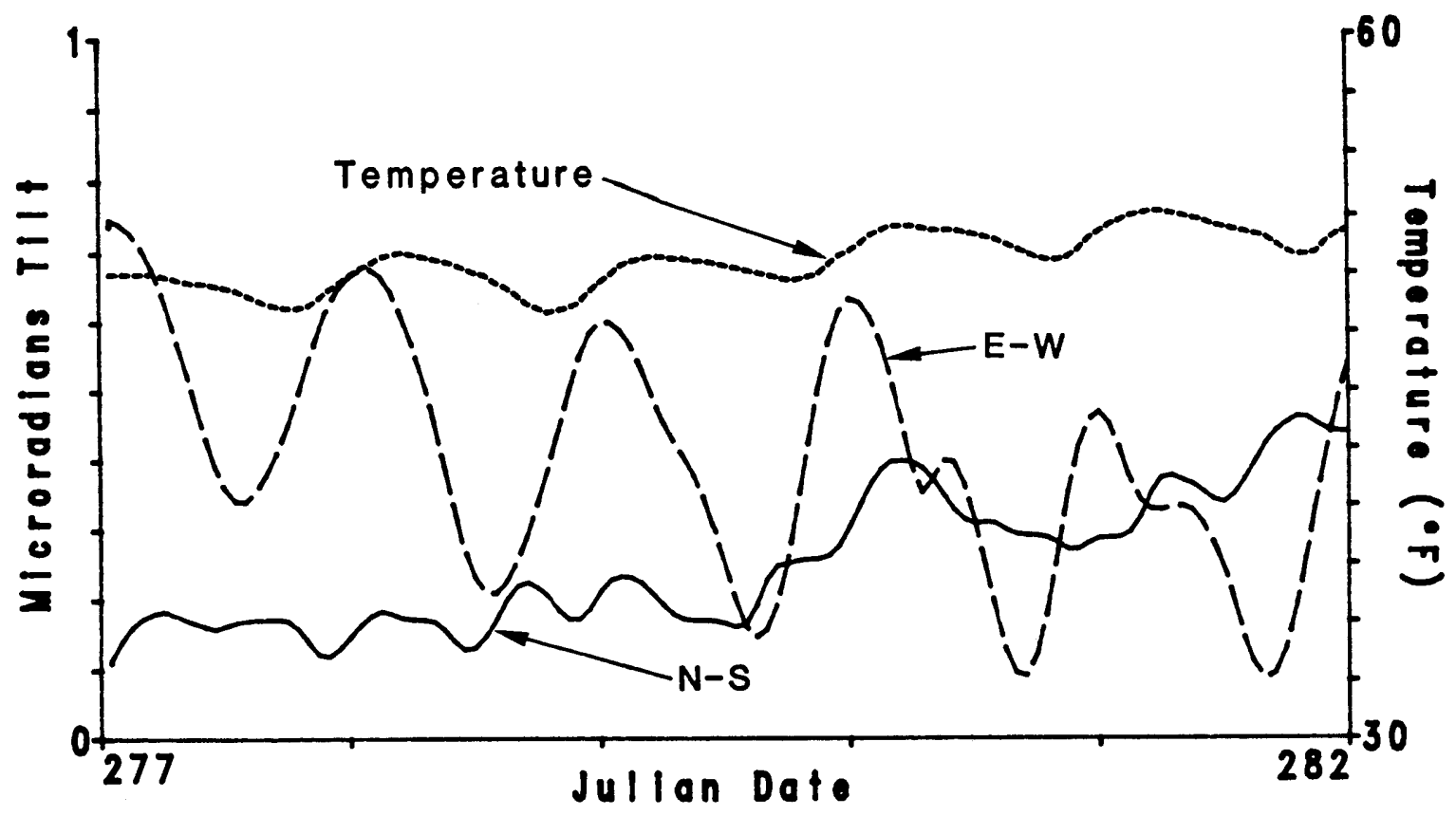

Figure 17. Three component plot showing the detrended and smoothed north-south tilt axis, the east-west tilt axis, and the corresponding temperature record for the PSU \#2 tiltmeter site between Julian days 277 and 282 .

small to have been recorded at the USGS sites. Further resolution and investigation of these signals was not attempted. However, the recording of these signals at the PSU sites indicate the sites were functioning at expected performance levels.

One major non-volcanic phenomena commonly experienced by tiltmeters is instrument drift. Instrument drift is the electromechanical deviation of the instrument with time. In this study, isolation of instrument drift was difficult. Positive identification of instrument drift at any of the sites was impossible since the system the tiltmeters were monitoring may not have been static during the study long enough for a baseline to be established. Since several of the sites are on shallow slopes or are in close proximity to slopes, 
instrument drift could be the result of soil creep at the site. The resolution of long term tilt vectors (see Table II) also indicates soil creep as a possible cause of instrument drift at both PSU sites and the June Lake site since resultant tilt vectors at the sites indicated down slope directions.

Spurious short term fluctuations effecting a single tilt component were recorded at all of the sites. The USGS sites were effected more often than the PSU sites. These fluctuations were identified through visual examination and removed when directly attributable to mechanical problems. The fluctuations commonly represented a single data point, whose value was unrelated to surrounding data points. Suspected cause of the fluctuations is in the electronic circuitry and transmission of data rather than rapid attitude change of the tiltmeter station. The problem seems to be seasonal, attributable to temperature sensitive electronics or high wind conditions (Murry and Furukawa, personal communication, 1982).

\section{A. COMPARISON OF ERUPTIVE SEQUENCES}

\section{JULY ERUPTION}

The first eruption during this study took place on July 22, 1980 at 17:14 PDT (00:14 GMT on Julian Day (JD) 205). Tiltmeters functioning during this period were Ape Cave North and June Lake (see Figure 9). This eruption had three major explosive events within a period of two hours, each event was accompanied by small shallow earthquake swarms. There was no post-explosive dome growth associated with this eruption. Other major statistics concerning this eruption 
can be found in Appendix $C$.

Plots of raw and smoothed tiltmeter data for a time period of five days bracketing the eruption are shown in Figures 18 and 19. The statistics indicating the pre-eruption tilt vector orientation and tilt rate, the post-eruption tilt vector orientation and tilt rate, and the net tilt since JD 180 are given in Table III. A diagram showing the general direction and relative magnitude of tilt deformation vectors before and after the July eruption can be seen in Figure 20.

The general direction of the tilt vectors five days preceding the eruption indicate that the deformation center was to the north of the tiltmeters in the Mount St. Helens area (Figure 20). Constraints on the exact location of the deformation center are poor due to lack of data from the other tiltmeter sites. Geodetic measurements (Swanson and others, 1981) indicate the primary area of deformation was centered at Mount St. Helens.

From JD 184 until the eruption, the base line tilt value (value of predictable daily tilt) for Ape Cave North tiltmeter (Figure 18) indicated a relative deflationary trend of the mountain. The rate amounted to a daily average of $.3 \mathrm{\mu rad} / \mathrm{day}$ deflation. Baseline tilt values for the June Lake site (Figure 19), preceding the eruption, also recorded a similar deflationary trend of .2 $\mathrm{\mu rad} / \mathrm{day}$ (see Table III). Although the June Lake tiltmeter (Figure 19) did not operate during the eruption (telemetry problems, not instrument malfunction), after the eruption, tilt vector orientation indicated continuation of the deflationary trend of Mount St. Helens at a decreased rate. The tilt vector orientation at the Ape Cave North site (Figure 18) indicated 

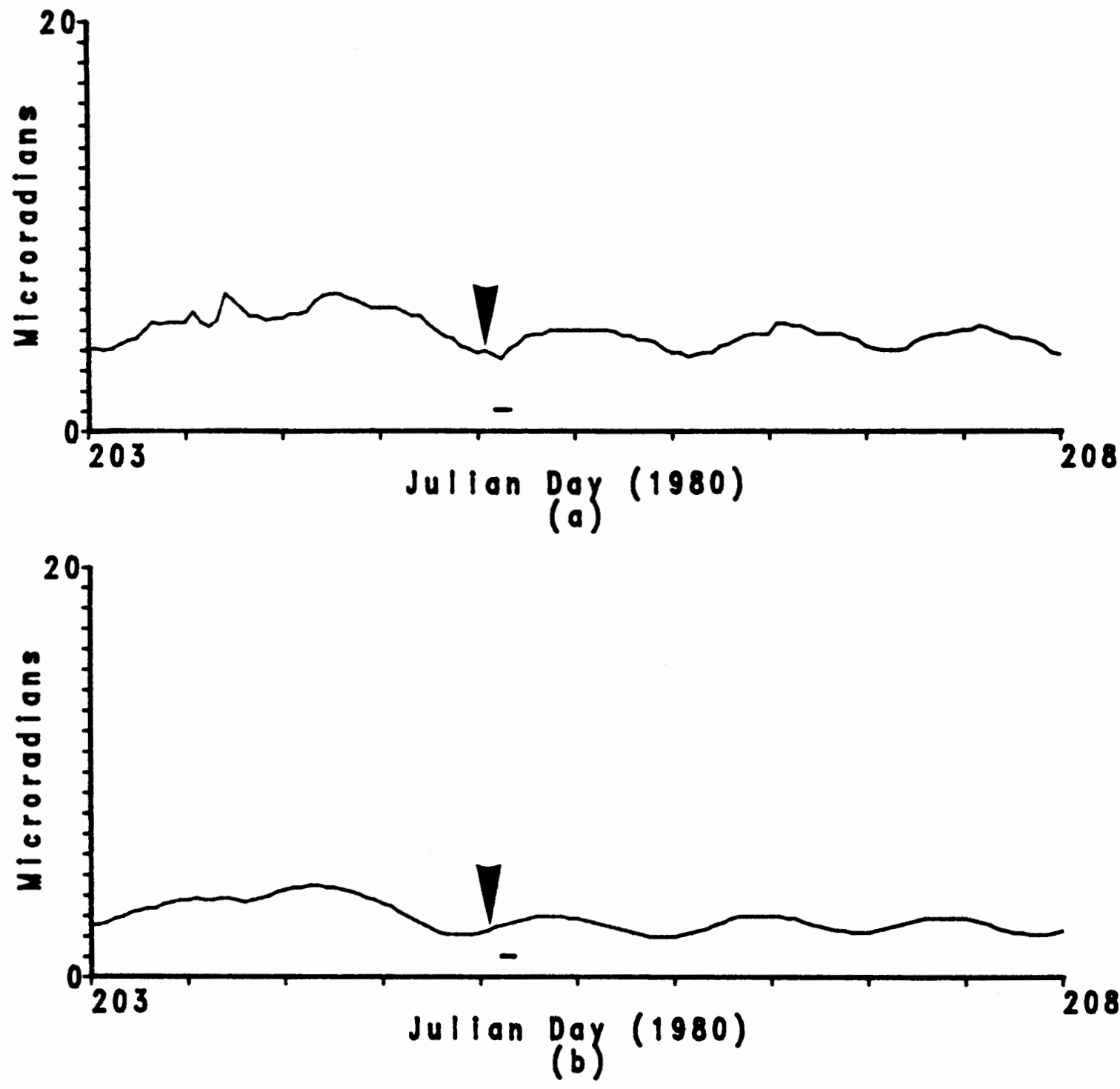

Figure 18. Plots of raw and smoothed tiltmeter data from Ape Cave North tiltmeter for the period of July 21, 1980 through July 25, 1980. Figure 18a. is the raw tilt data for the north-south axis of tilt. Figure 18b. shows the same north-south axis after smoothing. Eruption onset is indicated by a vertical arrow. The period of highest seismic activity is marked by a solid horizontal bar. A decrease in recorded values indicates a north positive tilt (relative inflation). 

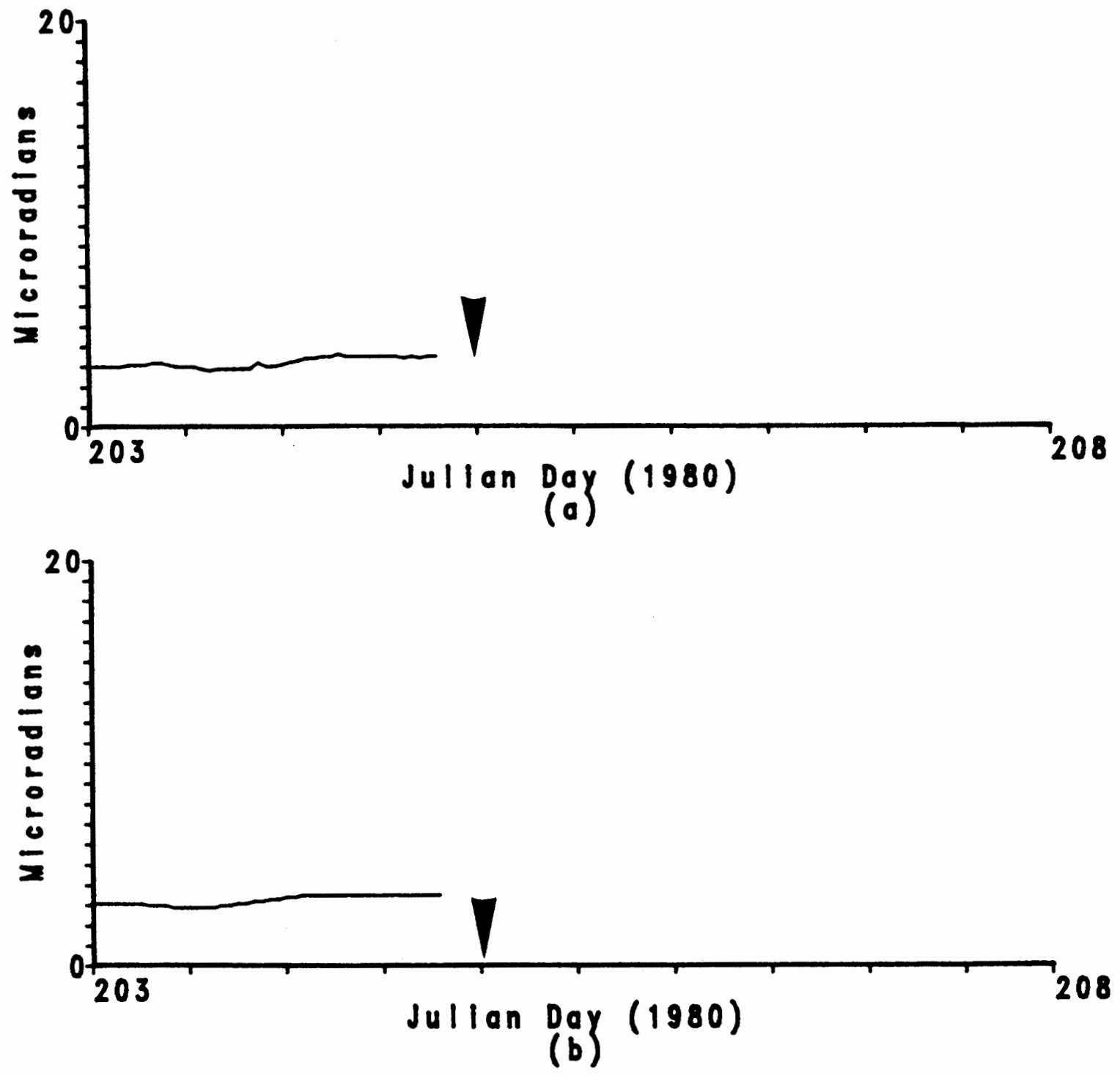

Figure 19. Plots of raw and smoothed tiltmeter data from June Lake tiltmeter for the period of July 2l, 1980 through July 25, 1980. Figure 19a. is the raw tilt data for the north-south axis of tilt. Figure 19b. shows the same north-south axis after smoothing. Eruption onset is indicated by an arrow. A decrease in recorded values indicates a north positive tilt (relative inflation). 


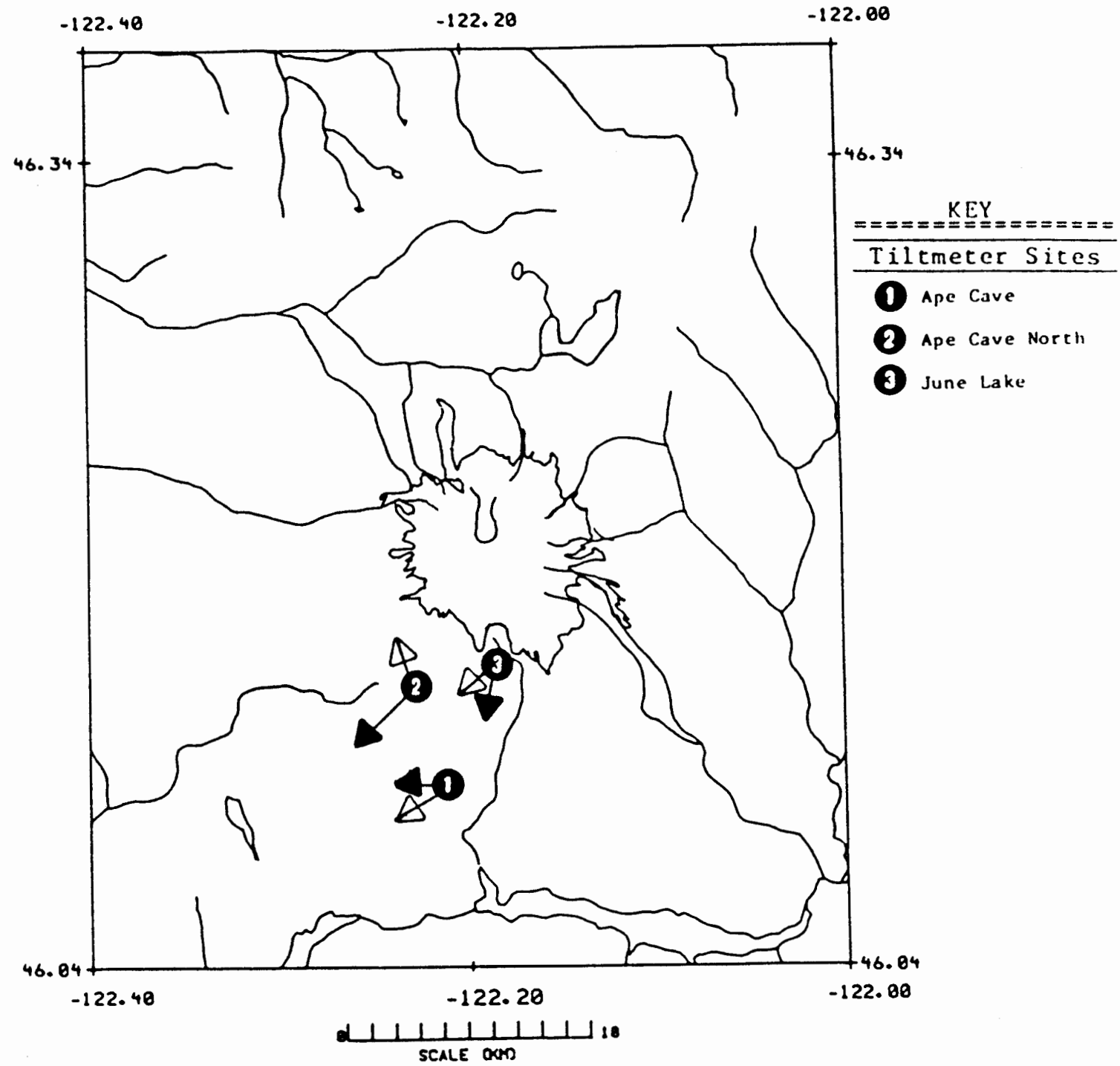

Figure 20. Diagram showing the relative magnitudes and direction of tilt from the tiltmeters before and after the July 25, 1980 eruption. Pre-eruption vectors are indicated by hollow arrows. Post-eruption vectors are indicated by solid arrows. 
TABLE III

PRE-ERUPTION TILT VECTOR ORIENTATION, PRE-ERUPTION TILT RATE, POST-ERUPTION TILT VECTOR ORIENTATION, POST-ERUPTION TILT RATE, NET TILT SINCE JULIAN DAY 180 AT MOUNT

ST. HELENS FOR THE JULY 22, 1980 ERUPTION.

\begin{tabular}{|c|c|c|c|c|c|}
\hline & \multicolumn{2}{|c|}{$\begin{array}{l}\text { Pre-eruptionl } \\
\text { tilt vector }\end{array}$} & \multicolumn{2}{|c|}{$\begin{array}{l}\text { Post-eruption } 2 \\
\text { tilt vector }\end{array}$} & \multirow{2}{*}{$\begin{array}{c}\text { Net } \\
\text { tilt } \\
\text { change }\end{array}$} \\
\hline & orientation & rate/day & orientation & rate/day & \\
\hline Ape Cave & s60W & .4 & N9 OW & .6 & 9.4 \\
\hline \multicolumn{6}{|l|}{ Ape Cave } \\
\hline North & $S 47 W$ & .2 & Nl 9W & -.5 & 3.8 \\
\hline June Lake & Sl2W & .4 & S4 5W & .4 & 8.7 \\
\hline $\begin{array}{r}2 \text { post-e } \\
3 \mathrm{All} r a \\
\text { values in }\end{array}$ & $\begin{array}{l}\text { n records s } \\
\text { on records } \\
\text { d net chang } \\
\text { e relative }\end{array}$ & $\begin{array}{l}\text { ce Juli } \\
\text { or five } \\
\text { in mic. } \\
\text { flation }\end{array}$ & $\begin{array}{l}180 . \\
\text { fter the er } \\
\text { ans of tilt } \\
\text { unt st. Hel }\end{array}$ & $\begin{array}{l}\text { ption. } \\
\text { Positive } \\
\text { is. }\end{array}$ & til \\
\hline
\end{tabular}

a continued deflationary trend until JD 216 when trend changed to inflationary. This is possibly related to the next major explosive eruption on August 7.

The tiltmeter at Ape Cave was not functioning during the eruption, but was functioning prior to JD 203 and after JD 206 (see Appendix A). The Ape Cave tiltmeter recorded a deformation pattern similar to the Ape Cave North station, with a daily tilt fluctuation of about $3 \mu \mathrm{rad} /$ day. Baseline values for Ape Cave prior to the eruption indicated that deformation was in a deflationary sense relative to the mountain. After the eruption the deformation vector rotated to indicate that the mountain was slowly inflating.

Visual evaluation of the data from Ape Cave North (Figure 18) and June Lake (Figure 19) tiltmeter sites indicated that no apparent 
correlation existed between the sites during this eruption other than the general tilt direction. Cross-correlation analysis confirmed the conclusions of the visual evaluation.

\section{AUGUST ERUPTION}

The second eruption during the study occurred August 7, 1980 at 16:23 PDT (23:23 GMT Julian Day 220). This eruption consisted of both explosive and dome building components. The two eruptive columns produced during this eruption were preceded by several hours of harmonic tremor. After the second eruptive column had dissipated, deep earthquakes followed and a small dome was extruded. The eruption lasted for about 4 days. Total output of the eruption was $0.7 * 10^{6} \mathrm{~m}^{3}$ of magma. Domal subsidence followed the eruption, possibly indicating draining of magma back into the chamber (Swanson and others, 1981). An additional small explosive exuption occurred during the afternoon of August 15 .

The tiltmeters in operation during this eruption were; Ape Cave, Ape Cave North, June Lake, PSU \#3 and Blue Lake (see Figure 9). Stability of the Blue Lake site is highly suspect due to mechanical problems during this eruption, but is included since it was functioning. Each of the tiltmeters recorded a small change in tilt that equates to inflation of the region generally to the North of the tiltmeters. Statistics indicating the pre-eruption tilt vector orientation and rate, the post-eruption tilt vector orientation and rate, and the net tilt since the July 22, 1980 eruption are given in Table IV.

Deformation recorded by the tiltmeters for the period between the July 22 eruption and the August 7 eruption generally indicated an 
TABLE IV

PRE-ERUPTION TILT VECTOR ORIENTATION, PRE-ERUPTION TILT RATE, POST-ERUPTION TILT VECTOR ORIENTATION, POST-ERUPTION TILT RATE, NET TILT SINCE LAST MAJOR ERUPTION AT MOUNT ST. HELENS FOR THE AUGUST 7, 1980 ERUPTION.

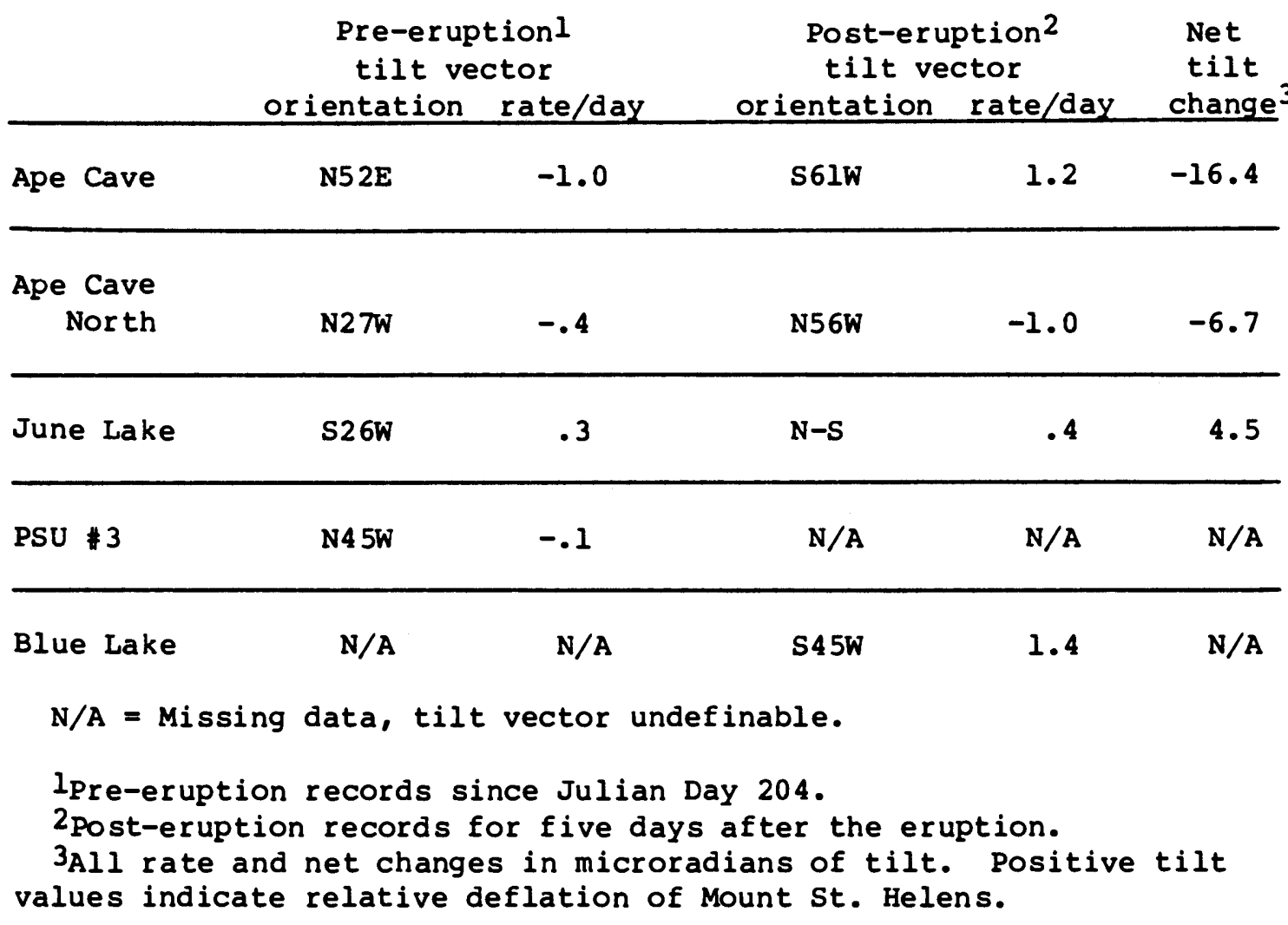

inflationary baseline tilt. Plots of raw and smoothed tiltmeter data for a period three days before the eruption to two days following the eruption are shown in Figures 21 through 25. Shown in Figure 26 is a diagram indicating the direction and relative magnitudes of tilt deformation vectors before and after this eruption.

Ape Cave tilt site (Figure 21) recorded a deflationary trend preceding the August eruption of approximately .9 $\mathrm{\mu rad} / \mathrm{day}$. Following the eruption the site showed an inflationary trend of about 1 prad/day. 

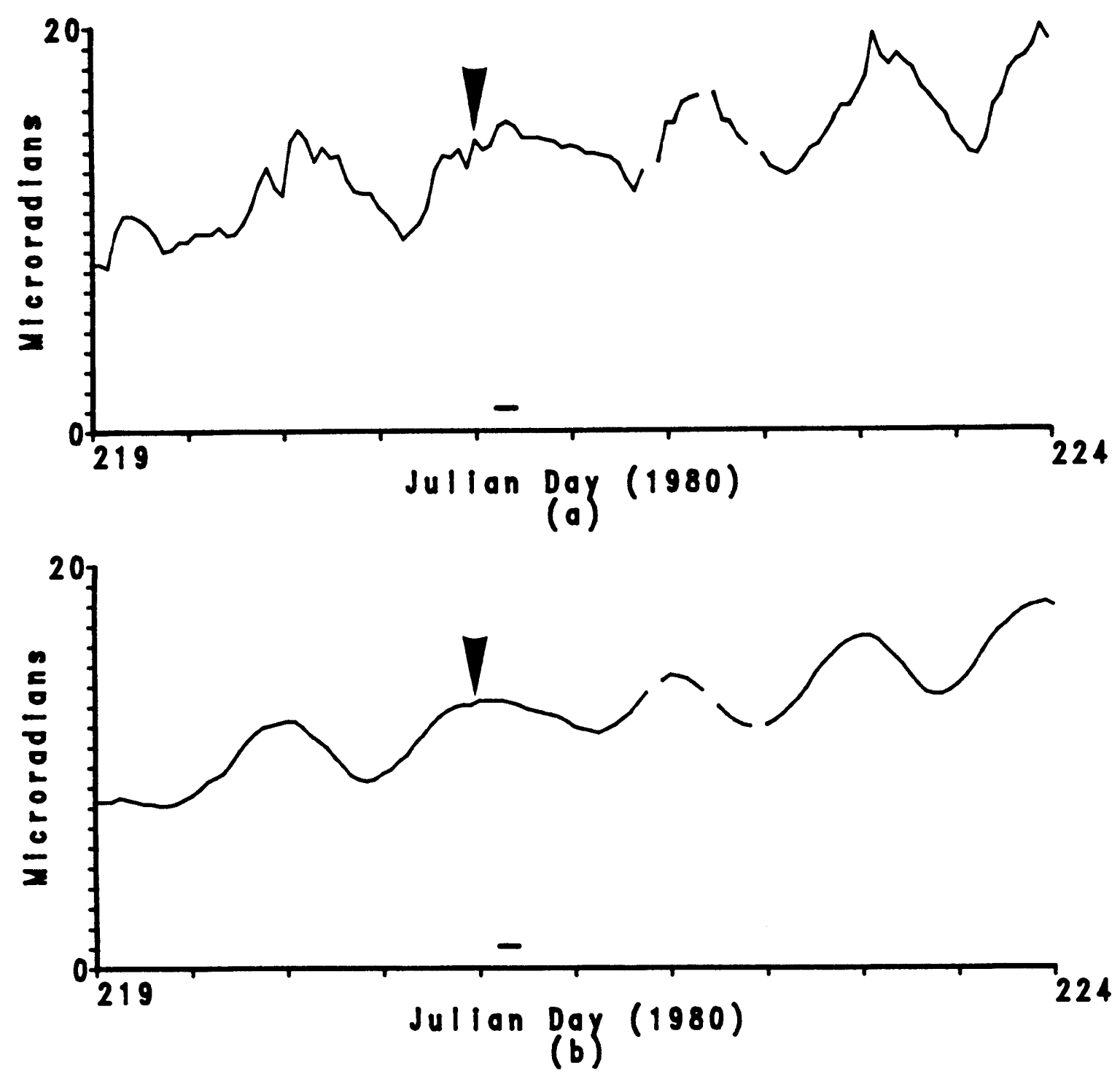

Figure 21. Plots of raw and smoothed tiltmeter data from Ape Cave tiltmeter for the period of August 5, 1980 through August 9, 1980. Figure 2la. is the raw tilt data for the north-south axis of tilt. Figure 2lb. shows the same north-south axis after smoothing. Eruption onset is indicated by a vertical arrow. The period of highest seismic activity is marked by a solid horizontal bar. A decrease in recorded values indicates a north positive tilt (relative inflation). 

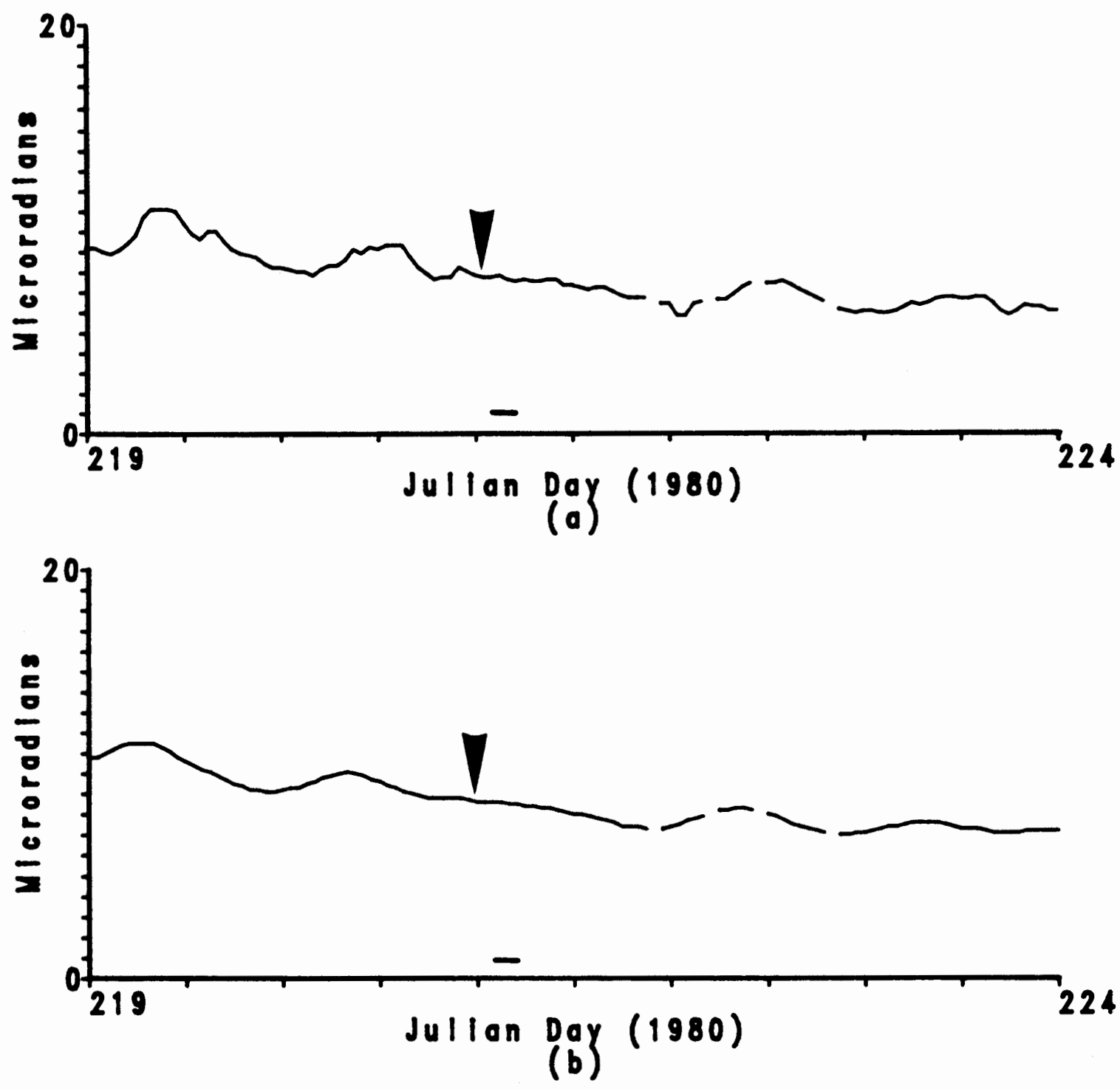

Figure 22. Plots of raw and smoothed tiltmeter data from Ape Cave North tiltmeter for the period of August 5, 1980 through August 9, 1980. Figure 22a. is the raw tilt data for the north-south axis of tilt. Figure 22b. shows the same north-south axis after smoothing. Eruption onset is indicated by a vertical arrow. The period of highest seismic activity is marked by a solid horizontal bar. A decrease in recorded values indicates a north positive tilt (relative inflation). 

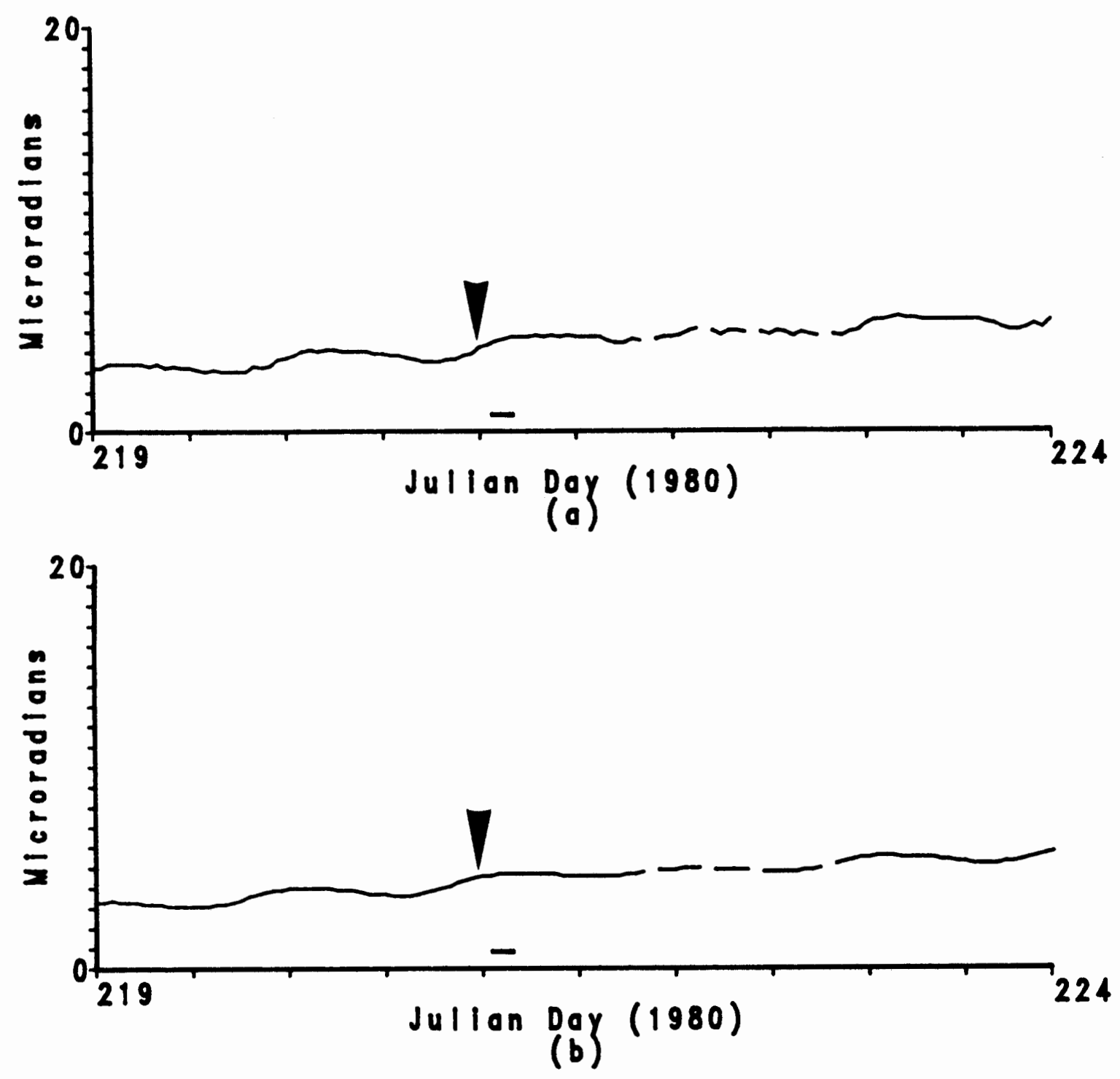

Figure 23. Plots of raw and smoothed tiltmeter data from June Lake tiltmeter for the period of August 5, 1980 through August 9, 1980. Figure 23a. is the raw tilt data for the north-south axis of tilt. Figure 23b. shows the same north-south axis after smoothing. Eruption onset is indicated by a vertical arrow. The period of highest seismic activity is marked by a solid horizontal bar. A decrease in recorded values indicates a north positive tilt (relative inflation). 

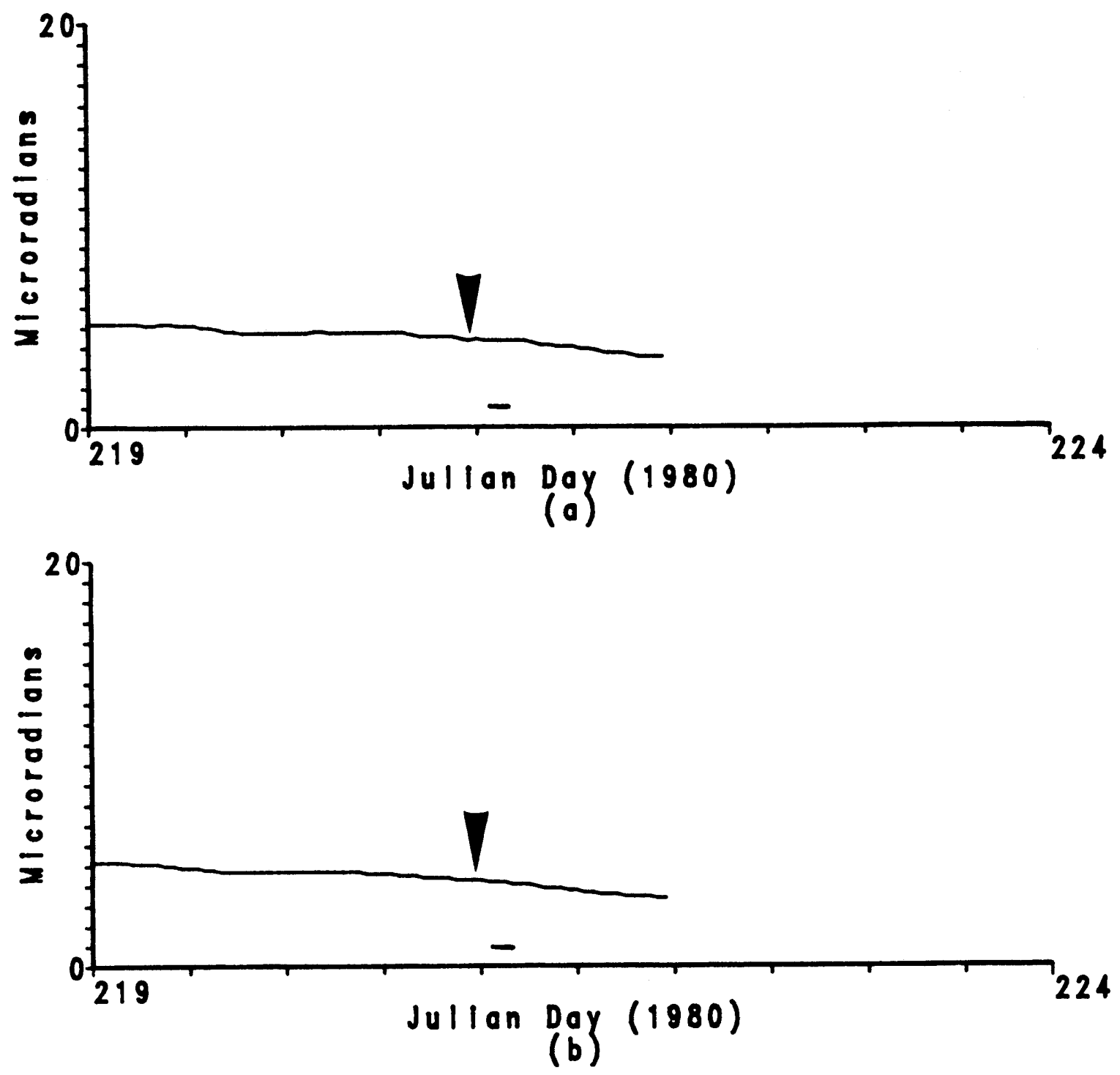

Figure 24. Plots of $r$ aw and smoothed tiltmeter data from PSU \#3 tiltmeter for the period of August 5, 1980 through August 9, 1980. Figure 24a. is the raw tilt data for the north-south axis of tilt. Figure 24b. shows the same north-south axis after smoothing. Eruption onset is indicated by a vertical arrow. The period of highest seismic activity is marked by a solid horizontal bar. A decrease in recorded values indicates a north positive tilt (relative inflation). 

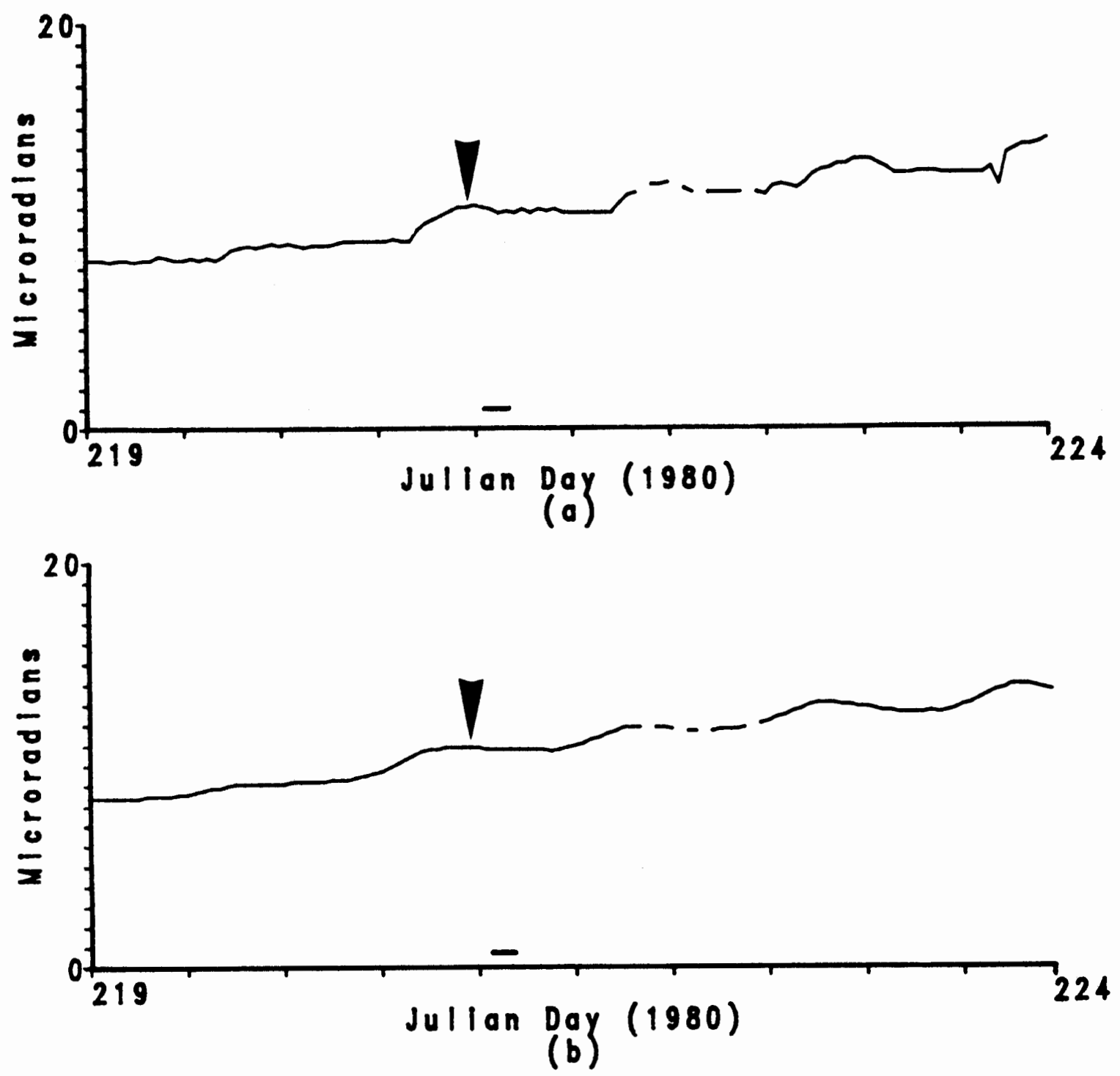

Figure 25. Plots of $\mathrm{r}$ aw and smoothed tiltmeter data from Blue Lake tiltmeter for the period of August 5, 1980 through August 9, 1980. Figure 25a. is the raw tilt data for the east-west axis of tilt. Figure 25b. shows the same east-west axis after smoothing. Eruption onset is indicated by a vertical arrow. The period of highest seismic activity is marked by a solid horizontal bar. A decrease in recorded values indicates an east positive tilt (relative inflation). 


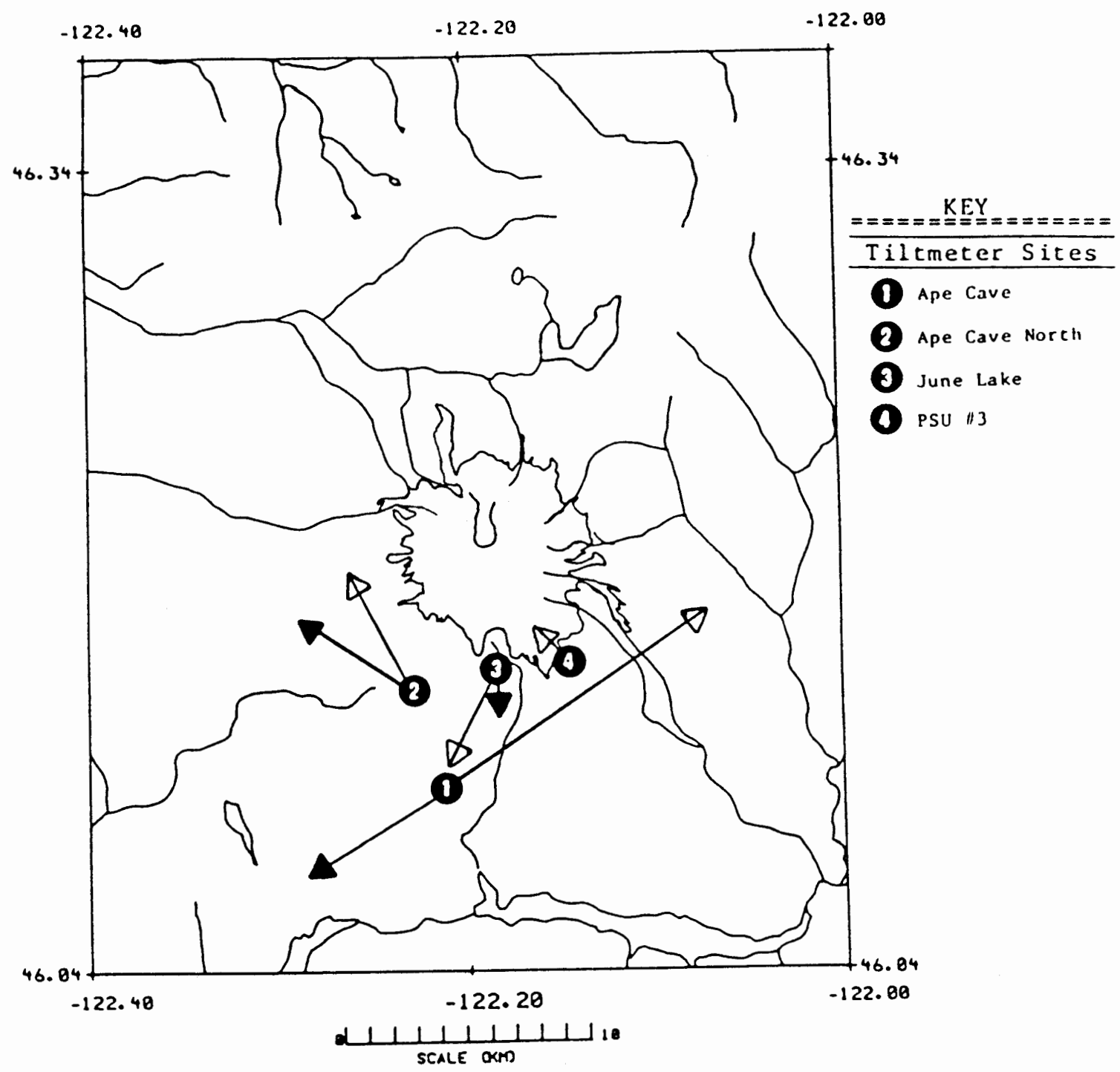

Figure 26. A diagram of the tilt vector directions and relative magnitudes recorded before and after the August 7, 1980 eruption. Pre-eruption vectors are indicated by hollow arrows. Post eruption vectors are indicated by solid arrows. 
The Ape Cave North tilt site (Figure 22) recorded a general inflationary trend to the data, with inflation increasing to $1 \mathrm{\mu rad} / \mathrm{day}$ between JD 216 and the eruption. Following the eruption inflationary movement continued at a rate $.5 \mu \mathrm{rad} /$ day through JD 232 when inflation increased to $3 \mu \mathrm{rad} / \mathrm{day}$ for a four day period.

The June Lake tilt site (Figure 23) recorded continual deflationary movement between the July and August eruptions. This deflationary trend amounted to an average of .5 $\mu \mathrm{rad} / \mathrm{day}$. On day 216 the deflation trend increased to approximately . $1 \mathrm{\mu rad} /$ day . This shallow trend continued until the eruption. After the eruption the trend returned to a .5 urad/day rate of deflation.

The PSU \#3 tilt site (Figure 24) was in operation for only one day prior to the eruption. The general direction of tilt at this site indicted an average inflationary trend of .6 urad/day. The quality of the data recorded at this site for this eruption is very low due to the extremely short operational period involved prior to the eruption.

The Blue Lake tilt site (Figure 25) indicated that a possible deflation was taking place during the eruption. Since the site was mechanically unstable directly before and after the eruption, the tilt vector directions and magnitudes are of little value.

Visual evaluation of all resultant tiltmeter records during this eruption indicated that only minimal correlation existed between any of the sites. Cross-correlation analysis indicated minimal correlation between tiltmeter sites, confirming the visual evaluation.

\section{OCTOBER ERUPTION}

The October eruption occurred on October 16, 1980 at 21:58 PDT 
105:58 GMT on Julian Day 291). The eruption consisted of five separate explosive columns over a period of two days (see Appendix C), a pyroclastic flow, destruction of the old August dome complex and creation of a new dome. Unlike previous eruptions where dome growth occurred (see Table 1, Appendix C), the dome growth took place over a period of two days. Total magmatic output for this eruption was of $1.5 * 10^{6} \mathrm{~m}^{3}$ of material.

Tiltmeters in operation during this eruption where; Ape Cave, Ape Cave North, June Lake, and PSU \#2 (see Figure 9). Statistics indicating the pre-eruption tilt vector orientation and rate, the post-eruption tilt vector orientation and rate, and the net tilt since the August 7, 1980 eruption are given in Table V.

The general direction of the tilt since the August eruption was that of continued inflation of the region to the north of the tiltmeters. Indicating this to the greatest extent were Ape Cave and Ape Cave North sites. The June lake site continued the deflationary trend evident in the last two eruptions. Deformation recorded by the tiltmeters for the period of August 11 to October 15 (see Figures 10 through 15) indicated a general deflationary baseline tilt trend except for the PSU \#3 site which recorded an inflationary trend. Plots of raw and smoothed tiltmeter data for the period JD 289 through JD 299 are shown in Figures 27 through 30. Shown in Figure 31 is a diagram indicating tilt deformation vectors before and after this eruption.

On approximately JD 284 both components of the Ape Cave tiltmeter (Figure 27) changed pattern. The north-south component changed from a inflationary trend of approximately 4 urad/day to a deflationary trend 


\section{TABLE V}

PRE-ERUPTION TILT VECTOR ORIENTATION, PRE-ERUPTION TILT RATE, POST-ERUPTION TILT VECTOR ORIENTATION, POST-ERUPTION TILT RATE, NET TILT SINCE LAST MAJOR ERUPTION AT MOUNT

ST. HELENS FOR THE OCTOBER 16, 1980 ERUPTION.

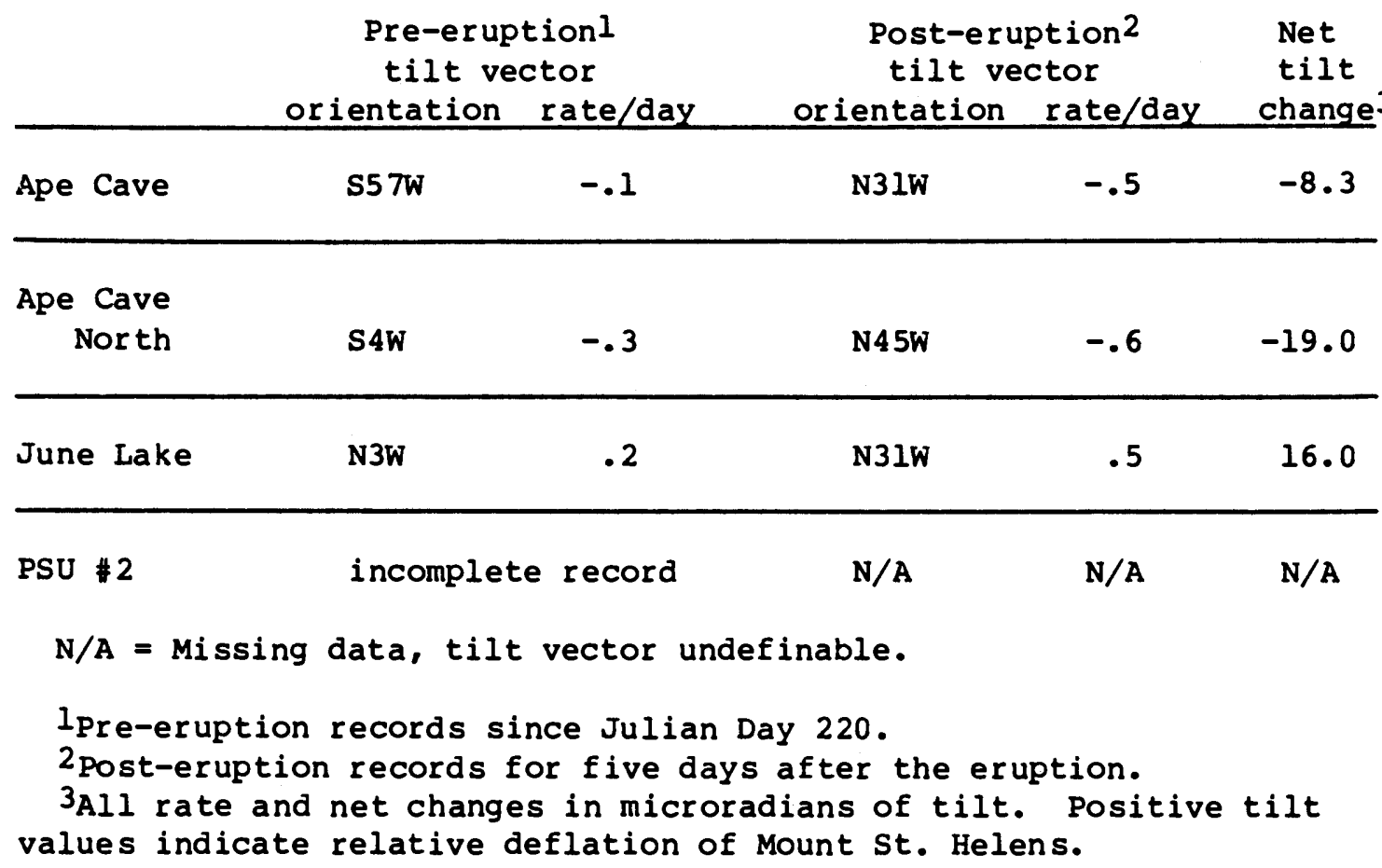

of about $2 \mathrm{\mu rad} / \mathrm{day}$ for a period lasting about two days. The east-west axis changed at about the same time from an east up trend of $2 \mu r a d / d a y$ to a west up trend of 1 urad/day starting at about the same time. The tilts on both axis remained relatively flat until JD 288 where the east-west axis again began to show an east up tilt of $1 \mu \mathrm{rad} / \mathrm{day}$ and the north-south axis showed a north up tilt of 1 urad/day. The first eruption was preceded by an inflationary tilt increase and was followed by deflationary tilt movement of the north-south axis, and the east-west axis indicated continual east up tilt of about 1 urad/day. The second eruption started eleven hours after the first, with 

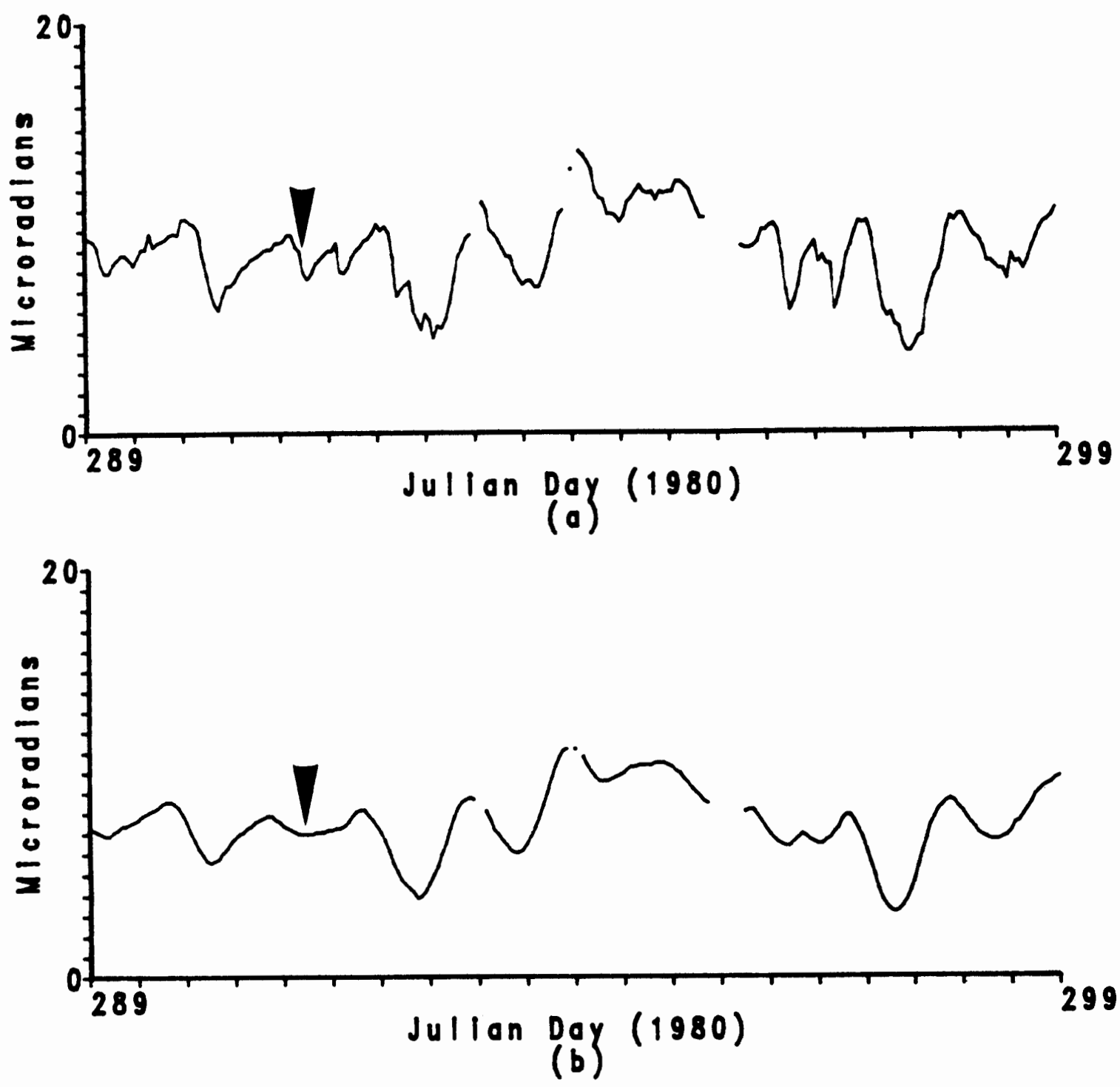

Figure 27. Plots of $r$ aw and smoothed tiltmeter data from Ape Cave tiltmeter for the period of October 14, 1980 through October 23, 1980. Figure 27a. is the raw tilt data for the north-south axis of tilt. Figure 27b. shows the same north-south axis after smoothing. Eruption onset is indicated by a vertical arrow. A decrease in recorded values indicates a north positive tilt (relative inflation). 

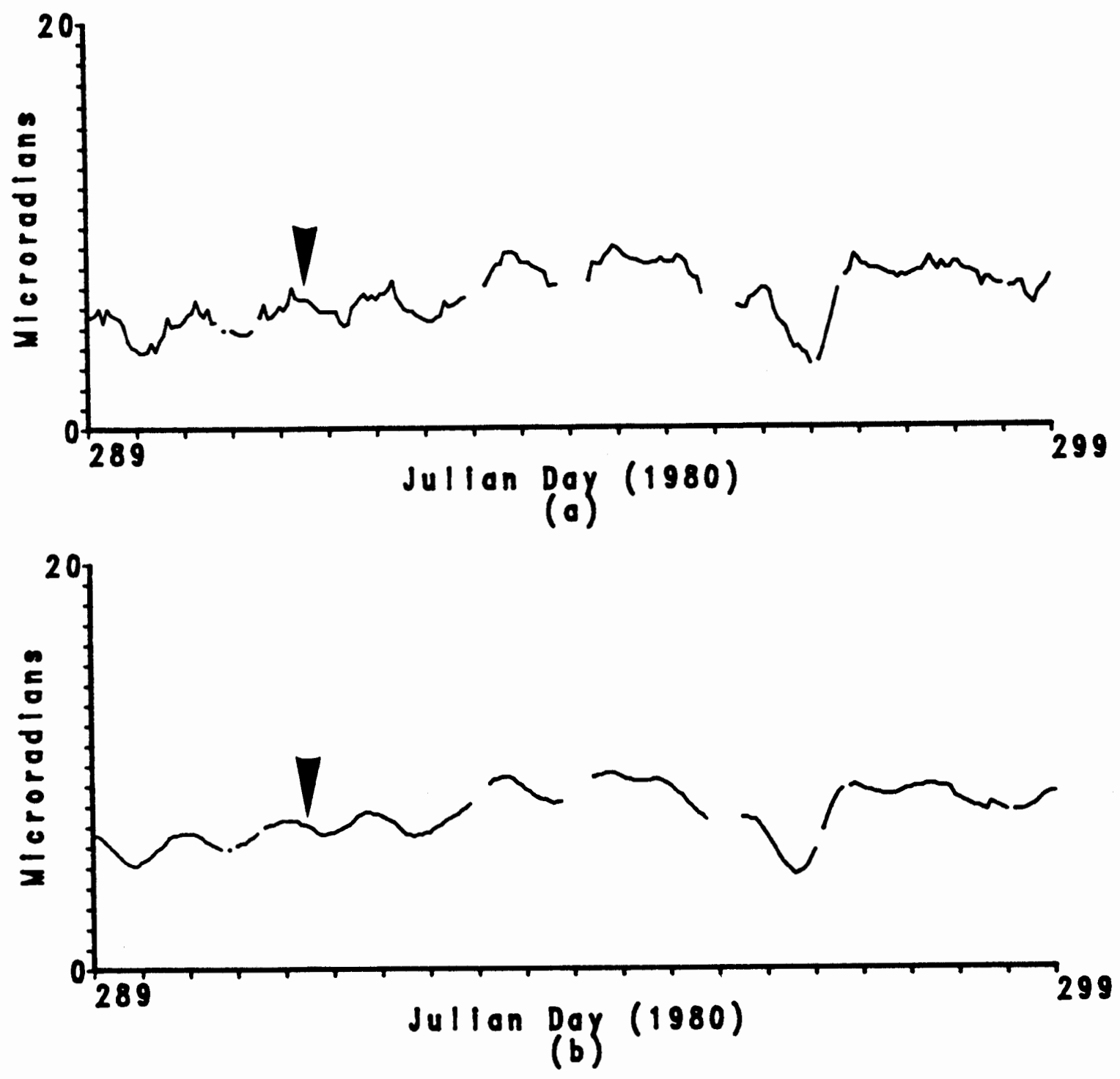

Figure 28. Plots of $r$ aw and smoothed tiltmeter data from Ape Cave North tiltmeter for the period of October 14, 1980 through October 23, 1980. Figure 28a. is the raw tilt data for the north-south axis of tilt. Figure 28b. shows the same north-south axis after smoothing. Eruption onset is indicated by a vertical arrow. A decrease in recorded values indicates a north positive tilt (relative inflation). 

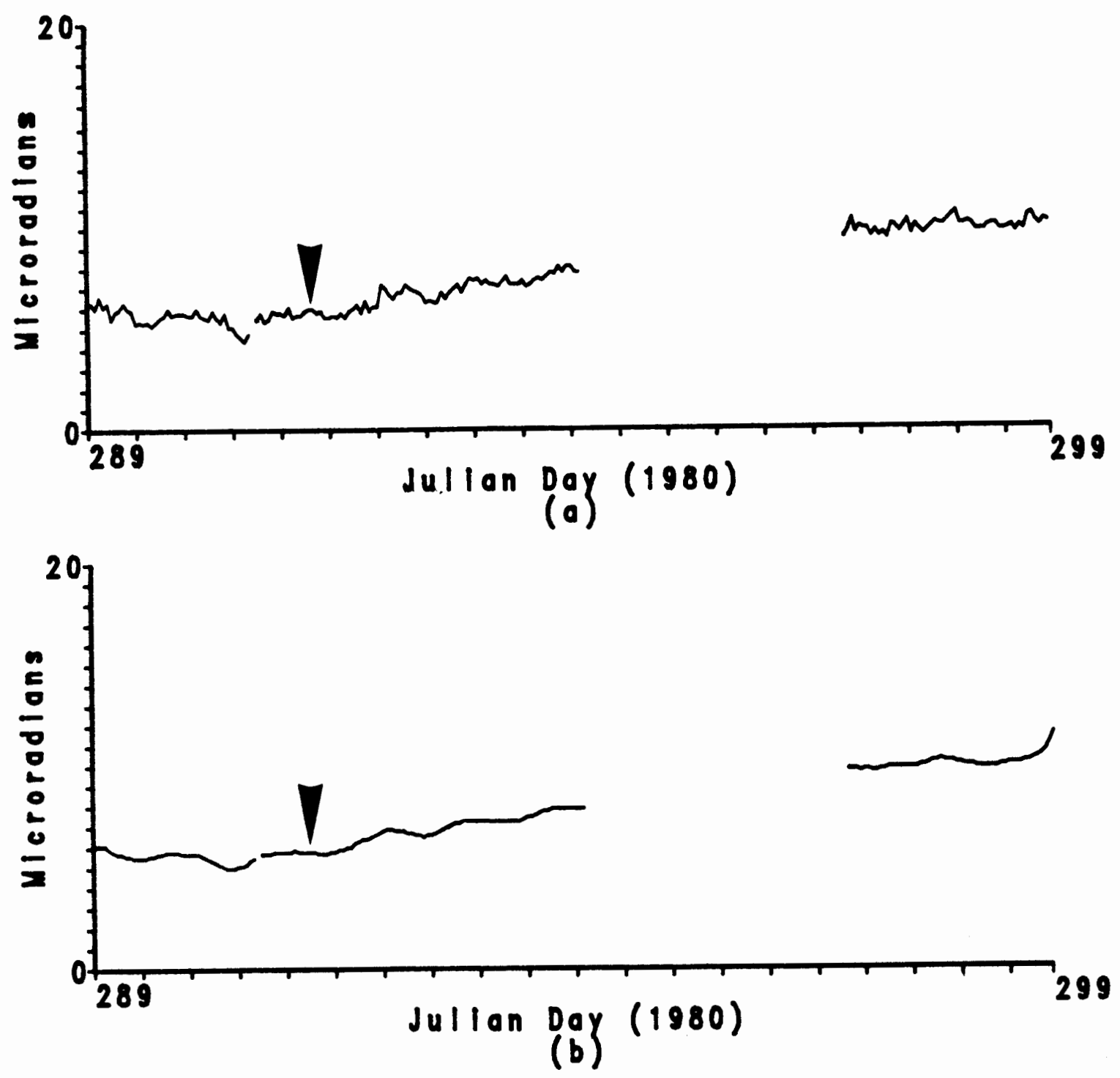

Figure 29. Plots of raw and smoothed tiltmeter data from June Lake tiltmeter for the period of October 14, 1980 through October 23, 1980. Figure 29a. is the raw tilt data for the north-south axis of tilt. Figure 29b. shows the same north-south axis after smoothing. Eruption onset is indicated by a vertical arrow. A decrease in recorded values indicates a north positive tilt (relative inflation). 
68
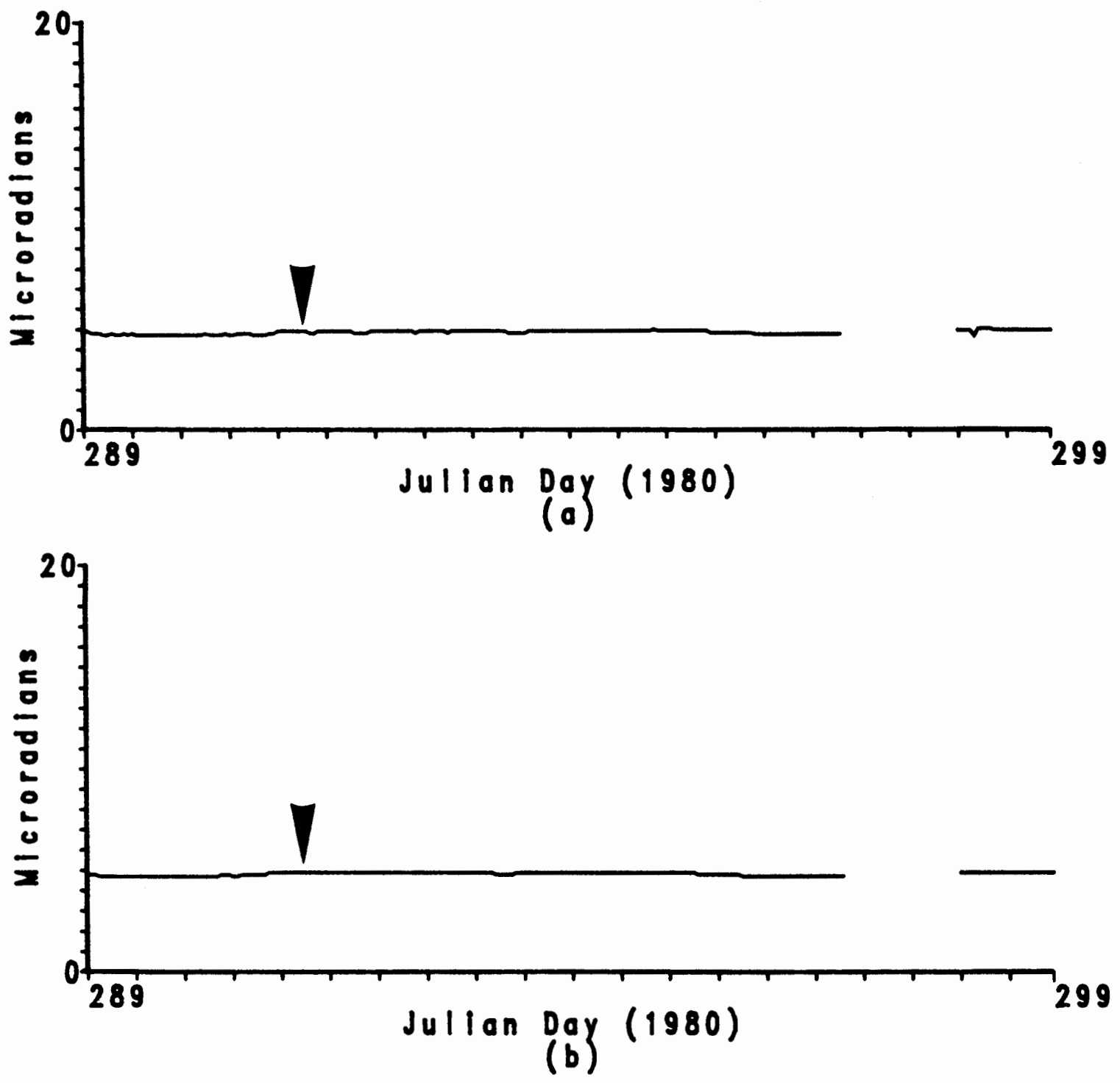

Figure 30. Plots of raw and smoothed tiltmeter data from PSU \#2 tiltmeter for the period of October 14, 1980 through October 23, 1980. Figure 30a. is the raw tilt data for the north-south axis of tilt. Figure $30 \mathrm{~b}$. shows the same north-south axis after smoothing. Eruption onset is indicated by a vertical arrow. A decrease in recorded values indicates a north positive tilt (relative inflation). 


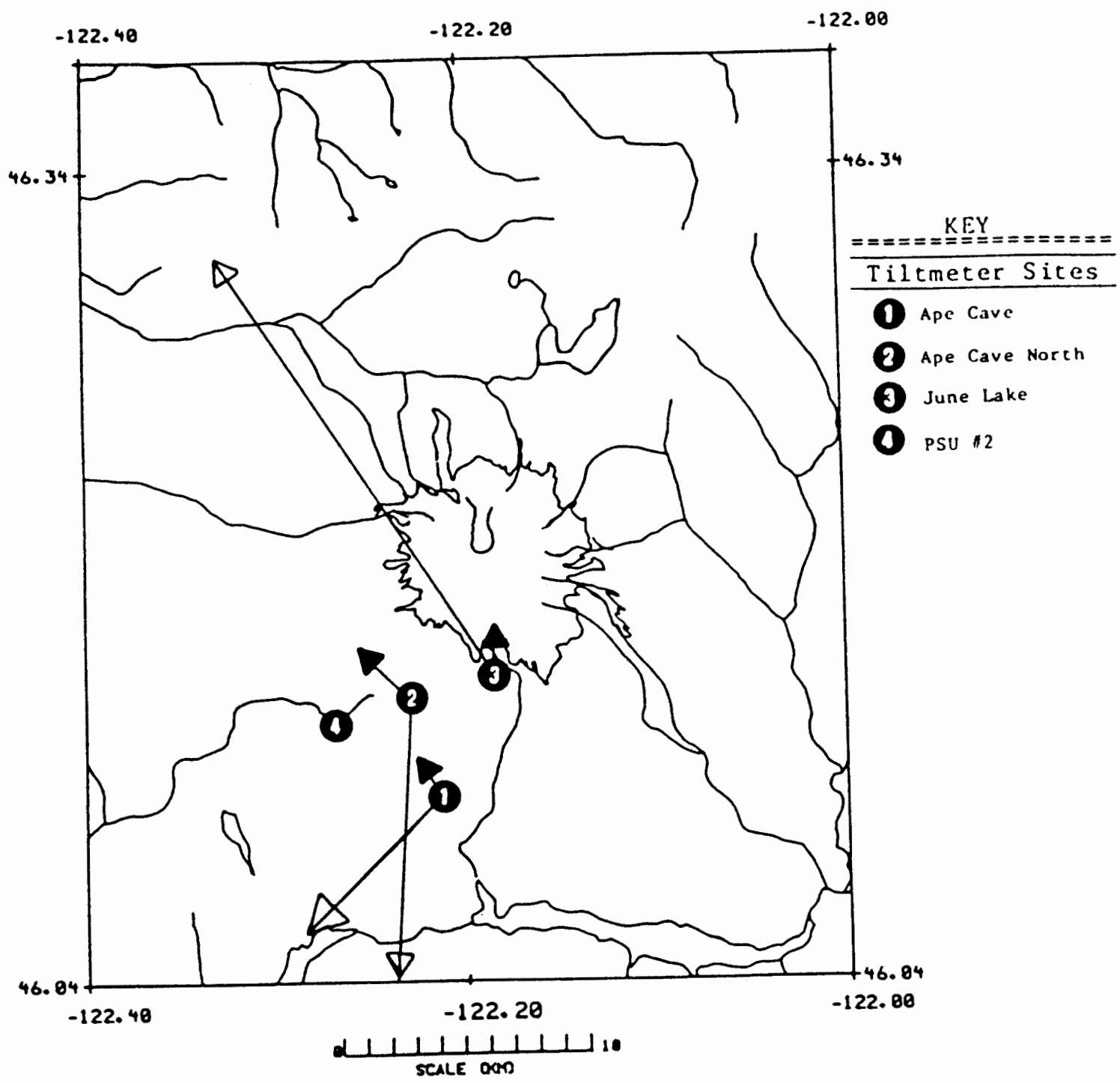

Figure 31. A diagram of the tilt vector directions and relative magnitudes recorded before and after the October 16, 1980 eruption. Pre-erpution vectors are indicated by hollow arrows. Post-eruption vectors are indicated by solid arrows. 
continued east up tilt of the east-west axis but with the north-south axis showing a deflationary tilt of about $1 \mu \mathrm{rad} / \mathrm{hr}$. The tilt direction of the north-south axis distinctly changed trend at approximately 01:00 GMT JD 292. The north-south axis began showing a rapid inflationary increase of about $2 \mu \mathrm{rad} / \mathrm{hr}$ until about $0400 \mathrm{hrs}$. GMT when tilt direction changed to the deflationary sense and at $0512 \mathrm{hrs}$ the third eruptive pulse occurred. This deflation lasted for about 2 hours and then changed back to inflation. The east-west axis also changed tilt orientation reflecting the north-south axis changes although lagging it by about 4 hours and at a smaller amplitude. Tilts continued in the inflationary sense until approximately 1230 when they again changed back to deflationary. The fourth eruptive event occurred at 1935 and signaled the start of a major deflationary pattern of 2 $\mu \mathrm{rad} / \mathrm{hr}$ until the the final explosive event started at $2128 \mathrm{hrs}$. GMT. Following the last event the formation of a dome complex occurred over the next two days.

The Ape Cave North tiltmeter (Figure 28) preformed in a very similar pattern to the Ape Cave tiltmeter except that in general the amplitude of the changes where not nearly as large. Signals recorded by the Ape Cave North station were of larger amplitude for the east-west tilt axis than the north-south axis. This is probably due to the more westerly orientation of the site. The signals at Ape Cave North also lagged behind the Ape Cave signals in general by about 1 or 2 hours. The overall direction of tilt during the eruptive period was south positive and west positive, which translates to an overall subsidence in the region to north-east of the mountain. 
The June Lake site recorded essentially no change during the eruptive period. There was a very small change in tilt to a possible south positive orientation on about JD 291 (Figure 29), but the change was about 1 prad/day. The east-west axis recorded continued minor east positive tilt preceding and throughout the eruptive period of about $.5 \mu \mathrm{rad} / \mathrm{day}$.

The PSU \#2 tiltmeter site (Figure 30 ) indicated essentially no change during, before or directly after the eruption. The north-south component indicated negligible tilt in any direction, while the eastwest component had a minimal west positive tilt.

Visual evaluation of the data recorded during this eruptive period (Figures 27 through 30 ) indicated a possible correlation existed between eruptive cycles and tiltmeter vector fluctuations for the Ape Cave and Ape Cave North sites, although the amplitude of the recorded signal at Ape Cave was much stronger than Ape Cave North. Crosscorrelation of the resultant tilt data confirmed that Ape Cave and Ape Cave North had remotely similar patterns (correlation coefficient, less than .6).

\section{DECEMBER ERUPTION}

The December was the last eruption during the study period. Start of this eruption is uncertain because poor weather conditions prevented visual observation and no eruptive column was detected by radar. Shallow earthquakes signaled the approximate start of the eruption on December 27, 1980 (Julian Date 362). This eruption is unique in this study due to the lack of associated explosive activity characteristic of previous eruptions (Appendix C). The new dome growth took place 
without removal of the previous dome. Dome growth lasted for a period of 7 days with cessation of output occurring sometime January 4, 1981 (Appendix C). The total magmatic output for the December eruption was $3.6 * 10^{6} \mathrm{~m}^{3}$.

By the time this eruption occurred, the PSU tiltmeters had been rendered inactive; weather conditions making the equipment inaccessible. Tiltmeters in operation during the December eruption were: Ape Cave, Ape Cave North, and June Lake (see Figure 9). Statistics indicating the pre-eruption tilt vector orientation and rate, the post-eruption tilt vector orientation and rate, and the net tilt since the October 22, 1980 eruption are given in Table VI.

TABLE VI

PRE-ERUPTION TILT VECTOR ORIENTATION, PRE-ERUPTION TILT RATE, POST-ERUPTION TILT VECTOR ORIENTATION, POST-ERUPTION TILT RATE, NET TILT SINCE LAST MAJOR ERUPTION AT MOUNT ST. HELENS FOR THE DECEMBER 1980 ERUPTION.

Pre-eruptionl

tilt vector orientation rate/day $\begin{array}{cl}\text { Post-eruption } & \text { Net } \\ \text { tilt vector } & \text { tilt }\end{array}$ orientation rate/day change ${ }^{3}$

\section{Ape Cave}

$\mathrm{N} / \mathrm{A}$

$\mathrm{N} / \mathrm{A}$

see * below

N/A

\footnotetext{
Ape Cave

North

$\mathrm{N} / \mathrm{A}$

$\mathrm{N} / \mathrm{A}$

see * below

N/A

June Lake

$\mathrm{N} I 5 \mathrm{~W}$

.7

see * below

49.7

$\mathrm{N} / \mathrm{A}=$ Missing data, tilt vector undefinable.

* The December eruption was not yet finished when the study concluded.

lPre-eruption records since Julian Day 290.

2 post-eruption records for five days after the eruption.

3 All rate and net changes in microradians of tilt. Positive values indicate relative deflation of Mount St. Helens.
} 
Tilt recorded at each of the sites between October 19, 1980 and December 27, 1980 (see Figures 10 through 13) indicated that there was an overall subsidence of Mount St. Helens. Tilt trends between JD 361 and the eruption (JD 362) indicated a slight inflationary trend to the North of the tiltmeter sites. This trend reversed after the eruption again to deflationary. Plots of raw and smoothed tiltmeter data between JD 357 and JD 367 are shown in Figures 32 through 34. A diagram showing the general direction and magnitude of tilt deformation vectors before and after the December eruption is given in Figure 35 . The Ape Cave tiltmeter site signal reception quality was decreasing before this eruption (Appendix A). Cause of the decreased reception quality was presumed to be weather related. Signal loss for the north-south axis was experienced for a twenty four day period between JD 335 and JD 361 (see Figure 10). This means that tilt trend analysis between the October and December eruptions is meaningless for this site. However the east-west tilt component was functioning the majority of the time, indicating a general east positive tilt until JD 354 when the axis orientation changed to a west positive tilt.

During the eruption the north-south axis of the Ape Cave tiltmeter (Figure 32) indicated a possible extremely minor north positive orientation. The east-west axis returned to an east positive orientation on JD 366.

The Ape Cave North site experienced major telemetry or instrument problems between JD 340 and JD 355 (see Figure 11), making assumptions about long term trends between the October and December of low value. The speculated trends of the north-south axis during this period is 

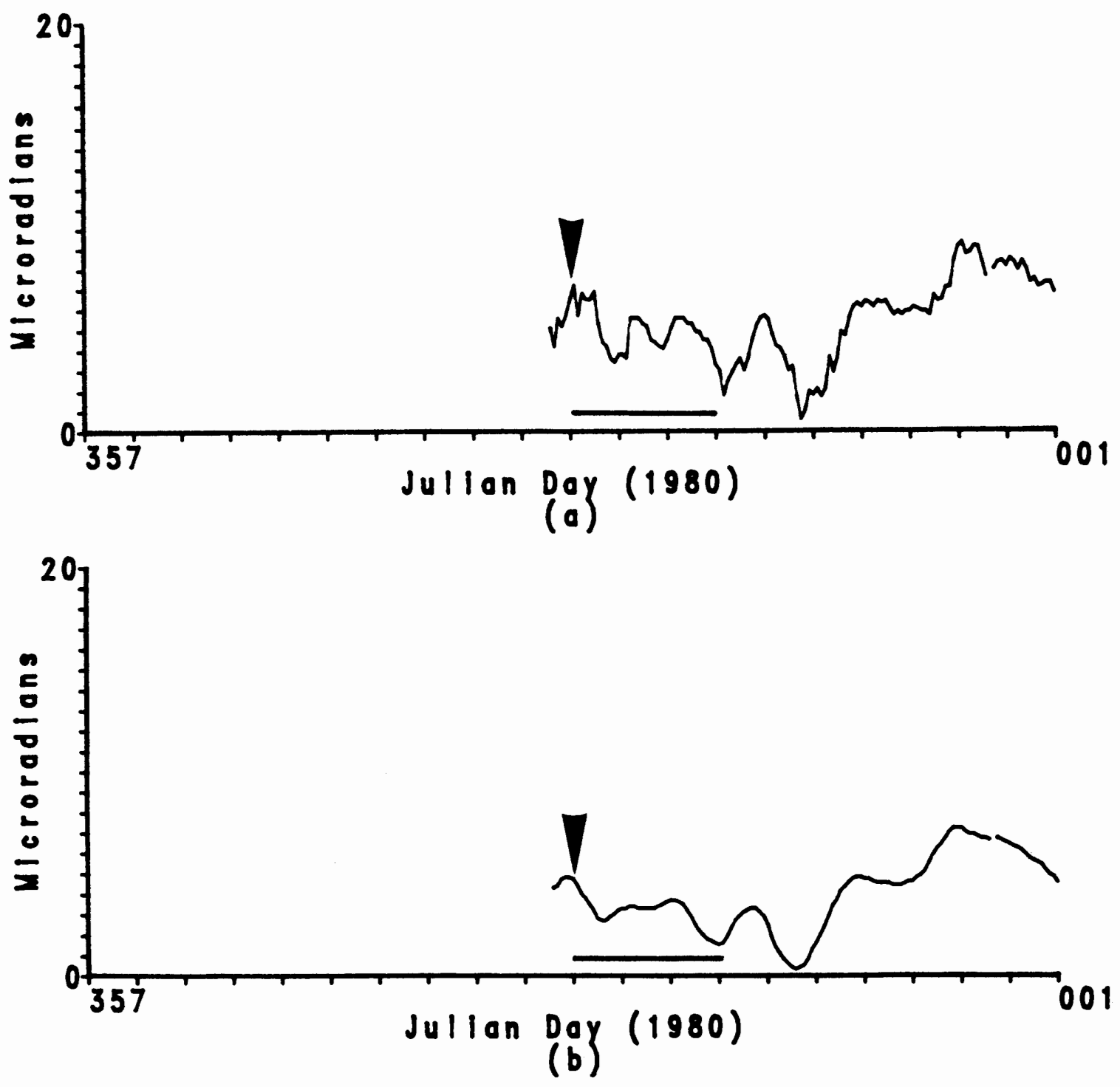

Figure 32. Plots of raw and smoothed tiltmeter data from Ape Cave tiltmeter for the period of December 26, 1980 through December 31, 1980. Figure 32a. is the raw tilt data for the north-south axis of tilt. Figure $32 \mathrm{~b}$. shows the same north-south axis after smoothing. Eruption onset is indicated by a vertical arrow. The period of highest seismic activity is marked by a solid horizontal bar. A decrease in recorded values indicates a north positive tilt (relative inflation). 

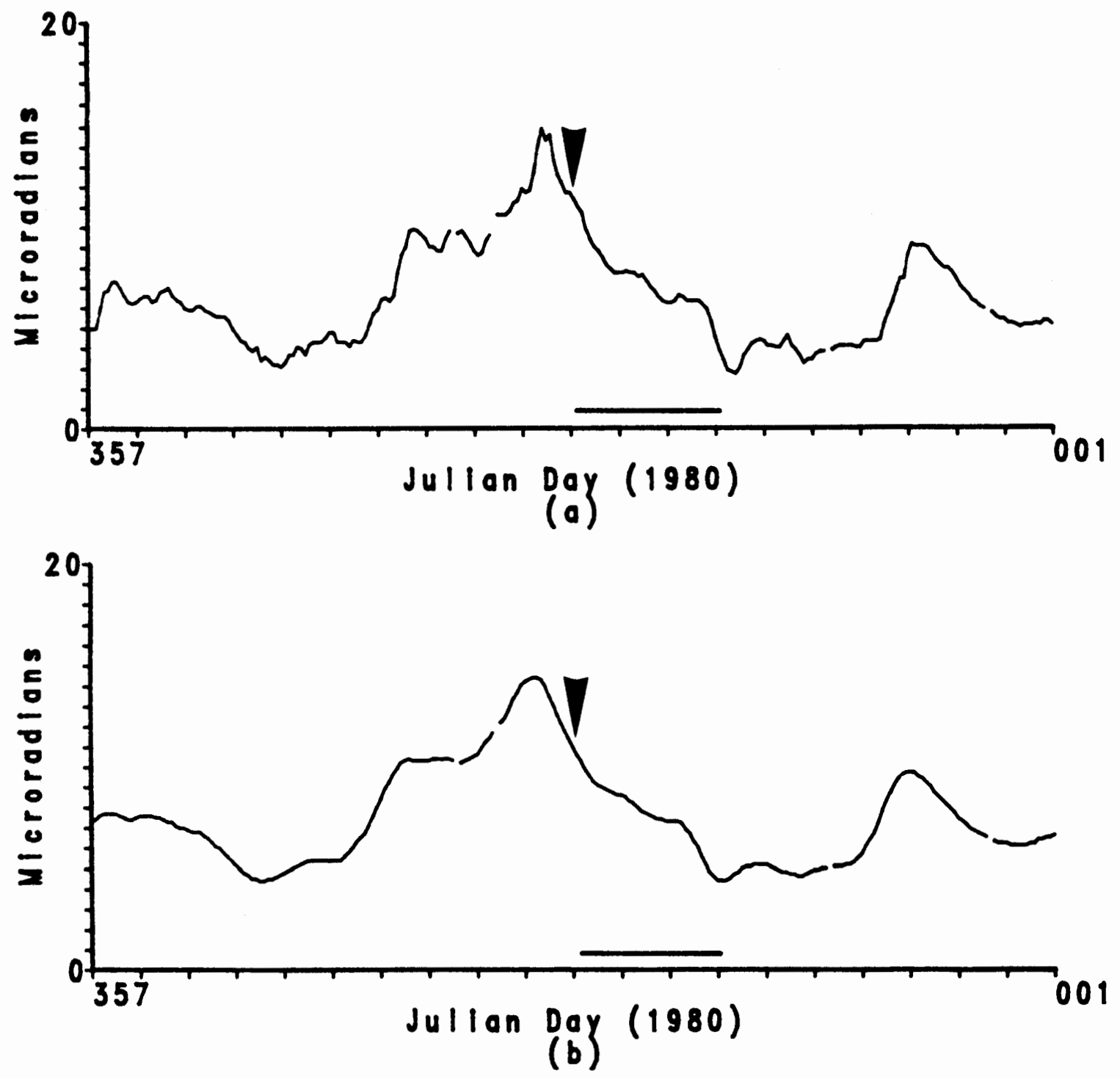

Figure 33. Plots of raw and smoothed tiltmeter data from Ape Cave North tiltmeter for the period of December 26, 1980 through December 31, 1980. Figure 33a. is the raw tilt data for the north-south axis of tilt. Figure $33 \mathrm{~b}$. shows the same north-south axis after smoothing. Eruption onset is indicated by a vertical arrow. The period of highest seismic activity is marked by a solid horizontal bar. A decrease in recorded values indicates a north positive tilt (relative inflation). 

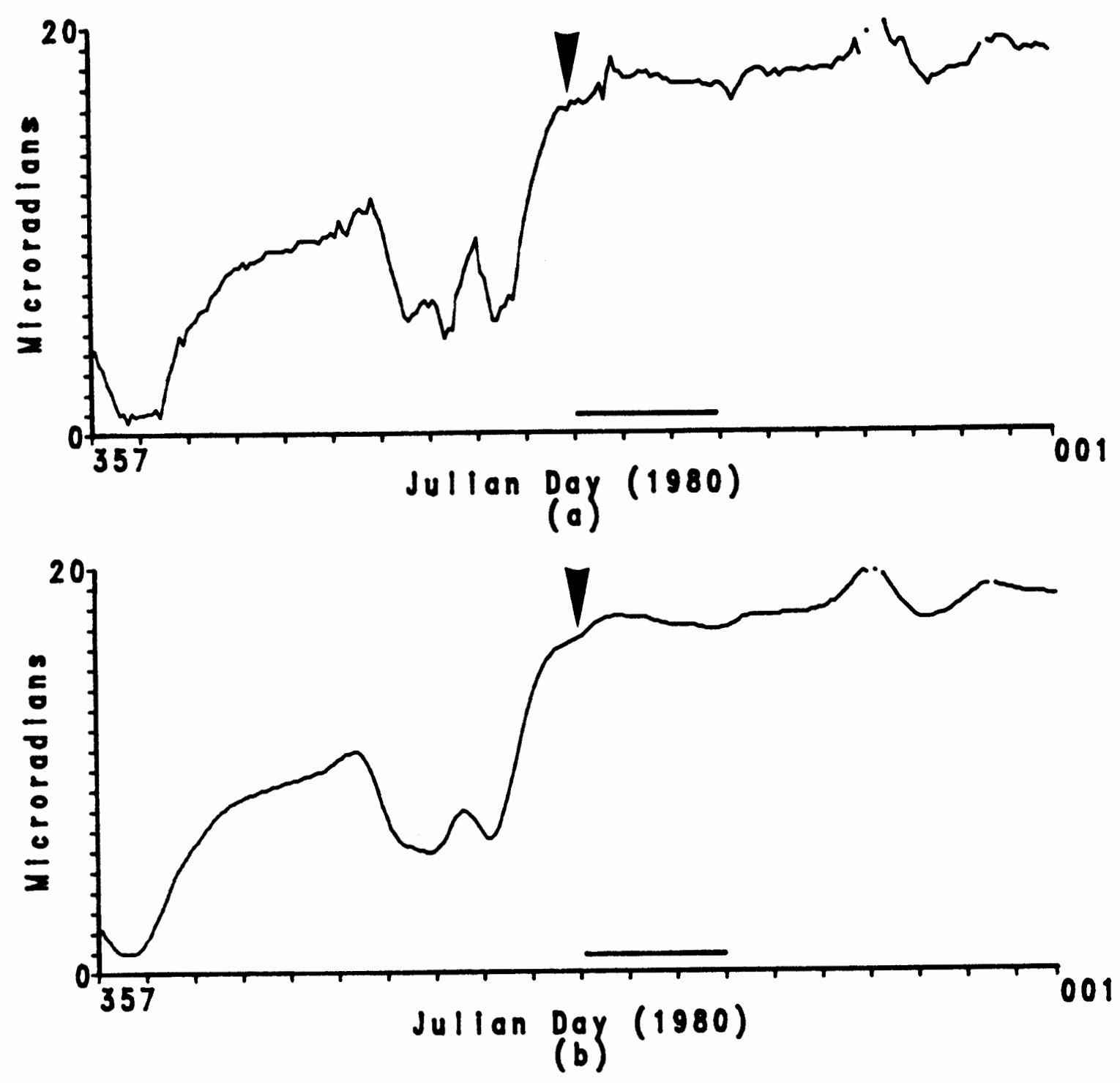

Figure 34. Plots of raw and smoothed tiltmeter data from June Lake tiltmeter for the period of December 26, 1980 through December 31, 1980. Figure 34a. is the raw tilt data for the north-south axis of tilt. Figure $34 \mathrm{~b}$. shows the same north-south axis after smoothing. Eruption onset is indicated by a vertical arrow. The period of highest seismic activity is marked by a solid horizontal bar. A decrease in recorded values indicates a north positive tilt (relative inflation). 


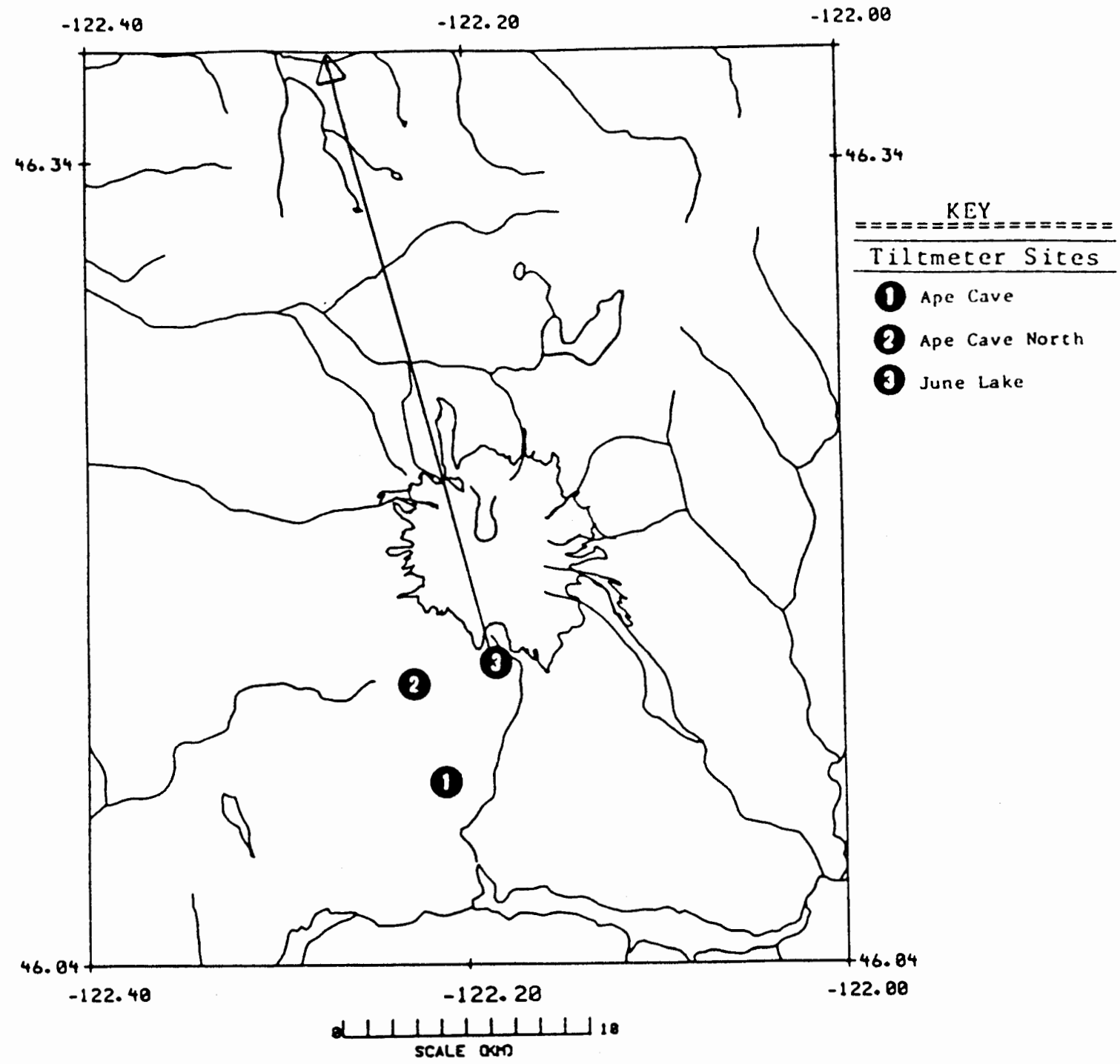

Figure 35. A diagram of the tilt vector directions and relative magnitudes recorded before and after the December 1980 eruption. Pre-eruption vectors are indicated by hollow arrows. Post-eruption vectors are indicated by solid arrows. 
that it remained relatively flat. The east-west axis underwent major changes in comparison to the north-south axis, but analysis of tilt direction between JD 340 and JD 355 is of little value.

During the eruption period JD 355 through JD 366 the Ape Cave North site was apparently functioning properly (Figure 33). Between days JD 355 and JD 361, the north-south axis recorded a south positive tilt orientation and the east-west axis showed a east positive tilt orientation. After JD 361 these orientations rotated to the opposite direction and again rotated back on JD 364.

The June Lake site indicated a slight inflationary trend relative to the mountain approximately fifteen to sixteen days prior to JD 361 (Figure 34). Another change in trend occurred JD 361, with rapid deflation of approximately 10 urad for a twelve hour period again on the north-south axis. Following this twelve hour period, tilt trends returned to a very minor deflationary pattern for the remainder of the eruptive period. The east-west axis remained relatively flat compared to the north-south axis, in general indicating a slight east positive tilt (relative deflation) until JD 356 when a short term inflation took place. Following the inflation, which lasted approximately four to six days, east positive tilt resumed.

Visual evaluation of the resultant tiltmeter records during this eruption (Figures 32 through 34) indicated that minimal correlation of trends existed between the sites. Cross-correlation analysis confirmed the conclusions of the visual evaluation. 


\section{CHAPTER VII}

\section{THEORETICAL MODELS}

Evaluation of the results from the tiltmeters based on available geologic, geodetic, geochemical and seismic information is the next phase of this study. This involved the integration of results obtained from the tiltmeters and other monitoring techniques.

As discussed in Chapter II.C, a major right lateral strike slip fault zone (SHz) that trends north $5^{\circ} \mathrm{w}$ through the Mount $S t$. Helens region. This fault zone could be a primary controlling factor in the location of the magmatic conduit for Mount St. Helens (Weaver and others, 1983). The location of seismic activity between 1980 and 1983 at Mount St. Helens (see Figure 5) also suggests that a northeast trending fault may also be resultant of the volcanic activity and a controlling factor of future activity (Weaver and Malone, 1983).

Results of geodetic deformation surveys conducted during 1980 (Swanson and others, 1981) indicated measurable amounts of deformation was associated with several of the eruptions during this period. During this study, the flanks of the mountain characteristically had measurable deformational changes during explosive eruptions (July 22 and August 7) and minimal deformation during non-explosive dome building eruptions (August 7 and December 23). The deformation surveys also indicated that patterns of resultant deformation to the north and east of Mount St. Helens varied from the south and west sides. The 
common deformation pattern before explosive eruptions was that of symetrical inflation of the mountain. Following explosive eruptions, the deformation to the north and east was negligible while marked deformation occurred to the south and west.

Surface deformation resulting from the intrusion of magma can be used to describe the shape, volume and depth of an idealized subsurface deformation source (Mogi, 1958). Using surface deformation data (tiltmeter and geodetic) and seismic information, models of the subsurface deformation source can be constructed. The purpose of modeling in this study was to correlate measured surficial deformation to specific volcanic events.

Two models were chosen to approximate the deformation patterns that accompanied each eruption. The first model, developed by Mogi (1958) uses a single pressurized magma chamber with a small cylindrical conduit. The second model applies the concepts of the first model to a system containing two vertically aligned pressurized magma chambers. Both models assume that the primary deformation source is definable and that lateral migration of the source with time has not occurred. Further explanation and assumptions made about each model can be found in their respective sections in the following text.

\section{A. MOGI MODEL (single magma chamber)}

The first major practical interpretation of ground deformation relative to magma chamber inflation was developed by Mogi (1958). Mogi based his work on a hypothesis originated by Yamakawa (1955). The method Mogi used assumed that the earths surface is a semi-infinite 
body approximating an elastic material in: 1) the short term, where the earths surface responds instantaneously to short period disturbances (i.e. instantaneous summit deflation caused by material loss due to eruption) and, (2) the long term, where the period of deformation may be years in length (i.e. the slow filling of a magma chamber). Mogi also assumed that deformation is caused by a small spherical source (point source) with associated hydrostatic pressure within the earths crust. An additional assumption made here is that the pressure change is equatable to volume change and that both are essentially equivalent. Theoretical calculations of the deformation are based on the conceptual drawing of an idealized system shown in Figure 36. The deformation in this idealized system is the result of spherical displacement in an elastic half space. Based on this idealized system Mogi developed equations relating pressure change, chamber volume and source depth to horizontal and vertical displacements at the Earth's surface. These equations and related derivations are illustrated and more fully explained in Appendix B.

Based on physical conditions present at Mount St. Helens after the May 18, 1980 eruption, an additional condition was placed on the model. Since the conduit ends at the crater floor, the distance to the center of the intruding spherical body was calculated relative to the crater floor rather than the summit. Also the loading caused by the edifice will be considered constant for this study. This is necessary because the effects of differential loading due to the shape of the remaining edifice are not fully understood. With the rapid unloading of the system resulting from the May 18, 1980 eruption either in an 


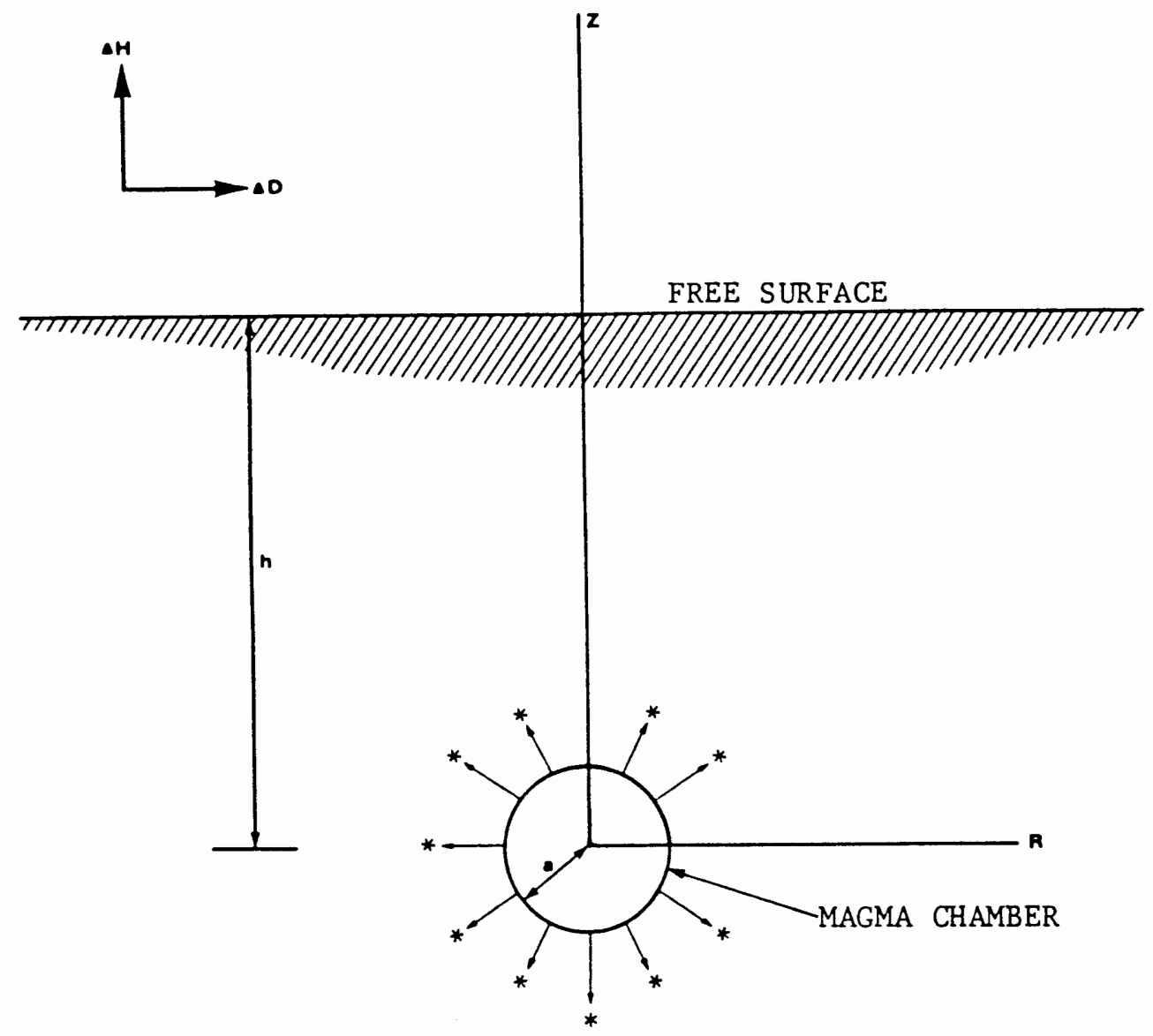

Figure 36. Idealized diagram of a Mogi volcanic system showing the major axis of stress as described by Machado (1974).

inelastic or viscous response could be a major complication (Denlinger, 1983, personal communication).

The deformation source below Mount st. Helens is known to have caused both horizontal and vertical expansion of the mountain during the study period (Swanson and others, 1981). Geodetic survey measurements of vertical deformation at Mount st. Helens indicated that 20 to $70 \mathrm{~cm}$ of subsidence occured during the study period. Calculation of an idealized cumulative deformation model for the entire study period (Figure 37 ), used results of the geodetic surveys as maximum and minimum boundary conditions in conjunction with 


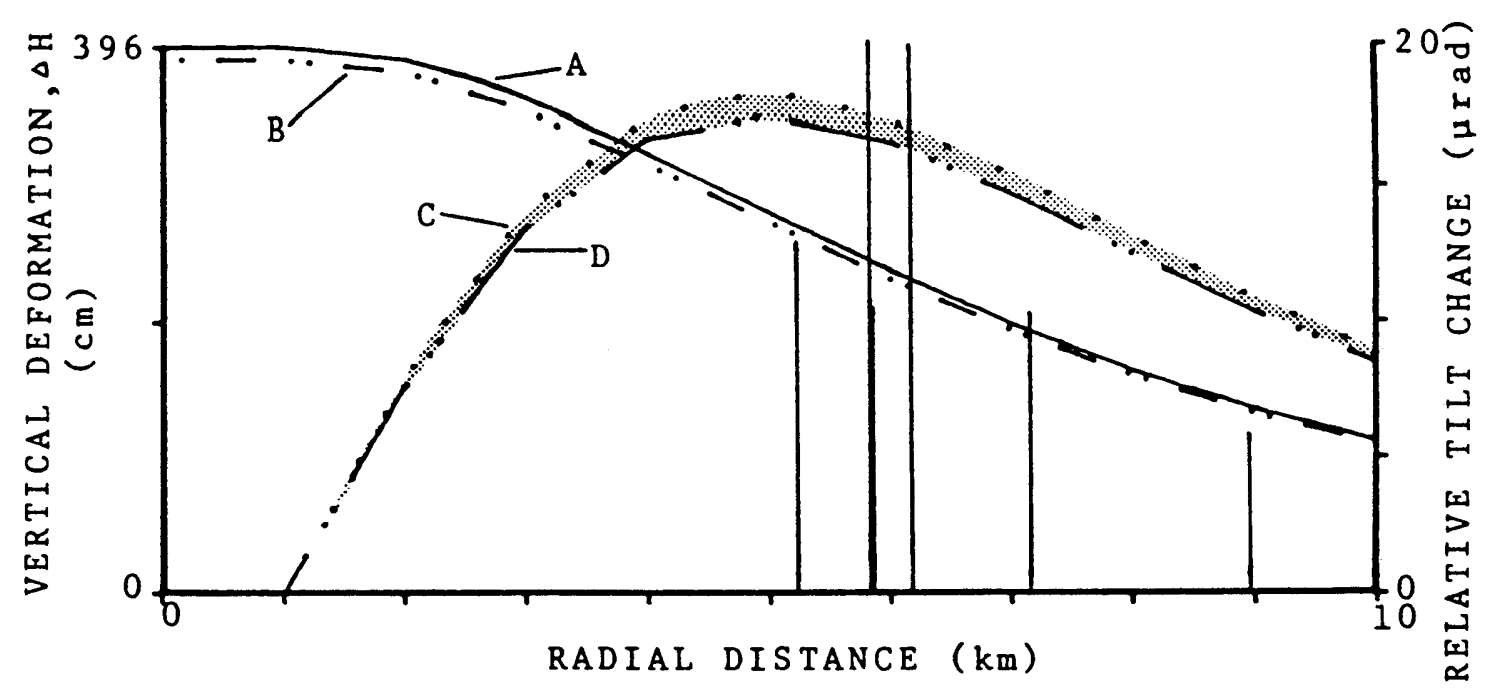

Curve A parameters

$$
\begin{aligned}
\text { volume change } & =.24 \mathrm{~km}^{3} \\
\text { source depth } & =9.0 \mathrm{~km} \\
\mathrm{v} & =.75 \\
\mathrm{H} & =70 \mathrm{~cm}
\end{aligned}
$$

Curve B parameters

$$
\begin{aligned}
\text { volume change } & =.24 \mathrm{~km}^{3} \\
\text { source depth } & =15.7 \mathrm{~km} \\
\mathrm{v} & =.75 \\
\mathrm{H} & =21 \mathrm{~cm}
\end{aligned}
$$

Figure 37. Surficial deformation diagram representing the projected maximum and mimimum theoretical vertical deformation from a point source. Line $A$, indicates the maximum deformation boundary and line $B$, indicates minimum deformation boundary. Line $C$ indicates calculated tilt for deformation indicated by line $A$, and line $D$ indicates calculated tilt for deformation indicated by line $B$. The shaded region is the area of possible modeled relative tilt change values. Vertical lines indicate generalized tiltmeter locations and relative tilt change at the site. Horizontal axis values are relative to vent termination in crater of Mount St. Helens.

measured output volumes (see Table I). Shown in Figure 37 are the deformation curves for 20 and $70 \mathrm{~cm}$ of vertical displacement, tilt curves for the same vertical displacements and, relative tilt changes for the individual tiltmeter sites. Ideally the relative tilt change recorded at any of the tiltmeter sites should be in the shaded area between the two tilt curves. 
Results of modeling deformation for the entire study period (Figure 37), with deformation caused by removal of material alone, indicated that the minimum modeled deformation tilt curve was generally larger than recorded tilt at most of the sites. The deformation curve from a subsidence of $70 \mathrm{~cm}$ results in tilt changes of about 80 urad (50 cm) and $30 \mu \mathrm{rad}(31 \mathrm{~cm})$ at horizontal distances of $6 \mathrm{~km}$ and $9 \mathrm{~km}$ respectively from a deformation source (source depth $=9 \mathrm{~km}$, magma volume removed $=.24 \mathrm{~km}^{3} ;$ Lipman and others, 1981). A subsidence of $20 \mathrm{~cm}$ results in relative tilt changes of about $11.5 \mu \mathrm{rad}(20.3 \mathrm{~cm})$ and 9.2 urad $(16 \mathrm{~cm})$ at horizontal distances of $6 \mathrm{~km}$ and $9 \mathrm{~km}$ respectively from a deformation source (source depth $=+15 \mathrm{~km}$, magma volume removed $=.24 \mathrm{~km}^{3}$ ). Large deviations from the model by several of the tiltmeters in terms of tilt vector direction indicate non-volcanic deformation as a major factor in deformation at these sites.

The modeled deformation pattern expected from a large mass at a depth of $7 \mathrm{~km}$ is shown in Figure 38. A chamber diameter of $1.5 \mathrm{~km}$ was used, based on seismic information (Scandone and Malone, 1983). Also shown in Figure 38 is the resultant deformation curve from removal of a small portion of this mass $\left(.24 \mathrm{~km}^{3}\right)$ equivalent to the amount erupted during 1980. The deformation pattern created by a large deep chamber is only minimally effected by removal of material from that chamber at distances of greater that $5 \mathrm{~km}$, with the modeled tilts less than 6 urad. Expected deformation from removal of material equal to any of the eruptions of late 1980 from a large chamber would result in tilt changes of less than 1 urad at horizontal distances greater than $5 \mathrm{~km}$. 


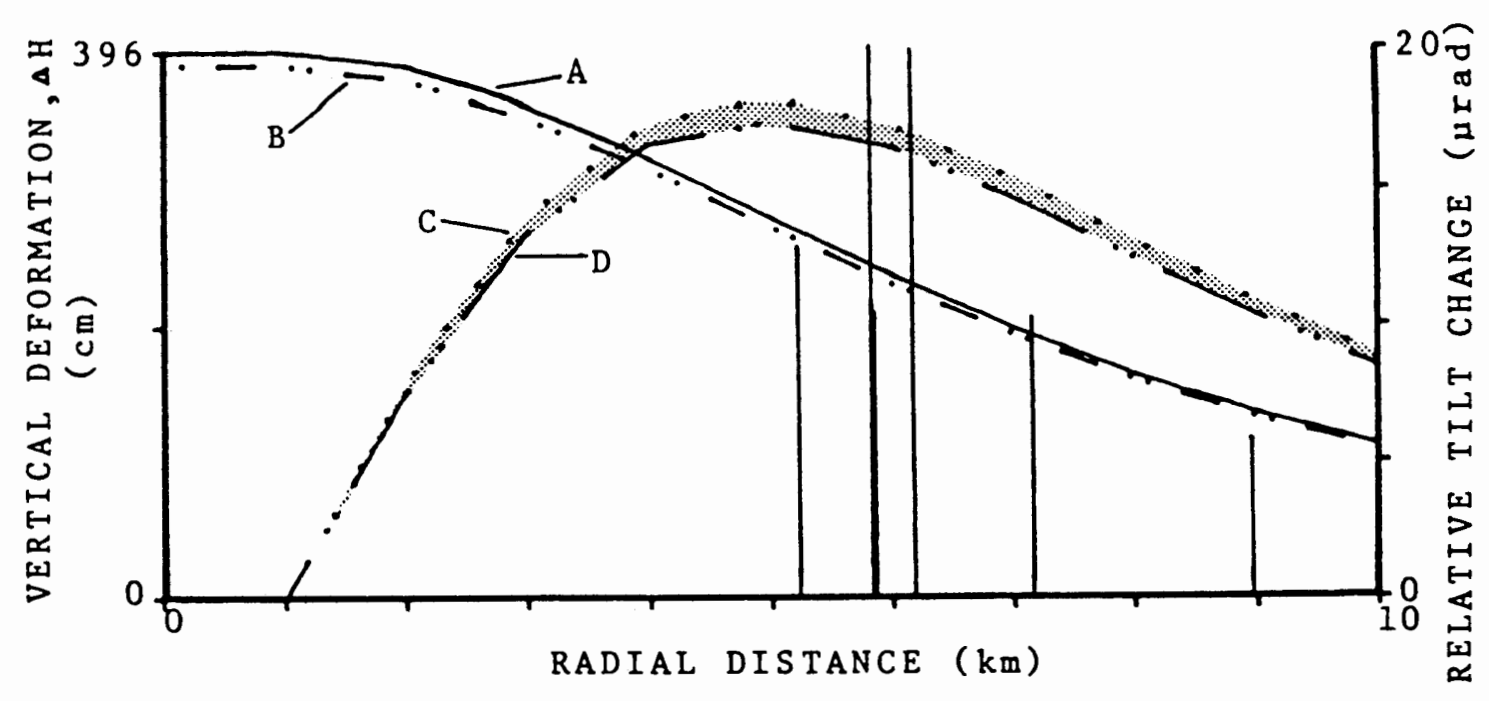

Curve A parameters

$$
\begin{aligned}
\text { chamber volume } & =10.0 \mathrm{~km}^{3} \\
\text { source depth } & =7.75 \mathrm{~km} \\
\mathrm{~V} & =.75 \\
\mathrm{H} & =396 \mathrm{~cm}
\end{aligned}
$$

Curve B parameters

$$
\begin{aligned}
\text { chamber volume } & =9.76 \mathrm{~km}^{3} \\
\text { source depth } & =7.75 \mathrm{~km} \\
\mathrm{~V} & =.75 \\
\mathrm{H} & =387 \mathrm{~cm}
\end{aligned}
$$

Figure 38. Idealized deformation patterns resulting from a large volume at depth. Line $A$, indicates the predicted deformation pattern caused by a magmatic body before removal of volcanic products and line $B$, indicates the predicted deformation pattern caused by removal of a volume equivalent to the 1980 eruptive products. Line $C$ indicates calculated tilt for deformation indicated by line $A$, and line $D$ indicates calculated tilt for deformation indicated by line $B$. The shaded region is the area of possible relative tilt change values. Vertical lines indicate generalized tiltmeter locations and relative tilt change at the site. Horizontal axis values are relative to vent termination in crater of Mount st. Helens.

\section{B. MOGI MODEL (multiple magma chamber)}

This model is based on the assumption that the system is composed of two separate chambers, a large lower chamber at a depth greater that $6 \mathrm{~km}$ supplying magma and a small upper chamber at a relatively shallow 
depth $(2 \mathrm{~km} \pm 1 \mathrm{~km})$ that acts as a temporary holding chamber directly preceeding eruptive periods (Figure 39). This hypothesis is based on the following factors; (1) there have been only minor compositional changes in the extruded magma (Table 7) (Casadevall and others, 1983), (2) that two pressure sources can be inferred from geodetic data (Swanson, 1981), (3) that an ascertainable vertical zonation of hypocenter locations exists below Mount st. Helens (Weaver, Zollweg and Malone, 1983) and (4) that inner-crater tiltmeters recorded large deformations prior to dome building eruptions during 1981 and 1982 (Dzurisin, Westphal and Johnson, 1983), while far field tiltmeters indicated changs of less than 1 rad.

The changes in bulk chemistry (Table 7) during 1980 were minor, the only recognizable change being a fluctuation of approximately 28 in $\mathrm{SiO}_{2}$ concentration. This change could be reflecting the removal of the relatively light constituents from the magma chamber by degassing and eruptive removal making later eruptions slightly more mafic. Crystallinity of the eruptive proaucts is also increasing, indicative of material being derived from a more crystal-rich volatile-poor region of the magma chamber (Cashman and Taggert, 1983). Decreases in $\mathrm{CO}_{2}$ and $\mathrm{SO}_{2}$ gas emmission since May 1980 also indicate that additional new magma has not entered the system (Casadevall and others, 1983). The geochemical results indicate that only one large (greater than 5 $\mathrm{km}^{3}$ ) magma chamber has produced all of the eruptive products since 1980 (Casadevall, 1983, personal communication) •

Results of geodetic surveys for the eruptions of August 7 , October 17, and December 26, 1980 indicated that measurable 


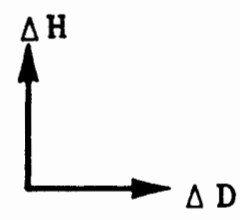

FREE SURFACE

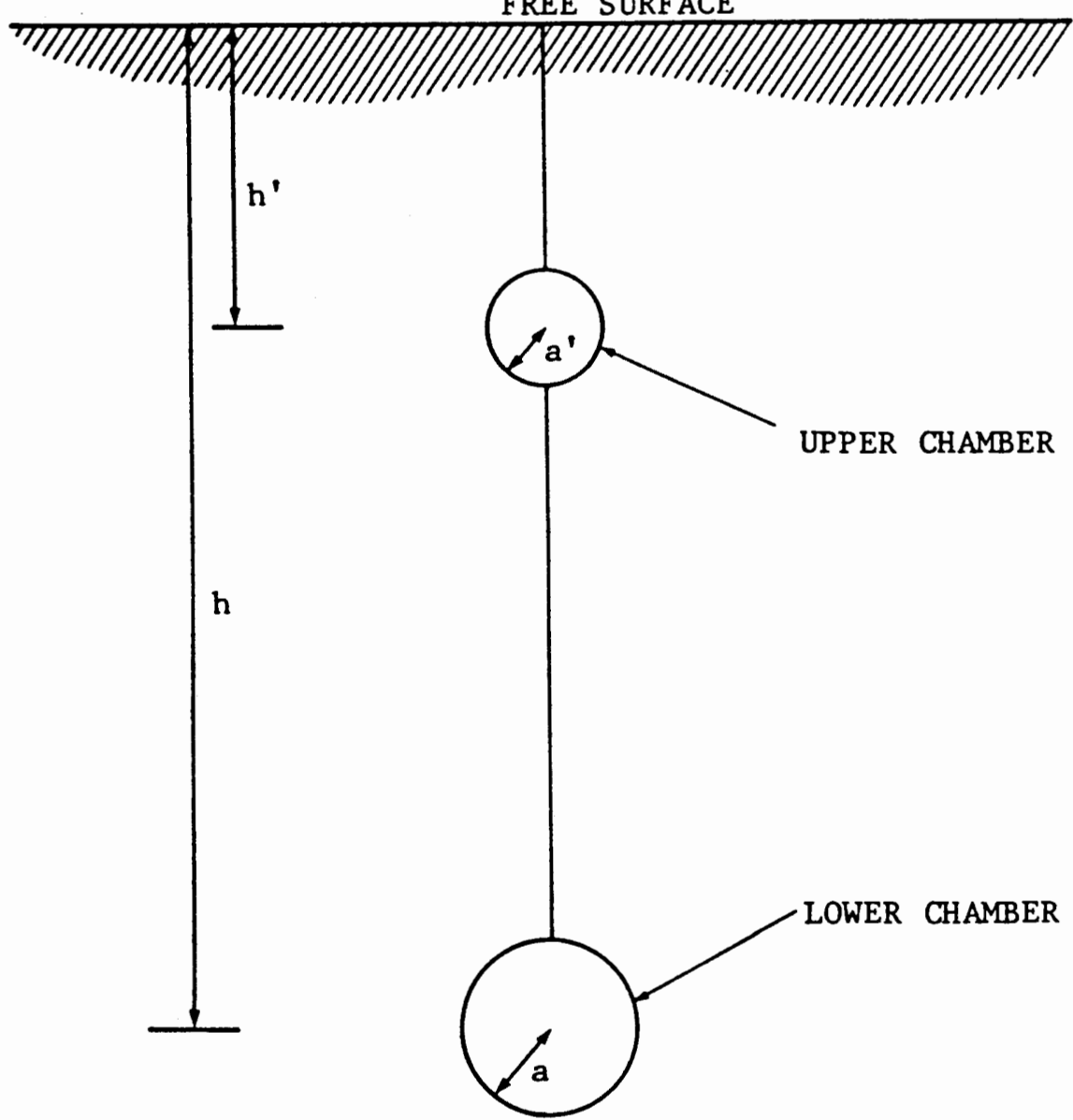

Figure 39. Idealized diagram of a two chamber volcanic system.

deformation was localized to the crater area of Mount st. Helens (Swanson and others, 1981). The deformation measured on the exterior slopes of the mountain indicated that negligible deformation accompanied these same eruptions. This was contrary to the explosive eruptions of May, June, July and August 1980, where significant 
TABLE VII

AVERAGE CHEMICAL ANALYSIS IN WEIGHT PERCENT, OF ERUPTIVE PRODUCTS FROM MAJOR ERUPTIONS OF MOUNT ST. HELENS, WASHINGTON BETWEEN JUNE 1980 AND DECEMBER 1980.1

\begin{tabular}{lccccc}
\hline & JUNE & JULY & AUGUST & OCTOBER & DECEMBER \\
\hline $\mathrm{SiO}_{2}$ & 63.65 & 61.93 & 62.75 & 62.22 & 63.20 \\
$\mathrm{Al}_{2} \mathrm{O}_{3}$ & 17.60 & 18.13 & 17.70 & 17.84 & 18.00 \\
$\mathrm{Fe}_{2} \mathrm{O}_{3}$ & 4.35 & 5.27 & 5.09 & 5.23 & 5.10 \\
$\mathrm{MgO}$ & 1.99 & 1.99 & 2.31 & 2.42 & 2.28 \\
$\mathrm{CaO}$ & 5.07 & 5.67 & 5.37 & 5.61 & 5.46 \\
$\mathrm{Na}_{20}$ & 4.58 & 4.5 & 4.53 & 4.48 & 4.52 \\
$\mathrm{~K}_{20}$ & 1.28 & 1.19 & 1.25 & 1.19 & 1.27 \\
$\mathrm{TiO}_{2}$ & .63 & .67 & .67 & .69 & .68 \\
$\mathrm{P}_{20} \mathrm{~N}_{5}$ & .08 & .2 & .11 & .15 & .07 \\
$\mathrm{MnO}$ & .08 & .09 & .07 & .07 & .12 \\
\hline
\end{tabular}

1 Modified from: Lipman and others, 1981; Sarana-Wojcicki and others, 1981; Rowley and others, 1981

deformations of the exterior slopes were measured. Besides indicating a change in eruptive styles, the lack of deformation of the exterior slopes of the volcano would also tend to indicate that a change in the pressure and magmatic supply rates had occurred. It is conjectured here that changes in the deformation patterns and explosive activity indicate the formation of a more fully developed or "mature" magmatic conduit system. for the mountain. With developement of a "mature" conduit, the zone of major pressure and deformation change was displaced 
from the top of the major lower chamber (depth approximately $7 \mathrm{~km}$ ) to a much shallower depth (approximately $1-2 \mathrm{~km}$ ) where the confining pressure and magmatic pressure are in static equilibrium.

An additional argument for the formation of a small shallow chamber evolves from mathematical studies of the inner-crater deformation patterns. Modeling of the thrust faults and movement of the infamous "rampart" (Swanson and others, 1981) area of the crater has been undertaken by Roger Denlinger (1984, personal communication). Preliminary results indicate that a best fit model might be a homogenous plate with a piston exerting vertical pressure at the center, three sides of the plate held static and the fourth side remaining free. This equates the plate to the crater floor, with the confinement of the three sides resulting from loading by the crater walls. By modeling the deformation this way, a small piston applying a vertical stress to the plate would cause formation of in shear fractures adjacent to the point of maximum vertical stress on the static sides of the plate, the unconfined side deforming laterally without shearing. This equates to the thrust faults that first appeared in December 1980 in association with lateral movement away from the dome of the "rampart" (Swanson and others, 1981; Chadwick and others, 1983). The formation of radial cracks in the crater floor in september 1980 also fits this type of deformation model, indicating vertical and radial stress increases which resulted in tensional failure of the plate prior to vertical shearing which culminated in the thrust faulting.

By plotting hypocenter depth against time for eruptions during this study (Figures 40,41, 42 and 43), two primary levels of seismic 


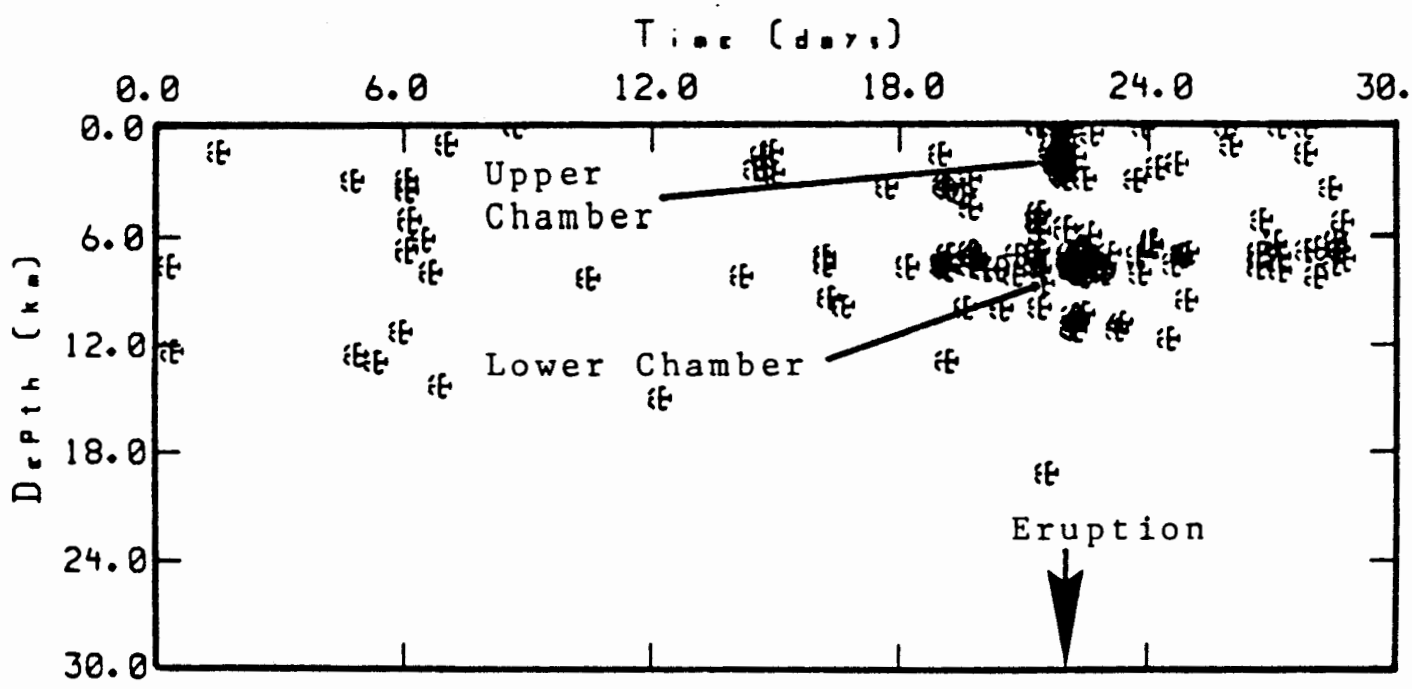

Figure 40. Time verses depth plot of relative hypocenter locations under the Mount St. Helens crater. Shown is the July eruption during the period of July 1,1980 through July 31 , 1980. Increasing symbol size indicates relative magnitude increase.

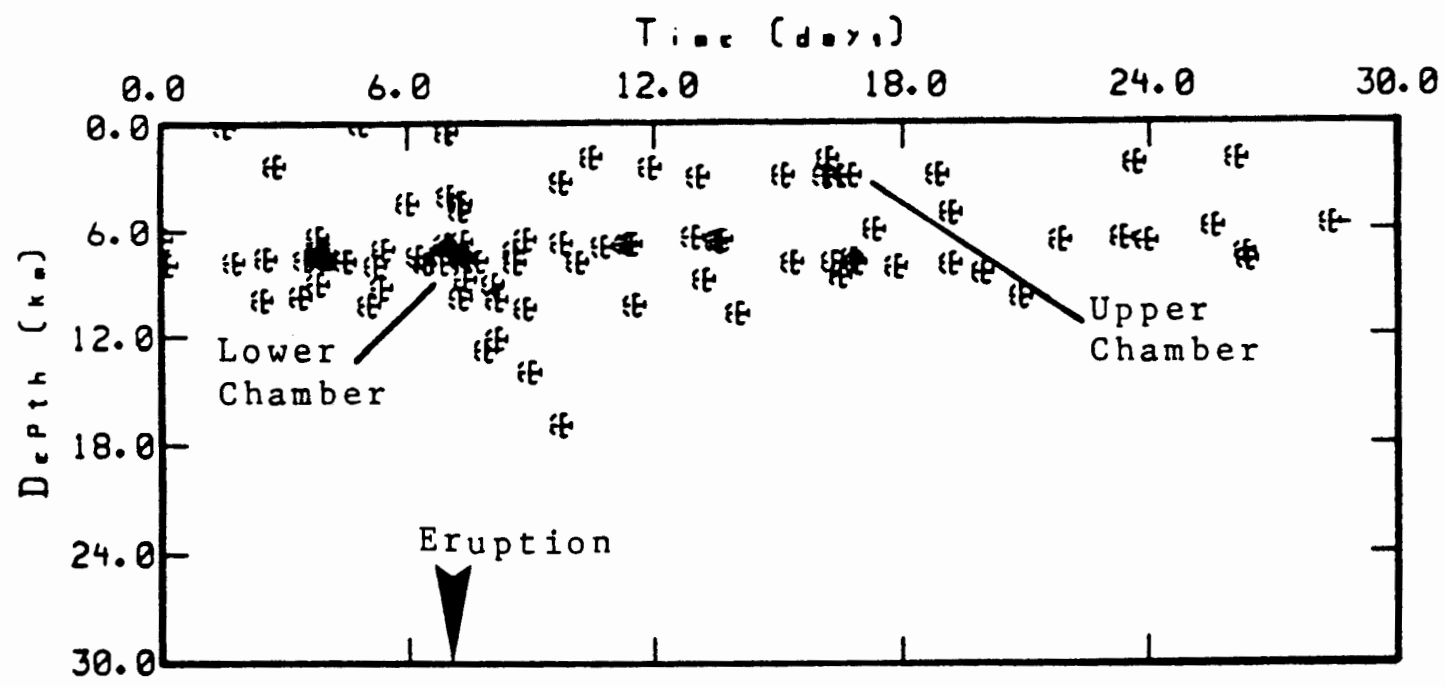

Figure 41. Time verses depth plot of relative hypocenter locations under the Mount St. Helens crater. Shown is the August eruption during the period of August 1, 1980 through August 31, 1980. Increasing symbol size indicates relative magnitude increase. 


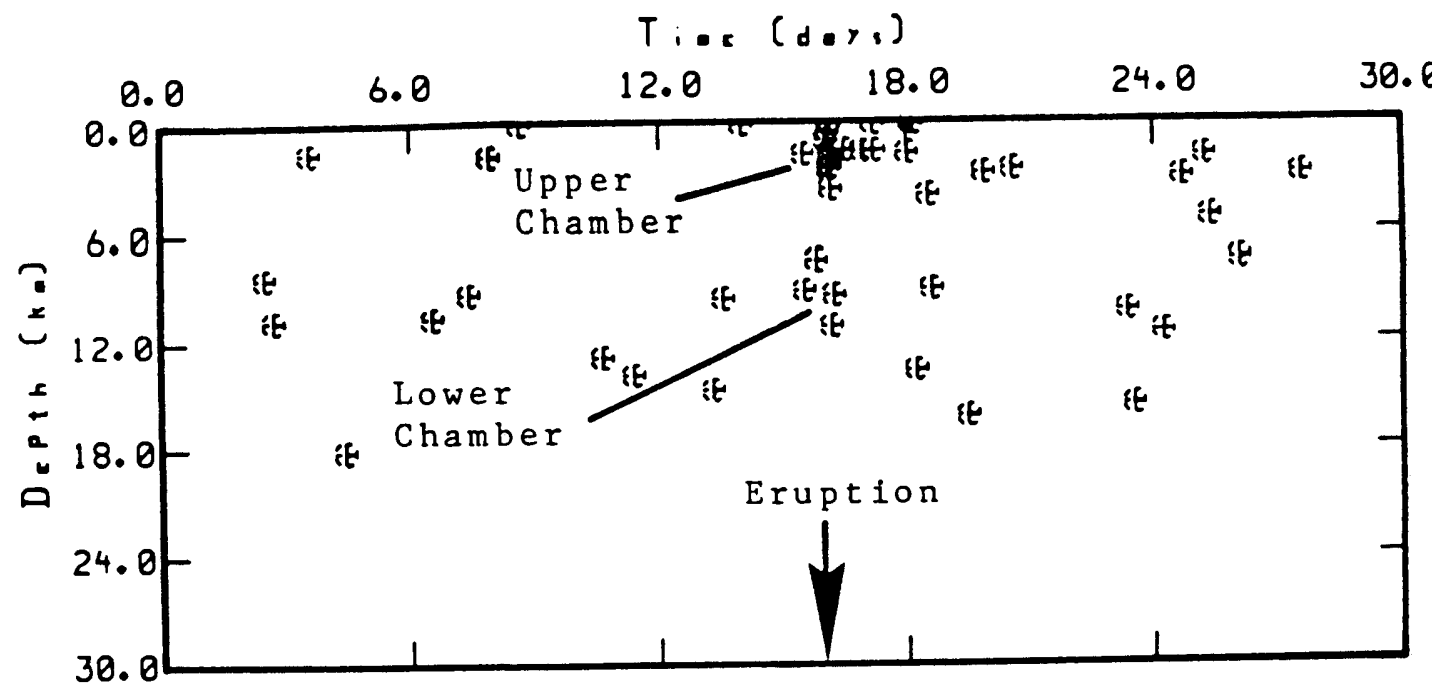

Figure 42. Time verses depth plot of relative hypocenter locations under the Mount St. Helens crater. Shown is the October eruption during the period of October 1,1980 through october 31,1980 . Increasing symbol size indicates relative magnitude increase.

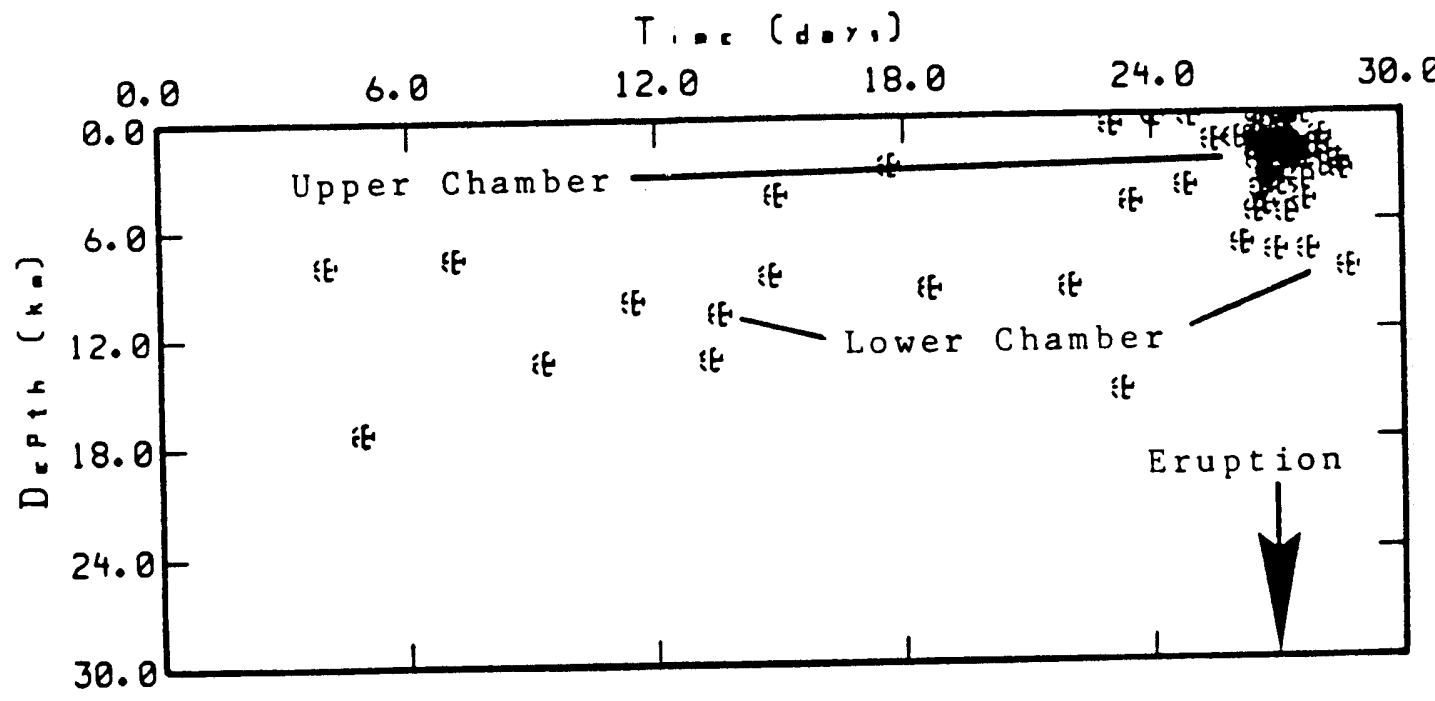

Figure 43. Time verses depth plot of relative hypocenter locations under the Mount St. Helens crater. Shown is the December eruption during the period of December 1, 1980 through December 31,1980 . Increasing symbol size indicates relative magnitude increase. 
disturbance are indicated below the mountain. The first zone is localized at about $1-2 \mathrm{~km}$ and the second starts at about 6-8 $\mathrm{km}$ and extends downward to about $15 \mathrm{~km}$. Directly preceding the major eruptions of 1980, definite increases in both shallow ( $2 \mathrm{~km} \pm 1 \mathrm{~km})$ and deep $(+7 \mathrm{~km})$ earthquakes occurred (Scandone and Malone, 1983). However, evidence of upward seismic migration can not be documented during these same events (Endo, 1983, personal communication).

As in the single chamber model, the two chamber model presented here consists of pressurized spheres in an elastic half space. Vertical deformation boundary conditions used for the two chamber system were the same values used for the single chamber model, with maximum and minimum vertical displacements of $70 \mathrm{~cm}$ and $20 \mathrm{~cm}$ respectively. Further development and explaination of this model can be found in Appendix B.

The two chamber deformation model shown in Figure 44 used an upper chamber depth of $2 \mathrm{~km}$ and a volume of $.24 \mathrm{~km}^{3}$; and a lower chamber depth of $9 \mathrm{~km}$ and a volume of $10.0 \mathrm{~km}^{3}$. These upper chamber volume figure represents the maximum magmatic output of all eruptions during 1980 (see Table II), while the depth represents the average depth of the near surface pre-eruptive seismic activity (see Figures $40,41,42,43)$. The lower chamber volume figure represents a possible chamber volume based on geochemical (Casadevall, 1983, personal communication) and seismic evidence (Scandone and Malone, 1983). Upper chamber depth was also controlled by the need to cause localized deformation in the inner-crater area without adding to relative deformation at distances greater than $2 \mathrm{~km}$. 


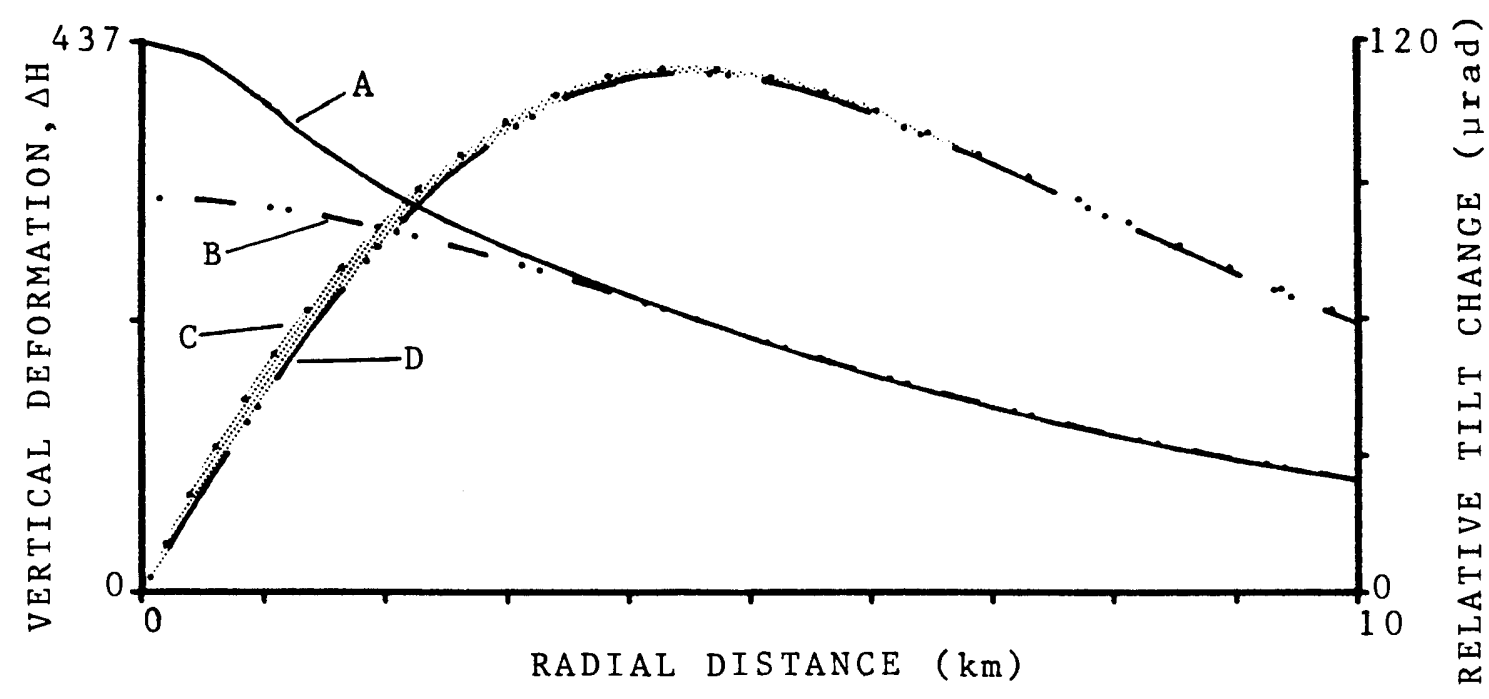

\section{Curve A parameters}

upper chamber volume $=.24 \mathrm{~km}^{3}$

upper chamber depth $=2.0 \mathrm{~km}$

lower chamber volume $=10.0 \mathrm{~km}^{3}$

lower chamber depth $=9.0 \mathrm{~km}$

$$
\begin{aligned}
& v=.75 \\
& H=437 \mathrm{~cm}
\end{aligned}
$$

Curve B parameters

$$
\begin{aligned}
\text { upper chamber volume } & =.24 \mathrm{~km}^{3} \\
\text { upper chamber depth } & =5.0 \mathrm{~km} \\
\text { lower chamber volume } & =10.0 \mathrm{~km}^{3} \\
\text { lower chamber depth } & =9.0 \mathrm{~km} \\
\mathrm{v} & =.75 \\
\mathrm{H} & =317 \mathrm{~cm}
\end{aligned}
$$

Figure 44. Idealized deformation patterns caused by a two chamber system. The solid line A, indicates the proposed maximum deformation boundary and the dashed line $B$, indicates a minimum deformation boundary. Line $C$ indicates calculated tilt for deformation indicated by line $A$, and line $D$ indicates calculated tilt for deformation indicated by line $B$. The shaded region is the area of possible relative tilt change values. For graphical clearity, the deformation difference between curve $A$ and curve $B$ is approximately $2.5 x$ the deformation measured by geodetic means. The shaded region is the area of possible relative tilt change values.

Results obtained from the model in Figure 44 indicated that the basic differences between the two chamber model and the single chamber model (Figure 38 ) are the large increase in relative deformation at horizontal distances up to $2 \mathrm{~km}$ from the deformation source and the slight decrease in relative deformation at horizontal distances greater 
than $5 \mathrm{~km}$. Both models indicated that modeled relative tilt changes at radial distances greater than $5 \mathrm{~km}$ were generally greater than measured tilt changes.

The plot of idealized deformation curves characterizing a two chamber system that could have existed for the October 1980 eruption is shown in Figure 45. In Figure 45, the deformation curve labeled "A" was derived by letting the upper chamber volume be equivalent to the volume of material output during the eruption (see Table II). The deformation curve labeled " $B$ ", was derived by removing all of the material in the upper chamber and leaving the uppper chamber empty. Results of the model indicate that the volume of magma ouput during the eruption would cause a relative tilt change of less than 2 urad at radial distances greater than $6 \mathrm{~km}$ from the vent. These changes in tilt primarily reflect the small volume loss of the lower chamber because lateral effects from the upper chamber are limited. This means that tiltmeter sites used for this study would have been incapable of recording volcanic events of this magnitude reliably because of background "noise" levels.

At distances up to $1.5 \mathrm{~km}$, the deformation vector for the lower chamber is near vertical and very large with resultant tilt being negligable, while resultant tilts caused by the upper chamber vary greatly within the same distance but deformation caused by the chamber is small. Had inner-crater tiltmeter sites (sites within $1.5 \mathrm{~km}$ of the vent) been present during the study, the model predicts that changes of at least $75 \mu \mathrm{rad}$ would have been recorded. 


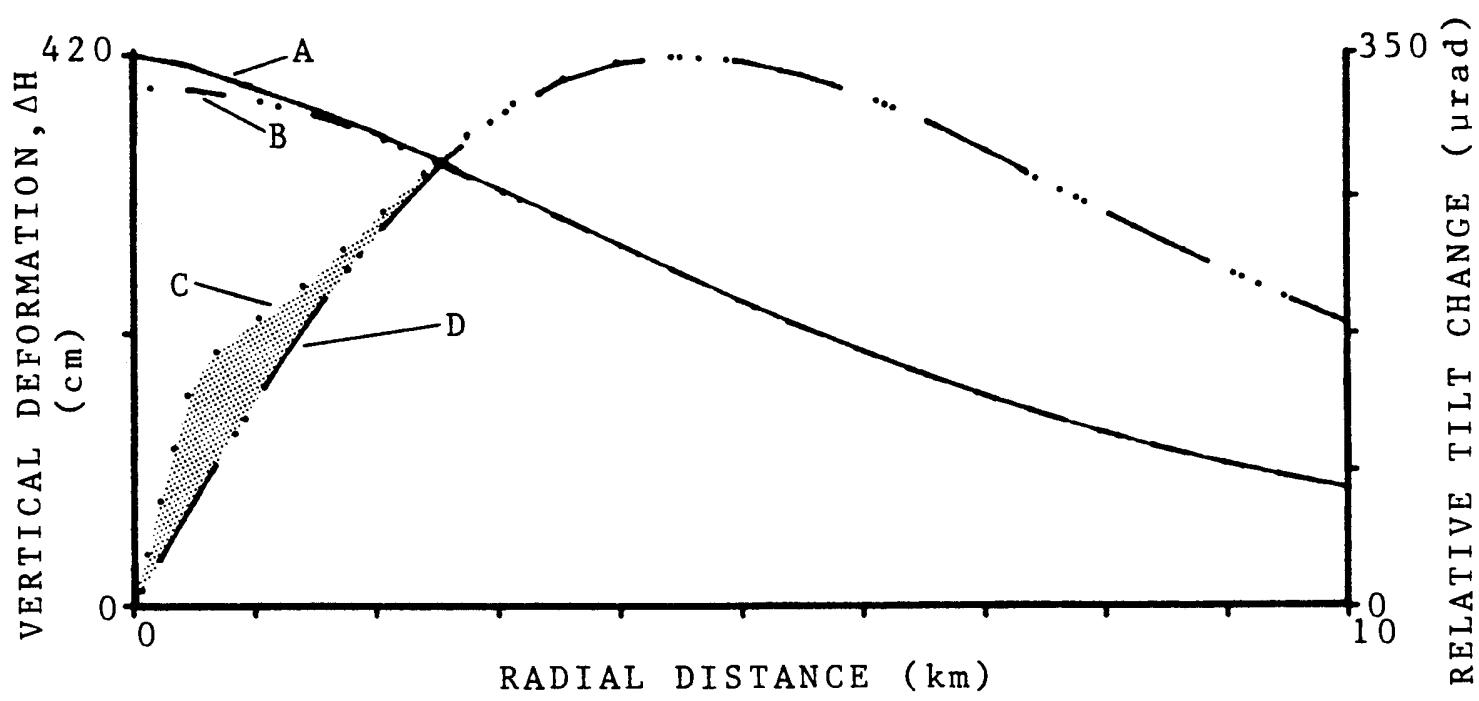

Curve A parameters

upper chamber volume $=.001 \mathrm{~km}^{3}$ upper chamber depth $=1.0 \mathrm{~km}$

lower chamber volume $=10.0 \mathrm{~km}^{3}$ lower chamber depth $=7.75 \mathrm{~km}$

$v=.75$

$\mathrm{H}=420 \mathrm{~cm}$
Curve B parameters

upper chamber volume $=.000 \mathrm{~km}^{3}$ upper chamber depth $=1.0 \mathrm{~km}$

lower chamber volume $=9.99 \mathrm{~km}^{3}$ lower chamber depth $=7.75 \mathrm{~km}$

$v=.75$

$\mathrm{H}=402 \mathrm{~cm}$

Figure 45. Idealized deformation diagram of a two chamber magmatic system that could have existed during the October, 1980 eruption. The solid line $A$, indicates the pre-eruptive deformation boundary and the dashed line $B$, indicates the post-eruption deformation boundary. Iine $C$ indicates calculated tilt for deformation indicated by line $A$, and line $D$ indicates calculated tilt for deformation indicated by line $B$. The shaded region is the area of possible relative tilt change values. Horizontal axis values are relative to vent termination in crater of Mount st. Helens. 
CHAPTER VIII

\section{DISCUSSION}

\section{A. DISCUSSION OF RESULTS}

The results attained from this study indicate that deformation patterns recognizable by the use of tiltmeters at distances greater than $5 \mathrm{~km}$ from the deformation source have had minimal value in real time monitoring of the volcanic system at Mount st. Helens since June 1980. Prior to this time, tilt offsets directly attributable to large explosive events were recorded and the tilt records used to confirm geodetic results.

The differences in the physical specifications of the tiltmeters seem to have major effect on the data, although the site stability problems encountered with the borehole tiltmeters in general indicates that the use of borehole tiltmeters in relatively unconsolidated mudflow deposits in this area substantially increases the systems susceptibility to long term non-volcanic changes. The thermal insulation provided by the caves, and the stability of the rock unit at the site makes the platform tiltmeter installations the most reliable in terms of consistent data output.

All of the tiltmeters in the study were affected by diurnal disturbances. Other major cyclic fluctuations of 8,12 and 72 hours where also recorded at all installations. The assumed cause of the 12 hour cycle is temperature fluctuation. 
The long term deformation records for all the borehole tiltmeter sites indicate the predominant signal at each of the sites was the result of downhill soil creep in the local area of the tiltmeter. These sites all recorded a distinct overall tilt vector orientation correlative to the major down slope direction adjacent to the installation.

Comparison of the tilt records by both visual and mathematical methods for the entire study period indicated that only minimal correlation existed between tiltmeter sites with respect to Mount st. Helens in terms of recording volcanic deformation. The best correlation of tilt records to environment was between resultant tilt vectors and soil creep at the tiltmeter sites. The comparison of resultant tilt vector directions (Table II) indicated that each of the borehole tiltmeters responded to unique primary deformation sources (i.e. site specific deformation) rather than deformation related to volcanic activity at Mount st. Helens. The platform tiltmeters appear to have responded to long term changes caused by volcanic activity at Mount st. Helens, but generally indicated no change in the short term to volcanic activity.

One feature of the tilt records not seen during the study period was the recording of instantaneous tilting caused by eruptive events, as recorded during the May 18 and May 25, 1980 eruptions (Figure 46, Dvorak and others, 1981). However during the October eruption, resultant tilt vectors from the Ape Cave and Ape Cave North tiltmeter sites may have shown the individual eruptive pulses, but other tiltmeter sites in operation recorded no change in tilt. Possible explanations 


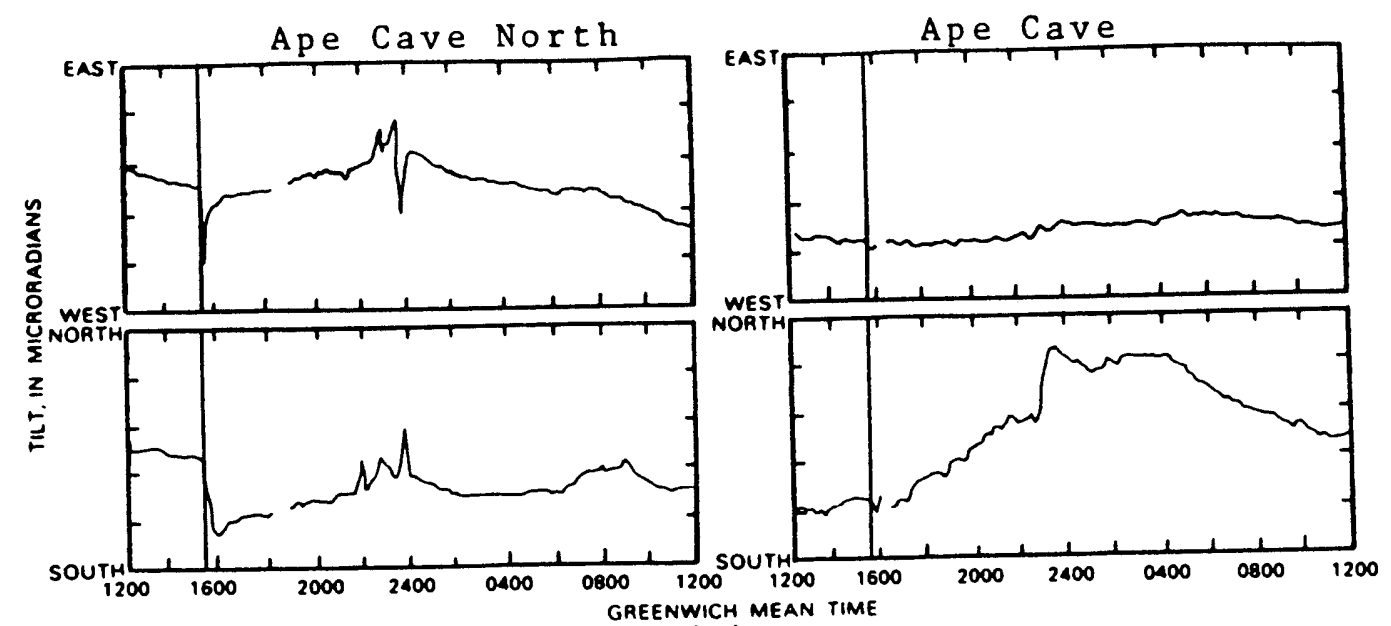

(A)
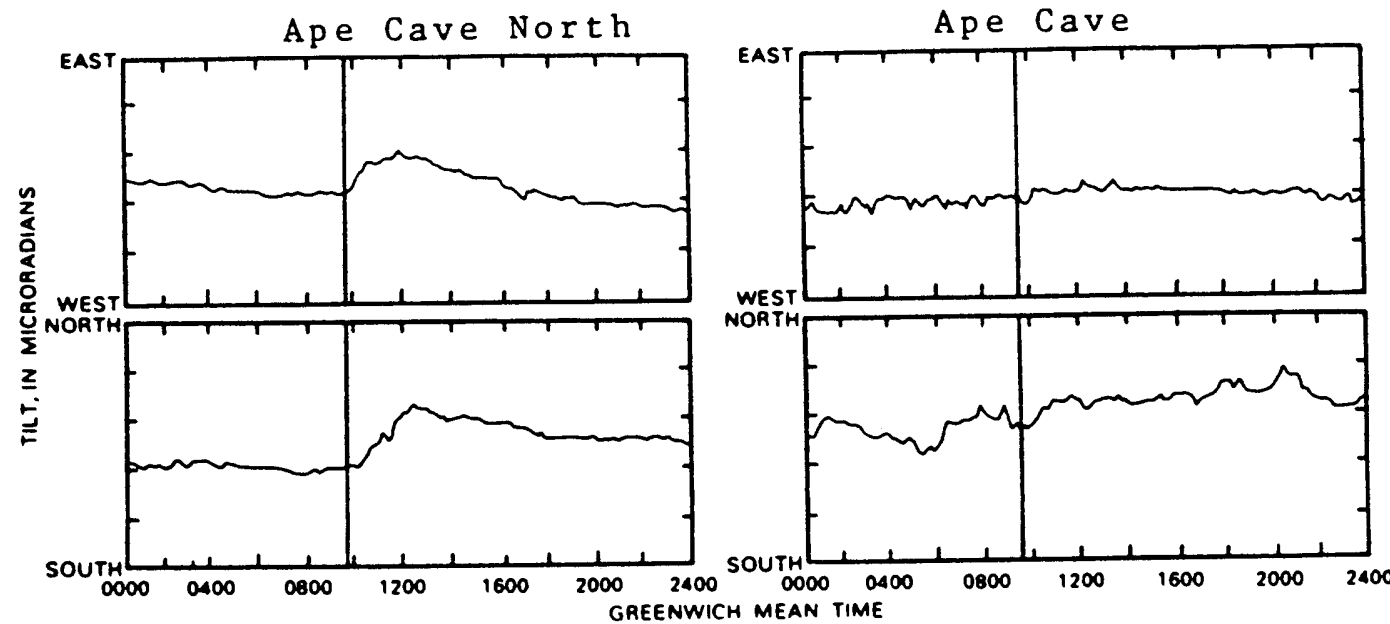

(B)

Figure 46. Plot of resultant tilt from Ape Cave and Ape Cave North tiltmeter stations for the May 18 and May 25, 1980 eruptions. Vertical lines indicate onset of major seismic activity as indicated by seismic data. Figure $46 a$ is data for the May 18 eruption; $46 \mathrm{~b}$ is data for the May 25 eruption (from Dvorak and others, 1981).

for the lack of eruption associated instantaneous surface deformation

are: (1) that major strain patterns developed prior to the May 18, 1980 eruption were released by the eruptions of May 18 and May 25 with subsequent eruptions encountering a lower resistance to magmatic rise; 
(2) that the structure of the magmatic conduit was poorly defined prior to June 12, 1980, requiring greater pressure generation within the main chamber to effect magma ascent, creating larger differences in deformation between pre-eruption pressure increase to post-eruption pressure decrease; or (3) that after the May 25 eruption, lateral effects of the instantaneous tilting are limited because the depth of the primary deformation source was now about $1 \mathrm{~km}$, where a second small chamber is postulated to exist (Dzurisin, Westphal and Johnson, 1983). Results of modeling indicated a lack of correlation between the tiltmeters and what could be expected from an idealized volcanic system of the types chosen for the models. When both the tilt and geodetic survey records were used together, the two chamber model for the system seemed to fit best for late 1980 eruptions, while the single chamber model worked best for early 1980 eruptions.

\section{B. PROBLEMS AND SOURCES OF ERROR}

Problems and errors present in this study are divided ińto two main groups; 1) those involved with initial data collection and data entry, and 2) those involved with the analysis of the data. In the data collection portion of this study problems associated with instrument instabilities, telecommunication, record transcription and manual data entry into the computer hindered data analysis. In the data analysis portion of the study errors in mathematical reduction, model generation, and interpretation influenced the conclusions made about the data.

Missing data and the improper transcription of data into the 
computer were common problems. Large sections of missing or unuseable data resulted from poor site location or major telemetry problems. With large sections of missing data, the relationships between segments of data becomes uncertain making comparative evaluation of data sets difficult.

Models used in this study were based on static conditions relevant for a given time period. The relevance of each model depends on the approximation of conditions at Mount st. Helens for a given time period. Because of this, prediction of error in the comparison of real data and theoretical models is, at best, considered to be within an order of magnitude.

\section{SYSTEM IMPROVEMENTS}

Since this study was based on data collected during a specific time frame, additions to or modifications of the system that have been made since that time have not be included. Post study additions included the installation of several new experimental type platform tiltmeters made by Jim Westfall, arranged in a north-south array within the crater area, .1 $\mathrm{km}$ to $2 \mathrm{~km}$ from the dome. A new DEC PDP 1l/03 micro-computer was added to the system for real time data collection, eliminating keypunch data entry with it's associated data entry errors, and increasing data analysis speed.

Reliability of the telemetry network remains a problem, correction of which would make the data collection portion of the system very strong. New telemetry equipment (Murray, 1983, personal communication) is being designed and built. The antenna system is being improved by 
the installation of higher quality equipment so that weather effects can be negated (Furukawa, 1982, personal communication).

The tiltmeter network should also be expanded now that the danger from large explosive type eruptions appears to have passed. Installation of additional tiltmeters around the base of the mountain within a $5 \mathrm{~km}$ radius could add appreciably to the understanding of the deformation patter $n$ around the base of the mountain and allow for a more complete analysis of the location of the deformation center or centers beneath the mountain. Creation of a dry tilt network (Yamashita, 1981) around the base of the mountain, reoccupied at regular intervals, might be another more cost effective way of monitoring major changes in the deep chamber in case of another May 18 type of eruption. 


\section{CHAPTER IX}

\section{Summary and Concluding Remarks}

In retrospect the results obtained from this study evaluated the applicability of far field tiltmeters monitoring to both explosive and non-explosive volcanic activity at Mount St. Helens. Records from the tiltmeters at a distance greater than $5 \mathrm{~km}$ from the deformation source indicated at best only minor tilt fluctuations presumably due to volcanic deformation. Based on the magnitudes of eruptions during the study, the ability to predict eruptions by rapid changes in tilt, is not possible with the tiltmeters used in this study. Iong term analysis of the tiltmeter data indicates that variations in tilt trend can be recognized for the platform tiltmeters.

Based on the final results of this study, the relative amounts of tilt recorded by each tiltmeter correlated reasonably well to the minimum theoretical values based on models generated using Mogi's deformation hypothesis. The variances in geographic settings (i.e. site condition) was most prominent in the overall effectiveness of the individual tiltmeter. The tiltmeters that were located in relatively unconsolidated debris generally recorded large amounts of non-volcanic deformation. This non-volcanic deformation was most likely due to instrument settling problems, vegetation growth near the sites and soil creep in the area of the site. Because of the problems associated with instruments in unconsolidated terrain, further installation of borehole 
tiltmeters should be confined to the more consolidated formations surrounding Mount St. Helens.

The existence of two distinct magma chambers in this system can not be thoroughly substantiated by far field tiltmeter data alone. Including information from deformation surveys (Swanson and others, 1981), seismic evaluation (Scandone and Malone, 1983; Weaver, Zollweg and Malone, 1983), modeling of inner-crater deformation patterns (Denlinger, 1984, personal communication), and inner-crater tiltmeter networks (Dzurisin, Westphal and Johnson, 1983) with the far field tiltmeter data, enough deformational evidence exists to argue effectively for the two chamber system.

Evidence from geochemical studies also indicates that a large volume of magma $\left(+0.3 \mathrm{~km}^{3}\right)$ was required to achieve the output levels of gas $\left(\mathrm{SO}^{2}\right.$ and $\mathrm{CO}_{2}$ ) through 1980 (Casedevall and others, 1981; Harris and others, 1981; Casedevall and others, 1983). Evaluation of mineral characteristics of eruptive products of the 1980 eruptions also indicate that a single source of magma supply has existed for all of the eruptions, becoming more differentiated with time (Cashman and Taggert, 1983; Melson, 1983).

A hypothesis presented by Lipman and others (1981) suggested that a small chamber was emplaced at a shallow depth during the May 18, 1980 eruption. Another possibility is that a small chamber developed with time at a shallow depth in conjunction with a large lower chamber, af ter the May 18, 1980 eruption. This shallow chamber not being emplaced as the result of a single eruption but rather forming as a feature of a continually changing magmatic system. 
It is conjectured here that the magmatic system of Mount st. Helens matured through the summer of 1980 , establishing the current magmatic system by December, 1980. A possible scenario for the early magmatic system is as follows: Early 1980 eruptions emanated from a single large $(+1.5 \mathrm{~km}$ diameter) chamber located at a depth of between 6 to $8 \mathrm{~km}$ (Figure 47). Stress fields surrounding the system, created

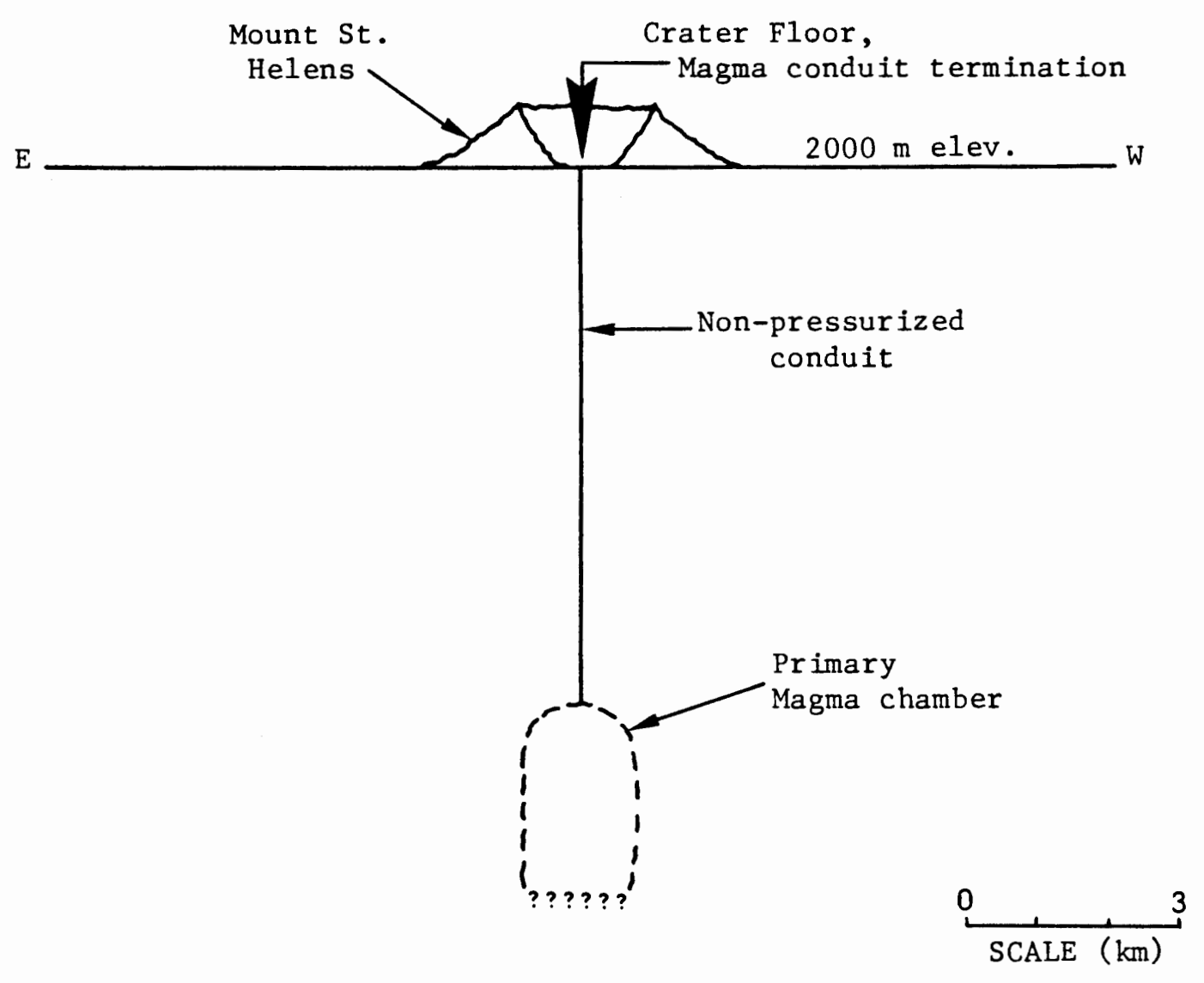

Figure 47. Proposed chamber shape and depth model for early 1980 eruptions of Mount St. Helens. 
during the initial eruptive activity of April, 1980 with the emplacement of a new chamber or the rejuvenation of magma into a existing chamber were largely aleviated by the eruption of May 18, 1980. Subsequent explosive eruptions of May, June, July and August further decreased the stresses present at the chamber country rock interface (6 to $8 \mathrm{~km}$ ). With a decreased stress field surrounding the chamber, upward magmatic movement was more easily initiated. Throughout the early explosive eruptions the magmatic conduit probably remained relatively unpressurized and was subject to post-eruption collapse. After the August 1980 eruption occurred and the majority of the remaining main volital rich magma was drawn out of the chamber, the conduit became more defined and a new chamber began to develop at about $1 \mathrm{~km}$. This $1 \mathrm{~km}$ depth, is the level at which forces controlling the ascent of the magma (hydrostatic pressure) are held momentarily static by forces in opposition to this movement. The ascending magma accumulates at this level until sufficient hydrostatic pressure is acquired to overcome the confining pressure and force the magma to the surface in a piston like form.

After the July 22 eruption, post explosion dome growth became more common. By December of 1980, large explosive eruptions were no longer occurring, a trend that has continued through March, 1984. The lack of large explosive eruptions since December 1980 is thought to have been caused by relative stabilization of the main magmatic chamber by removal of a majority of the volital-rich magma (Cashman and Taggert, 1983). The magmatic system at Mount St. Helens formed by September 1980 and present through March 1984 might be constructed is as follows: The lower main chamber with a radius of approximately $.75 \mathrm{~km}$ at a depth 
of 6-8 km (Scandone and Malone, 1983). This chamber was of sufficient volume to supply all the eruptions to date (March 1984) without suffering mineral depletion (Cashman and Taggert, 1983; Melson, 1983) or volume loss collapse. The second chamber in the system would be located at a shallow depth (approximately $1 \mathrm{~km}$; Weaver, Zollweg and Malone, 1983) vertically above the main chamber. Its existence resulted from a change in the stress fields allowing the formation of a relatively small (less than $.007 \mathrm{~km}^{3}$ ) "pulsating" chamber (Figure 48). This second chamber acted as a short term repository for the magma while awaiting a pressure increase to push it to the surface, the chamber size indicative of the amount of magmatic output and pressure for any given eruption. Basic shape of the second chamber is possibly vertically elongate, formed as a southward widening of the conduit (much like a blister). The main volume of the chamber belongs to the original magmatic conduit. The structure of the connecting magmatic conduit would then be a relatively small pressurized conduit between the lower main chamber and the second chamber that maintains an approximate cross sectional area of less than $75 \mathrm{~m}^{2}$. Connecting the second chamber to the surface is a relatively non-pressurized conduit that attains an approximate cross sectional area of up to $150 \mathrm{~m}^{2}$ during eruptions.

A system of this type would allow for the explanation of large inner-crater deformation and lack of exterior deformation. If this is the type of system that the tiltmeters were recording, then changes in the far field tiltmeters would be very small. The usefulness of the far field tiltmeters for monitoring the system as long as it remains in 


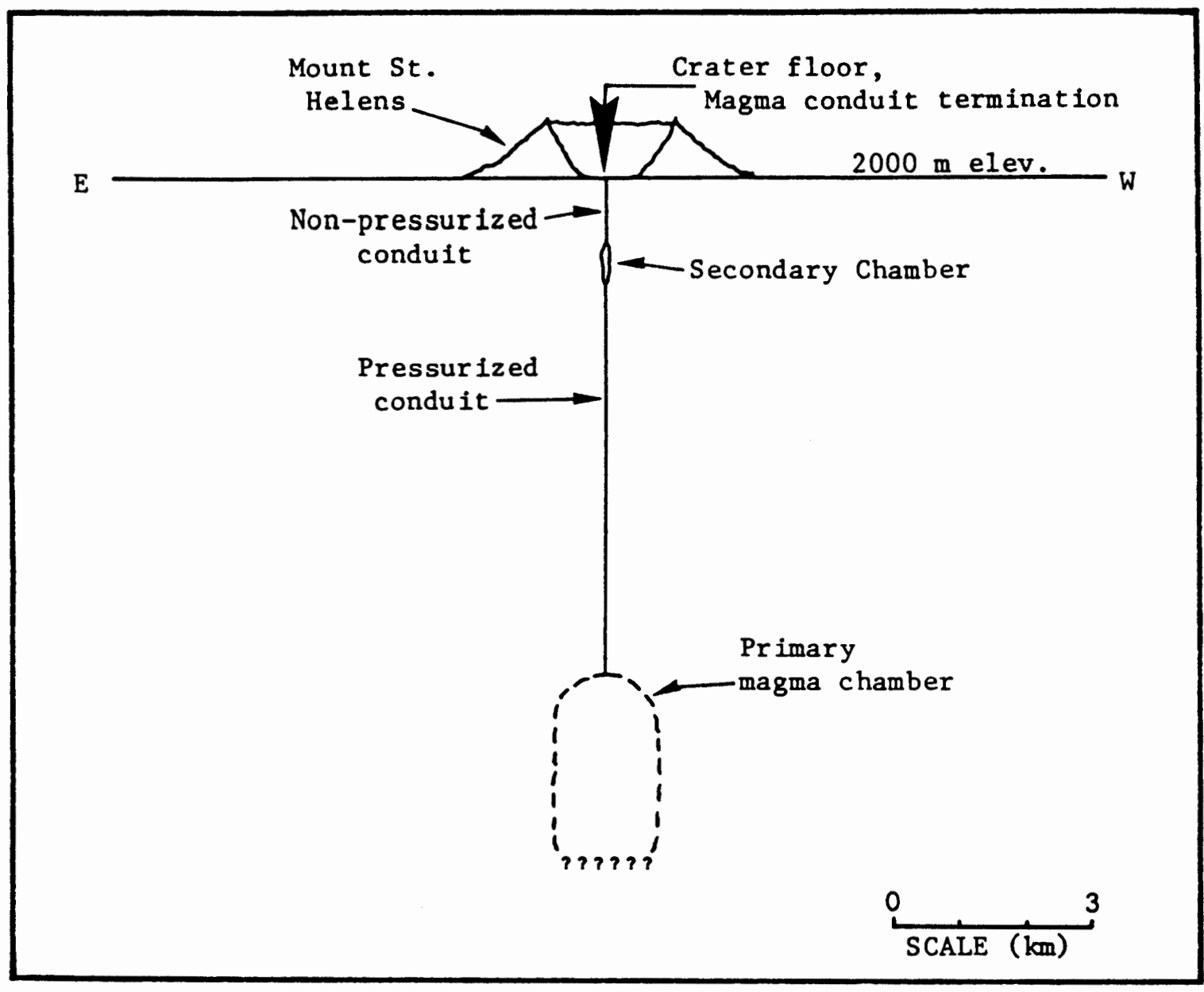

Figure 48. Proposed chamber shape and depth model for late 1980 eruptions of Mount st. Helens. Shown are predicted stress fields and other things relevant to this model.

a dome building state will be minimal. If however the state of the magmatic system should begin to change, with large increases in tilt at these stations, it could be expected that either the lower chamber top surface has changed dramatically (vertical movement or diameter increase) or that new magma has been added to the lower system (causing increased chamber volume). In either case the major change of the system could indicate the potential return of major explosive activity to the mountain. 


\section{BIBLIOGRAPHY}

Axelsson, Gudni, 1980, Tidal tilt observations in the Krafla geothermal area in North Iceland: Oregon State Univ. Masters Thesis., 86 p.. unpub.

Bath, M., 1973, Spectral analysis in geophysics: Elsevier Scientific Pub. Co.. Amsterdam, 563 p.

Berger, J., 1975, A note on thermoelastic strains and tilts: Jour. Geophy. Res., 80, (2), p. 274-277.

Bodvarsson, G., Axelsson, G., and Johnson, A., 1980, Exploration of volcanic geothermal energy resources based on rheological

techniques: Final Report for the U.S. Dept. of Energy, 156 p.

Braile, L. W., 1970, The isostatic conditions and crustal structure of Mount st. Helens as determined from gravity data: Univ. Wash. masters thesis, $37 \mathrm{p} .$, unpub.

Brigham, E. Oran, 1974, The fast fourier transform: Prentice-Hall Publishing Co., Englewood Cliffs, N.J., 252 p.

Casadevall, T. J., Rose, W., Gerlach, T., Greenland, L. P., Ewert, J., Wunderman, R., and Symonds, R., 1983, Gas emmissions and the eruptions of Mount St. Helens through 1982: Science, vol. 221, no. 4618 , p. 1383-1385.

Cashman, K. V. and Taggert, J. E., 1983, Petrologic monitoring of 1981 and 1982 eruptive products from Mount St. Helens: Science, vol. 221 , no. 4618, p. 1385-1387.

Chadwick, W. W., Swanson, D. A., Iwatsubo, E. Y., Helicker, C. C., and Leighley, T. A., 1983, Deformation monitoring at Mount St. Helens in 1981 and 1982: Science, vol. 221, no. 4618, p. 13781380 .

Christiansen, R. L. and Peterson, D. W., 1981, Chronology of the 1980 Eruptive Activity, in Lipman, P. W., and Mullineaux, D. R., eds., The 1980 eruptions of Mt. St. Helens, Washington: U.S. Geol. Surv. Prof. Paper 1250, p. 17-30.

Claerbout, J. F., 1976, Fundimentals of Geophysical Data Processing: McGraw-Hill Book Co... 274 p.

Crandell, D. R., 1971, Postglacial lahars from Mount Rainier volcano, Washington: U.S. Geol. Surv. Prof. Paper 667, 75 p. 
Crandell, D. R., and Mullineaux, D. R., 1973, Pine Creek volcanic assemblege at Mount St. Helens, Washington; U.S. Geol. Surv. Bull. 1382-A, $23 \mathrm{p}$.

1978, Potential hazards fom future eruptions of Mount St. Helens volcano, Washington: U.S. Geol. Surv. Bull. 1383-C, 26 p.

Crandell, D. R., Mullineaux, D. R., Miller, R. D., and Rubin, M., 1962, Pyroclastic deposits of recent age at Mount Rainier, Washington: U.S. Geol. Surv. Prof. Paper, 45 D, D64-D68.

Danes, Z. F., 1969, Gravity exploration of the Cascade Mountains, Washington [abs.]: Trans. Amer. Geophys. Union, 50, p. 61.

Davis, J. C., 1973, Statistics and data analysis in geology; John wiley and Sons, Inc.. New York, 550 p.

Dvorak, J., Okamura, A. T., Mortensen, Carl, and Johnston, M. J. S., 1981, Summary of electronic tilt studies at Mount St. Helens, in Lipman, P. W., and Mullineaux, D. R., eds., The 1980 eruptions of Mt. St. Helens, Washington: U.S. Geol. Surv. Prof. Paper 1250, p. 169-174.

Dzurisin, D. , Westphal, J. A., and Johnson, D. J., 1983, Eruption prediction aided by electronic tiltmeter data at Mount st. Helens: Science, vol. 221, no. 4618, p. 1381-1382.

Fiske, R. S., 1963, Subaqueous pyroclactic flows in the Ohanapechosh Formation, Washington: Geol. Soc. of America Bull., vol. 74, p. 391-406.

Fiske, R. S., and Kinoshita, W. T., 1969, Inflation of Kilauea volcano prior to its 1967-1968 eruption: Science, vol. 165, p. 341-349.

Foxworthy, B. L., and Hill, M., eds., 1982, Volcanic eruptions of 1980 at Mount St. Helens, the first 100 days: U.S. Geol. Surv. Prof. Paper $1249,124 \mathrm{p}$.

Greeley, R., and Hyde, J. H., 1972, Lava tubes of the Cave basalt, Mount St. Helens, Washington: Geol. Soc. Amer. Bull., vol. 83, p. 23972418.

Hammond, P. E., 1979, A tectonic model for evolution of the Cascade range, in Cenozoic paleogeography of the western United States; Pacific Section: Soc. Economic Paleontologists and Mineralogists, p. 219-238.

Harris, D. M., Sato, Motoaki, Ca sadevall, T. J., Rose, W. I., and Bornhorst, T. J., 1981, Emission rates of $\mathrm{CO}_{2}$. from plume Measurements, in Lipman, P. W., and Mullineaux, D. R., eds., The 1980 eruptions of Mt. St. Helens, Washington: U.S. Geol. Surv. Prof. Paper 1250, p. 201-219. 
Hopson, C. A., 1971, Eruptive sequence at Mount St. Helens, Washington: Geol. Soc. of Amer. Abs. with Programs, vol. 3, no. 2, p. 138. 1981. Preliminary geologic map of Mount St. Helens., unpub.

Hopson, C. A., and Melson, W. G., 1980, Mount St. Helens eruptive cycles since 100 A.D. [abs.]: EOS, Trans. of the American Geophysical Union, vol. 61, no. 46, p. 1132-1133.

Hyde, J. H., 1970, Geologic setting of Merrill Lake and evaluation of volcanic hazards in the Kalama river valley near Mount $S t$. Helens, Washington: U.S. Geol. Surv., Open File Rept. 70-169, $17 \mathrm{p}$.

1975, Upper Pliestocene pyroclastic-flow deposits and lahars south of Mount St. Helens volcano, Washington: U.S. Geol. Surv. Bull. 1383-B, $20 \mathrm{p}$.

IMSL, 1982, The IMSL library: IMSL, Inc., Houston, Texas.

Kinemetrics, 1975, Operating instructions for model TM-lB biaxial tiltmeter: Kinemetrics, Pasadena, Cal., 8 p.

Kinoshita, W. T., Koyanagi, R. Y. , Wright, T. L., and Fiske, R. S., 1969, Kilauea volcano: The 1967-1968 summit eruption: Science, vol. 166, p. 459-468.

Kinoshita, W. T., Swanson, D. A., and Jackson, D. B., 1974, The measurement of crustal deformation related to volcanic activity at Kilauea volcano, Hawaii, in Civetta, L., Gasparini, P., Loungo, G., Rappola, A., eds., Physical volcanology: developments in solid earth geophysics, no. 6.: Elsevier Scientific Pub. Co., p. 87-115.

Lipman, P. W., and Mullineaux, D. R., eds., 1981, The 1980 eruption of Mount St. Helens, Washington, in Lipman, P. W., and Mullineaux, D. R., eds., The 1980 eruptions of Mt. St. Helens, Washington: U.S. Geol. Surv. Prof. Paper 1250, 844 p.

Lipman, P. W., Norton, D. R., Taggart, J. E., Brandt, E. L., and Engleman, E. E., 1981, Compositional variations in 1980 magmatic deposits, in Lipman, P. W., and Mullineaux, D. R., eds., The 1980 eruptions of Mt. St. Helens, Washington: U.S. Geol. Surv. Prof. Paper 1250 , p. 631-640.

Machado, F., 1974, The search for magmatic reservoirs, in Civetta, L., Gasparini, P., Luongo, G. , Rappola, A., eds., Physical volcanology: developments in solid earth geophysics no. 6 .: Elsevier Scientific Pub. Co., p. 255-273. 
Malone, S. D., Endo, E. T., Weaver, C. S., Ramey, J. W., 1981, Seismic monitoring for eruption prediction: in Lipman, P. W.., and Mullineaux, D. R., eds., The 1980 eruptions of Mt. St. Helens, Washington: U.S. Geol. Surv. Prof. Paper 1250, p. 803-814

Melson, W. G., 1983, Monitoring the 1980-1982 eruptions of Mount St. Helens; compositions and abundances of glass: Science, vol. 221 , no. 4618, p. 1387-1391.

Mogi, K., 1958, Relations between the eruptions of various volcanoes and the deformation of the ground surfaces around them: Bull. Earthq. Res. Inst. 36, p. 99-134.

Mortensen, C. E., Iwatsubo, E. Y., Johnston, M. J. S., Myren, G. D., Keller, V. G., and Murray, T. L., 1977, U.S.G.S. tiltmeter networks, operation and maintenance: U.S. Geol. Surv. Open File Rept. 77-655, $28 \mathrm{p}$.

Mortensen, C. E., 1978, The analysis of tiltmeter data; in Proceedings of conference 7 , stress and strain measurements related to earthquake prediction: U.S. Geol. Surv., Open File Rept. 79-370, p. 364-392.

Mullineaux, D. R., and Crandell, D. R., 1960, Late recent age of Mount St. Helens volcano; Washington: U.S. Geol. Surv. Prof. Paper, 400-B, p. 307-308.

1981, The eruptive history of Mount St. Helens, in Lipman, P. W., and Mullineaux, D. R., eds., The 1980 eruptions of Mt. St. Helens, Washington: U.S. Geol. Surv. Prof. Paper 1250, p. 3-15.

Nakamura, K., 1977, Volcanos as possible indicator of tectonic stress orientation - principle and proposal: Jour. of Volcanology and Geothermal Res., vol. 2, p. 1-16.

Riddihough, R., 1977, A model for recent plate interactions off Canada's west coast: Canadian Jour. of Earth Sciences, vol. 14, p. 384-396.

Rodgers, G. C., 1979, Earthquake fault plane solutions near Vancouver Island: Canadian Jour. of Earth Sciences, vol. 16, p. 523-531.

Rowley, P. D., Kuntz, M. A., Macleod, N.S., 1981, Pyroclastic-flow deposits: in Lipman, P. W., and Mullineaux, D. R., eds., The 1980 eruptions of Mt. St. Helens, Washington: U.S. Geol. Surv. Prof. Paper 1250 , p. 489-512.

Sarna-Wojcicki, A. M., Meyer, C. E., Woodward, M. J., and Lamothe, P. J., 1981, Composition of air-fall ash erupted on May 18, May 24, June 12, July 22, and August 7: in Lipman, P. W., and Mullineaux, D. R., eds., The 1980 eruptions of Mt. St. Helens, Washington: U.S. Geol. Surv. Prof. Paper 1250, p. 667-682. 
Scandone, R. and S. Malone, 1983, Magma supply, magma discharge, and readjustment of the feeding system of Mount St. Helens during 1980. (in review).

Swanson, D. A., Jackson, D. B., Koyanogi, R. Y., and Wright, T. L., 1976, The February 1969 East Rift eruption of Kilauea volcano, Hawail: U.S. Geol. Surv. Prof. Paper $891,30 \mathrm{p}$.

Swanson, D. A., Lipman, P. W., Moore, J. G., Heliker, C. C., Yamashita, K. M., 1981, Geodetic monitoring after the May 18 eruption, in Lipman, P. W., and Mullineaux, D. R., eds., The 1980 eruptions of Mt. St. Helens, Washington: U.S. Geol. Surv. Prof. Paper 1250, p. 157-168.

Tryggvason, Eysteinn, 1978, Subsidence events in the Krafla area, preliminary report based on tilt and distance measurements: Nordic Volcanological Inst., Univ. of Iceland $7814,65 \mathrm{p}$.

Verhoogen, Jean, 1937, Mount St. Helens, a recent Cascade volcano: California Univ. Dept. of Geol. Sciences Bull., vol. 24, no. 9, p. 263-302.

Weaver, C. J., Zollweg, J. E., and Malone, S. D., 1983, Deep earthquakes beneath Mount St. Helens: Evidence for magmatic gas transport ?: Science, vol. 221, no. 4618, p. 1391-1393.

Weaver, C. J., and Smith, S. W., 1983, Regional tectonic and earthquake hazard implications of a crustal fault zone in Southwestern Washington: Jour. Geophys. Research, vol. 88, no. B12, p. 1037110383.

Weaver, C. J., W. C. Grant, S. A. Malone, E. T. Endo, 1981, Post-May 18 Seismicity: Volcanic and tectonic implications, in Lipman, P. W.. and Mullineaux, D. R., eds., The 1980 eruptions of Mt. St. Helens, Washington: U.S. Geol. Surv. Prof. Paper 1250, p. 109-121.

Yamakawa, N., 1955, On the strain produced in a semi-infinite eleastic solid by an interior source of stress: J. Seismol. Soc. Jap., vol. 8, p. 84-98 (in Japanese).

Yamashita, K. M., 1981, Dry tilt: A ground deformation monitor as applied to the active volcanoes of Hawail: U.S. Geol. Surv. Open-File Report 81-523, $17 \mathrm{p}$.

Yokoyama, I., 1974, Crustal deformations assosiated with volcanic activities. in Green, R., (editor), Recent crustal movements and associated seismic and volcanic activity: Tectonophysics, 23 (4): p. 349-360. 
APPENDIX A

PLOTS OF RAW MONTHLY TILTS

This appendix contains monthly plots of raw data from each of the tiltmeters described in the main text (see Chapter 3, Figure 9). All of the plots where drawn in reference to GMT (Grenwich Mean Time) and Julian Date starting January 1, 1980. If further definition of the exact time in terms of day and month the reader is referred to the Julian Date conversion chart (Figure 49).

For purposes of $\mathrm{Y}$-axis consistency and clarity the components of tilt have been moved relative to this axis to permit them to be plotted on the same graph. For complete plots of the data during the time period of the study refer to Figures 10 through 15 in the main text body.

In all of the plots, the following standardized symbols have been used;

$$
\begin{aligned}
& E-W=\text { East, West component of tilt. } \\
& N-S=\text { North, South component of tilt. }
\end{aligned}
$$

The following is a listing of the figures contained in this appendix ; 


\section{JULIAN DATE CALENDAR}

FOR LEAP YEARS ONLY

\begin{tabular}{|c|c|c|c|c|c|c|c|c|c|c|c|c|c|}
\hline Day & Jan & Feb & Mar & Apr & May & June & July & Aug & Sep & Oct & Nor & Dec & Day \\
\hline 1 & 001 & 032 & 061 & 092 & 122 & 153 & 183 & 214 & 245 & 275 & 306 & 336 & 1 \\
\hline 2 & 002 & 033 & 062 & 093 & 123 & 154 & 184 & 215 & 246 & 276 & 307 & 337 & 2 \\
\hline 3 & 003 & 034 & 063 & 094 & 124 & 155 & 185 & 216 & 247 & 277 & 308 & 338 & 3 \\
\hline 4 & 004 & 035 & 064 & 095 & 125 & 156 & 186 & 217 & 248 & 278 & 309 & 339 & 4 \\
\hline 5 & 005 & 036 & 065 & 096 & 126 & 157 & 187 & 218 & 249 & 279 & 310 & 340 & 5 \\
\hline 6 & 006 & 037 & 066 & 097 & 127 & 158 & 188 & 219 & 250 & 280 & 311 & 341 & 6 \\
\hline 7 & $\infty 07$ & 038 & 067 & 098 & 128 & 159 & 189 & 220 & 251 & 281 & 312 & 342 & 7 \\
\hline 8 & $\infty 08$ & 039 & 068 & 099 & 129 & 160 & 190 & 221 & 252 & 282 & 313 & 343 & 8 \\
\hline 9 & $\infty 09$ & 040 & 069 & 100 & 130 & 161 & 191 & 222 & 253 & 283 & 314 & 344 & 9 \\
\hline 10 & 010 & 041 & 070 & 101 & 131 & 162 & 192 & 223 & 254 & 284 & 315 & 345 & 10 \\
\hline 11 & 011 & 042 & 071 & 102 & 132 & 163 & 193 & 224 & 255 & 285 & 316 & 346 & 11 \\
\hline 12 & 012 & 043 & 072 & 103 & 133 & 164 & 194 & 225 & 256 & 286 & 317 & 347 & 12 \\
\hline 13 & 013 & 044 & 073 & 104 & 134 & 165 & 195 & 226 & 257 & 287 & 318 & 348 & 13 \\
\hline 14 & 014 & 045 & 074 & 105 & 135 & 166 & 196 & 227 & 258 & 288 & 319 & 349 & 14 \\
\hline 15 & 015 & 046 & 075 & 106 & 136 & 167 & 197 & 228 & 259 & 289 & 320 & 350 & 15 \\
\hline 16 & 016 & 047 & 076 & 107 & 137 & 168 & 198 & 229 & 260 & 290 & 321 & 351 & 16 \\
\hline 17 & 017 & 048 & 077 & 108 & 138 & 169 & 199 & 230 & 261 & 291 & 322 & 352 & 17 \\
\hline 18 & 018 & 049 & 078 & 109 & 139 & 170 & 200 & 231 & 262 & 292 & 323 & 353 & 18 \\
\hline 19 & 019 & 050 & 079 & 110 & 140 & 171 & 201 & 232 & 263 & 293 & 324 & 354 & 19 \\
\hline 20 & 020 & 051 & 080 & 111 & 141 & 172 & 202 & 233 & 264 & 294 & 325 & 355 & 20 \\
\hline 21 & 021 & 052 & 081 & 112 & 142 & 173 & 203 & 234 & 265 & 295 & 326 & 356 & 21 \\
\hline 22 & 022 & 053 & 082 & 113 & 143 & 174 & 204 & 235 & 266 & 296 & 327 & 357 & 22 \\
\hline 23 & 023 & 054 & 083 & 114 & 144 & 175 & 205 & 236 & 267 & 297 & 328 & 358 & 23 \\
\hline 24 & 024 & 055 & 084 & 115 & 145 & 176 & 206 & 237 & 268 & 298 & 329 & 359 & 24 \\
\hline 25 & 025 & 056 & 085 & 116 & 146 & 177 & 207 & 238 & 269 & 299 & 330 & 360 & 25 \\
\hline 26 & 026 & 057 & 086 & 117 & 147 & 178 & 208 & 239 & 270 & 300 & 331 & 361 & 26 \\
\hline 27 & 027 & 058 & 087 & 118 & 148 & 179 & 209 & 240 & 271 & 301 & 332 & 362 & 27 \\
\hline 28 & 028 & 059 & 088 & 119 & 149 & 180 & 210 & 241 & 272 & 302 & 333 & 363 & 28 \\
\hline 29 & 029 & 060 & 089 & 120 & 150 & 181 & 211 & 242 & 273 & 303 & 334 & 364 & 29 \\
\hline 30 & 030 & & $\infty 00$ & 121 & 151 & 182 & 212 & 243 & 274 & 304 & 335 & 365 & 30 \\
\hline 31 & 031 & & 091 & & 152 & & 213 & 244 & & 305 & & 366 & 31 \\
\hline
\end{tabular}

(USE IN 1964, 1968, 1972, etc.)

Figure 49. Julian day conversion chart for Leap year use only. 


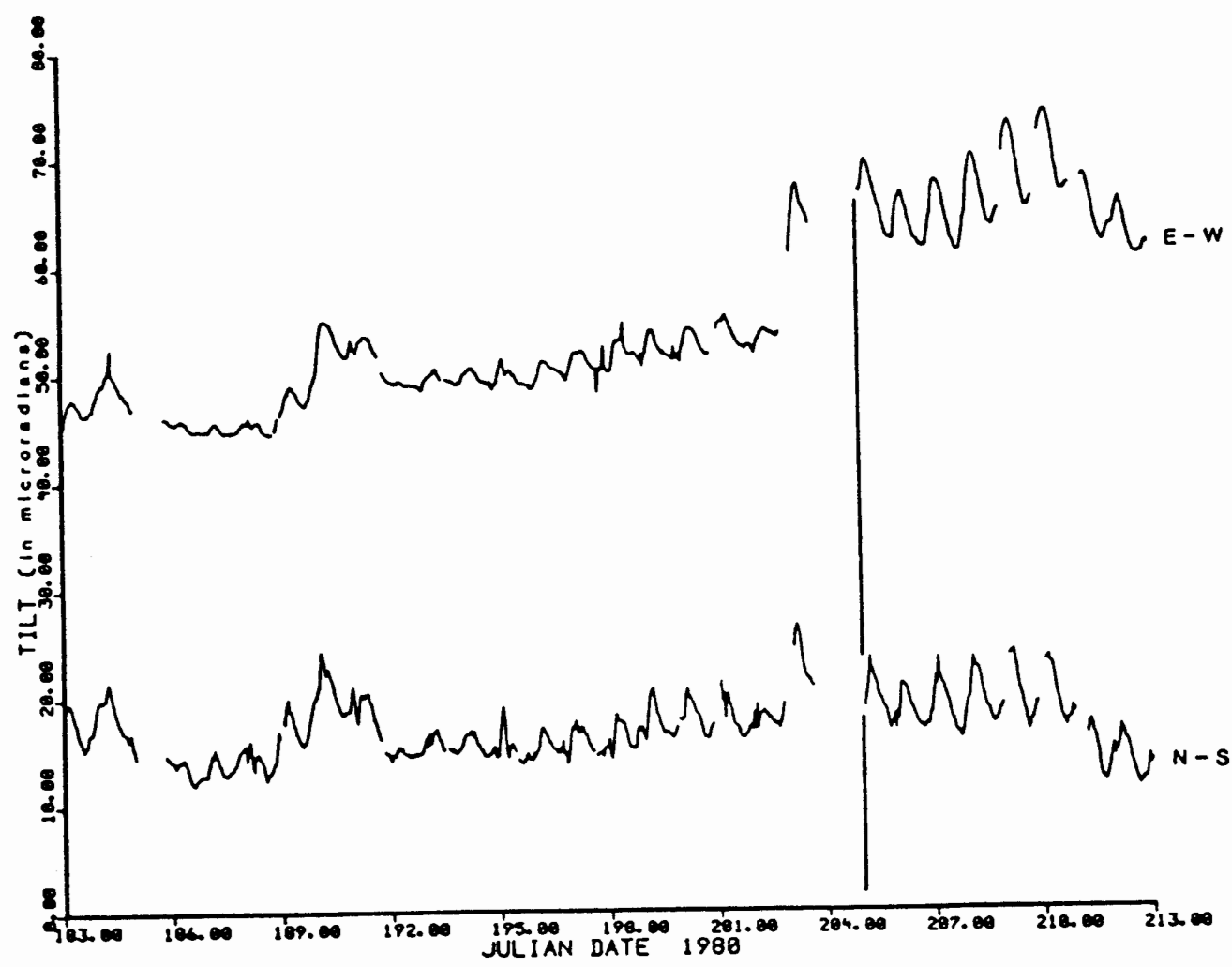

Figure 50. East-west and north-south components of tilt at Ape Cave tiltmeter site. A decrease in recorded values indicates East or North positive (inflation). Values are uncorrected hourly averages starting July 1,1980 and continuing through July 30, 1980. Times are all GMT equivalents. Vertical lines indicate eruption onsets as determined from seismic records. Gaps in the data indicate periods periods where no usable data was collected. 


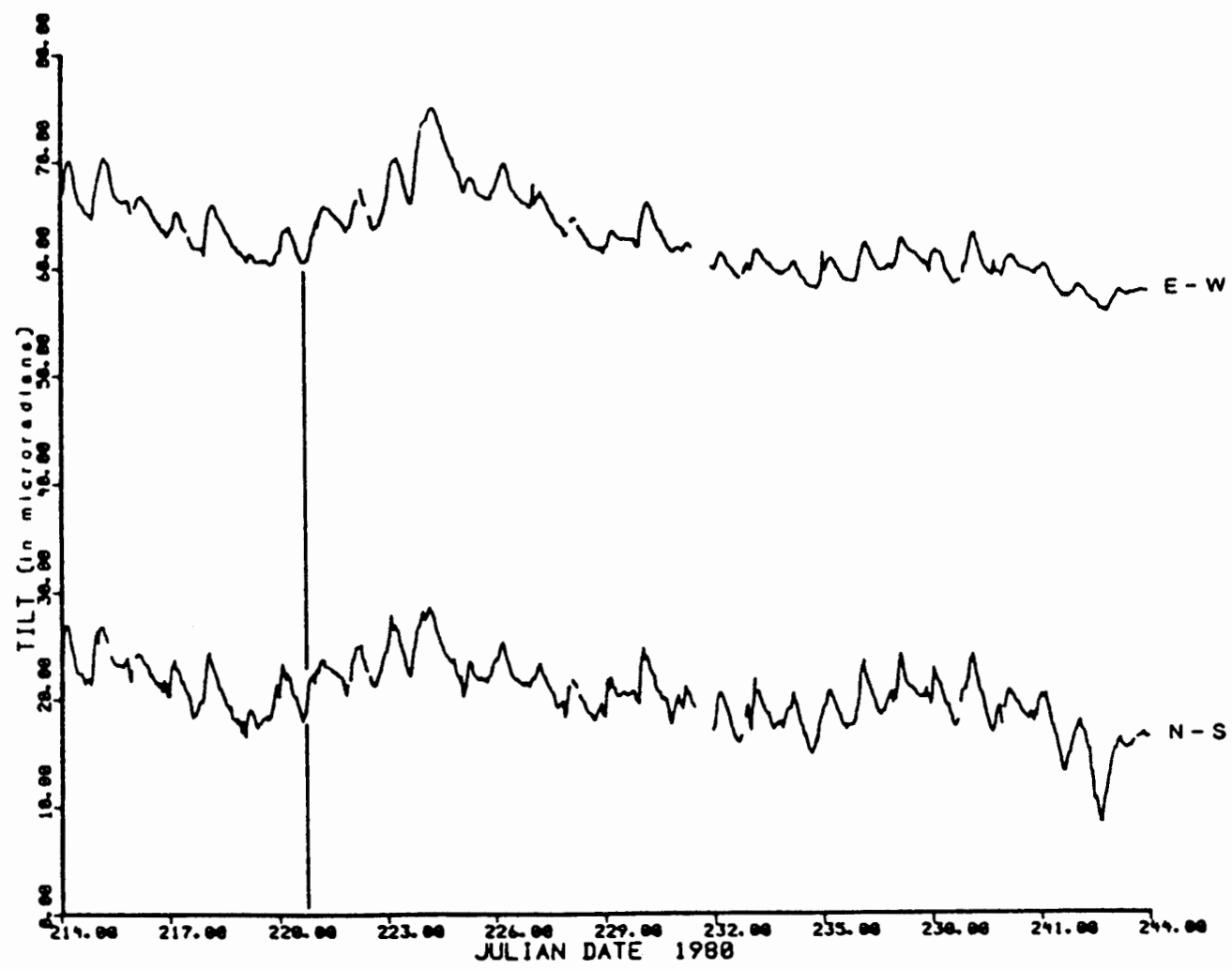

Figure 51. East-west and north-south components of tilt at Ape Cave tiltmeter site. A decrease in recorded values indicates East or North positive (inflation). Values are uncorrected hourly averages starting August 1,1980 and continuing through August 30,1980 . Times are all GMT equivalents. Vertical lines indicate eruption onsets as determined from seismic records. Gaps in the data indicate periods periods where no usable data was collected. 


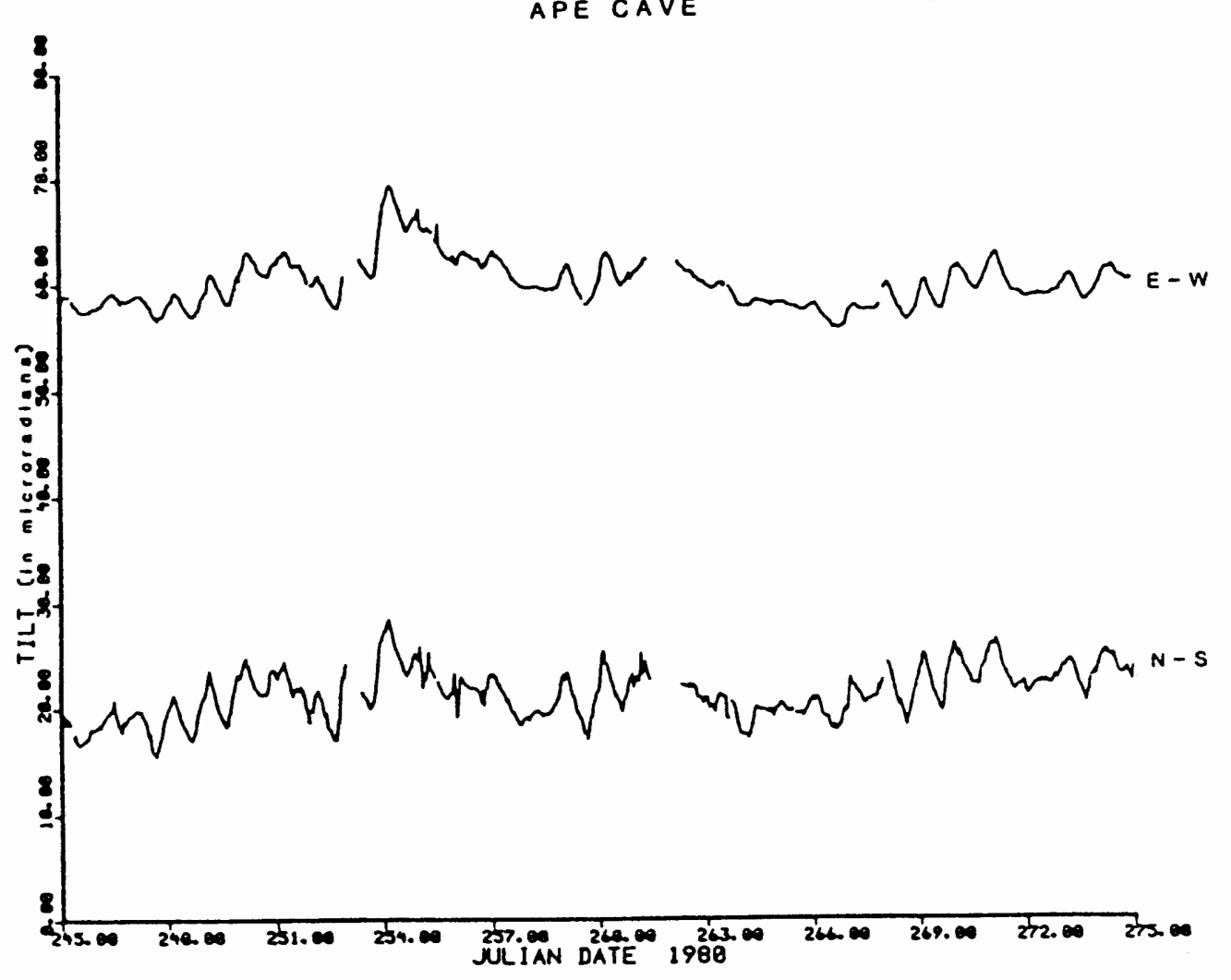

Figure 52. East-west and north-south components of tilt at Ape Cave tiltmeter site. A decrease in recorded values indicates East or North positive (inflation). Values are uncorrected hourly averages starting September 1,1980 and continuing through September 30,1980 . Times are all GMT equivalents. Gaps in the data indicate periods periods where no usable data was collected. 


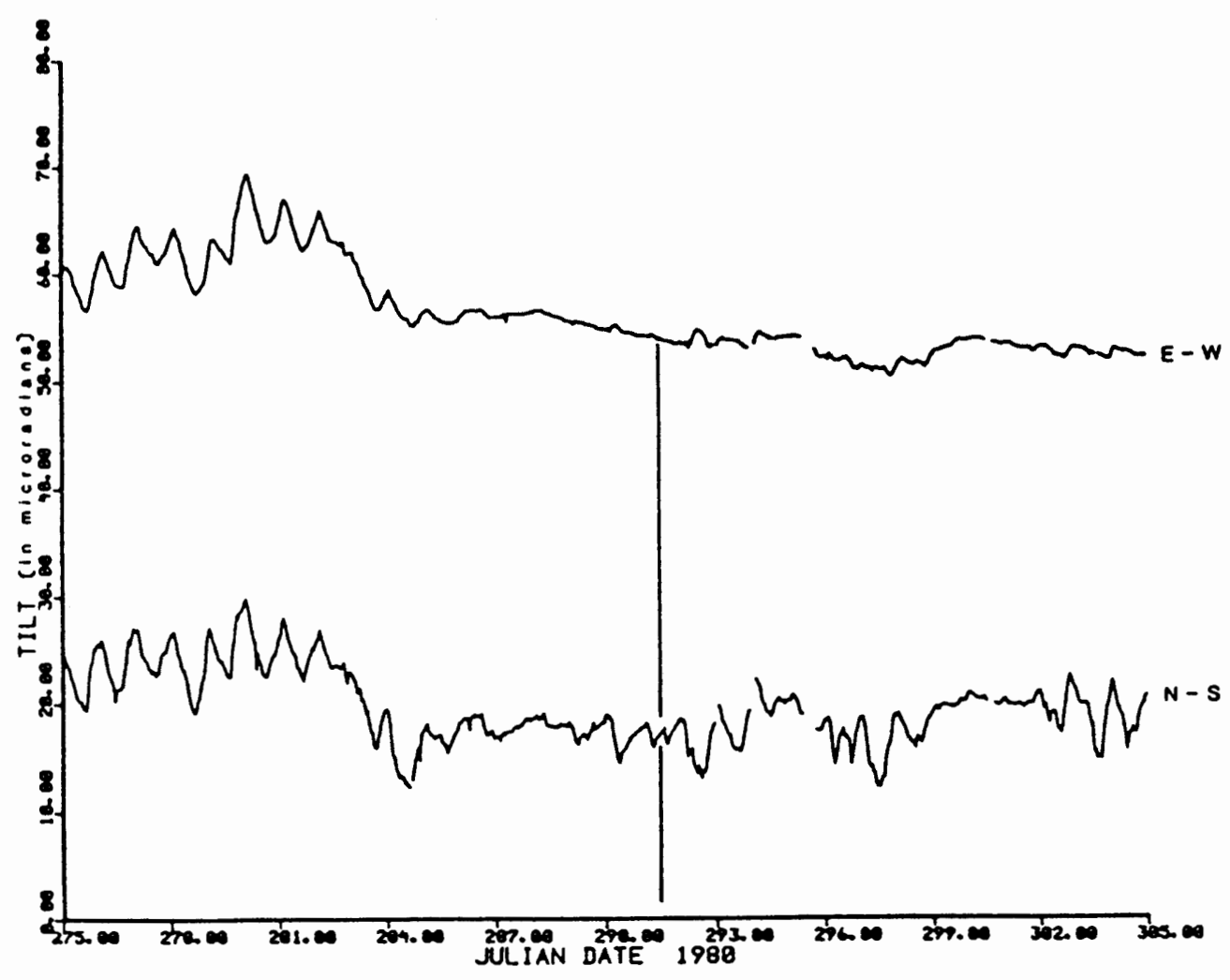

Figure 53. East-west and north-south components of tilt at Ape Cave tiltmeter site. A decrease in recorded values indicates East or North positive (inflation). Values are uncorrected hourly averages starting October 1,1980 and continuing through October 30, 1980. Times are all GMT equivalents. Vertical lines indicate eruption onsets as determined from seismic records. Gaps in the data indicate periods periods where no usable data was collected. 


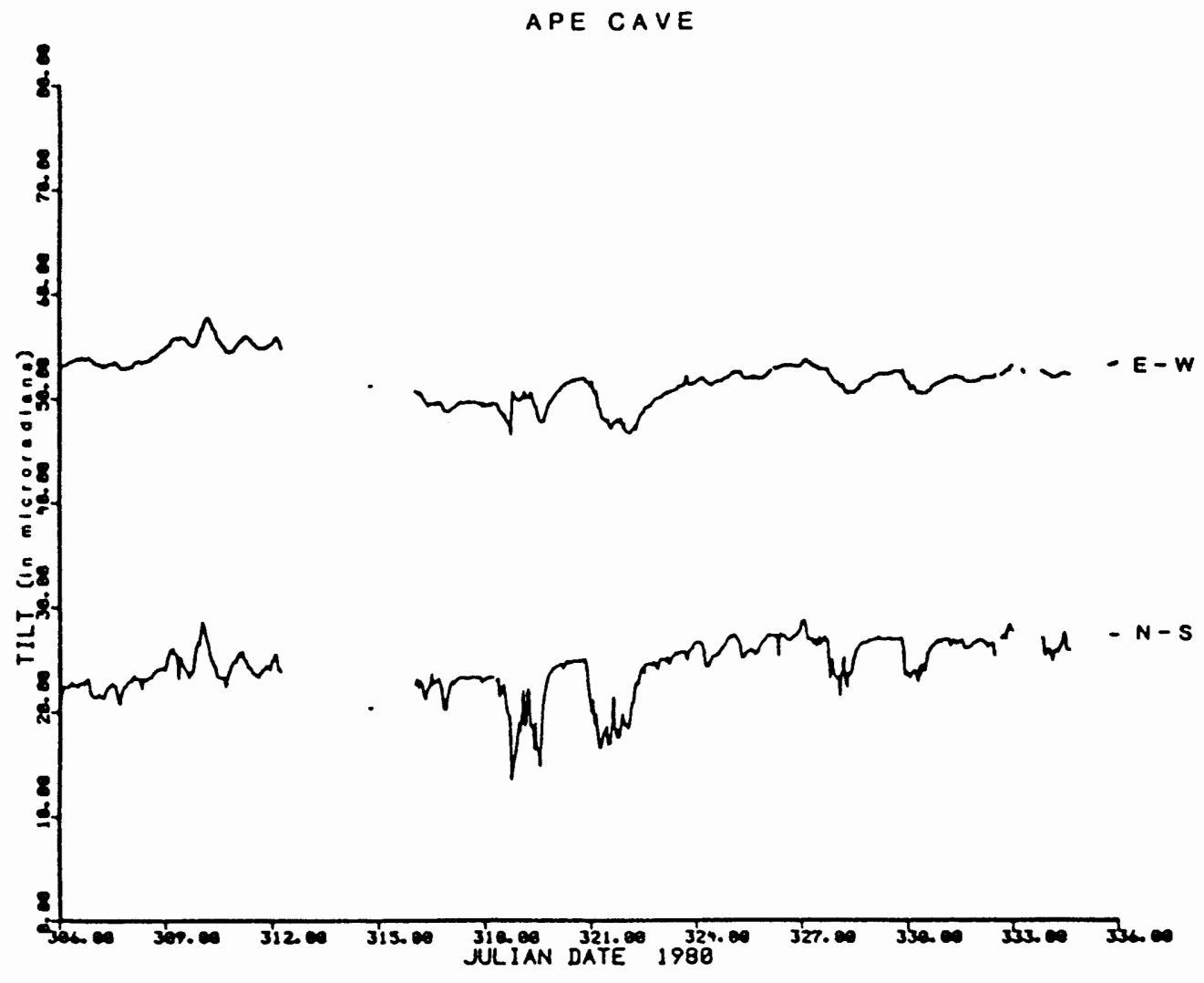

Figure 54. East-west and north-south components of tilt at Ape Cave tiltmeter site. A decrease in recorded values indicates East or North positive (inflation). Values are uncorrected hourly averages starting November 1,1980 and continuing through November 30,1980 . Times are all GMT equivalents. Gaps in the data indicate periods periods where no usable data was collected. 


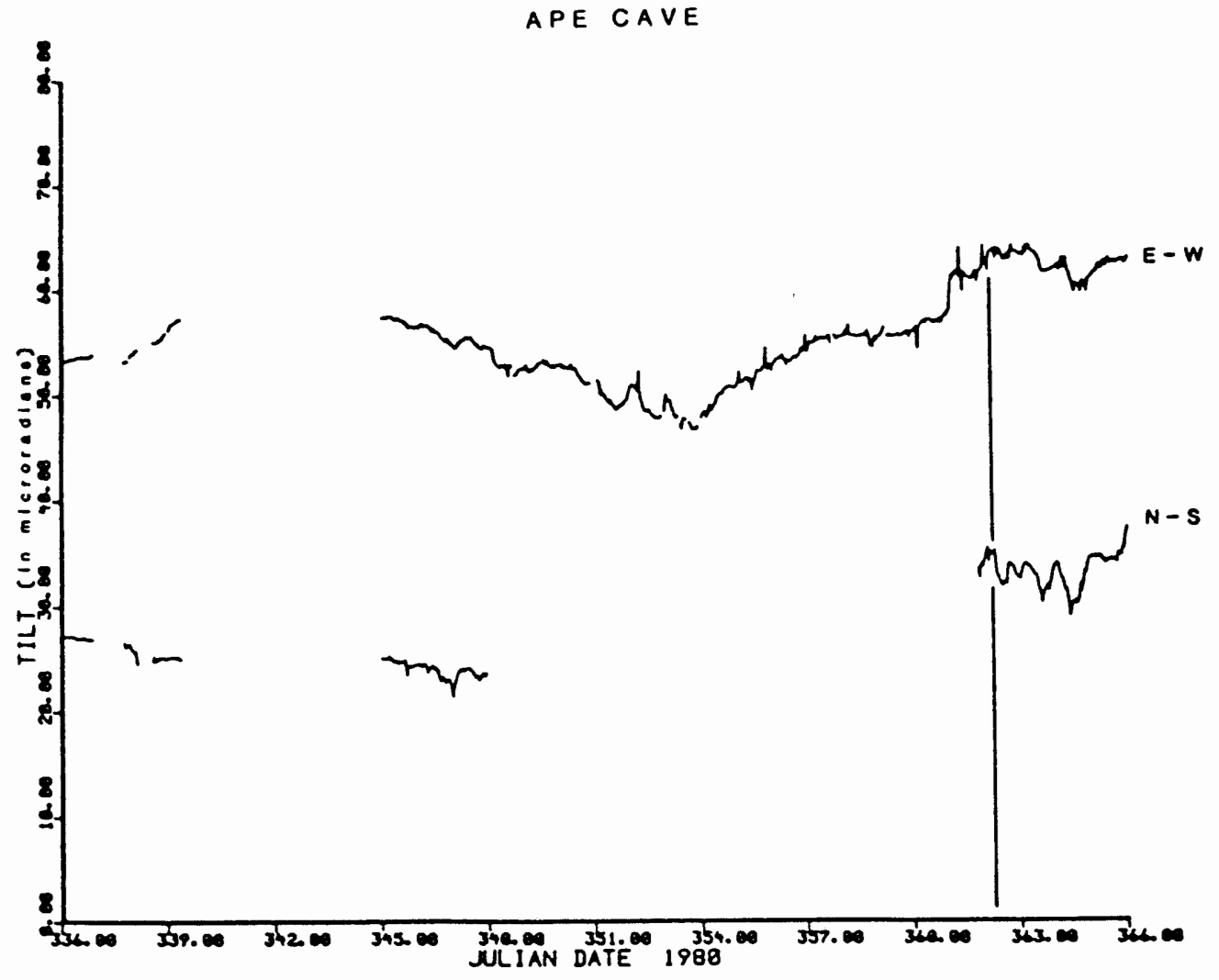

Figure 55. East-west and north-south components of tilt at Ape Cave tiltmeter site. A decrease in recorded values indicates East or North positive (inflation). Values are uncorrected hourly averages starting December 1,1980 and continuing through December 30, 1980. Times are all GMT equivalents. Vertical lines indicate eruption onsets as determined from seismic records. Gaps in the data indicate periods periods where no usable data was collected. 


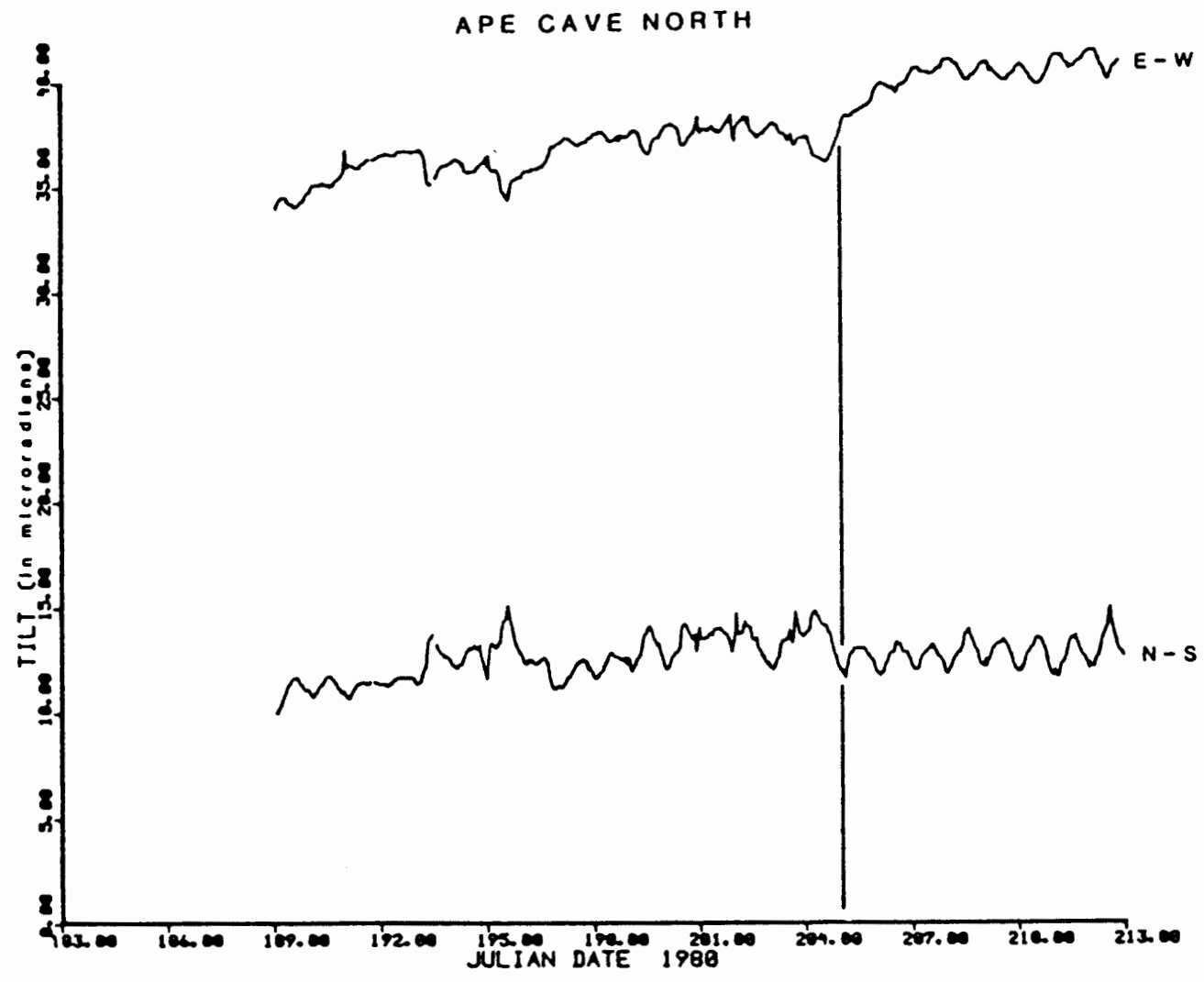

Figure 56. East-west and north-south components of tilt at Ape Cave North tiltmeter site. A decrease in recorded values indicates East or North positive (inflation). Values are uncorrected hourly averages starting July 1,1980 and continuing through July 30,1980 . Times are all GMT equivalents. Vertical lines indicate eruption onsets as determined from seismic records. Gaps in the data indicate periods periods where no usable data was collected. 


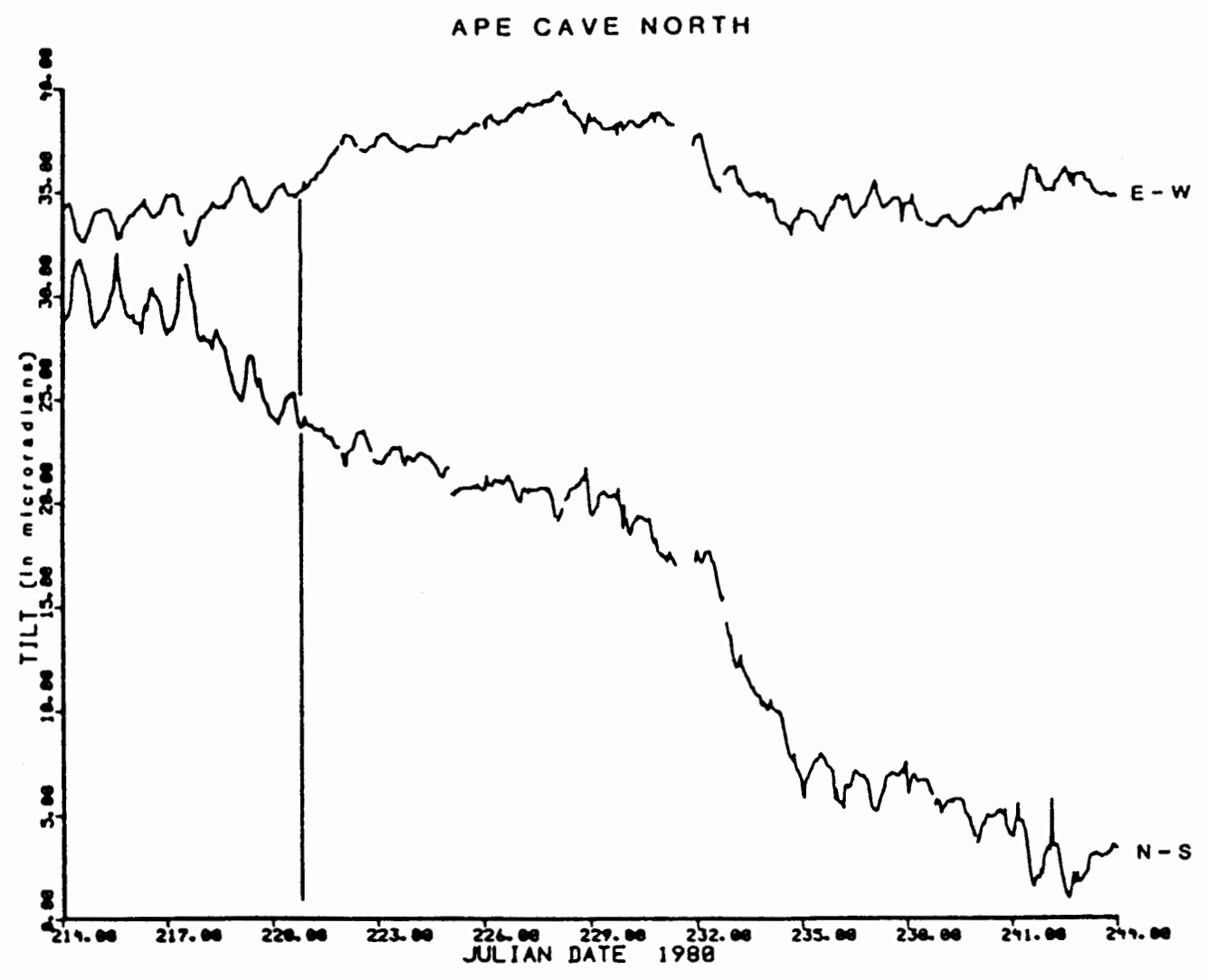

Figure 57. East-west and north-south components of tilt at Ape Cave North tiltmeter site. A decrease in recorded values indicates East or North positive (inflation). Values are uncorrected hourly averages starting August 1,1980 and continuing through August 30, 1980. Times are all GMT equivalents. Vertical lines indicate eruption onsets as determined from seismic records. Gaps in the data indicate periods periods where no usable data was collected. 


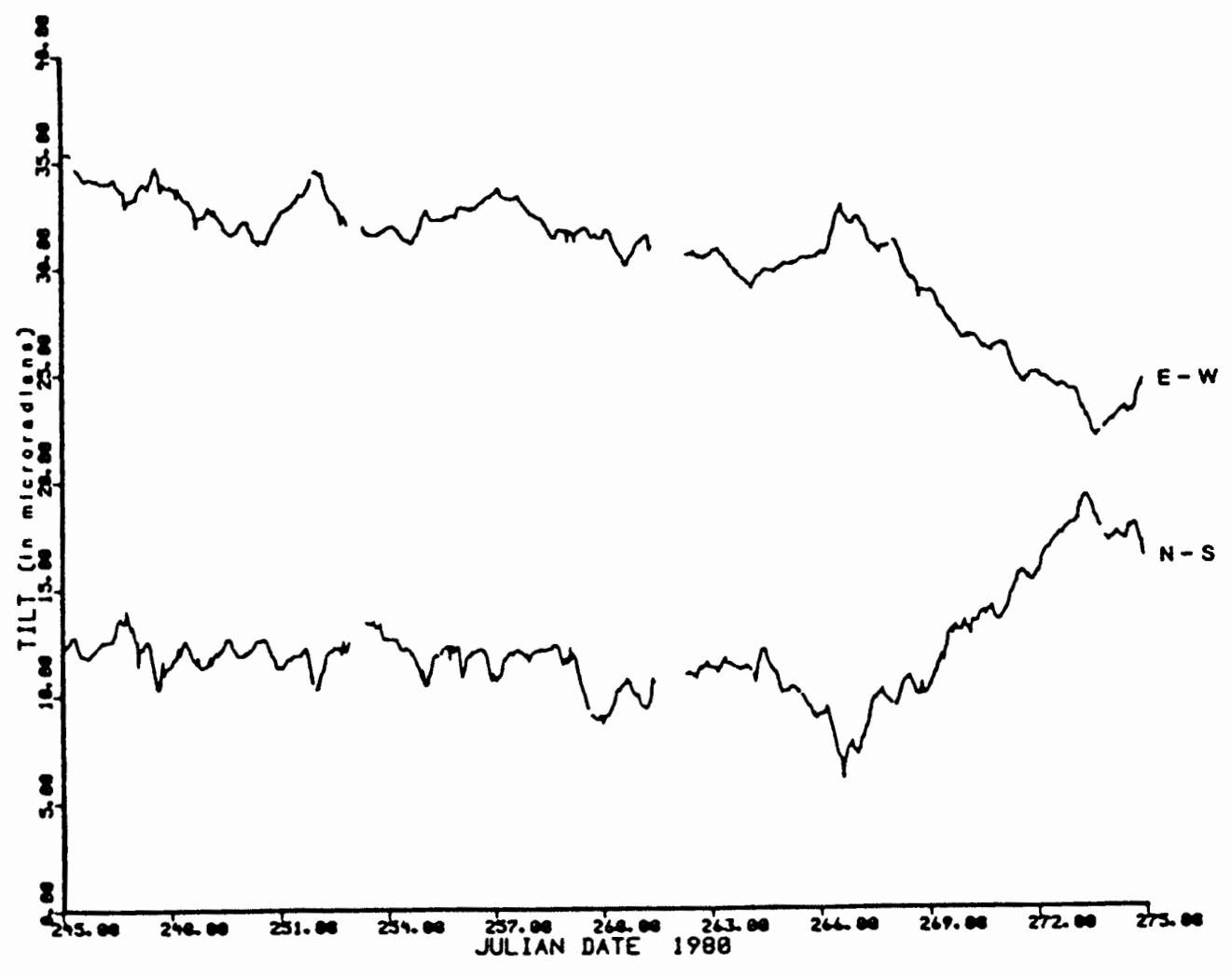

Figure 58. East-west and north-south components of tilt at Ape Cave North tiltmeter site. A decrease in recorded values indicates East or North positive (inflation). Values are uncor rected hourly averages starting September 1, 1980 and continuing through september 30,1980 . Times are all GMT equivalents. Gaps in the data indicate periods periods where no usable data was collected. 


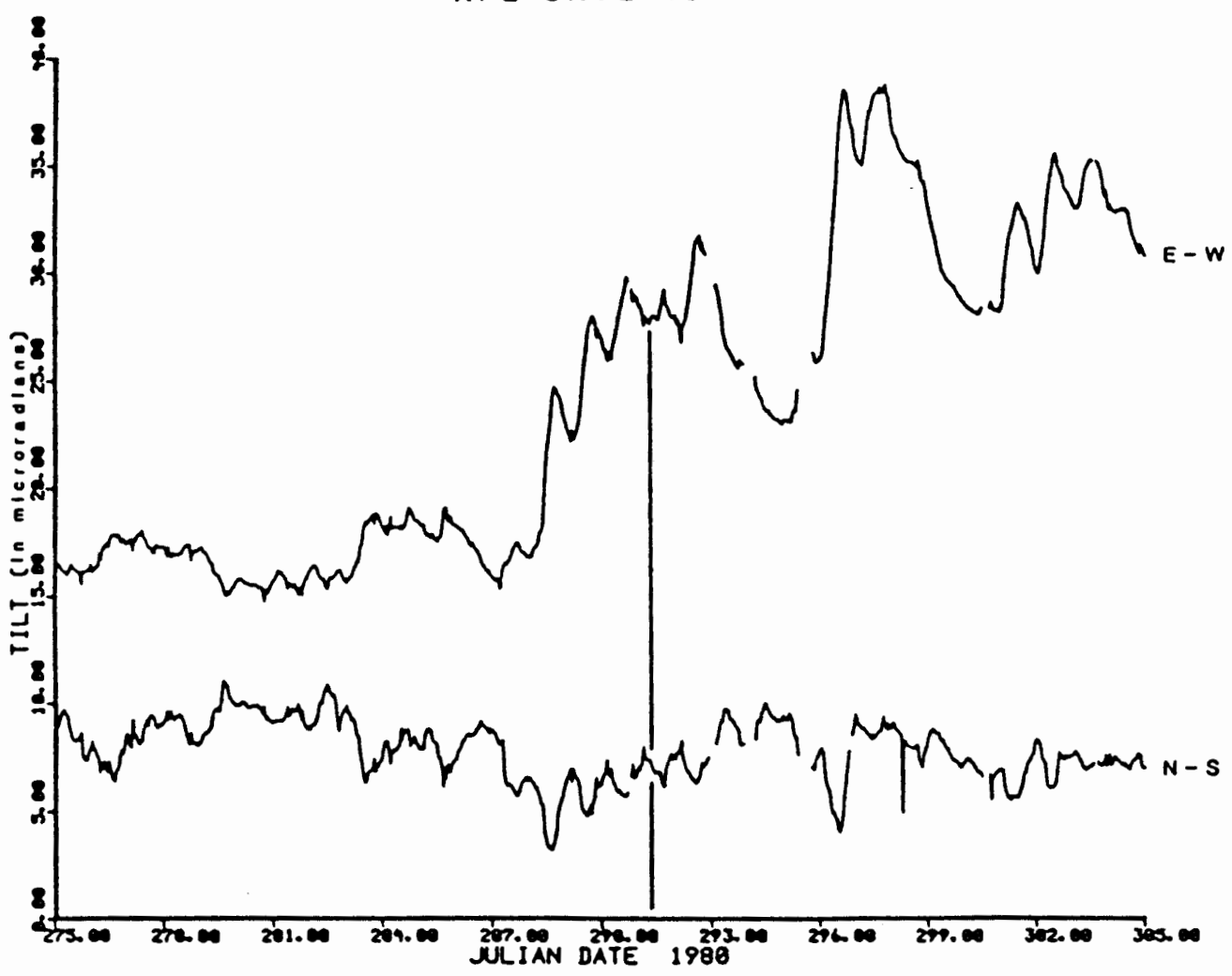

Figure 59. East-west and north-south components of tilt at Ape Cave North tiltmeter site. A decrease in recorded values indicates East or North positive (inflation). Values are uncorrected hourly averages starting October 1, 1980 and continuing through October 30, 1980. Times are all GMT equivalents. Vertical lines indicate eruption onsets as determined from seismic records. Gaps in the data indicate periods periods where no usable data was collected. 
APE CAVE NORTH

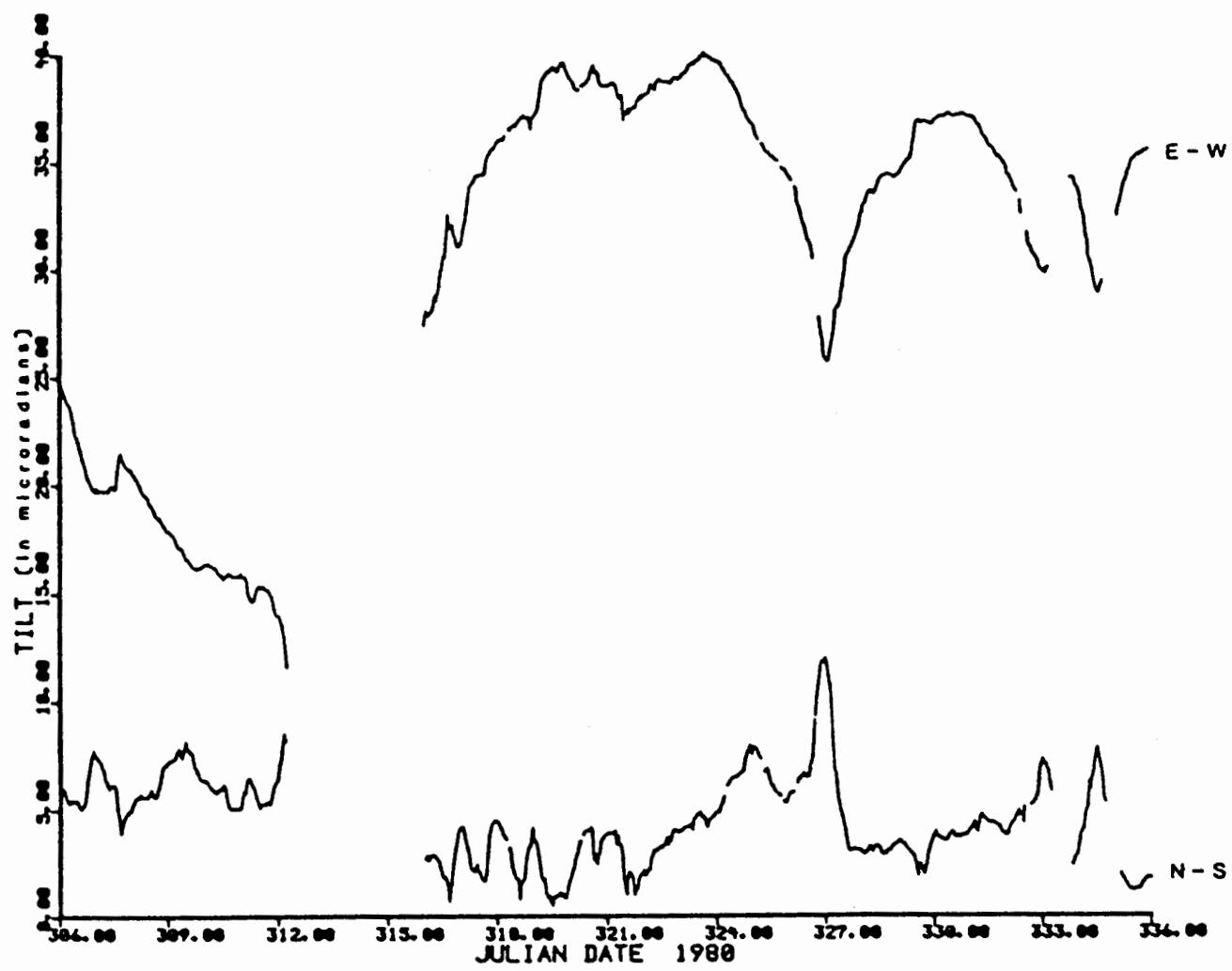

Figure 60. East-west and north-south components of tilt at Ape Cave North tiltmeter site. A decrease in recorded values indicates East or North positive (inflation). Values are uncorrected hourly averages starting November 1,1980 and continuing through November 30, 1980. Times are all GMT equivalents. Gaps in the data indicate periods periods where no usable data was collected. 
APE CAVE NORTH

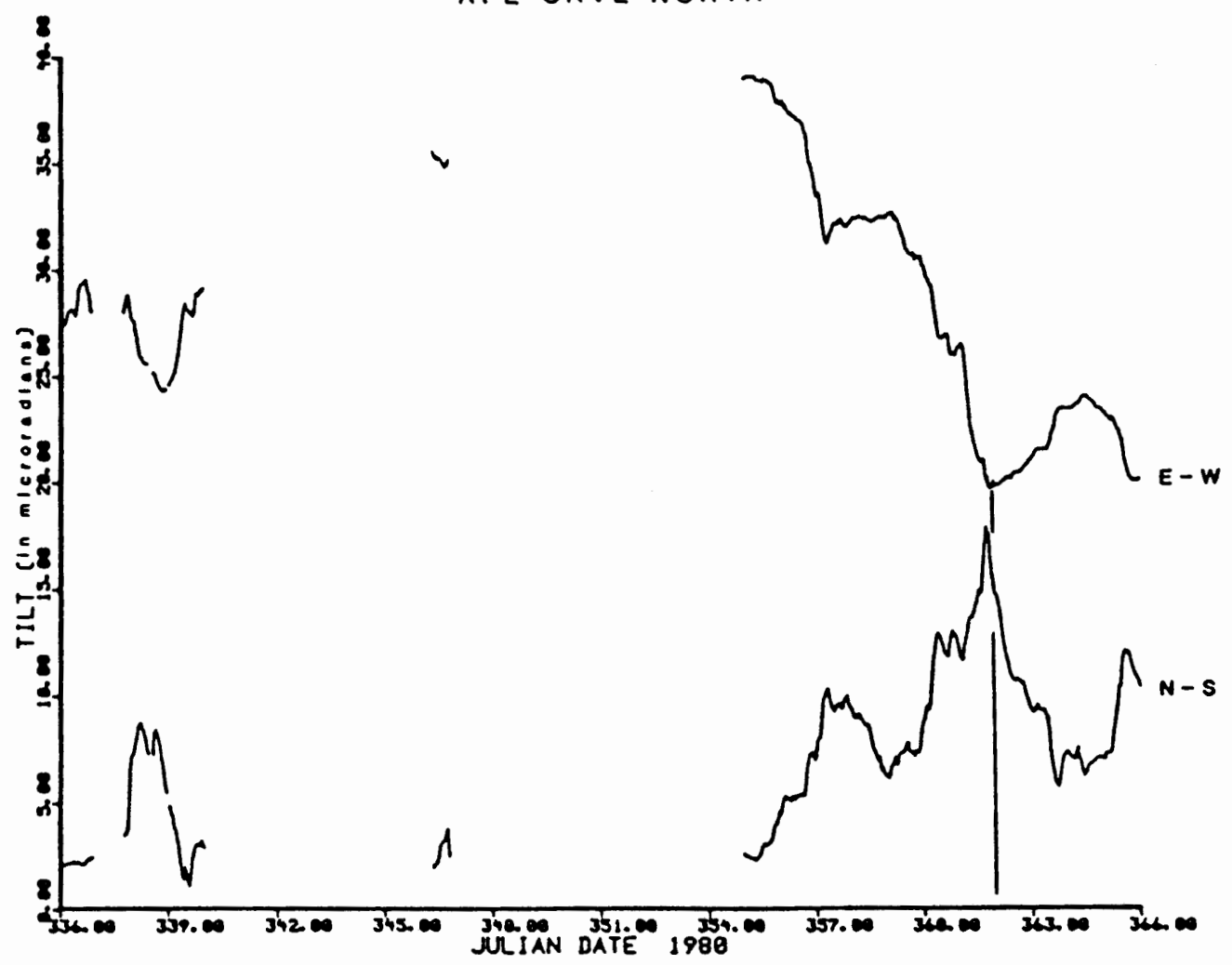

Figure 61. East-west and north-south components of tilt at Ape Cave North tiltmeter site. A decrease in recorded values indicates East or North positive (inflation). Values are uncorrected hourly averages starting December 1, 1980 and continuing through December 30, 1980. Times are all GMT equivalents. Vertical lines indicate eruption onsets as determined from seismic records. Gaps in the data indicate periods periods where no usable data was collected. 


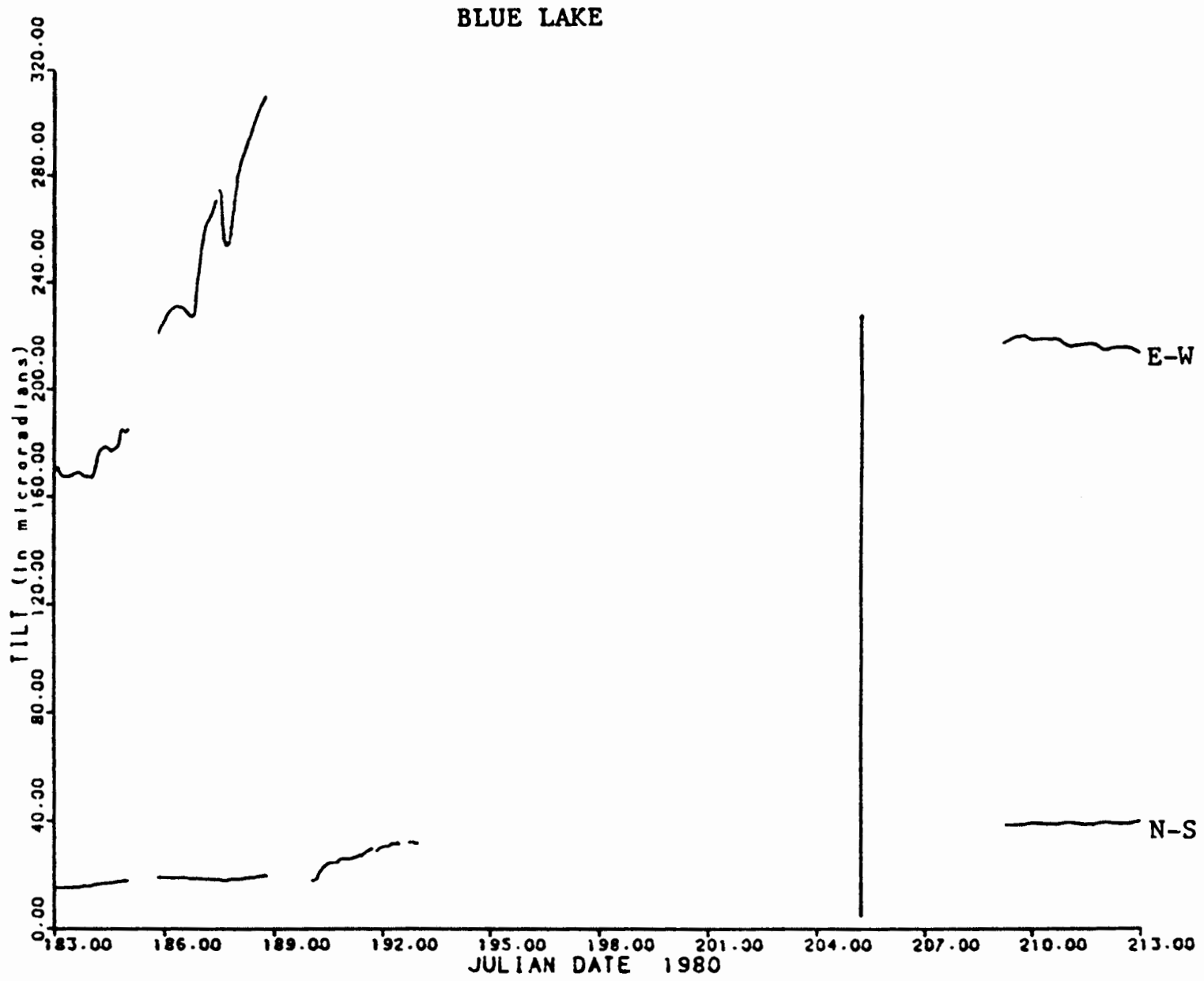

Figure 62. East-west and north-south components of tilt at Blue Lake tiltmeter site. A decrease in recorded values indicates East or North positive (inflation). Values are uncorrected hourly averages starting July 1,1980 and continuing through July 30, 1980. Times are all GMT equivalents. Vertical lines indicate eruption onsets as determined from seismic records. Gaps in the data indicate periods periods where no usable data was collected. 


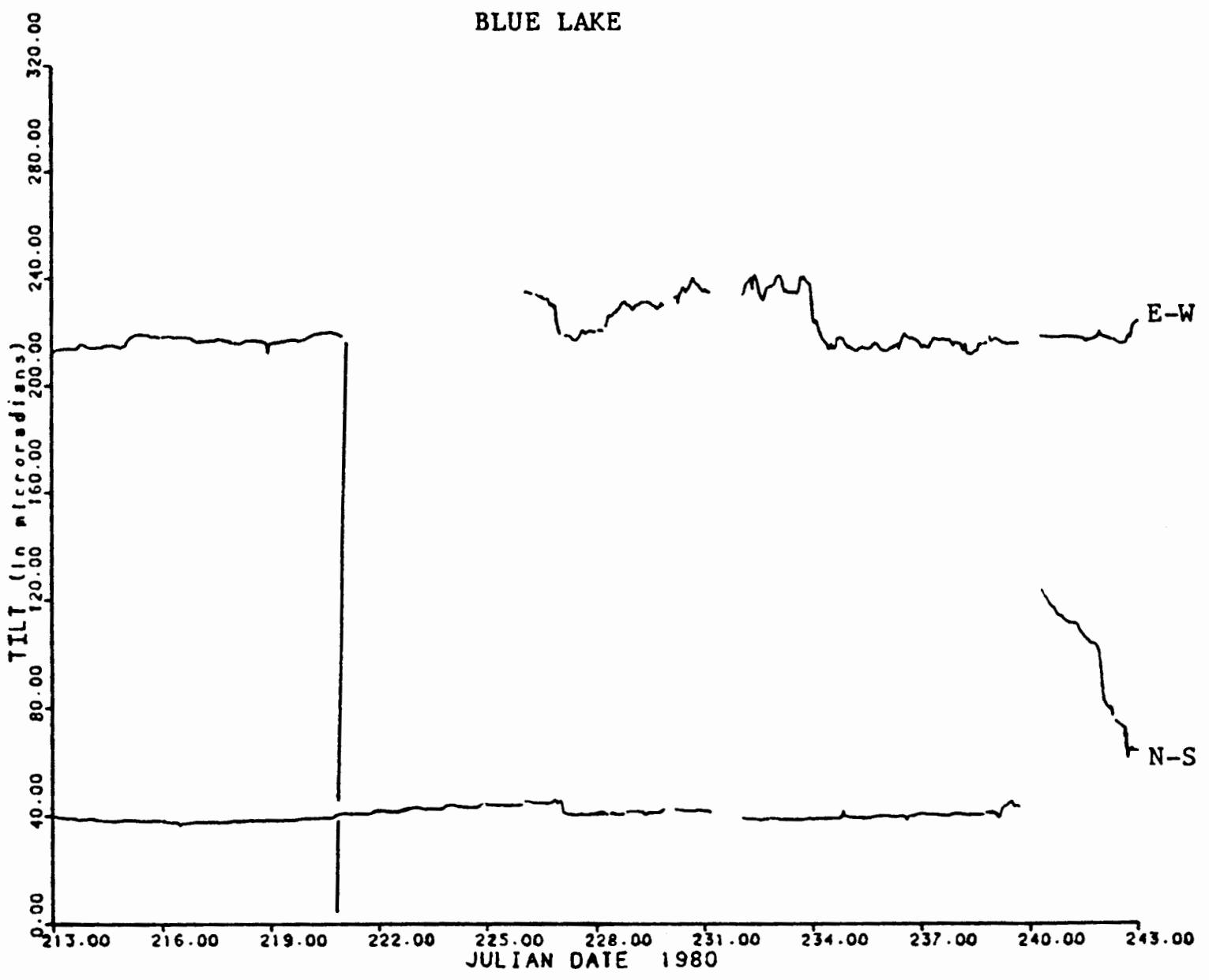

Figure 63. East-west and north-south components of tilt at Blue Lake tiltmeter site. A decrease in recorded values indicates East or North positive (inflation). Values are uncorrected hourly averages starting August 1,1980 and continuing through August 30 , 1980. Times are all GMT equivalents. Vertical lines indicate eruption onsets as determined from seismic records. Gaps in the data indicate periods periods where no usable data was collected. 


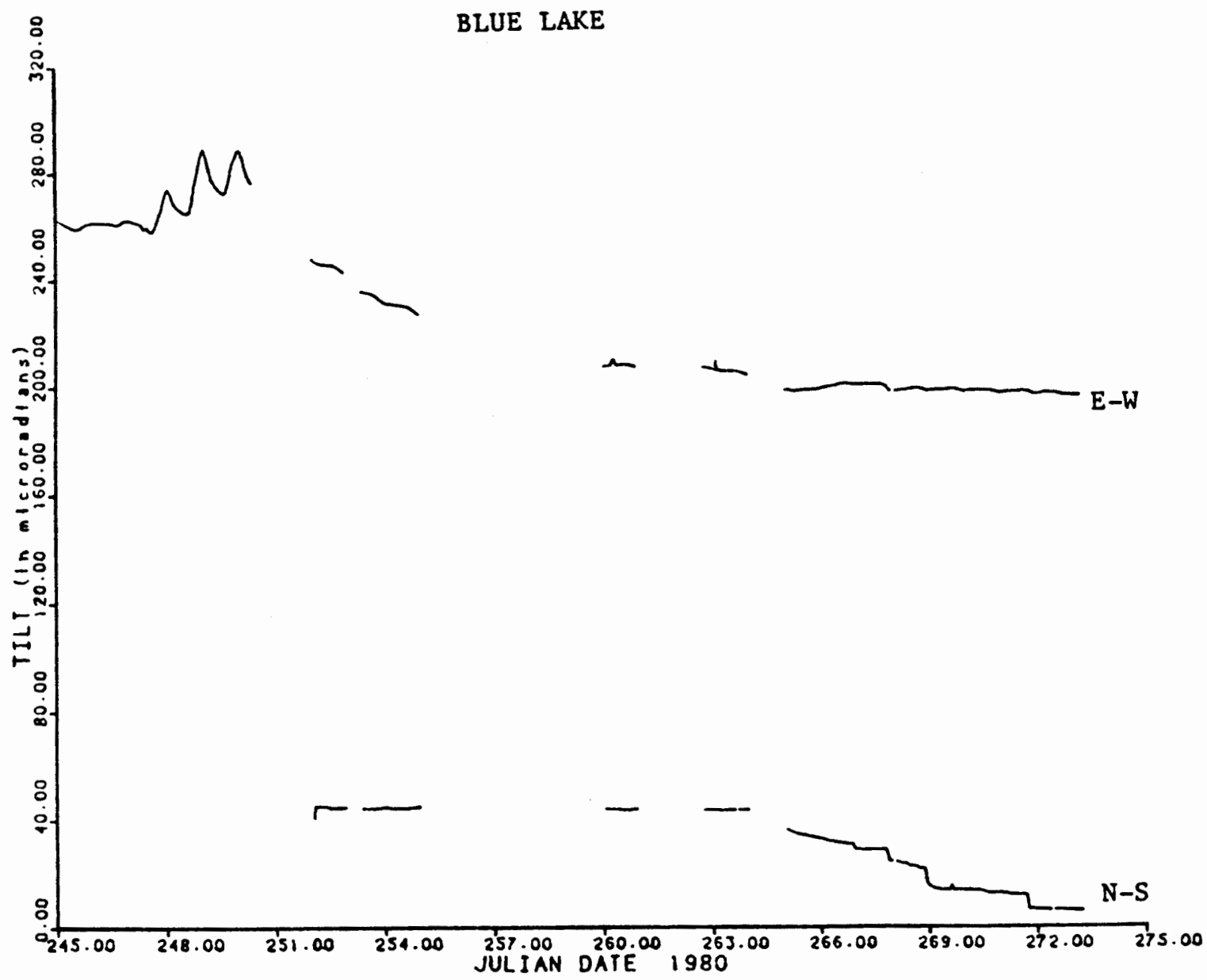

Figure 64. East-west and north-south components of tilt at Blue Lake tiltmeter site. A decrease in recorded values indicates East or North positive (inflation). Values are uncorrected hourly averages starting september 1, 1980 and continuing through September 30, 1980. Times are all GMT equivalents. Gaps in the data indicate periods periods where no usable data was collected. 


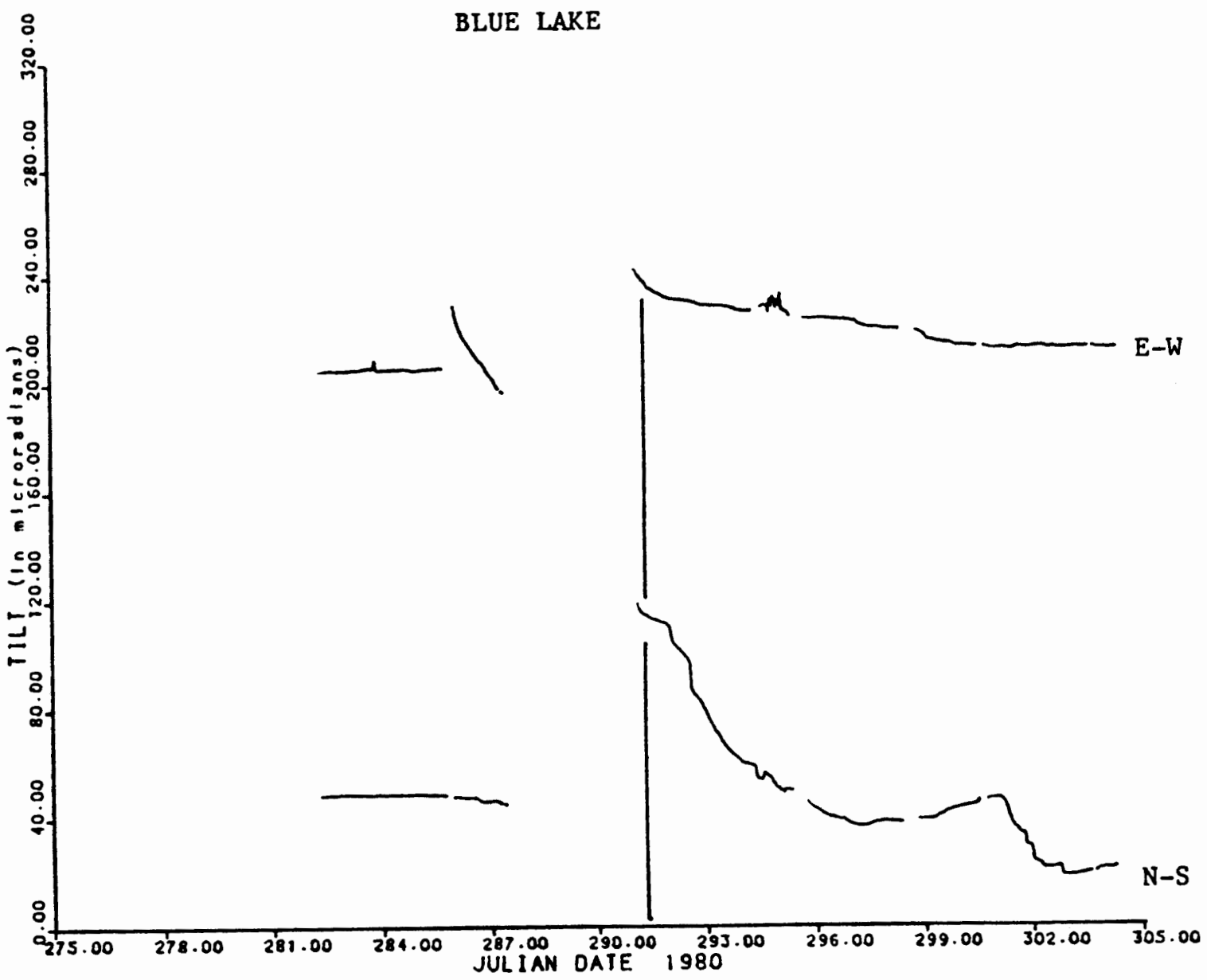

Figure 65. East-west and north-south components of tilt at Blue Lake tiltmeter site. A decrease in recorded values indicates East or North positive (inflation). Values are uncorrected hourly averages starting October 1,1980 and continuing through october 30, 1980. Times are all GMT equivalents. Vertical lines indicate eruption onsets as determined from seismic records. Gaps in the data indicate periods periods where no usable data was collected. 


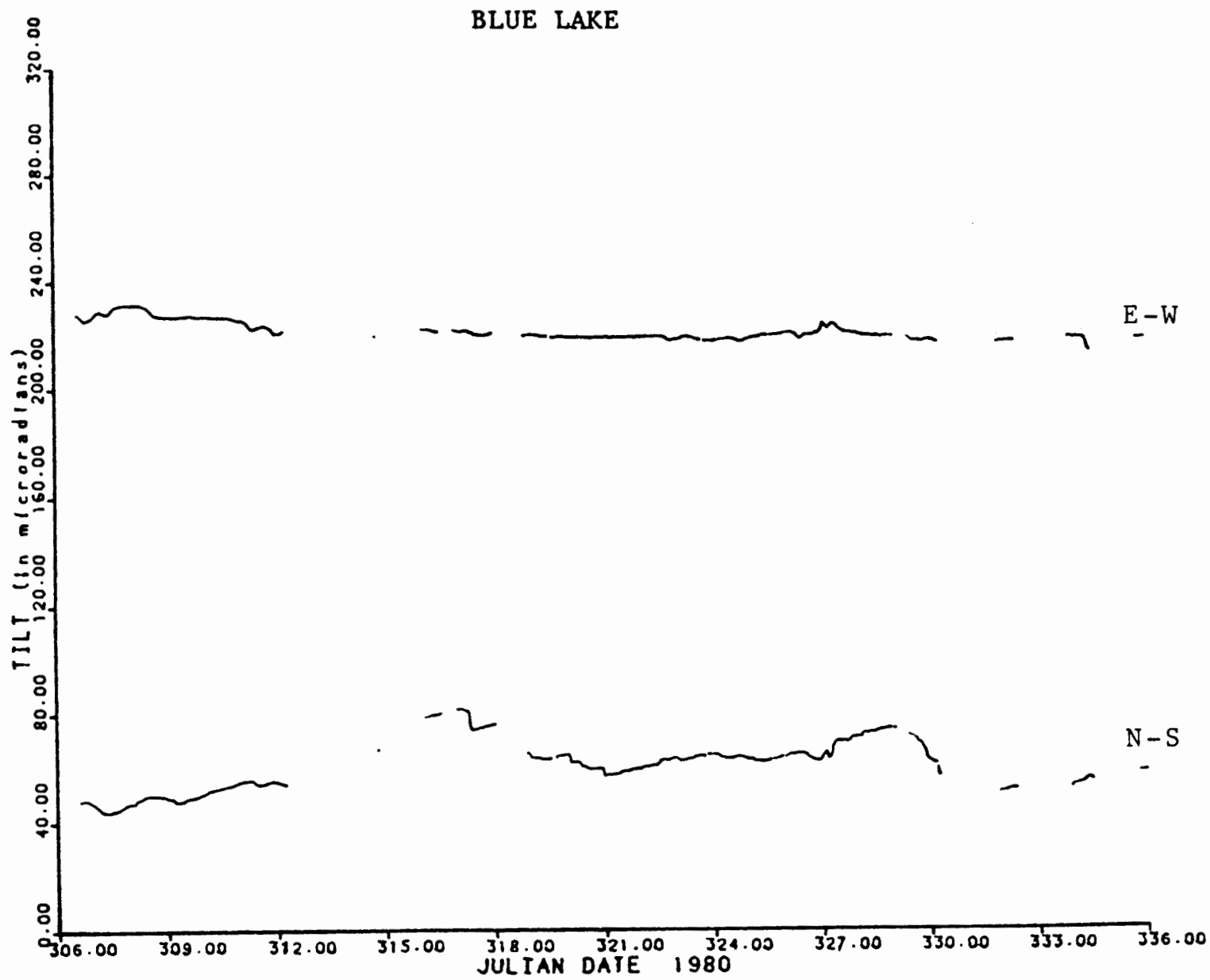

Figure 66. East-west and north-south components of tilt at Blue Lake tiltmeter site. A decrease in recorded values indicates East or North positive (inflation). Values are uncorrected hourly averages starting November 1, 1980 and continuing through November 30, 1980. Times are all GMT equivalents. Gaps in the data indicate periods periods where no usable data was collected. 


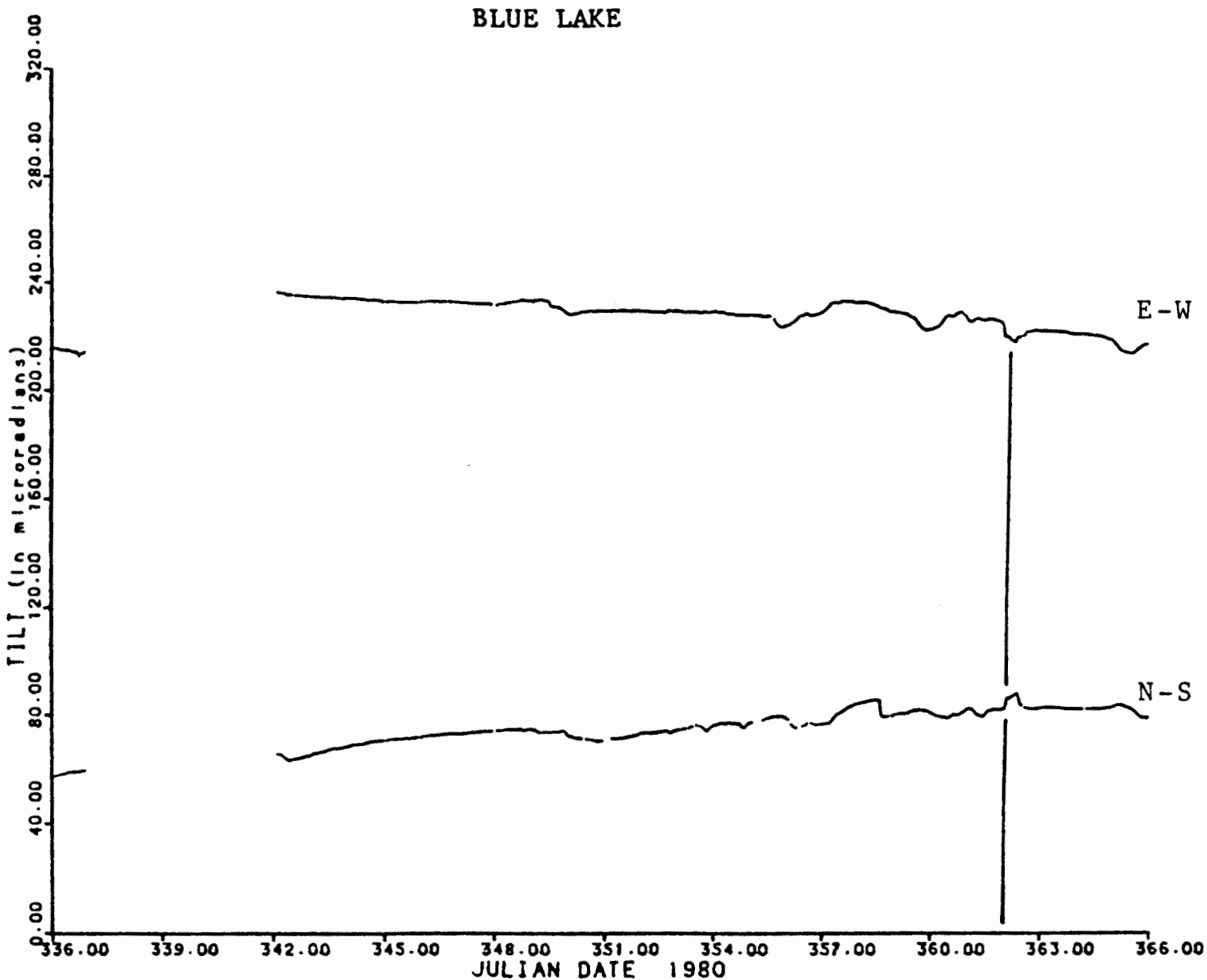

Figure 67. East-west and north-south components of tilt at Blue Lake tiltmeter site. A decrease in recorded values indicates East or North positive (inflation). Values are uncorrected hourly averages starting December 1,1980 and continuing through December 30,1980 . Times are all GMT equivalents. Vertical lines indicate eruption onsets as determined from seismic records. Gaps in the data indicate periods periods where no usable data was collected. 


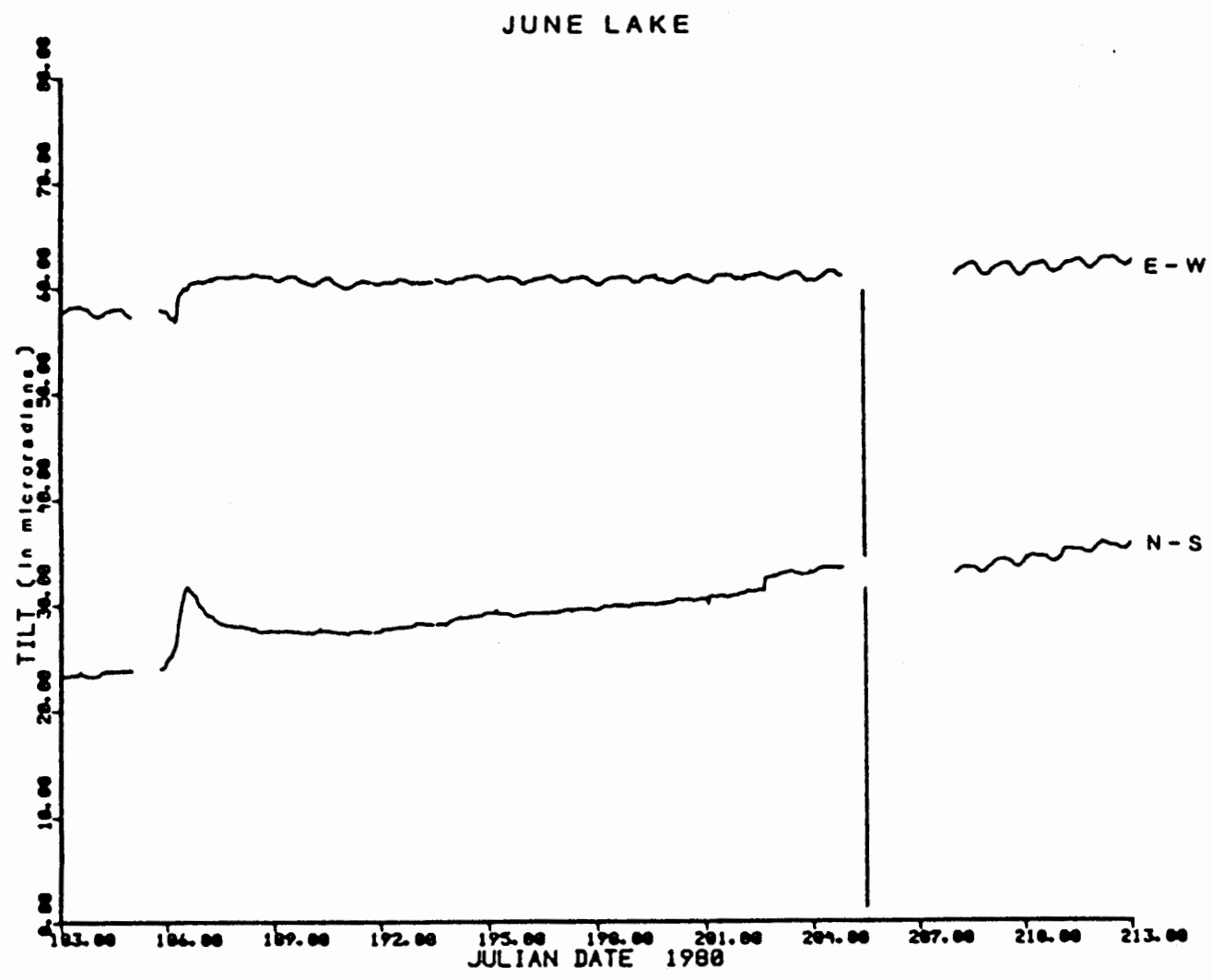

Figure 68. East-west and north-south components of tilt at June Lake tiltmeter site. A decrease in recorded values indicates East or North positive (inflation). Values are uncorrected hourly averages starting July 1,1980 and continuing through July 30,1980 . Times are all GMT equivalents. Vertical lines indicate eruption onsets as determined from seismic records. Gaps in the data indicate periods periods where no usable data was collected. 


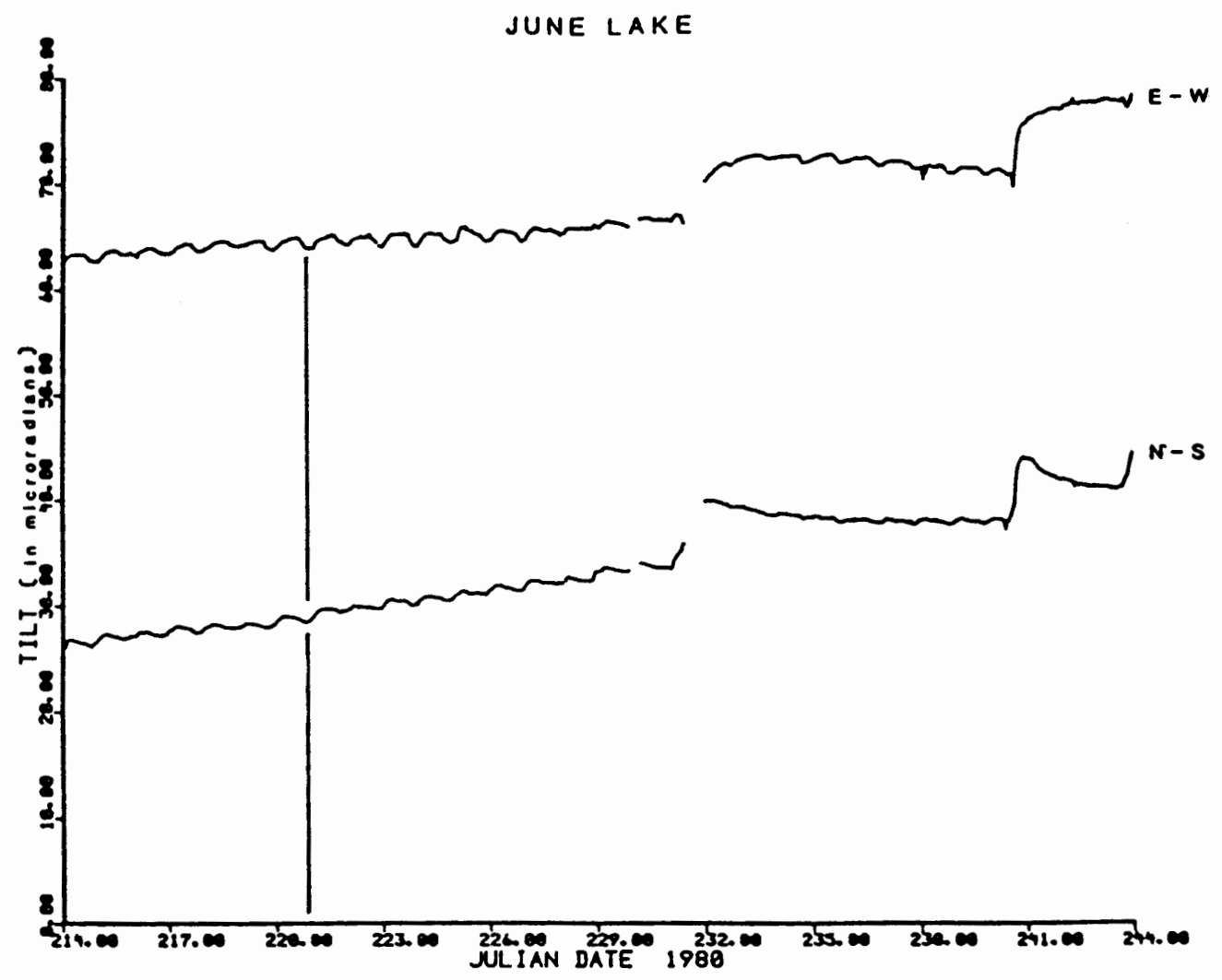

Figure 69. East-west and north-south components of tilt at June Lake tiltmeter site. A decrease in recorded values indicates East or North positive (inflation). Values are uncorrected hourly averages starting August 1, 1980 and continuing through August 30, 1980. Times are all GMT equivalents. Vertical lines indicate eruption onsets as determined from seismic records. Gaps in the data indicate periods periods where no usable data was collected. 


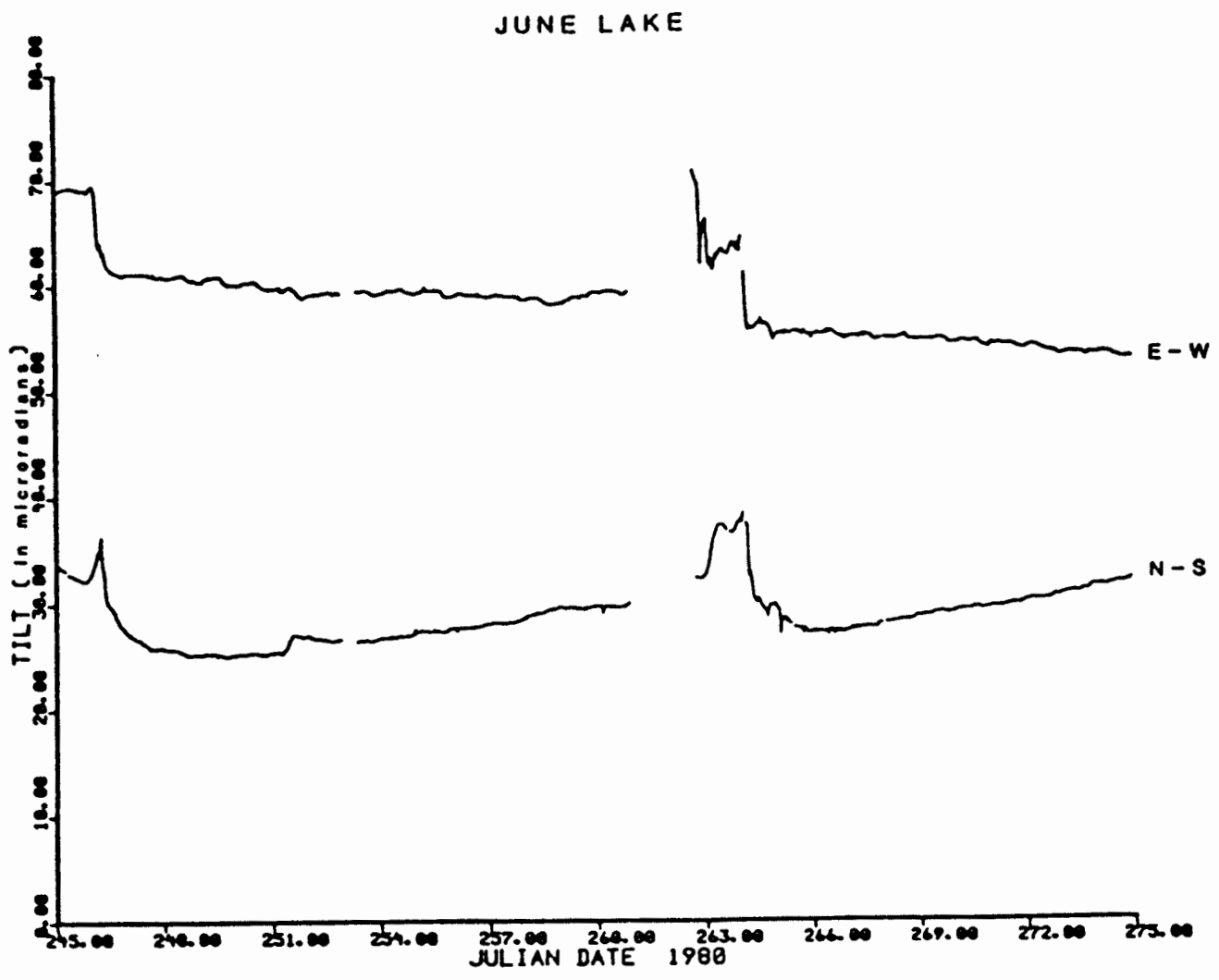

Figure 70. East-west and north-south components of tilt at June Lake tiltmeter site. A decrease in recorded values indicates East or North positive (inflation). Values are uncorrected hourly averages starting september 1, 1980 and continuing through September 30, 1980. Times are all GMT equivalents. Gaps in the data indicate periods periods where no usable data was collected. 


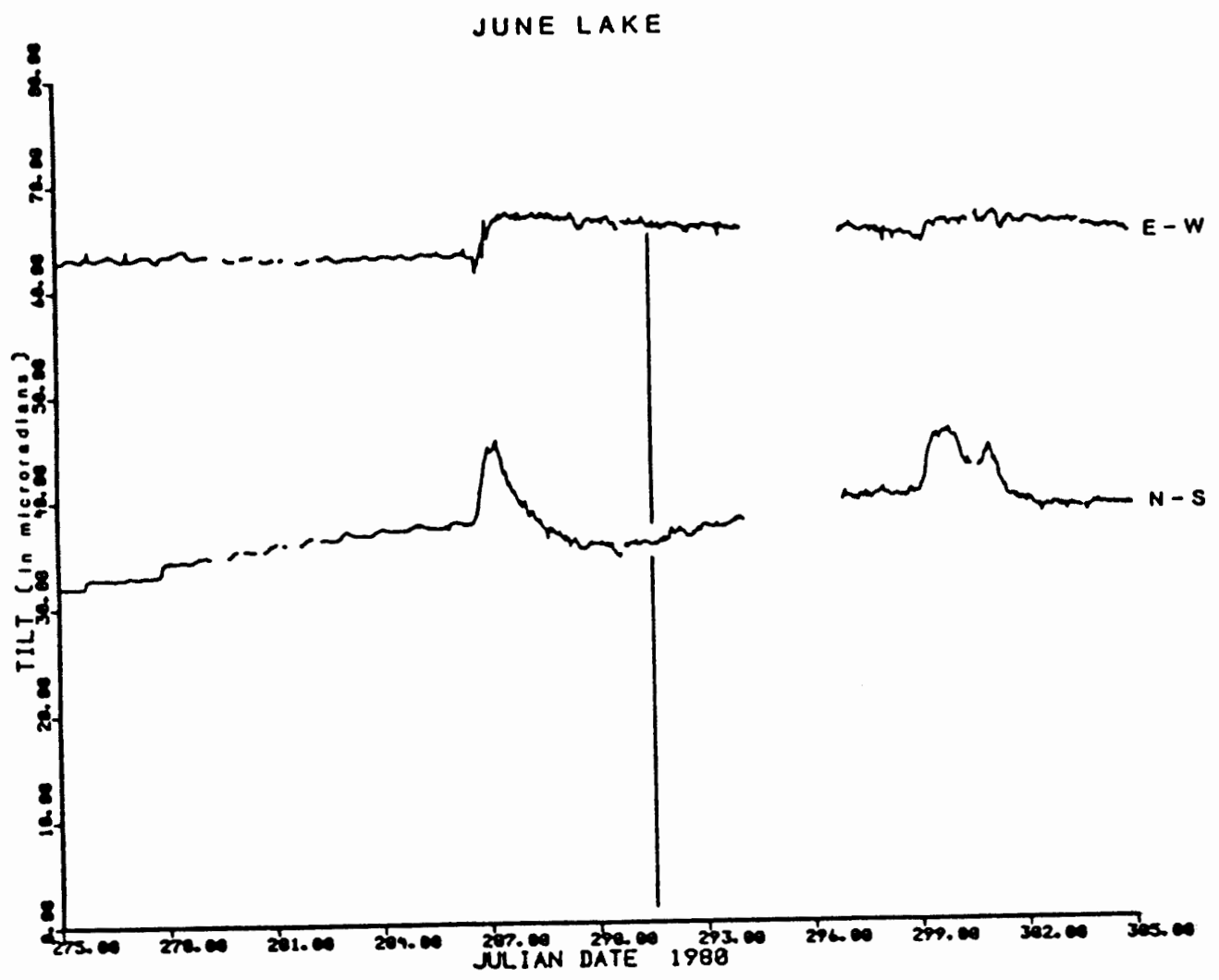

Figure 71. East-west and north-south components of tilt at June Lake tiltmeter site. A decrease in recorded values indicates East or North positive (inflation). Values are uncorrected hourly averages starting October 1, 1980 and continuing through October 30, 1980. Times are all GMT equivalents. Vertical lines indicate eruption onsets as determined from seismic records. Gaps in the data indicate periods periods where no usable data was collected. 
JUNE LAKE

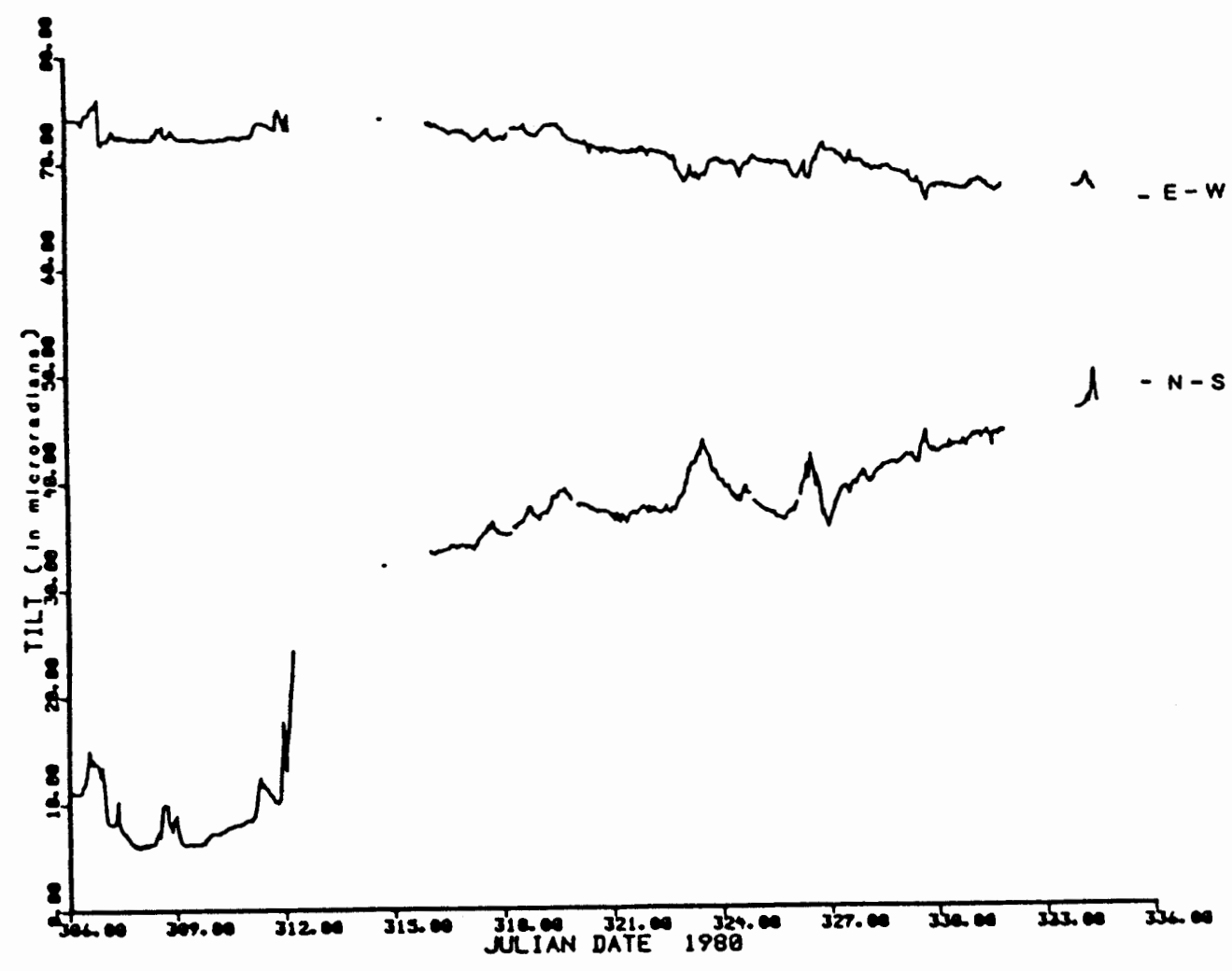

Figure 72. East-west and north-south components of tilt at June Lake tiltmeter site. A decrease in recorded values indicates East or North positive (inflation). Values are uncorrected hourly averages starting November 1, 1980 and continuing through November 30, 1980. Times are all GMT equivalents. Gaps in the data indicate periods periods where no usable data was collected. 


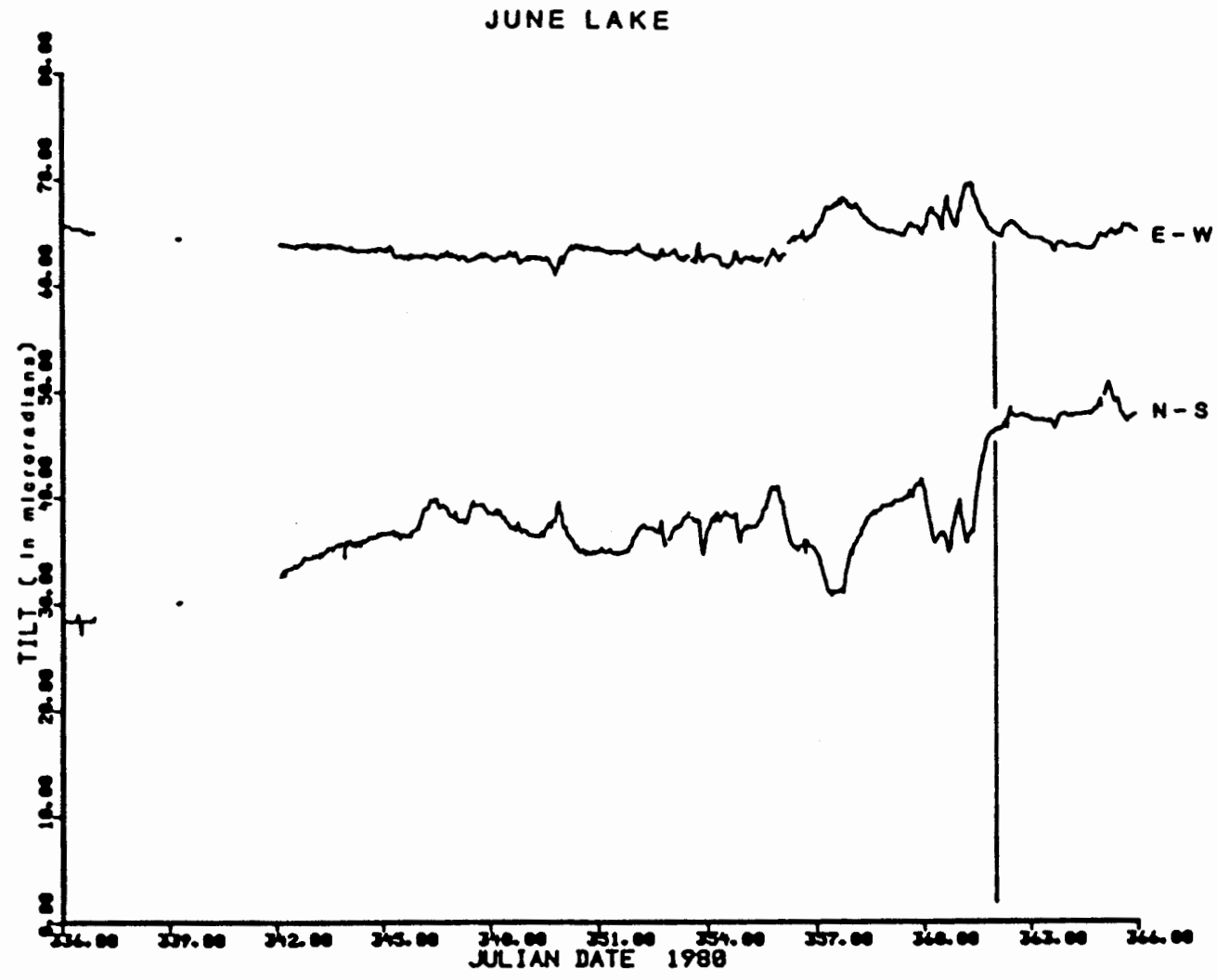

Figure 73. East-west and north-south components of tilt at June Lake tiltmeter site. A decrease in recorded values indicates East or North positive (inflation). Values are uncorrected hourly averages starting December 1, 1980 and continuing through December 30, 1980. Times are all GMT equivalents. Vertical lines indicate eruption onsets as determined from seismic records. Gaps in the data indicate periods periods where no usable data was collected. 


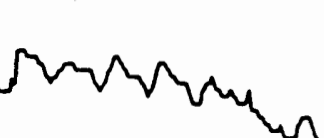

Mrung $\frac{1}{103.20}$ $186.00 \quad 189.00$ 192.00

Figure 74. East-west and north-south components of tilt at PSU \#2 tiltmeter site. A decrease in recorded values indicates East or North positive (inflation). Values are uncorrected hourly averages starting July 1,1980 and continuing through July 30, 1980. Times are all GMT equivalents. Vertical lines indicate eruption onsets as determined from seismic records. Gaps in the data indicate periods periods where no usable data was collected. 


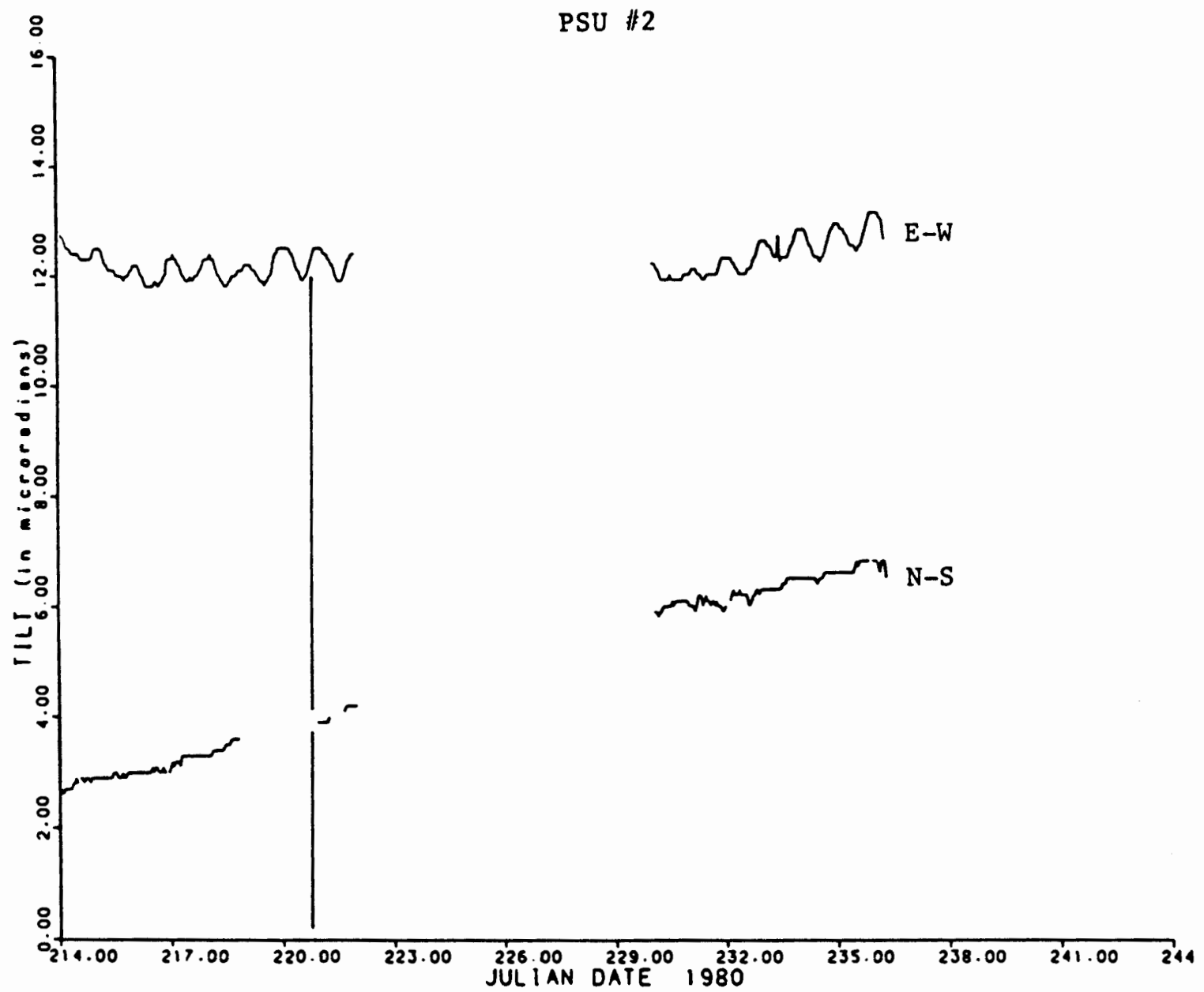

Figure 75. East-west and north-south components of tilt at PSU \#2 tiltmeter site. A decrease in recorded values indicates East or North positive (inflation). Values are uncorrected hourly averages starting August 1,1980 and continuing through August 30, 1980. Times are all GMT equivalents. Vertical lines indicate eruption onsets as determined from seismic records. Gaps in the data indicate periods periods where no usable data was collected. 


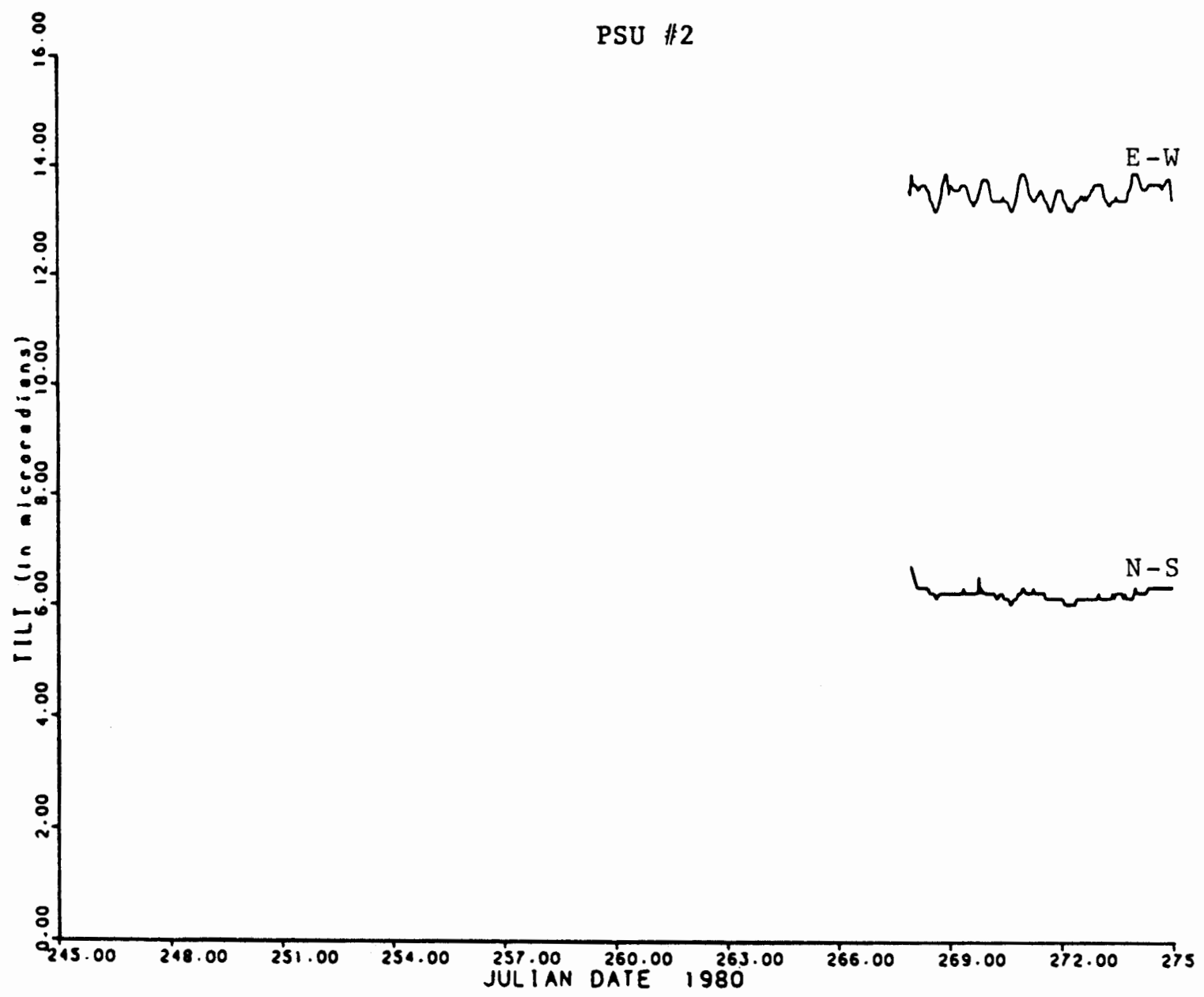

Figure 76. East-west and north-south components of tilt at PSU $\$ 2$ tiltmeter site. A decrease in recorded values indicates East or North positive (inflation). Values are uncorrected hourly averages starting September 1,1980 and continuing through September 30,1980 . Times are all GMT equivalents. Gaps in the data indicate periods periods where no usable data was collected. 


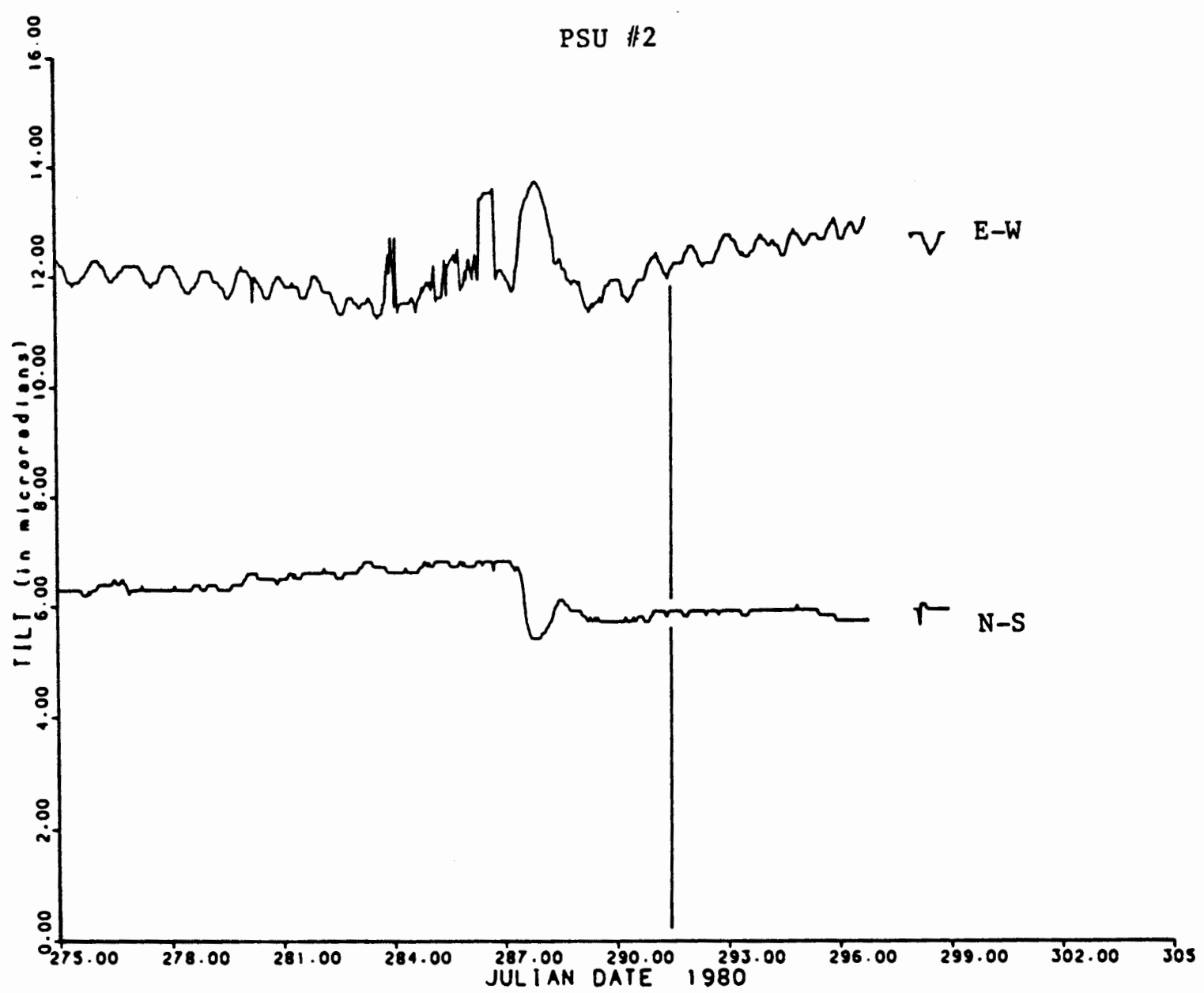

Figure 77. East-west and north-south components of tilt at PSU $\$ 2$ tiltmeter site. A decrease in recorded values indicates East or North positive (inflation). Values are uncorrected hourly averages starting October 1,1980 and continuing through October 30, 1980. Times are all GMT equivalents. Vertical lines indicate eruption onsets as determined from seismic records. Gaps in the data indicate periods periods where no usable data was collected. 


\section{8}

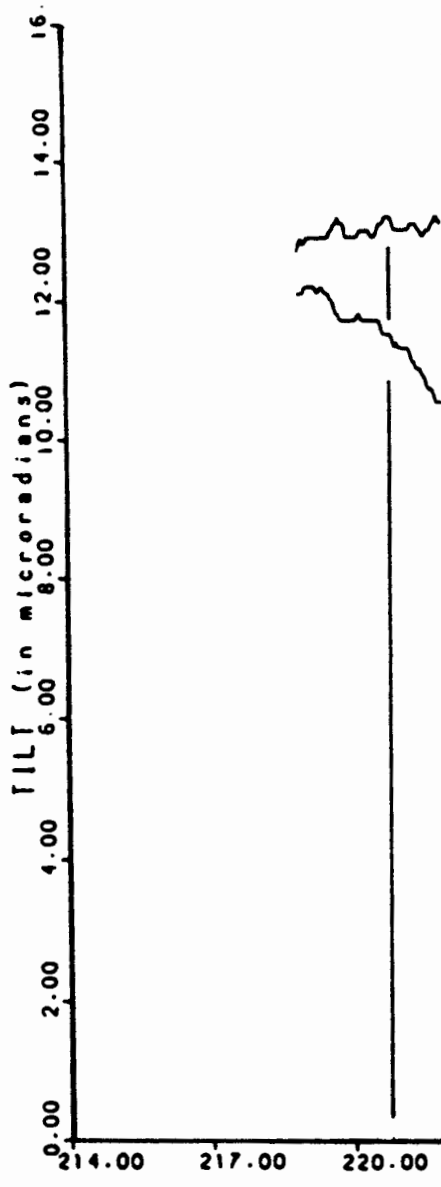

PSU \#3
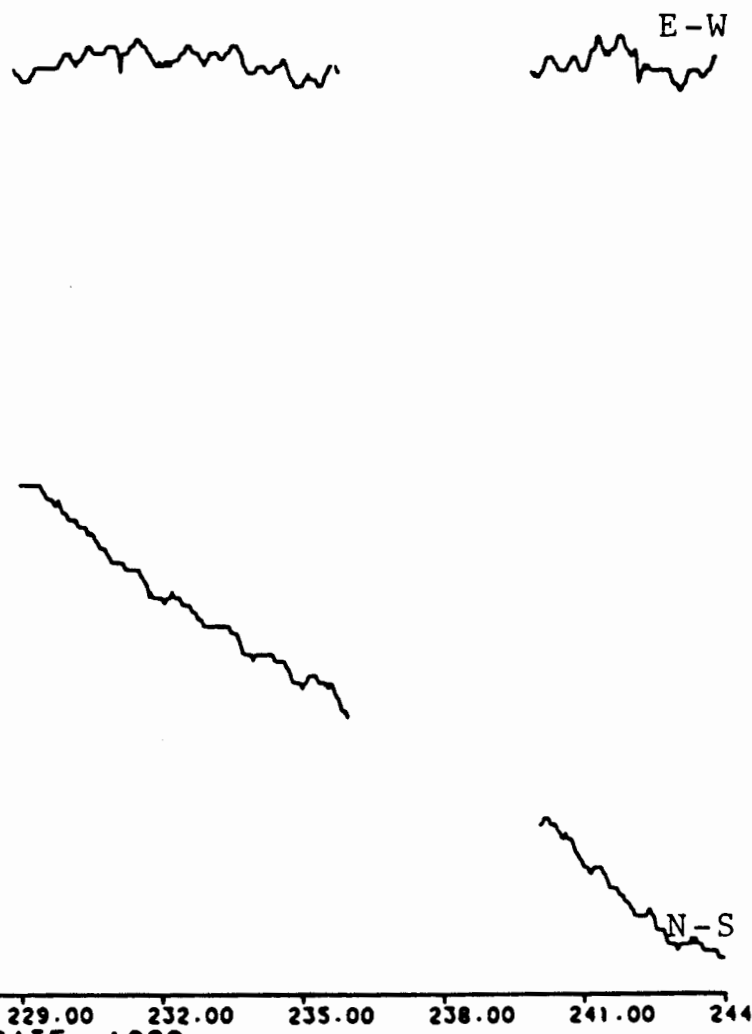

Figure 78. East-west and north-south components of tilt at PSU \#3 tiltmeter site. A decrease in recorded values indicates East or North positive (inflation). Values are uncorrected hourly averages starting August 1,1980 and continuing through August 30, 1980. Times are all GMT equivalents. Vertical lines indicate eruption onsets as determined from seismic records. Gaps in the data indicate periods periods where no usable data was collected. 


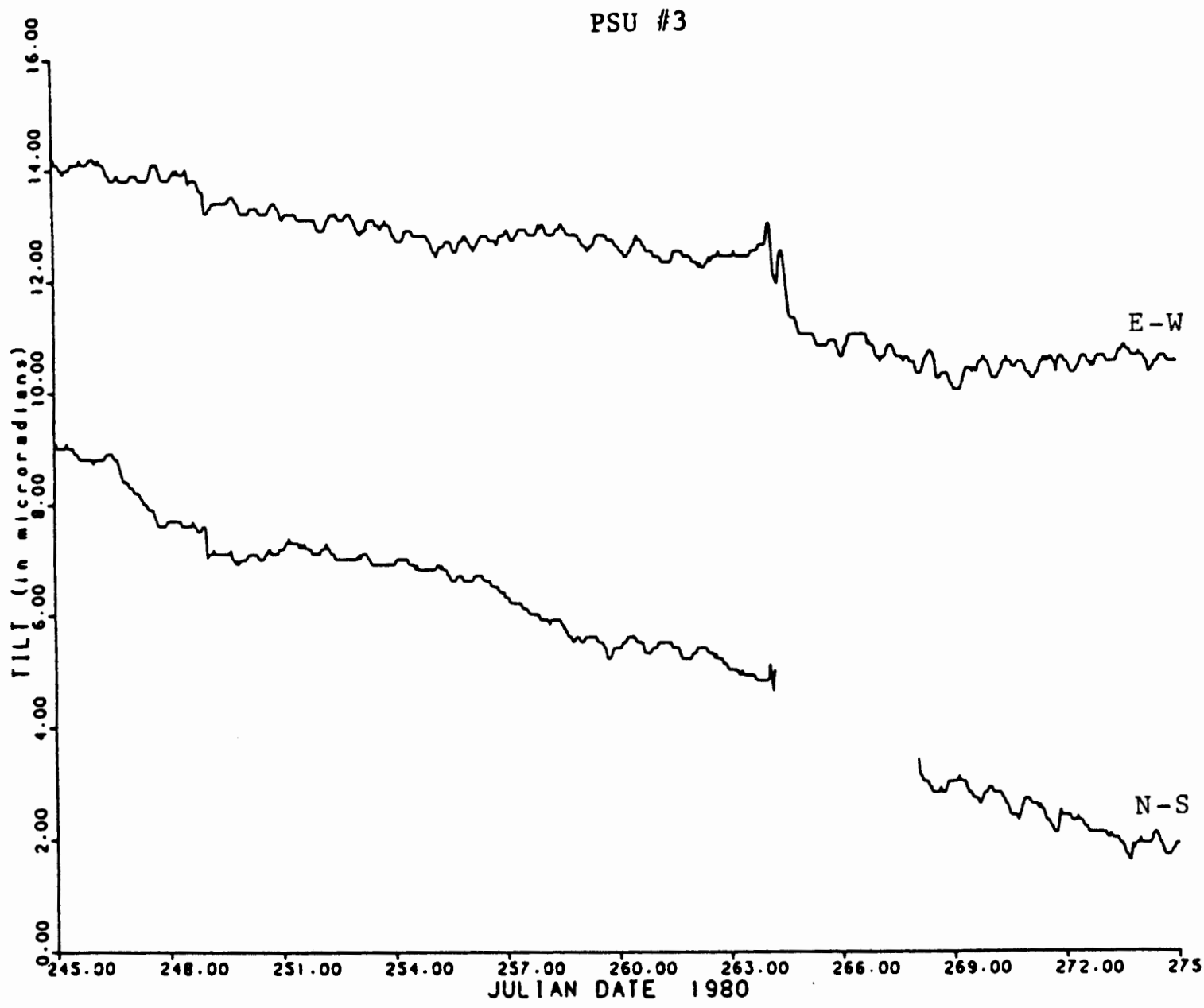

Figure 79. East-west and north-south components of tilt at PSU \$3 tiltmeter site. A decrease in recorded values indicates East or North positive (inflation). Values are uncorrected hourly averages starting September 1, 1980 and continuing through September 30, 1980. Times are all GMT equivalents. Gaps in the data indicate periods periods where no usable data was collected. 


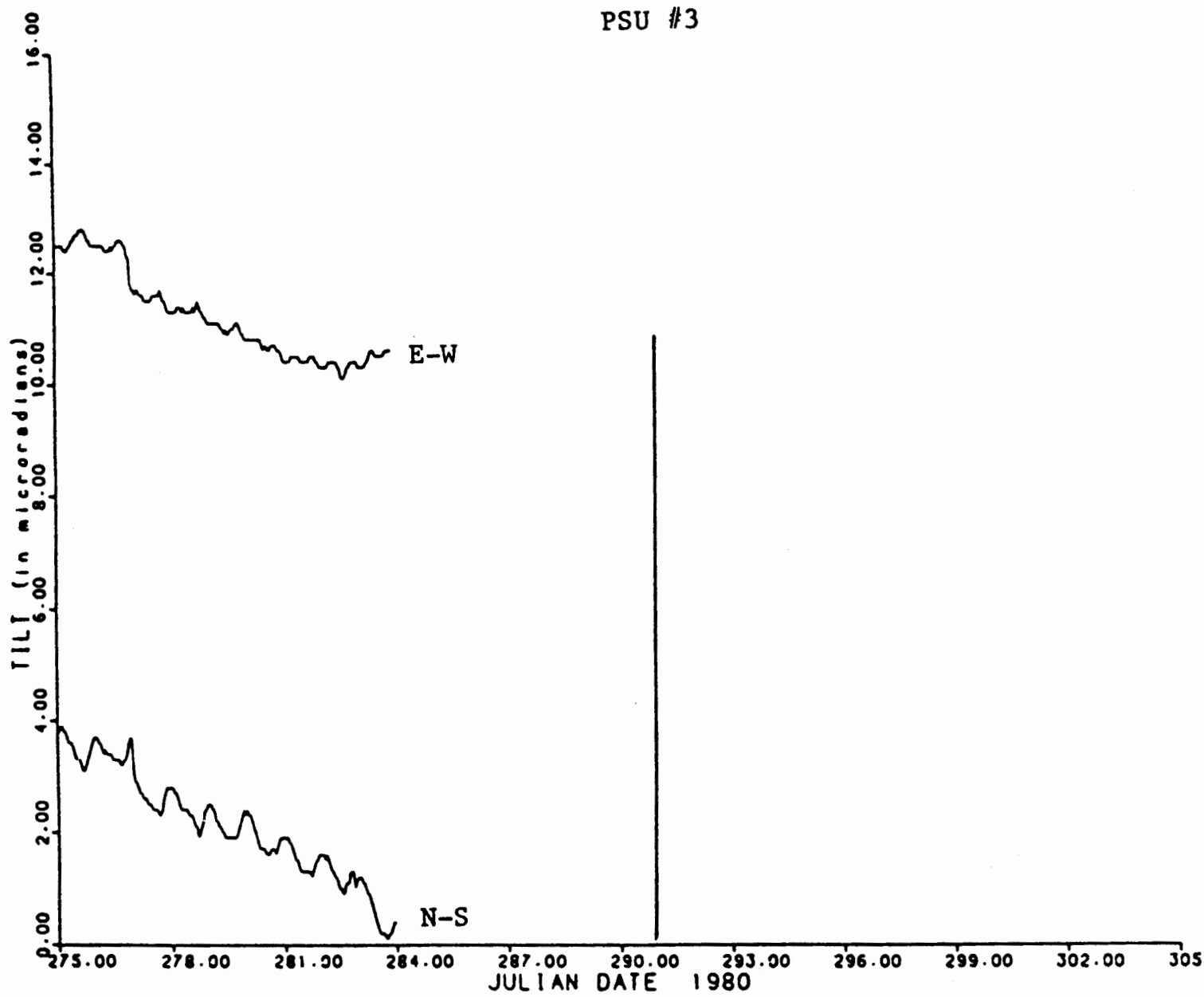

Figure 80. East-west and north-south components of tilt at PSU \#3 tiltmeter site. A decrease in recorded values indicates East or North positive (inflation). Values are uncorrected hourly averages starting October 1,1980 and continuing through October 30, 1980. Times are all GMT equivalents. Vertical lines indicate eruption onsets as determined from seismic records. Gaps in the data indicate periods periods where no usable data was collected. 


\section{EQUATION DERIVATIONS}

This appendix contains mathmatical derivations and explanation of models used within the main text body.

$$
\text { MOGI MODEL (single chamber) }
$$

Primary assumptions made for this model;

1) The deformation is caused by a spherical source within the earths crust.

2) That the earths crust behaves as an elastic body for short periods, but is linearly-elastic for long term deformation.

3) That volume change is essentially equal to pressure change in this system.

4) That deformation at Mount St. Helens is the result of a definable magmatic body.

5) That deformation is symetrical about the conduit.

The initial equations describing deformation from a single spherical source (Mogi, 1958) at the surface are given below.

$$
\begin{array}{r}
U_{r}=\frac{a^{3} P}{4 \mu} * \frac{R}{\left[(z+2 f)^{2}+R^{2}\right] \frac{5}{2}} * 5 a^{2}+14 f z+8 f^{2}-R+ \\
\frac{a^{3} P}{4 \mu} \frac{R}{\left(z^{2}+R^{2}\right) \frac{3}{2}}+\frac{R}{\left[(z+2 f)^{2}+R^{2}\right] \frac{3}{2}}
\end{array}
$$


$U_{z}=\frac{a^{3} P}{4 \mu} * \frac{1}{\left[(z+2 f)^{2}+R^{2}\right] \frac{5}{2}} * 7 z^{2}+38 f z^{2}+68 f^{2} z+4 f R^{2}+$

$$
\frac{a^{3} P}{4 \mu} \frac{R}{\left(z^{2}+R^{2}\right) \frac{3}{2}}+\frac{z+2 f}{\left[(z+2 f)^{2}+R^{2}\right] \frac{3}{2}}
$$

where: $U_{r}=$ radial component of displacement

$\mathrm{U}_{\mathbf{z}}=$ vertical component of displacement

$\mathrm{a}=$ radius of sphere with hydrostatic pressure

$P=$ change in hydrostatic pressure in sphere

$f=$ depth to center of sphere from surface

$\mu=$ Lame's constant

$R=$ radial distance from the source

Based on equations 1 and 2 if the radius of the sphere less than $1 / 2$ the depth, the form of the deformation curve is then only a

function of depth with displacements directly dependent on volume change (a) and radial distance from the source (R).

Equations 1 and 2 have been simplified (Walsh, 1975; Kinoshita, Swanson, and Jackson, 2974) to the following:

$$
\begin{aligned}
& H=\frac{3 a^{3} p}{4 \mu}+\frac{f}{\left(f^{2}+d^{2}\right) \frac{3}{2}} \quad h_{0} \max a t d=0 \\
& d=\frac{3 a^{3} p}{4 \mu}+\frac{d}{\left(f^{2}+d^{2}\right) \frac{3}{2}}
\end{aligned}
$$

where: $\quad \mathbf{f}=$ depth to center of chamber

$d=$ horizontal displacement distance from source

$a=$ radius of spherical magna chamber

$\mu=$ Lame's constant

$P=$ change in hydro-static pressure in the sphere

The surficial deformation expressed in equations 3 and 4 is related to tilt change and volume change (Eaton, 1962; Dan Dzurisin, 1983, personal communication) by the following equations: 
$v=H_{0} 2 \pi f^{2}$

$t_{0}=\frac{\partial \Delta h}{\partial \Delta d}=-\frac{9}{4} * \frac{a^{3} p}{\mu f^{3}} * \frac{d / f}{\left(I+d^{2} / f^{2}\right)^{\frac{5}{2}}} \quad$ where $T_{\max }=T$ at $d=f^{2}$

where: $H_{0}=$ maximum vertical displacement at the surface $v$ = volume change in the chamber

$T(d)=$ tilt change at distance $d$

Using the above equations, computer programs were constructed to evaluate surface deformation. The boundary conditions used for calculation where; volume change (derived from field measurements) and, vertical change (measured by geodetic instruments).

MOGI MODEL (multiple chamber)

The equations for this model differ from those used in the single chamber Mogi model (1) by the addition of a second deformation source. The second deformation source being a very small chamber located directly above a large chamber with a conduit separating the two chambers.

Letting $f_{1}$ denote the depth to the first chamber, $f_{2}$ the depth of the second chamber, and assuming that u(rigidity) and P(pressure amplitude) are constant in both chambers, the resulting equations are:

$\Delta d=\frac{3 a^{3} p}{4 \mu}+\frac{d}{\left(f_{1}^{2}+d^{2}\right) \frac{3}{2}}+\frac{3 b^{3} p}{4 \mu}+\frac{d}{\left(f_{2}^{2}+d^{2}\right) \frac{3}{2}}$ 
$\Delta h=\frac{3 a^{3} p}{4 \mu}+\frac{f}{\left(f_{1}^{2}+d^{2}\right) \frac{3}{2}}+\frac{3 b^{3} p}{4 \mu}+\frac{f}{\left(f_{2}^{2}+d^{2}\right) \frac{3}{2}}$

where:

$h=$ amount of vertical displacement

$d$ = amount of radial displacement

$a=$ radius of sphere (upper chamber)

$b=$ radius of sphere (lower chamber)

$P=$ pressure amplitude

$\mu=$ ridgitity

$f_{1}=$ depth to the center of the upper chamber

$f_{2}=$ depth to the center of the lower chamber

All the assumption stated about the single chamber Mogi model are applicable here. Additional assumptions made for this model are:

1) There exists in the magmatic system two distinct chambers, the upper chamber modifying the surface deformation pattern, the lateral extent of the modification being very limited in comparison to the deformation pattern created by the lower chamber.

2) That deformation resulting from the second chamber is symetrical with respect to the magmatic conduit termination.

As in the single chamber model, computer programs were constructed to evaluate the surface deformation. Boundary conditions used for this model were the same as those in the single chamber model.

\section{REFERENCES}

Eaton, J. P., 1962, Crustal structure and volcanism in Hawaii: Crust of the Pacific Basin Geophysical Monograph, no. 6, p. 13-29.

Kinoshita, W. T., Swanson, D. A., and Jackson, D. B., 1974, The measurement of crustal deformation related to volcanic activity at Kilauea volcano, Hawaii, in Civetta, L., Gasparini, P., Loungo, G., Rappola, A., eds., Physical volcanology: developments 
in solid earth geophysics, no. 6.: Elsevier Scientific Pub. Co., p. 87-115.

Mogi, K., 1958, Relations between the eruptions of various volcanoes and the deformation of the ground surfaces around them: Bull. Earthq. Res. Inst. 36, p. 99-134.

Walsh, J. B., 1975, An analysis of local changes in gravity due to deformation: Pure Applied Geophysics 113, p. 97-106. 


\section{APPENDIX C}

CHRONOLOGY OF EVENTS: July, 1980 through December, 1980

$01 \mathrm{Jul} 1980$ Occasional deep, small earthquakes recorded around Mount st. Helens extending from the Elk Lake area $15 \mathrm{~km}$ north-northwest to Marble Mountain $10 \mathrm{~km}$ south-southeast of the volcano.

22 Jul 1980 Major explosive eruption, destroying the June dome Buildup of small shallow earthquakes over several hours preceded the eruption; up to 20 events per hour were recorded

1714 PDT first ash eruption

duration 6 minutes
maximum height 45,000 feet

1825 PDT second ash eruption, with pyroclastic flow on north flank duration 22 minutes maximum height 60,000 feet

1901 PDT third and final ash eruption, with pyroclastic flow duration $2 \mathrm{hrs} .40 \mathrm{~min}$. maximum height $\quad 45,000$ feet

1910 PDT beginning of small deep earthquakes

07 Aug 1980 Major explosive eruption and emplacement of dome eruptive activity preceeded by several hours of harmonic tremor

1627 PDT first eruptive column and minor ahs flow

2232 PDT second eruptive column followed by deep earthquakes duration 2 hours eruptive activity proceded by several hours of small shallow earthquaks

16 Oct 1980 Major explosive eruption with the emplacement of the first major dome. The event was precedded by several hours of shallow earthquakes

2158 PDT 16 oct. first plume

0928 PDT 17 Oct. second plume; confirmed pyroclastic flow maximum height 47,000 feet

2112 PDT 17 oct. third plume maximum height $\quad 45,000$ feet 
1235 PDT 18 oct. fourth plume

maximum height 25,000 feet

1428 PDT 18 oct. fifth plume

maximum height 20,000 feet

1520 PDT 18 oct. first observation of new dome

(August dome was destroyed)

height 5 meters

width 25 meters

19 Oct 1980 Measurement of final dome growth of October dome

$\begin{array}{lr}\text { diameter } & 200 \text { meters } \\ \text { height } & 40 \text { meters }\end{array}$

13 Dec 1980 Small portion of southeast sector of october dome was blow out

25 Dec 1980 slight increase in shallow earthquakes beneath the crater

27 Dec 1980 Earthquake Erequency increased to 3-4 events per hour and continued for most of the day

28 Dec 1980 Extrusion of new dacitic dome, forming the December lobe to the composite dome.

0900 PDT First observation of the new December lobe

By January 4, 1981, the new December lobe had finished growing with the approximate final dimensions for the composite dome being:

$\begin{array}{lr}\text { diameter } & 200-300 \text { meters } \\ \text { height } & 90 \text { meters } \\ \text { approximate total volume } & 5 \times 106 \mathrm{~m}^{3} \\ \text { Total magmatic output } & \\ \text { for } 1980 & .24 \times \mathrm{km}^{3}\end{array}$

